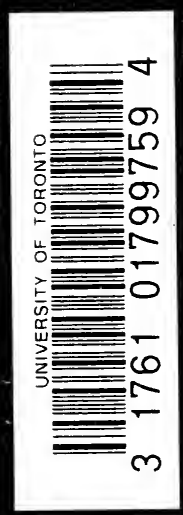




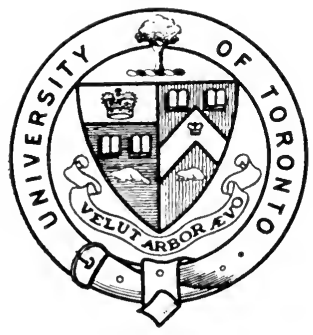

Donated

by

William McClinton 
$i 50$ Jakthil Lulow

Sturale 
Digitized by the Internet Archive in 2007 with funding from Microsoft Corporation 




\section{A TEXT-BOOK OF}

\section{MILITARY HYGIENE}

AND

\section{SANITATION}

BY

FRANK R. KEEFER, A. M., M. D.

L.IEUTENANT-COLONEL, MEDICAL CORPS, UNITEI) STATES ARMY; PROFHSSOR OF MILITARY HYGIENE, UNITED STATES MILITARY ACADEMY, WEST POINT

\section{ILLUSTRATED}

PHILADELPHIA AND LONDON

\section{W. B. SAUNDERS COMPANY}




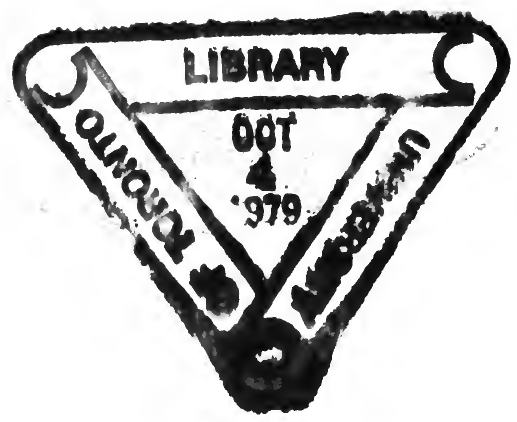

Copyright, I I $_{4}$, by W. B. Saunders Company
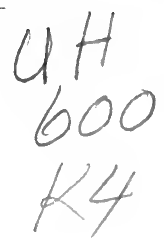

PRINTED IN AMERICA

$$
\text { PRESS OF }
$$

W. B. SAUNDERS COMPANY PHILADELPHIA 


\section{PREFACE}

The chapter on Physical Training has been written for this book by Captain H. J. Koehler, U. S. Army (Director of Physical Training at the United States Military Academy, West Point, and an expert of international repute).

The majority of the illustrations not otherwise credited were prepared by Mr. Stockbridge, of the Department of Drawing, U. S. M. A., through the courtesy of the head of that Department.

In the discussion of "Alcohol and other Narcotics," the aim has been to enable pupils to form an intelligent opinion upon the whole subject and especially to distinguish between mere assertion and scientific evidence. While certain of the data in this chapter cannot be accepted as wholly proved, they yet represent the views of the ablest investigators everywhere. With a clear comprehension of the matter, each one may then determine for himself what his personal relations with these substances shall be.

To save the time of the pupil and to avoid the necessity for a dictionary, a glossary of technical terms used herein is appended.

July, 1914.

Frank R. Keefer. 



\section{CONTENTS}

CHAPTER I

The Care of Troops.

CHAPTER II

RECRUIȚS AND RECRUITING....................... 23

CHAPTER III

Personal Hygiene......................... 31

CHAPTER IV

Physical Training......................... 41

CHAPTER V

Preventable Diseases. . . . . . . . . . . . . . 59

CHAPTER VI

Clothing.................................... 90

\section{CHAPTER VII}

Equipment. . . . . . . . . . . . . . . . 108

CHAPTER VIII

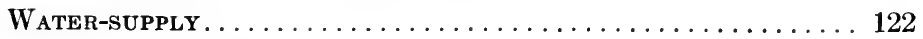

CHAPTER IX

Foods and Their Preparation................... 139 
The Sanitation of Posts, Barracks, and Transports...... 161

\section{CHAPTER XI}

The Hygiene and Sanitation of Marches, Camps, and

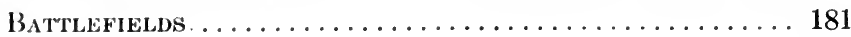

\section{CHAP'TER XII}

The Disposal of Wastes.................... 206

\section{CHAPTER XIII}

Tropical and Arctic Service. ...................... 235

\section{CHAPTER XIV}

Venereal Diseases......................... 250

\section{CHAPTER XV}

Alcohol and Other Narcotics................... 258

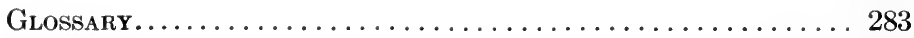

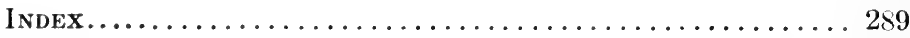




\section{MILITARY HYGIENE}

\section{CHAPTER I \\ THE CARE OF TROOPS}

Definitions.-Hygiene is a science whose laws have to do with the preservation of the health. Sanitation is an art whereby man endeavors to carry out the laws of hygiene. Health is a normal condition of body and mind. Disease is any departure from a state of health. Military hygienesometimes referred to as the "care of troops"-embraces hygiene and sanitation in their relations to an army. In modern military usage the adjective sanitary is applied not only to hygienic procedure, but also to troops and organizations of the Medical Department.

Scope of Military Hygiene.-The practice of military hygiene covers all points which relate to the public health of a civil community - and something more. Public health concerns itself with everything which may unfavorably affect the physical condition of individuals in such a community; in other words, it has to do with man and his environment. This involves a consideration of soil, air, water, climate, habitations, ventilation, heating, care of the person, food, clothing, exercise, occupation, habits, parasites, com- 
municable diseases, disinfection, disposal of refuse, sanitary laws, and vital statistics. 'The "something more" is the set of conditions incident to the march, the camp, and battle, which greatly modify the circumstances and increase the difficulties met in the application of sanitary procedures. A knowledge of public health thus falls far short of the requirements for the military service, and physicians called from civil life in time of war, without previous military training, find themselves not qualified properly to safeguard the health of the troops entrusted to their care.

Functions of Medical Officers.-Misconceptions as to the functions of the Medical Department are not uncommon even in the army. Since, in time of peace, the medical officer is best known through his relation to the sick, his more important duties may be overlooked. His prime function is, in peace or war, not the cure, but the prevention, of disease. In war time the evacuation of the sick and wounded to the rear, that they may not encumber the army, is next in importance. The care of the sick, essential though it is from ethical and political considerations, thus assumes relative insignificance from the military standpoint.

Military Failure Due to Preventable Diseases.-In all the wars of history (with the doubtful exception of the RussoJapanese conflict) much more disability and many more deaths have resulted from disease than from wounds. Campaigns which should have succeeded have frequently failed because of the utter breakdown of armies from preventable diseases, such as cholera, plague, typhoid, typhus, smallpox́, malaria, dysentery, and yellow fever. The invasion 
of Canada by Montgomery and Arnold in 1775 was unsuccessful because of the enormous percentage of losses from small-pox and dysentery. Napoleon's plan to found a colonial empire in what is now the Southern United States failed because 15,000 men of his fine army, sent out for that purpose in 1802, perished in Santo Domingo of yellow fever and other tropical diseases. The British in the Crimea lost twenty-five times more men from disease than from wounds. Brief as was the war with Spain, deaths from sickness in our army were over seven times more numerous than were those from injury. Even in the Balkan War, recently terminated, the Bulgarian campaign (carried on at first with such fiery vigor and astonishing success) broke down largely because of epidemic disease. The occurrence in one day of about 30,000 cases of a choleraic dysentery was a more vital factor than was the Turkish resistance in the check of the Bulgarian Army at Chatalja and its failure to capture Constantinople.

Results of Prophylaxis.- Up to recent years a high percentage of disease and death during war time has been accepted as unavoidable, and but little effort made to prevent the one or to lessen the other, but the great increase in knowledge of the causes of disease has given us weapons with which to fight these, and the application of sanitary principles has resulted in a marked diminution in many affections now shown to be preventable. The annual death-rate for that half of the United States which keeps reliable statisties has decreased nearly 20 per cent. in the last generation. The average length of life at present is about forty-five years, and it is estimated that methods of disease prevention (so- 
called prophylaxis), if properly applied, can add fifteen years to this. The sanitarians of our army have kept pace with advances along this line and, since the Spanish War created opportunities for them, have been pioneers in blazing trails through uncharted wildernesses of disease. The conquest of yellow fever in Cuba, of hookworm disease in Porto Rico, of pernicious malaria in Panama, of beriberi among Philippine scouts, of typhoid fever in the army itself, are but a few examples of the marvelous results of the application, to great problems met, of the principles of disease prevention. More recently it has been shown in the large camps along the Mexican border that troops can be maintained under canvas in one place for prolonged periods without an increase in sickness beyond the rates usual in garrisons. As a matter of fact, in time of peace at least, sick rates from preventable diseases are now much less in military than in civil communities.

The Soldier and Disease Prevention.- Soldiers are specialists in a certain branch of human endeavor, the practice of which entails additional risks and creates the necessity for care in avoidance thereof. The risks of battle cannot be avoided, but those of the march and the camp can, as will be shown, be entirely escaped or greatly lessened by the exercise of reasonable caution. The prevention of disease is of supreme importance to officers of the line because the efficiency of the troops they command is dependent upon health. The vital military factor is the soldier himself, and the avoidance of wastage in this particular needs no emphasis. A trained soldier is of more value than are several raw recruits. 
If such soldier can be kept in the ranks, or returned thereto promptly after sickness or injury, the system is a great asset to the company commander and to the army. But such a system can be instituted and maintained only by full and hearty co-operation between line and sanitary officers, in association with a high state of discipline. That elusive something, known to us under the French term esprit, is engendered and fostered in troops chiefly by confidence in their officers, and one of the best ways to gain that confidence is by letting the men see and feel the active interest taken in their welfare.

Enforcement of Sanitary Regulations.-When sanitary regulations are promulgated for the guidance of enlisted men, it is often desirable to let them know the reasons therefor. Most of our men are intelligent, thinking individuals, and if their reason is appealed to, compliance is apt to be more thorough than when a mere command is given, without explanation. On the other hand, the issuance of an order by no means ensures compliance. Every order must be followed up, to see that it is carried out promptly and habitually. For this purpose inspections must be made early and often. If a disposition to shirk is observed, delinquents must be punished. Unless the system of inspection and responsibility is thorough and complete and duties of subordinates dovetail or overlap, work will be neglected, because certain things are nobody's business. A medical officer is on the staff of his commander in an advisory capacity. This relation should not be lost sight of. Recommendations of sanitary officers should be heeded and enforcéd by commanders. 
That one who promptly and firmly supports his sanitary adviser soon finds the sanitation of his camp or garrison maintained at a high standard by those most directly responsible, namely, the company commanders.

Improvidence of Soldiers.-Experience teaches us that we cannot expect the enlisted man to care for himself, so we must be "guide, philosopher, and friend" to him. A Confederate leader (Wise) has well said, "To appreciate fully the truth that 'men are but children of a larger growth,' one must have commanded soldiers. Without constant guidance and governance and punishment they become careless about clothes, food, ammunition, cleanliness, and even personal safety. They will at once eat or throw away the rations furnished for several days, never considering the morrow. They will cast aside or give away their clothing because today is warm, never calculating that the next day they may be suffering for the lack of it. They will open their cartridgeboxes and dump the contents on the roadside to lighten their load, although a few hours later their lives may depend upon having a full supply. When they draw their pay, their first object is to find some way to get rid of it as quickly as possible. An officer, to be really efficient, must add to the qualities of courage and firmness those of nurse, monitor, and purvevor for grown-up children, in whom the bumps of improvidence and destructiveness are abnormally developed." 


\section{CHAP'TER II \\ RECRUITS AND RECRUITING}

Mistaken Views of Public.-Not every man is suitable for a soldier. The public-including many members of the medical profession in civil life - has the idea that any male over seventeen years of age and not enfeebled by senility or disease may be enlisted and perform efficient service. Nor is every able-bodied man suitable for military purposes. He may be undesirable as to character, mentality, habits, education, or temperament. Furthermore, though the individual may be muscularly strong, he may possess some physical defect which, though negligibie in his ordinary vocation, is almost certain to develop into a disqualifying defect in the military service. Thus, when we read the boastful utterances of Jingo orators about "a nation in arms," "ten millions of men will rise to repel the invader," and the like, we must realize that, from the standpoint of physical fitness alone, the vast majority of these millions is totally ineligible. A man may be a good insurance risk and yet be entirely unfitted for a soldier.

Small Percentage Qualified.-In time of peace a sufficient number of applicants ordinarily present themselves, so that our small army may be recruited out of good material. The number of men rejected for one reason or another, but chiefly on account of physical deficiencies, greatly exceeds those 
accepted. Only 1 in 3 or 4 is taken by officers on recruiting duty in cities, and this percentage is still further reduced by a rigid medical scrutiny at recruit depots, to which provisionally accepted applicants are sent prior to taking the oath of enlistment.

High Motives, Special Abilities. - The motive actuating an applicant for enlistment-such as a spirit of adventure, a desire to wear the uniform, or even a strong sentiment of patriotism - is not a satisfactory substitute for physical fitness. While it is true that some weedy individuals may develop to an adequate degree, or may even exhibit a rare courage or marked endurance under strain, experience shows ovėrwhelmingly that such is the exception and not the rule. Exceptional recommendations as to character, ability, or knowledge of useful trades should be allowed to influence us only where such relative defects as slight deficiencies in height or weight are concerned. And it is important to bear in mind that there must be not merely the absence of disease or abnormality, but also freedom from any tendency thereto.

Lowered Standards.--At times of special urgency there is apt to be great pressure directed to the lowering of the standards. Militia organizations may desire to be transferred to the volunteer service intact; officers of newly organized regiments are anxious to fill the ranks; or, a real emergency exists. Even at such times, unless the emergency be acute, the pressure should be resisted, for the inferior material is unlikely to reach the firing-line. The defective men break down at the first strain and, never having rendered real service to their country, are promptest to demand pen- 
sions. Woodhull quotes Vegetius (a celebrated Roman military writer) as follows: "An army raised without due regard to the choice of recruits was never yet made a good army by any length of service."

Regulars, Volunteers, Militia, Conscripts. - In our military system recruits may be considered under four heads, namely, Regulars, Volunteers, Militia, and Conscripts. Recruits for the first three are all volunteers, in the sense that they apply for enlistment of their own free will. Those for the last are compulsorily chosen in the absence of a sufficient number of voluntary applicants. Regulars are carefully selected by trained officers of the line and medical staff. Volunteers are picked in like manner, but, owing to the inexperience of examiners or pressure to lower the standards somewhat, the material is not always equal to that of the Regulars. This is shown by the fact that in the Civil and Spanish wars deaths from disease and discharges for disability were nearly twice as great among the Volunteers. In the widest sense the militia is the whole number of males of the country who are competent and available for military service. Specifically, the term is applied to the organized militia, these being the men who form the military organizations in the service of the several states. As these organizations-now known as the National Guard-are not ordinarily liable for hard field service, some states do not require a very high standard of physical fitness. When, therefore, in conformity with existing law, the organized militia may be called into the service of the United States, it will be found that from one-half to two-thirds of certain regiments are physically ineligible. It is 
an interesting but readily understandable fact that, whereas voluntary applicants for enlistment endeavor to conceal defects, conscripts try to escape service by magnifying existing lefects or feigning non-existent ones. In the examination of conscripts, therefore, a skeptical attitude of mind should be maintained toward alleged disabilities.

System of Examination.-Up to 1907 the physical examinations were made largely by civilian physicians, employed under contract, at recruiting stations in cities. Under this system great losses of men occurred as a result of disabilities discovered after the recruit had been sworn in. At the same time the government spent much money for the transportation and clothing of these defectives, while company commanders became dissatisfied on account of the poor quality of the material sent them. As a result of these undesirable features a system has been developed whereby line officers make a careful preliminary examination at their recruiting stations, and forward likely candidates to depots. At the latter points army medical officers examine these candidates, weed out the defective ones, and enlist those qualified. The Surgeon General reports that "the present recruiting system operates in a highly satisfactory manner and furnishes to the army recruits of far better quality than when they were examined under the former system."

Principal Defects.- The physical deficiencies which cause the greatest number of rejections for our army are: venereal diseases, heart abnormalities, defective vision or hearing, foot deformities, and poor physique. While it is not to be expected that line officers on recruiting duty shall be able to 
detect obscure affections of the internal organs, there are many grosser defects which are readily apparent to them. Such are: deformities, skin eruptions, pallor, emaciation, inebriety, venereal disease, defective development of parts, lice, dirty person, rupture, piles, stiff joints, varicose veins, flat feet, indecent tattooing, etc. Furthermore, internal disease may be suspected from shortress of breath, a thumping heart, dimness of visin, or irrgular pulse following moderate exertion.

Character.-The character of the applicant should be determined as accurately as possible. He may satisfy all the physical requirements, but when the recruiting officer asks himself the question, "Would I be willing to have this man in my company?" there is often a decided negative. And this test is a useful one to apply with respect to the intelligence of the applicant, his knowledge of English, and his general appearance. The moral qualifications may be guessed from his features and gaze (open, frank or averted), his manner (direct or furtive and hang-dog), his person and clothing (clean or dirty). He may present the well-known appearance of a drunkard or a tramp. Drug habits may be indicated by numerous marks of the hypodermic needle or very dilated or contracted pupils. A marked disproportion of features or limbs may be indications of degeneracy, or his body may be much tattooed, some of the subjects being of an obscene or otherwise offensive nature.

Mental and Nervous Condition.-The mental and nervous condition is important. Many defectives-especially among the foreign born-pass the initial observation and some even 
the medical examination, for no class of cases is so difficult to determine without an extended observation. Nevertheless, a nervous, shifty, or excitable manner; wandering attention; defective memory; inability to give prompt or direct replies to questions; sudden, jerky movements, will frequently indicate an unstable nervous system or defective mentality.

Age.-Youth is a serious physical defect. We sometimes read the erroneous statement that the Civil War was fought by boys, but in that war, as in all those of history, undeveloped, immature youths succumbed to the fatigues and privations of campaign in vastly greater proportion than grown men. Prior to the age of twenty-one the bones are not fully formed, the muscles lack endurance, and the heart is unduly susceptible to overstrain. On the other hand, men over thirty, unless thay have led an active, alert life, are apt to be muscle-bound and mentally slow. The limits of age for our service are, in time of peace, eighteen to thirtyfive. It is, therefore, to be seen that minors may be legally accepted in spite of the knowledge that great commanders have, for centuries past, protested against the recruitment of boys for their armies. From a physiologic standpoint the truly desirable minimum is twenty-two years.

Height, Weight, Chest.-In the absence of actual disease conditions, the physical attributes which chiefly determine the acceptance or rejection of an applicant for enlistment are the height, the weight, and the chest measurements. In normal individuals these bear a fairly definite relation to each other, which relation is set down in official tables. Men 
whose chest circumference, at rest, is below 32 inches, should not be accepted, for such a chest has not sufficient air capacity. The present minimum of height is 5 feet 4 inches. The question of height is not quite so important now as in the days of shock action. Other things being relatively equal, the smaller man is generally quicker in his movements and has more endurance. In these days of specialism we might well accept vigorous men who are a little shorter than the present requirement for special service, thus releasing others of standard height for the fighting line. With respect to weight, men of the "wiry" type may be accepted when they are but a few pounds under the standard, but the mistake must not be made of confusing these with cases of defective or arrested development. In these latter, deficiency in weight, pallor, flabby muscles, a flat chest, sloping shoulders, and generally poor physique denote a feeble constitution.

Records.-It is essential, for the protection of the government, that careful records be made: $(a)$ of all departures from the normal, including minor ones which are not considered disqualifying, and $(b)$ of means of identification. The first is needed as a defense against unjust claims for pension. The second leads to the detection of criminals, deserters, bounty jumpers, and dishonorably discharged men who enlist fraudulently.

Depots.-Owing to the widespread derivation of recruits, depots for their collection and training are frequently afflicted with one or more kinds of contagious diseases, brought by some who have contracted them elsewhere. It has sometimes happened that measles, mumps, or other communi- 
cable disease has developed in parties of men sent from depots, during the trip or shortly after arrival at their destination. Army posts have thus been frequently infected, while the health of the traveling public has been endangered. If, therefore, such a disease exists at depots, the men who have been exposed to contagion should be isolated, in separate squads, until the period of incubation of that particular disease is past. If a case develops in any one squad, none but members of that squad have been exposed to it and the others may safely be forwarded. A similar procedure is advisable in camps.

Vaccinations.-One of the first requirements after the enlistment of a man is to have him vaccinated against small-pox and typhoid fever. This is a very important procedure, looking to his future health and that of the army.

General Order No. 66.- The remarks in this chapter are intended to emphasize the importance of sound recruits and sound methors of recruiting. The most important part of the whole subject, namely, the physical examination of the recruit, is not dealt with herein, for the reason that War Department General Order No. 66, series of 1910, is an excellent presentation thereof.

If in Doubt, Reject.-Recruiting is a highly important duty, for upon those to whom it is entrusted rests the responsibility for the physical, mental, and moral standard of the whole army. Officers assigned to this duty should keep in mind constantly the maxim, If in doubt, reject. 


\section{CHAPTER III}

\section{PERSONAL HYGIENE}

Nature and Importance.-Personal hygiene means preservation of health by attention to the care of the body. It is obvious that such care is essential to keep the physical character of the soldier up to the proper standard. Napoleon is reported to have said, "The most important quality of the soldier is his ability to support fatigue and privation; physical courage is only second." Whether or not this be true, it must be apparent to any thinking individual that personal merits, including courage, are of little avail to the military man if he has not bodily vigor.

Formation of Correct Habits.-Military efficiency in an individual, then, rests upon certain considerations, chief among which are health, strength, and activity. To secure and keep these qualities it is essential for every man to form such habits as experience has shown to be necessary. These habits are: personal cleanliness; regulation of diet; avoidance of excesses (particularly in eating, drinking, and sexual matters); wearing suitable clothing; keeping the bodily processes at work (kidneys, bowels, skin); taking sufficient exercise, preferably in the open air; devoting a proper part of each day to rest of body and mind, with recreation for the latter; maintaining the surroundings in which one lives, in a cleanly state. 
Anatomy and Physiology.-In the discussion of this branch of our subject, an elementary knowledge of anatomy and physiology must be assumed, as the scope of this work does not permit of instruction in these topics.

Personal Cleanliness.-The maintenance of personal cleanliness is even more necessary in the military service than in civil life. This is due in part to the violent exercises required of the soldier, with the resultant dirt and sweat, but especially because so many live together within a small space.

Baths and Bathing.- The most important requirement to insure cleanliness is bathing. Baths are necessary partly to rid the skin of external impurities, but chiefly to keep open the "pores," which are the mouths of the sweat-glands, whose product carries away large amounts of waste and poisonous matters from the blood. Each man has a preference for a certain temperature of the water in which he takes his bath; this varies from freezing to hot. A cold bath is stimulating and is to be preferred for a vigorous man, provided he "reacts" well and feels a glow on emerging from the bath and rubbing down. The cold bath is not suited to elderly men nor to those whose circulation is poor. The proper time for cold bathing is on arising in the morning, not at bedtime, as sometimes indulged in.

It is worthy of mention that the practice of cold bathing often breaks up the habit of "taking cold," to which certain people are liable.

Hot and warm baths are soothing and best remove surface dirt; they are grateful means of reducing muscular soreness 
after exertion, and will often induce sleep in a restless, wakeful person.

The most desirable means of bathing is perhaps in a tub in which the whole body may be immersed; in default of this and particularly in barracks, the shower-bath is very satisfactory. If means for complete bathing are not available, careful attention should, in any event, be given to the daily cleansing of the armpits, crotch and feet, as well as the hands and face. The hands should be washed after defecation and urination, lest they convey disease germs. The nails must be well kept and clean. On the march, if no water is available, a vigorous "dry rub" with a coarse towel will be found refreshing as well as cleansing. The scalp should be washed at least once or twice a month and should be stimulated daily by brisk rubbing with a brush or the fingers.

Care of the Teeth.-Every man should own a good tooth brush and use it with a tooth powder or mild antiseptic (listerine for instance) at least twice a day. If no tooth powder is available, wood ashes or wood charcoal make efficient substitutes.

Clothing.- Since clothing (especially the underwear) when soiled with sweat and dust is irritating to the skin and gives off disagreeable odors, it is necessary to keep this as clean as the body. The soldier cannot keep his person clean if his garments are filthy. Therefore, whenever possible, the soiled clothing should be washed (and with soap if it can be had). If the articles are of wool, they should be washed in cold water and dried without wringing. On the march a man should have two suits of underclothes to wear on alter- 
nate days, thus ensuring cleanliness if the garments are regularly washed. If, at the end of the day's march, water is not available for this purpose, the garments should be dried, then beaten or well rubbed, and hung up in the air.

Skin Diseases.-In campaign, skin diseases due to animal parasites-especially lice and the itch mite-usually make their appearance and cause much disgust and discomfort. They must be watched for and report of their presence promptly made to the medical officer.

Diet.-In the soldier's life the diet is, of course, regulated as far as possible by the authorities, who design and issue the ration and train the cooks by whom the articles composing it are prepared. In campaign, military considerations may necessitate cutting away from the base of supply, so that soldiers are obliged to live on the resources of the country in which they are operating or even to subsist for a few days upon the emergency ration. Every soldier should be required to learn how to prepare his individual field ration, since the necessity for this frequently occurs in field service.

The character of the food taken should vary in accordance with the conditions of bodily vigor, occupation, climate, and food values. A vigorous man, doing heavz work, requires more nourishment than one of delicate physique following a sedentary pursuit. Climate is an important factor. Men serving in Alaska need a large amount of fats to serve as fuel in maintenance of the temperature balance. Those on duty in the Philippines require a large proportion of sugars and starches.

"Fletcherizing," that is, the chewing of food until it is 
completely disintegrated, makes eating a bore. Other food fads, such as strict vegetarianism or eating only when the sensation of hunger is felt, usually result in digestive disorders or loss of strength.

Dietary Dont's.-A few general dietary principles follow, which may perhaps best be expressed in the form of prohibitions:

Don't eat hurriedly.

Don't swallow a morsel till it is thoroughly broken up and mixed with the saliva by chewing.

Don't overload your stomach, but get up from the table feeling that you could eat a little more with relish.

Don't eat unripe or overripe fruit.

Don't eat anything, while away from camp or barracks, whose materials or mode of preparation may seem questionable.

Don't bring worry or a "grouch" to table with you.

Excess in Eating.-Overeating gives rise to biliousness and other forms of dyspepsia and overloads the body tissues with waste matters. These wastes are irritant substances and are just as likely as alcohol to cause kidney disease, gout, obesity, and hardening of the arteries. Beefy, overfed men are especially liable to apoplexy.

Excess in drinking means, to us all, overuse of drinks containing alcohol in some form. You will learn that the great majority of violations of discipline, trials by court-martial, and subsequent punishment in our army result from this particular excess. Habitual indulgence in alcohol brings, as certain rewards, a host of physical and mental ailments. 
Besides weakening men physically, alcohol tampers with their will power, disturbs their temper, and makes them less trustworthy even when sober.

Sexual Indulgence.-It is the popular idea that a young man must exercise the sexual function to some extent in order that he may retain his vigor. This belief is not founded on fact, for the sexual act is not necessary to preserve the health or powers of a man. Not only is this true, but it is equally true that sexual indulgence by young unmarried men is responsible for an immense amount of disease and suffering. This disease and suffering is borne not only by the men themselves, but, in a large proportion of cases, by the innocent women whom they afterward marry and by their children. The wives may be, and often are, infected years after an apparent cure has resulted, and the children are born diseased.

Masturbation.-The habit of masturbation is degrading and is likely to interfere with the normal development of the sexual organs. It may also be responsible for early loss of sexual power (impotence).

Clothing.-The prime purpose for which clothing is worn (other than that of decency) is to afford protection to the body against extremes of cold and heat. The materials used should, therefore, be such as to conserve the natural warmth of the body or to allow it to escape freely, in accordance with weather conditions. Clothing should not be permitted to interfere with the circulation of the blood, nor with the normal movements of the body.

Excretory Functions.-Our bodies, in the work their various parts must perform, manufacture certain waste prod- 
ucts which we call excretions. Now it is evident that if we do not get rid of these substances, they will clog up the body or even act as poisons. Nature has, therefore, designed certain avenues of escape for these excretions, and the chief of these are the skin, the kidneys, the bowels, and the lungs. The importance of the skin has already been dwelt upon. The kidneys can best be kept in good condition by drinking plenty of water (at least 6 or 8 glasses a day), which flushes these organs and dilutes the solid impurities of the urine. Constipation induces a variety of uncomfortable conditions, among which piles, headache, the state often called "biliousness," and mental depression are frequent; moreover, certain acute diseases seem more readily to attack a constipated person. Therefore, remember to keep your bowels open.

Lungs. - The lungs are an important avenue of escape for certain waste products, chief of which is carbon dioxid. The ventilation of living rooms thus becomes desirable to dilute or carry off these wastes, to renew that most vital element, oxygen, and to prevent overheating and undue moisture of the atmosphere, which latter are important factors tending to the diminution of vitality. The germs of diseases which affect the respiratory tract are thrown off into the air and are likely to be breathed by healthy individuals, who are thus in turn infected. "Colds" result more often from overheated, poorly ventilated rooms than as the result of drafts and chilling. Such colds are often contagious. The transmission of tuberculosis and such acute infectious diseases as measles, scarlet fever, influenza, and whoopingcough is favored by poor ventilation. 
Exercise.-A sufficient amount of exercise to maintain health is ordinarily provided by military drills and other duties requiring active movement. Nevertheless, the physical condition is further improved, muscular size and strength greatly increased, and the mental outlook rendered more cheerful by athletic exercises, whether in the open air or the gymnasium. A proper appreciation of the benefits of physical exercise may be gained by a mental comparison between the rugged condition of a man who exercises regularly, and the poorly developed muscles and sallow skin of another who has some occupation which keeps him indoors at work of a light sort. The improvement is brought about by the increased activity not merely of the muscles, but of every part of the body, including the heart, lungs, skin, digestive apparatus, etc. Like all good things, however, exercise may be overdone; excessive rapidity or irregularity of the heart's action and labored breathing are warnings to stop and rest. Soldiers in campaign-especially immature boys who are sometimes enlisted-are very liable to heart strain and an "irritable" condition of that organ.

Arteries. - "A man is as old as his arteries," and some men grow old in this respect much sooner than the average, so care must be taken to suit the exercise to their condition.

The amount and kind of exercise best suited to each must be determined, as these vary widely in different individuals. There are men who require the equivalent of a brisk 15-mile daily walk to keep in a satisfactory physical state, while the ordinary occupation of others suffices to maintain them in excellent health. 
Rest.-For the repair of damaged tissues and the relief of fatigue, a certain amount of rest for both mind and body is necessary. Different people vary considerably in their requirements, but it may be set down as a fair average that eight hours of sleep in each twenty-four hours are needed to keep the faculties at their best. In addition, work of any sort, physical or mental, must be intermitted by brief periods of relaxation. Mental overwork is very common in these days of complex civilization, and exhaustion of the nervous system (neurasthenia) takes a long time for its recovery.

Recreation.- The risk of overtaxing the mind is greatly lessened by measures of recreation, which may take any proper form most agreeable to the individual. The cultivation of a fad is of especial value. The habit of worry, of "crossing bridges before one comes to them," must be avoided. Fits of "the blues," if yielded to, tend to increase in number and length and finally to unfit one for work. In garrison, on transports, and particularly in winter camps during war time, we must make provision for measures of recreation. These are essential to promote cheerfulness and contentment, to prevent ennui, and to lessen the tendency to abuse of alcohol and tobacco, gambling, and perversion of the generative function. Entertainments of all sorts, but more particularly those participated in by the men themselves, competitions and contests, reading rooms, and opportunities for following and learning mechanical trades must be provided.

Cleanliness of Surroundings.-It is not sufficient merely to keep our bodies in a state of cleanliness by the measures previously outlined. We must also keep our surroundings 
-the house and grounds in which we live-well "policed," as the expression goes in our military service. It is selfevident that where people live - especially where many people are congregated in a small space- there much dirt will collect. This refers not so much to earthy particles as to the so-called organic materials which are derived from animal and vegetable sources. Under this head fall the body discharges, refuse from the kitchen, spit, decaying flowers and weeds, cigar stubs, floor and stable sweepings, and the like. These must be received in vessels specially kept for them and frequently removed, or they give off foul odors, pollute the ground, attract hosts of flies, and act as breeding-places for the germs of disease. 


\section{CHAPTER IV \\ PHYSICAL TRAINING}

Necessity for Bodily Activity.-Every human being is born with a natural craving for bodily activity, and it is largely upon the employment of this inherent instinct that the perpetuation and the survival of our species depends. Since the growth and development of the entire human organism in all its complexity is determined by the manner in which this craving is satisfied, it is necessary, under the present conditions of life, that it should conform to some well-defined, well-regulated methods, rationally applied, in order that the evolution of the ovum of origin from which the individual is derived, and which predetermines and defines his capabilities in all directions, may be restricted only by its limitations.

Physical Education More Vital than Mental.-From the beginning of civilization every state has been more or less seriously concerned with the development of the mental and moral possibilities of this germ-plasm, but, if we except the Greeks, whose theory of education and its results have not been equalled to the present time, none has as yet made any official effort to place the advancement of the physical possibilities upon the same high plane as the intellectual. For centuries the mind has been developed without regard to the body and ofttimes at the expense of the latter. Even today, 
in the light of all the progress that has been achieved, it would require more temerity than most educators possess to advance the perfectly sound doctrine, that because of its priority in the order of development of the human species, and by reason of the fact that it is the physical that determines the destiny of the intellectual, precedence should be given the former over the latter in any system of education founded upon a rational physiologic basis.

Dangers of Present Environment.-From a physical point of view, at least, all culture of civilization is unnatural, since it removes man farther and farther from the environment of his origin, and deprives him, in a greater or less degree, of the opportunity to use many of his faculties in the manner in which nature decreed they should be used. The primitive and simple methods of life that made for physical and moral hardihood have become obliterated, and in their stead we are living in an environment of artificiality. On the one hand we have a multitude of conveniences, luxuries, and affluence. On the other there are overcrowded communities with all their attendant evils, deprivations, and restrictions. These latter social conditions impose upon a very large portion of the inhabitants of all great centers with respect to labor, habitation, nourishment, morality, and general physical welfare, injurious circumstances which, if not constantly and persistently restricted, must, in the natural order of things, lead to the serious incapacity of any race

Hygienic Education.-It was only when unmistakable symptoms of the existence of such conditions began to manifest themselves in our own country that there was a general 
awakening to the urgency of the application of some efficient remedy to counteract them. But little attention had up to this time been paid to the enforcement of the principles of hygiene, personal and general, and as this was the remedy that must be depended upon to ameliorate this condition, every effort was made to bring the laws of clean and wholesome living within the understanding of all. The study of hygiene was introduced into the curriculum of even elementary schools; laws governing sanitation, habitation, food, etc., were enacted, and other steps were taken to impress the importance of these rules upon the public in general: as a result the average person today appreciates their necessity.

Importance to the State.- This remedy's chiefest adjunct, one that has been almost universally adopted, consists of various methods of physical training, comprising gymnastics, athletics, games, and sundry pastimes and accomplishments in which bodily effort dominates. While an immense amount of good has already been accomplished by the now rather general indulgence in the various forms of physical activity on the part of our people, and while the value of this indulgence and its importance is constantly finding more recognition, the full measure of the advantages they offer will never accrue to our citizens until physical training is made a compulsory part of the curriculum of all our schools and institutions of learning, and is treated with precisely the same dignity with which the intellectual requirements are treated. For it is only when it is recognized that " 'Tis not a soul, 'tis not a body. we are training, but a man, and we must not divide him," that we shall be doing our full duty to our fel- 
lows and to our country, which at present, on account of physical inefficiency, is forced to depend upon less than 50 per cent. of the male population between the ages of eighteen and forty-five, to bear arms in her defence.

Object of Training.-A rational course of physical training must have for its primary object the development of the human organism in its entirety by the employment of means that will give to each separate part of that organism, that which will aid in its development and assist it in the discharge of its peculiar functions, with the facility that nature intended, thereby establishing a corelation between these various organs that will produce the harmonious organic balance which is termed perfect health. In order to insure the maintenance of this balance, training must further endeavor to develop the recuperative and resistive powers of all the organs to such an extent that each has an excess amount of vigor at its disposal, against which it may draw in its own favor or in favor of the others when the exigency therefor presents itself.

\section{Interrelation Between Intellectual and Physical Func-} tions.-While the efficiency of other human qualifications is determined by physical fitness, the degree of the latter is often determined by the use that is made of the former. In other words, the amount and nature of the training, over and above that which is indulged in for the purpose of keeping the body in a healthful condition, is determined by the physical obstacles that the individual must surmount in order that he may exercise his intellectual faculties to the best advantage. A perfect relation between the two is possible only when the physical is prepared to back the intellectual with the necessary 
stamina. It is because of this fact that a great difference must exist between the training that prepares men for the ordinary pursuits of life and that which fits them for the military profession. With the former, it is a question of the individual and his personal needs, with only an indirect and indefinite bearing upon the welfare of the state. With the latter, it is a question of the individual only so far as his relation to the requirements of the service is concerned, while it has a direct and definite bearing upon the welfare of the state. The one is an independent, the other an interdependent, unit.

Physical Training for Military Purposes.-Training men physically for offensive and defensive purposes dates back to prehistoric times, and from that period to the present it alone has remained a constant and unvarying quantity in the preparation of men for military purposes. Then, as now, physical aptitude was the rock upon which every military establishment was founded, for experience has proved conclusively that upon it, more than upon all the other components of military education combined, success depends. The physical superiority of the Greeks, the unequaled hardihood of the Spartans, and the wonderful achievements of the Romans are all directly traceable to the effects of this training in ancient times, while in recent times the remarkable mobility of the Germans in 1870 and of the Japanese in 1904 can be attributed to no other reason than that of superior physical condition and training.

Modern Tendency.-The notable progress made in the art of war, which has not hesitated to seek the co-operation of all the sciences in its development, is constantly demanding 
a higher degree of intelligence on the part of its various individual units, with the result that there is a tendency, particularly in our service, to undervalue the importance of first principles in a direct ratio to the importance that is attached to the mentality. This tendency, if continued, is liable to lead to the impairment of our army's effectiveness by producing a condition wherein "the will is strong, but the flesh weak."

Requirements for the Military Service.-From a military point of view, the individual is considered only with reference to the service, whose requirements determine the nature and extent of his personal training, $i$. e., there are certain fixed standards that he must measure up to before he is considered a dependable effective. Since these requirements, as has been stated before, are far in excess of those demanded of men in the ordinary walks of life, with respect to degree, variety, and severity, it is not sufficient for a soldier to be healthy and organically sound; his profession demands more of him. He must possess more than the average amount of muscular strength, endurance, and organic vigor; he must be inured to the ill effects of exposure by having the powers of resistance, inherent in every individual, fully developed, so that he may be prepared to exchange the comparative comforts of garrison life for the hardships of field service at any time without diminishing his effectiveness. He must be trained to husband and use his physical faculties to the best advantage, and be taught to become skilful in everything pertaining to his profession, thus instilling him with confidence, self-reliance, and courage, which, after all, are 
physical qualities, as they induce men to dare because of the consciousness to do. Smartness, agility, and precision should also be insisted upon, since they are the physical expression of that mental activity which makes for self-control, self-respect, and personal neatness; these combined spell discipline, which in the military service is the synonym for success.

Effect of Exercise on Heart and Lungs.-Every muscular effort calls forth increased respiratory action; this is due to the fact that upon the respiratory system devolves the duty to supply the blood with oxygen for the repair of the bodily waste resulting from such activities. With increased respira- . tion the heart action is accelerated, thus augmenting the amount of blood passing through the lungs, where, in the maintenance of the functional balance, carbonic acid is given out and oxygen taken in. The respiratory and circulatory systems are so closely related from the view-point of physical training that it is difficult to divorce them. Exercise is a powerful stimulant to the heart, and, since this organ is a muscle, it grows in strength in proportion as the body grows, and declines in proportion as the muscular system is allowed to decline. As it is so closely concerned with every effort and so vital to well-being, it becomes the organ with which physical instructors should most concern themselves. By judicious exercise the heart may be developed until it is capable of responding to tasks that would result disastrously without this preparation. The greatest danger to the structure of the heart lies in the strain laid upon it by long-continued and excessive muscular efforts, especially of the legs and arms. 
Thus, running at a great rate of speed or for a long period; excessive use of the arms in the accomplishment of difficult gymnastic feats that require long-sustained exertion; rowing until the point of collapse is reached; wrestling and kindred contests that unduly tax the powers of endurance, should be avoided by all except those of superior strength and endurance. When it is a question of the ability of the heart to cope successfully with the strain that is intended to be placed upon it, it is always well to err upon the side of safety.

Racial Attributes to be Considered.-In determining upon a method of physical training, there are some fundamental essentials that must be taken into consideration if the fullest benefits are to be derived from it. Frequently it has been found that a method that has attained wonderful results in one country fails to produce like results when adopted in toto by another. Since the human organism is practically identical in all of the countries that have given this subject sufficient consideration to evolve methods peculiarly their own, the reason for this failure must be sought in the fact that these particular methods were originated to fit the racial characteristics of the people for whom they are intended, and that their failure when transplanted must be attributed to differences in mental characteristics and environment. Consequently, to be successful these factors must be carefully considered and recognized; the methods must be fitted to the race and not the race to the methods.

Classes of Methods. - The nature of the employment of the various means of physical training, carefully grouped into well-defined methods, is determined by the object it is sought 
to accomplish; hence, depending upon the particular objective, such training has been divided into the following classes:

A. Hygienic, whose object is the maintenance of general health.

B. Educational, the intent of which is not only hygienic, but also concerns itself with growth, development, the education of all the physical attributes in general, and the instilling of a thorough appreciation of the benefits accruing from the wholesome practice of regulated bodily activity.

C. Medical, or remedial, whose purpose is the restoration of health or the correction of physical defects.

D. Military, which concerns itself entirely with the training of men for military purposes.

Military Methods.-It is only with the last named that we shall deal here. From the complexity of the objects that the physical training of the soldier endeavors to realize, as enumerated heretofore, it might appear that the methods employed must be very diversified, complex, and wide in scope, but the contrary is true. It is no longer considered necessary to limit the means of a soldier's training almost entirely to those of an antagonistic nature in order to develop his combative qualities. The tendency is to simplify his training as much as possible; to use his weapon and the natural facilities available; and to employ only the simplest of gymnastic appliances as aids.

Instruction Material.--The following instruction material, properly applied, is ample to train men thoroughly and effectively and to keep them in excellent physical condition at all times: 
1. Setting-up exercises.

2. Marching, double timing, and running.

3. Rifle and sabre exercises.

4. Climbing.

5. Jumping and vaulting.

6. Applied gymnastics; apparatus.

7. Gymnastic contests.

8. Athletics and games.

9. Swimming.

Setting-up Exercises.-The setting-up exercises are the foundation upon which every well-organized method in military training must be founded. They require no appliances of any description, and can, therefore, be practised anywhere, out-of-doors or in the most restricted space, hygienic conditions being the only adjunct necessary to their success. By their means a more effective all-round development is made possible than by any other method. Muscular strength is developed and increased by them, and, since it is possible to bring any portion of the body into action, they are capable of imparting vigor and tone to the vital organs. By employing large muscle areas or by increasing the demands upon any one part, endurance is developed, while poise, dexterity, agility, and general co-ordination are promoted in a very high degree by the employment of movements that call for nerve control rather than for muscular exertion. The setting-up exercises should always precede the more strenuous forms of exercise, as they prepare the body for the greater exertion these forms demand.

Quick Time.-Marching in quick time, without equip- 
ment and for short duration, has little value as a developmental exercise, its object under ordinary conditions being the education of the soldier in proper poise, carriage, and gait. It is only when taken in connection with arm or leg exercises, with equipment or for long periods, that marching can be considered as a means to development. The benefits to the muscular, respiratory, and circulatory systems under such circumstances depend upon the degree of severity of the movements performed.

Double timing has for its purpose the quick advancement of troops with the least possible expenditure of physical effort: this is accomplished by diminishing leg motions, thereby curtailing the height of the thrust of the body when neither foot is upon the ground. Its greatest importance lies in teaching the men how to husband and conserve their muscular strength and how to control the respiration to the best advantage.

Running is the swiftest and physically the most expensive means of progression. It differs from double timing in the increased number and exaggerated character of the leg movements; in the increased force with which the body is thrust from the ground; and in the increased demand upon the muscles of the trunk and neck, which, by their contraction, give to the head and body that degree of immobility without which speed is impossible. It is almost entirely this contraction, which interferes seriously with regular respiration and which in turn affects the heart action, to which the breathlessness noticed in runners is due. Thus, while running will develop endurance as well as lung, heart, and leg 
power as no other form of exercise will, it does so with the ever-present liability to injury when carried to excess.

Rifle and Sabre.-Rifle exercises are extremely valuable in developing dexterity in the use of the weapon, and, on account of the weight of the piece, they develop the muscles of the back, arms, shoulders, and upper chest in a marked degree. When taken in connection with leg and trunk movements they are excellent aids in the development of organic vigor, especially of the heart and lungs, for those who possess the necessary strength to wield the piece to advantage.

For the mounted service the sabre, used ambidextrously, may be substituted for the rifle.

Climbing may be regarded as an applied exercise, since it prepares the men for the exigencies of the service by teaching them successfully to overcome obstacles that may be presented to them in the field. Climbing with hands and legs brings into action almost every muscle of the body, and, when the climbing is done with the hands alone or at a rapid rate with both hands and legs, it has a very marked effect upon the heart and lungs.

Jumping and vaulting are, essentially, applied forms of exercise; they are invaluable to a soldier, who, in the field, is constantly being confronted by obstacles which he must negotiate either by jumping or vaulting. Jumping, besides being a potent leg developer, is also a great factor in the development of agility and muscular co-ordination, and, when taken from a considerable height, of self-reliance. Vaulting develops the muscles of the arms and legs, and, since these members must work in unison, the sense of co-ordination be- 
tween the two is fostered in a high degree. Vaulting also promotes self-reliance and fearlessness.

Applied gymnastics are those forms of movements in which the soldier is instructed to overcome and surmount obstacles by means of his own exertions. These obstacles may be gymnastic appliances, such as horses, vaulting bars, and horizontal bars, or they may be natural objects, as fences, walls, and ditches. The purpose of these exercises is the muscular development of the body in general and of the arms and legs in particular, with special reference to strength, agility, dexterity, and confidence, in order to enable the soldier to accomplish these efforts with the least amount of physical exertion.

Gymnastic contests consist of the simpler forms of antagonistic exercises in which the contestants are pitted against each other. Their aim is the promotion of quickness of thought, perception and action, with definiteness of purpose. They require considerable skill and muscular effort, and for that reason make for endurance and vigor by affecting the vital organs in a more than moderate degree.

Athletics.-The value of athletic games to the military service is dependent upon the effect these have upon the mass and not upon the individual few. Training in these, in order to meet the requirements of the service, should have nothing in common with competitive athletics, but should be broad enough to reach out and include the development of every man, to the extent of his capabilities, in those branches of athletics whose utility to the service is unquestioned. In other words, they should have an applicable value, be educa- 
tional, recreative, and not spectacular, for it is the ability of the average of the mass that determines the efficiency of the whole.

In order to stimulate interest the men should be grouped into classes upon the basis of ability, and promoted or demoted as their progress or lack of it warrants.

Properly conducted athletics can be made a very decided factor in the scheme for the training of the soldier, since they embody all those qualities which, from time immemorial, have been considered so essential in the soldier. 'They require an abundance of muscular and nervous energy, endurance, hardihood, skill, courage, and reliance, and, as these qualities cannot be developed in a very high degree without a strict adherence to the laws of hygienic living, excesses of any description must be avoided by those wishing to excel. Athletics and athletic games are thus powerful and voluntary aids to discipline.

Swimming is of vital importance to all who are concerned with the service, and proficiency therein should be required of all, officers and men. Aside from its usefulness, it is one of the very best means to attain all-round development. The combinations and the character of the movements employed in swimming bring almost every group of muscles into action in a manner that is impossible in any other form of physical exercise. It adds materially to the powers of respiration, thereby increasing the size of the thorax and giving a decided tone to the lungs and heart. Not less important is its effect upon the moral qualities, confidence, reliance, 
judgment, and courage, all of which are promoted to a degree not equalled by any other means.

Factors to be Considered.-In employing the various means described above and embodying them into a defined method, the following factors must be considered:

(a) The condition and physical aptitude of the men.

(b) The facilities.

(c) The time.

(d) The instruction material.

Condition and Aptitude.-The question of physical aptitude and general condition of the men is a very important one, and should always determine the nature and extent of the task expected of them. Never, except in the more advanced classes, should the work be made the determining factor. In general, it is advisable to divide the men into three classes, viz., the recruit class, the intermediate class, and the trained soldier class. The work for each class should fit the capabilities of the members of the respective classes and be arranged progressively.

Facilities will necessarily influence the nature and extent of the work, but even with the most meagre ones an enterprising instructor need not despair of results, since the instruction material is applicable to all conditions.

Time is an important factor, and no method can be successful unless specified periods are arranged for in advance. During suspension of drills, at least five periods a week, of from thirty to forty-five minutes each, should be devoted to this training; during the drill period ten or fifteen minutes per day should be assigned to the setting-up exercises. 
When possible, these physical training drills should be held in the morning, about two hours after breakfast; at no time should they be held immediately after or before a meal.

Use of Material.-The proper use of the instruction material is undoubtedly the most important factor, for success is dependent upon its proper selection and application. Every exercise has a function peculiarly its own, and it is the sum of these exercises that constitutes the success of the method. When possible, every lesson should be planned to embrace $(a)$ setting-up exercises that call into action all parts of the body; (b) applied gymnastics; and (c) exercises that develop co-ordination and skill, such as jumping and vaulting. Exercises that employ the extensor muscles chiefly should be followed by others that employ the flexors; and those requiring a considerable amount of exertion should be succeeded by those in which exertion is reduced to a minimum. Exercises for one part of the body should be alternated with those for another: thus, arm movements should be followed by leg movements, and these, in turn, by others for the trunk, shoulder, or neck. The work must be conducted so that the men are developed harmoniously, and any tendency to develop one part or one side at the expense of the other must be avoided. All exercises should be performed energetically, and precision and accuracy should always be insisted upon; thus, while strength and endurance are being generated, activity, agility, and smartness are also promoted. Exercises should be selected that require activity and agility rather than those that require strength only. It should always be kept in sight that the exercises are, as a rule, the means and 
not the end, and if there is any doubt as to the amount of strain produced by an exercise, it should be modified in character or shortened in time. Underdoing is rectifiable; overdoing often is not. The object should be, not the production of experts, but the development of physically sound men by means in which the chance of bodily injury from overexertion or strain is reduced to a minimum.

Fatigue and Breathlessness.-In order to make the drills attractive the work should be made as varied as possible, for the mind exerts more influence over the body than do all the gymnastic paraphernalia. The men should never be exercised to the point of exhaustion; if there is any tendency to respiratory embarrassment, the exercise should be terminated and not resumed again until the men have recovered their breath. Proper breathing should always be insisted upon; "holding the breath," or breathing only when it can no longer be held, is injurious. Every exercise should, if possible, be accompanied by an uninterrupted act of respiration (inspiration and expiration) depending upon the nature of the exercise. Inhalation should always accompany that part of an exercise which tends to extend and elevate the thorax, while exhalation accompanies that part of an exercise that exerts pressure against the chest walls. Excessive and frequent breathlessness is not infrequently the cause of serious injury to the heart, to the lungs, or to both these organs; therefore, in cases where exercises produce that condition, it is advisable to recommend absolute rest or to order such slow movements as will tend to relieve the oppressed and taxed organs. Leg exercises, slowly executed, 
will equalize the circulation by drawing the blood from the trunk to the lower extremities, thereby lessening the heart's action and quieting the respiration.

Avoidance of Chill.-Muscular action produces an unusual amount of bodily heat, which should be lost gradually, otherwise the body will become chilled; it is advisable, therefore, to add some wrap after exercising and to be well protected when leaving the gymnasium or drill ground. The taking of cold baths when the body is heated (as is the case after violent exercise) should be discouraged. In individual cases such baths may appear beneficial; in a majority of cases, however, they cannot be used with impunity. Tepid baths are recommended. When impossible to bathe, the flannels worn while exercising should be stripped off, one garment at a time, the body sponged with tepid water, and then rubbed thoroughly with coarse towels. Flannel is the best material to wear next to the skin while exercising, as it absorbs the moisture of the body, protects it from drafts, and excites the skin mildly. The men may wear the ordinary athletic costume when weather conditions permit. 


\section{CHAPTER V}

\section{PREVENTABLE DISEASES}

In the first place, the fact must be recognized that there are no diseases peculiar to soldiers. There is not, by reason of their occupation or mode of life, any abnormal physical condition engendered which has not its counterpart among civilians. On the other hand, there are certain departures from a state of health to which soldiers are especially liable because of their work and environment. Newly raised troops and recruits generally have the highest disease rates. Old soldiers are inured to service and have learned how to care for themselves.

Dependency of Soldiers. - "The men who compose an army are drawn from civil life, in which each individual has, to a greater or less extent, independent control of his time, choice of occupation, selection of food and dwelling place, and general sanitary care. After enlistment, soldiers lose most of this independence; they are housed, clothed, fed, and exercised under regulations which it is beyond their power to amend; they are moved from one point to another, differing perhaps very widely in climatic and other conditions, under orders which they may not presume to question; their hours for sleep, meals, work, and recreation are fixed for them without consultation with them or without regard to individual or communal preference" (Harrington). 
Inexperienced Soldiers.- In our military system the absolute dependence on the will or neglect of a superior is especially prone to result in disease conditions, because of the ignorance and inexperience of militia and volunteers suddenly called into active service. The officers have little or no knowledge of the care of troops, while the men exhibit a recklessness and disregard for the laws of health peculiarly national. The American volunteer, unless firmly commanded, displays the utmost indifference to the ordinary rules of decency. He deposits his excrement where he happens to be; he drinks of any liquid he encounters which may be dignified by the name of water; he throws his wastes indiscriminately upon the camp ground, heedless of the fact that putrefactive changes will shortly make them offensive; he gleefully seeks opportunities for alcoholic and sexual excesses; and, in defense of his heaven-born liberties, he often declines to mend his ways because he enlisted to fight and not to perform menial occupations. The necessity on the part of line officers for familiarity with the preventable diseases to which the soldier is liable and with the fundamental sanitary principles necessary for their prevention thus becomes apparent.

Infection and Immunity.-Nearly all the so-called preventable diseases (and especially those of an epidemic character) are infectious; that is to say, they are caused by a specific germ or virus which is capable of being transmitted from one person to another. Germs are extremely minute living bodies, most of them being tiny vegetables, though some are microscopic animals. The vegetable germs are known as bacteria, but are classed as micrococci, bacilli, or spirilla, in accordance 
with their shape. Thus, a coccus is round; a bacillus, rod shaped; a spirillum, curved. Animal germs which cause

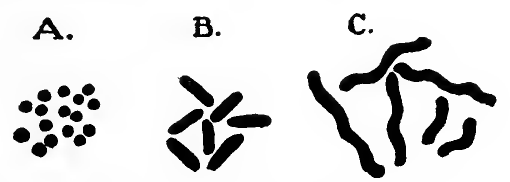

Fig. 1.-Disease germs of vegetable origin. Forms of bacteria: A, Cocci (or micrococci); B, bacilli; C, spirilla. Bacteria are extremely small, some being not more than $\frac{1}{50,000}$ inch long.

disease belong to the lowest class of the animal kingdom, the so-called protozoa. A protozoön is made up of a single cell. Not all persons are susceptible to the attacks of disease germs.

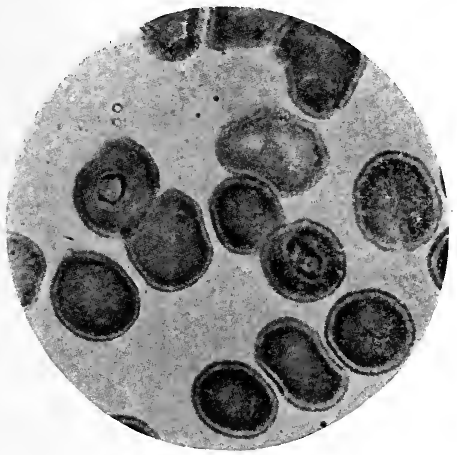

A

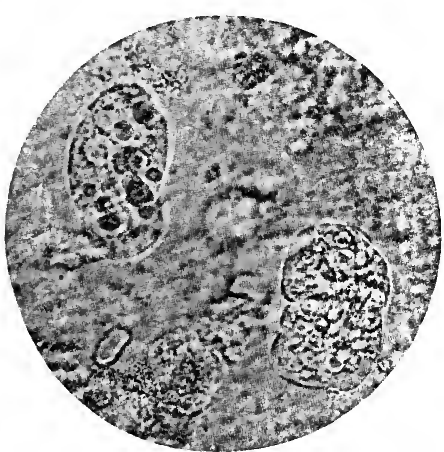

B

Fig. 2.-Disease germs of animal origin. A, Malaria: the germs are the darker objects seen inside red blood-corpuscles. The corpuscles are about $\frac{1}{3000}$ inch in diameter. B, Amebic dysentery: the round spots within the amebæ are blood-corpuscles which the former have captured. (From Bulletin No. 1, Office of the Surgeon General, United States Army, 1913.)

Some individuals possess a natural immunity to one or more diseases, while others may become immune through an attack of the disease or by vaccination against it. 
The Prime Source of Infection.-In the consideration of the subject of preventable disease, the one fact that overshadows all others is that the prime source of infection is the sick man. Air, food, water, insects are simply distributing agents. 'Therefore, the sick and the well must be separated, and any body wastes which may contain the infectious agent must be rendered harmless. It should be understood that all nature swarms with minute forms of life, though comparatively few of these will produce disease. Simple methods often suffice to destroy disease germs. Such methods include the use of physical agents (notably, heat) and chemicals. A chemical which kills the germs is known as a disinfectant. If its strength is not sufficient to kill, but is yet enough to retard microbic growth and activities, the agent is called an antiseptic. Sterilization is a term employed to indicate the complete destruction of all microscopic forms of life which may be contained in any substance.

Venereal Disease.-Of all the ills from which the soldier suffers, those consequent upon venery affect his efficiency to the greatest extent. Our army is made up mainly of young, unmarried men, freed from the moral restraints of home, often without opportunity for association with decent women and susceptible to the suggestions of the vicious. There must be some outlet for their surplus energies. They visit places of amusement, many of which are maintained with the sole object of pandering to vice, where strong liquor and the advances of lewd women combine to break down such moral defenses as they may possess. Unless prevented by legal enactment the lowest kinds of "dives" cluster round the 
entrances to army posts. The soldier has a right to his amusements and we must strive to furnish such as will attract him more than evil resorts; to secure the passage of laws preventing the establishment of low brothels at our gates; and to build up the moral stamina of our men by education.

Statistics show that at least a third of all women who give their bodies for immoral purposes are suffering from some form of venereal disease. This includes not merely the professional prostitute, but the chorus girl, "saleslady," or mill hand, who, to satisfy her love for finery or for other reasons, may eke out a scanty income by occasional lapses from virtue. It is a medical axiom that every prostitute becomes infected with syphilis inside of two or three years. It is, therefore, easy to see that the risks of contagion are very great.

This subject will be discussed more at length in a later chapter.

\section{Typhoid Fever}

Typhoid fever (or enteric, as the English call it) has for many years been known as "the scourge of armies." In our Civil War the Union Army had over 80,000 cases recognized as such, and there were probably as many more which, because of imperfect means of diagnosis, were thought to be malaria and other affections.

War of 1870. - The Germans, in the war with France in 1870 , had over 73,000 cases and nearly 7000 deaths, although active hostilities lasted but six months.

Boer War.-The British Army in South Africa, while fighting with the Boers, had 57,000 cases and 8000 deaths. 
War of 1898.- In our war with Spain we had 20,738 cases, with 1580 deaths, among 108,000 men, all occurring within three and a half months; 1 man in every 6 had the disease, while this proportion was increased to 1 in 5 among those regiments which never left the United States. Typhoid fever caused nine-tenths of all deaths occurring among troops encamped in the United States in 1898.

Such instances might be multiplied indefinitely, but enough has been said to show what an immense amount of sickness and military inefficiency - to say nothing of the suffering and death of individuals, with economic loss - this dreaded disease causes.

In Civil Communities.-Typhoid fever exists constantly in civil communities, and it is safe to say that 1000 men of military age could not be assembled anywhere in this country without at least one man bringing the disease along with him. It is estimated that in the United States we have annually about 400,000 cases of typhoid fever, with approximately 40,000 deaths. This means a death for every 10 persons attacked, and many who do not die never recover completely, but become chronic invalids or are crippled in various ways. In any event, a man will be disabled by an attack for at least three months, as convalescence is slow and protracted. Young men are peculiarly liable to the disease, which by preference attacks vigorous males between the ages of fifteen and forty. However, cases are by no means infrequent in later life.

Cause.-Typhoid fever is due to a tiny little vegetable germ-or, rather, to aggregations of billions and trillions 
of such germs - to which is given the name typhoid bacillus. When looked at under the microscope these germs, if suspended in a drop of water, are seen to have very active motion. They multiply with enormous rapidity, so that under favorable conditions a single germ may develop into millions within twenty-four hours.

How Spread.-Typhoid bacilli find the most favorable soil for their growth and increase in the bowels of human beings; they are usually found also in the urine of infected individuals. The disease is spread, therefore, by the discharges of such individuals gaining access to the intestinal canals of others through swallowing substances contaminated with the germ. This may happen directly by contact with a diseased person or indirectly through infected water, milk, uncooked fruit and vegetables, dust, flies, soiled hands, garments, bedding, or tentage.

If we had a perfect method of disposal of these waste products of the body, it would not be long before typhoid fever would cease to appear in epidemic form, and only an occasional case would be encountered as the result of direct contact with an infected individual. But, under the imperfect sanitary conditions of modern existence, it will be a long time before this is realized, and in the meanwhile we must employ such measures as will reduce to a minimum the risks of contact with infectious material.

Army Epidemics.-Typhoid fever is more likely to become epidemic in military than in civil life because of the greater difficulty in disposing of wastes, and the close crowding and intimate contact of young men under the conditions of camp 
and barrack life. A man affected with typhoid may scatter the germs of the disease widely before its existence is recognized in himself, since it frequently happens that mild cases are not detected for a week or two from their onset. Moreover, 3 or 4 persons in every 100 who have recovered from attacks continue to breed the germs in their bodies and to discharge them with their excretions. We call such chronically infected individuals carriers. Such a man, by defecating in the nearest brush, stepping just outside his tent at night to urinate, or failing to cover his discharges in the sink (whereby flies may have access to them, to convey the filth to food in nearby kitchens a little later) may be sowing the seeds of the scourge broadcast. Each man who thus offends seems to think he is the only one who does such a trick and so it won't do any harm. Unfortunately, many of his comrades are looking at the matter from the same point of view. And flies are not necessarily the agents in this matter. Let us again assume one infected individual in camp. His habits as to cleanliness may be bad or his opportunities therefor poor. At any rate, his hands are sure to be soiled with infectious material, which he transfers to everything he touches-clothing, bedding, towel, the cigars or matches he proffers to a comrade, and even the food of others which he handles-for he may be company cook or cook's police. His saliva is infectious and he fouls the common drinking cup or a pipe which another may use. Or, again, a soldier's shoes may be soiled with the filth deposited upon the ground by a careless comrade. This material is carried about the camp and into tents, and, since the typhoid bacillus may live for a 
time in the earth, a puff of wind or a friendly scuffle whirls the infected dust in the air, whence it is likely to be inhaled or blown upon food and thus swallowed. By such means not one but dozens of men are infected, and with each new case the risks grow in geometric progression. In the multitude of cases during the Spanish-American War, impure water played little or no part. The three factors almost wholly responsible for these cases were uncovered excreta, flies attracted thereby, and personal contact with infected individuals.

Prevention.-Now, what is the "ounce of prevention" in this case? It consists, first, in the preliminary antityphoid vaccination of men believed to be susceptible; second, in a campaign of education (which must be shared by line and medical officers alike) in the facts just related; third, in the protection of the water-supply; fourth, in the systematic and thorough disposal of excreta and organic wastes generally; and fifth, in sharp punishment for violations of sanitary regulations.

Antityphoid Vaccination.-In antityphoid injections we now have a method of protection against this disease which is quite as efficacious as is vaccination against small-pox. It is well known that an attack of typhoid usually protects a man against a subsequent attack. Only 1 case in 143 has typhoid a second time, and the method of protection referred to is found to confer immunity in a similar way and, it is thought, to an equal degree.

Its History.- The development of the method is interesting and its history will not be amiss. Acting upon the knowledge, 
heretofore mentioned, that an attack of typhoid protects against the disease subsequently by causing the formation in the blood of substances which are antidotal to the typhoid bacillus, an English investigator began, a few years ago, to experiment in the artificial production of these substances. He found that when he killed bacilli by subjecting them to heat, and then injected a quantity of them under the skin of an animal (in this case the guinea-pig) which is susceptible to the disease, he produced in the blood of this animal exactly such substances-called antibodies for convenience-as an attack of typhoid produces in the blood of man. Here, then; was his clue, which he followed up by injecting killed bacilli under the skin of some British soldiers going to the Boer War. The results were but fairly good, and it was only after some years of further experimentation that it was found that not enough antibodies were produced by a single dose and that a second and even a third injection, at intervals of about ten days, was necessary to produce satisfactory immunity. Since this stage of knowledge has been reached, the British and German armies have tested the procedure (now known as antityphoid vaccination), with strikingly good results.

Germans.-The Germans, in their campaign against the Herreros in Southwest Africa, 1904 to 1907, cut their typhoid rate in half by vaccinating a part of their soldiers. Those who, in spite of the treatment, were attacked by the disease, had mild cases which were seldom attended by complications.

British.-In 1908 the British vaccinated about 6000 of their soldiers in India and maintained nearly an equal number of unvaccinated men under similar conditions, in order to 
compare the results. It was found that seven times as many of the non-vaccinated contracted typhoid and that eleven times as many died of it. Moreover, all but 4 of the vaccinated men who contracted the disease received but one dose, while those 4 had very mild attacks. To make the comparison of results even more striking, it may be said that as many of the non-vaccinated died of this fever as were taken sick among the vaccinated individuals.

United States.-But it is in our own service that the procedure has been most thoroughly tested and its value definitely proved. Vaccinations of officers and men who volunteered for the purpose were commenced in 1909. The results were so good that in 1911 the procedure was made compulsory for all under forty-five years of age who had never had the disease. The navy followed suit, and immunization of both services is now practically complete. A single instance of the value of this prophylactic measure to our service will suffice. This takes the form of a comparison between an army division in Florida during the Spanish War in 1898 and a division in Texas during the border troubles of 1911. Conditions as to strength of command, climate, season, purity of water-supply, and duration of camp were approximately equal. The disposal of wastes was much superior in the latter camp, but the complete immunization of the Texas command by means of the antityphoid prophylactic constituted the conspicuous difference:

$\begin{array}{llcc}\text { Yean } & \begin{array}{c}\text { Mean } \\ \text { strength. }\end{array} & \begin{array}{c}\text { Cases of typhoid } \\ \text { (certain and } \\ \text { probable). }\end{array} & \begin{array}{c}\text { Deaths from } \\ \text { typhoid. }\end{array} \\ 1898 \ldots \ldots \ldots \ldots \ldots \ldots \ldots \ldots \ldots \ldots & 10,759 & 2.693 & 248 \\ 1911 \ldots \ldots \ldots \ldots \ldots \ldots \ldots \ldots & 12,801 & 2 & 0\end{array}$


Preparation.-The material employed is prepared in the Army Medical Laboratory at Washington, and, after sterilization by heat at a moderate temperature, a small percentage of disinfectant is added to insure its keeping properties and it is placed in sealed glass tubes. When a vaccination is to be made, the tip of the glass tube is broken off, the contents sucked up into a hypodermic syringe, and a small amount injected under the skin of the arm in the situation used for ordinary vaccination. Usually within three or four hours from the time of the injection the vaccinated man notices certain symptoms of the action of the substance. These are redness, swelling, and soreness for an inch or two about the site of the injection, with perhaps some headache, backache, feverishness, and a sick feeling. These symptoms vary in severity with different individuals, but in many thousands of doses administered to persons in our army, less than 1 per cent. have been followed by anything like severe reactions, while less than 5 per cent. show even moderate severity. In two-thirds of all cases practically no reaction has been observed other than a little soreness of the arm. Symptoms of the usual reaction may best be described by saying that one feels as if he were coming down with a cold, but, as recovery follows quickly, he realizes that it was merely the effects of the vaccine. This reaction lasts from four to fortyeight hours. In most cases, if the dose is administered in the afternoon, for instance, the symptoms are quite gone by the following morning. The discomforts attendant upon immunization against this dread disease are, therefore, much slighter and briefer than are those of a successful vaccination 
against small-pox and infinitely less painful than a visit to the dentist.

Immunity.-We do not yet know how long the immunity conferred in this manner will persist. However, we find that the vaccination produces in the blood a greater quantity of the so-called antibodies than is produced by an attack of the fever. We know that, as before mentioned, an attack of the disease protects, as a rule; throughout life. 'The experience of the English, who have been using the method longer than we, would seem to show that men were still protected after the lapse of two or three years. If the immunization lasts no longer than three years, this period would still be sufficient for us as military men, since no war in the present age is likely to last so long. Then, too, just as experience has shown the value of occasional re-immunizations against small-pox, it may be found desirable to repeat the antityphoid vaccination prior to special military operations involving increased risk from the disease.

This subject has received somewhat extended treatment because of its great importance. The military value of the discovery of a preventive for the scourge of armies is second only to that of vaccination against small-pox.

Much that has been said of typhoid fever applies equally to dysenteries and camp diarrheas, which also are due to specific germs residing in the intestines of infected individuals. These diseases occupy much space in the medical history of our army in earlier times, though at present they do not often appear in epidemic form. During our Civil War these oc- 
curred with much frequency and produced more sickness and mortality than any other form of disease.

\section{Dysentery}

Dysentery remains the most serious of the diseases to which our people in the Philippines are liable. Broadly speaking, dysentery is any inflammatory disease of the bowels in which blood and mucus appear in the stools. Based upon their causative factors there are two types, the one due to animal (protozoal), the other to vegetable (bacterial), parasites.

Amebic Type.-The principal form of dysentery under the first head is caused by an ameba, a minute animal consisting of a single cell. This is the type which causes most trouble in the Philippine Islands; it is also met with in our Southern States. The amebæ enter the body with food or water and produce inflammations and ulcerations of the large intestine, which are sometimes complicated by abscesses of the liver. Their natural home appears to be the human intestine, and from this source they contaminate foods (especially fruits and green vegetables) or drinking-water.

Bacillary Type.-The bacterial type of dysentery is caused by the bacillus dysenterice. Bacillary dysentery can only be told from the amebic form by an expert, but for our purposes this fact is unimportant, since our preventive measures are the same for both. This type is very widely distributed over temperate as well as hot climates, and is the one which is responsible whenever epidemic outbreaks occur in an army. The bacilli are conveyed from fecal matter to the mouth by contaminated food or drink. Flies are common agents of 
transference and personal contact plays as large a part as in typhoid. As a result of their ${ }^{3}$ presence in the bowel and the development of poisons (toxins) resulting from their activities, ulcerations of the large intestine, hemorrhages therefrom, and great prostration result. This form is usually more active and dangerous than the amebic, being sometimes almost as rapidly fatal as cholera.

Camp Diarrheas.-Diarrheas are very common in field service and may result from a variety of causes, such as bad food, poor cooking, or abdominal chilling. There is also an epidemic form (heretofore referred to as camp diarrhea) which attacks large numbers of men at one time and is severe in character. One cause of epidemic diarrhea is the dysentery bacillus, which occasionally manifests its activities thus, but any form of diarrhea is bad, since it not only rapidly weakens a man, but, by irritating the intestines, it increases the liability to attack by the more serious affections, typhoid fever and dysentery. Under conditions of active service the importance of "carriers" of typhoid, dysentery, and epidemic diarrheas is greater than in civil life. Indeed, these probably constitute the most important of all factors.

Prevention.-Preventive measures for all forms of dysenteries and camp diarrheas are identical with those for typhoid fever save in the matter of vaccination, for which we do not as yet possess an efficient agent. The water-supply should be carefully protected from fouling; the feces of men sick with these diseases should be disinfected or otherwise safely disposed of; the sick should be separated from the well; and all sources of irritation of the intestinal tract should be avoided. 


\section{Malaria}

The malarial fevers constitute an important class of diseases. Other names by which they are known are ague; chills and fever; remittent fever; intermittent fever. The dreaded Chagres fever of Panama is a form of pernicious malaria. There are three types of these fevers, each due to a different minute animal parasite which attacks the blood of man, but it is sufficient for our purpose here to know that all have a similar origin, namely, the bite of an infected mosquito. The method of transmission was discovered as recently as 1898 by a British Army surgeon.

Anopheles Mosquitoes.-Only one variety of mosquito (the anopheles)—which, however, has rather numerous species-is capable of transmitting the germs responsible for the disease. The mosquitoes may be recognized, in their adult or even in their larval forms, by peculiarities in their attitudes when at rest. The larvæ (popularly called "wigglers") of harmless (culex) mosquitoes lie head downward in the water in which they are developing, with only their breathing tubes in contact with the surface. Those of the anopheles lie parallel with the water's surface and just beneath it. Mosquitoes themselves, when resting, show opposite peculiarities; that is, the common forms lie parallel with the surface to which they cling, while the anopheles rest with their heads near the surface and their bodies angling away from it. Another point of difference is that the common form is humpbacked, while the anopheles is nearly straight 
from proboscis to tail. It is worthy of remark that only females are blood-suckers and thus transmitters of malaria. The male may readily be recognized by the feathery tuft on his head.

Mode of Transmission.-The transference of the infection from one man to another is accomplished in the following manner: A certain individual has malaria, which means that he has in his blood the germs which cause the disease. An anopheles mosquito bites

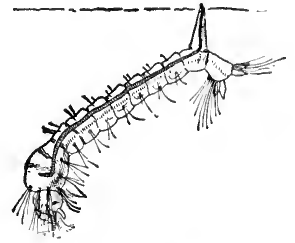

Fig. 3.--Larva of culex mosquito, resting at the surface of the water (after Howard). him and draws into her stomach, along with the blood, a number of these germs, which undergo a peculiar form of de-

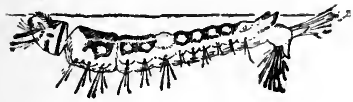

Fig. 4.-Larva of anopheles mosquito (after Howard).

velopment within her body. After this development is complete, this mosquito bites a healthy man, and, injecting a little saliva through her hollow proboscis in order to make the blood more fluid, she thus presents this second man with a number of undesirable guests in the shape of malarial parasites. These promptly attack such of the red corpuscles of his blood as are most available, and the cycle is complete. Thus, the conditions which must exist to favor the spread of malaria are: first, an infected human being; second, anopheles mosquitoes; third, healthy men;

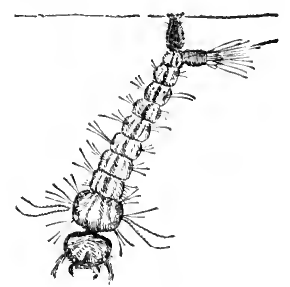

Fig. 5.-Larva of stegomyia mosquito (after Rosenau). and fourth, opportunity afforded to the mosquitoes. The germ of the disease is a microscopic, single-celled animal 
(protozoön). This germ was discovered in 1880 by a French Army surgeon.

Prevention.-Preventive measures are as follows: first, precaution against mosquito bites by the use of screens for

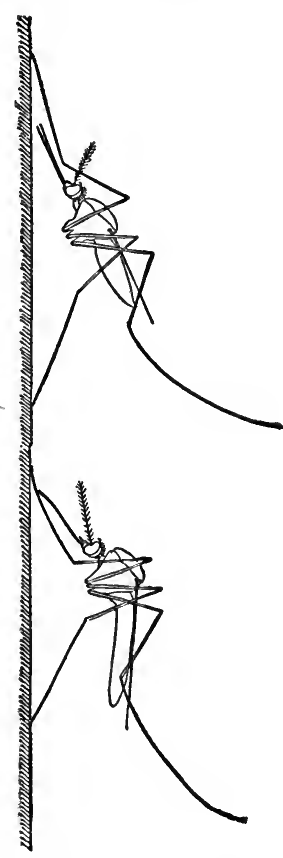

Fig. 6.-Adult mosquitoes; resting position on a wall. Anopheles above, culex below (Howard, after Waterhouse). doors and windows, bars for beds, and head-nets and gloves when necessary at night; second, the killing of mosquitoes in houses by fumigation, trapping, or other means; third, the destruction of their breeding-places (i.e., collections of standing water), associated with the cutting of high grass and underbrush near human habitations; and fourth, the routine administration (in malarious localities) of small doses of quinin to officers and men and attached civilians. When an individual is known to be infected, he should be screened with especial care to prevent access of mosquitoes to him. General Gorgas is of the opinion that when troops are marching through a malarious country the only practical measure for their protection is the administration of quinin. The theory of this procedure is that when the malarial parasites are introduced into the blood, they find there a substance hostile to them. He says further, that such anopheles mosquitoes 
as may bite soldiers in campaign, would not likely be infected unless the troops are quartered in or camped near some town. If the camp is occupied for more than a day or two the ground should, of course, be cleared and accumulations of water drained away or oiled.

\section{Tuberculosis}

Tuberculosis is what is commonly known as "consumption," because of the wasting away of the body which is an invariable accompaniment. The tubercle bacillus, which is responsible for this disease, may and does attack any part of the human body, but tuberculosis of the lungs so greatly preponderates that when we apply the term the pulmonary variety is generally meant. Though this affection may result from food (especially milk) containing the tubercle bacillus, the usual channel of infection is by way of the lungs, the germs being carried in the air. A soldier with the disease may, before the condition is suspected, infect the air of his squad room to such a degree that all other susceptible individuals therein may contract the disease.

Coughing and Spitting.-The germs are coughed up from their seat in the lungs; the spitting habit, as we know, is one deeply engrafted upon the American male; the germs resist death by drying to a remarkable degree. We are, therefore, likely to have in barracks the conditions best suited to the spread of this disease, namely, a number of susceptible individuals closely aggregated, an infected man who scatters his sputum carelessly about, and close air, breathed over and 
over because of the inadequate ventilation so dear to the average crowd.

Prevention.--The information just given readily suggests the means to be employed to prevent the spread of this affection, which are: first, the exercise of great care in recruiting, to exclude those in the early stages of the disease; second, the early recognition of such cases in the military service, with their removal to a special hospital; to this end, non-commissioned officers should be required promptly to report any man who has a persistent cough; third, ample air space per man in barracks; fourth, adequate ventilation must be provided for and its mechanism carefully guarded to insure its continuous operation. In this connection it is well to state that in our service the guard-house is the place most commonly infected, since it is usually overcrowded and the men of most careless habits are apt to be immured therein.

\section{Tonsillitis}

Tonsillitis and other throat affections are very common in barracks during cold weather and frequently cccur in company epidemics. When such is the case, ventilation is at fault, and it will usually be found that the men, for the sake of warmth, have stopped up the air inlets. Such throat affections are often quite severe and prostrating and may even resemble diphtheria at first. They are not usually due to any one specific germ, but rather to one or more varieties of ordinarily harmless bacteria residing in the throat, which have taken on virulent properties by reason of the lowered vitality of the tissues due to bad air. The sick should be isolated 
promptly and the tendency on the part of fresh-air cowards to plug up ventilation shafts in cold weather must be appreciated and combated.

\section{Influenza}

Influenza, commonly known as "the grip," occurs in epidemic waves which affect the civilian population equally with the military, but as this is clearly infectious, being due to a well-known bacillus, and is transmitted chiefly if not wholly by contact with the sick, such contact should be avoided as far as possible. The influenzal bacillus prefers to attack the respiratory system, but may affect the digestive tract or the membranes surrounding the brain and spinal cord instead. It is often a serious disease, since such complications as pneumonia, meningitis, and ear suppurations are not unusual. Marked depression of spirits is a frequent accompaniment. Many people are crippled in health for years after an attack.

\section{Colds}

Though seldom serious in symptoms or results, common colds are so frequent and temporarily disabling that they deserve mention here. Many of them are undoubtedly "catching," and persons suffering from them should take pains to avoid close contact with others. A large percentage of cases is due to overcrowding and faulty ventilation in barracks. Other causes are wet feet and chilling following overheating of the body's surface.

\section{Measles .}

We are apt to underrate the importance of this highly contagious disease, which, in time of war, when new levies of 
troops are brought together, becomes a really serious condition. City-bred recruits have usually had an attack in childhood, but those from country districts very likely have not encountered the infection. The disease is much more severe in its effects upon adults than upon children. In the Union Army during the Civil War there were 76,000 cases, with more than 5000 deaths. Among the Confederates whole brigades were temporarily disbanded on this account in the early part of the war. No means of prevention other than isolation of the sick and their attendants are at present known. Measles is due to a virus whose exact nature is as yet unrecognized.

\section{Mumps}

Mumps is also a contagious disease, and, like measles, causes much disability among newly raised troops. It is not so serious in its results as measles, but is a painful and disabling affection, especially when, as frequently happens, it attacks the testicles. Its ordinary characteristic is an inflammation of the salivary glands located in the neck near the angle of the jaw.

\section{Cerebrospinal Fever}

Cerebrospinal fever (meningitis) occurs with considerable frequency at recruiting depots, on transports, and in camps. Luckily, though many inhale the micrococcus which is its cause, but few are susceptible to the disease. Direct contact is responsible for the transference of the infection and "carriers" play a large part in its spread. It is a very deadly disease unless antimeningitic serum is used promptly. 
Early recognition of its presence in the command, rigid isolation of the sick and of such carriers as can be located, with disinfection of all discharges from their throats and noses, are the essentials in its prevention.

\section{Scarlatina}

Scarlatina (scarlet fever), though a highly contagious and dangerous disease; fortunately attacks adults but seldom, so does not need extended discussion in this treatise, but a case of sore throat, associated with a brilliant eruption on the skin, should be regarded as suspicious of this disease and immediately isolated.

\section{Diphtheria}

Diphtheria, another very contagious and serious affection, is far less feared since the discovery of its antitoxin. This substance has great value in the prevention of the disease as well as in its cure. It is given hypodermically to all persons exposed to the infection, as well as to the sick man.

\section{Small-pox}

Small-pox, the disease most dreaded by our forefathers because of its repulsiveness, its mortality, and its disfiguring effects, has been robbed of its terrors by the wonderful protection afforded by vaccination, but if the antivaccinationists had their way this loathsome pest would reappear, deadly as ever, since it is kept alive in many communities by those who evade the means of prevention.

Varioloid is simply a mild attack of small-pox. 


\section{Hookworm Disease}

Hookworm disease has recently been shown to be of great economic importance in Porto Rico and our own South. Curiously enough, the animal source of this affection, though its home is the human intestine, makes its way into the body of the person attacked through the skin and not by way of the mouth. The eggs are passed out with the feces and the larvæ-which constitute the infective form-hatch outside the body. The measures of prevention, therefore, consist of two things, namely, the proper disposal of excreta and the wearing of shoes.

\section{Dengue}

Dengue, better known as "breakbone fever," is a disease which causes much sickness among our people in the Philippines, but which, fortunately, does not terminate fatally. In common with malaria and yellow fever, it is transmitted by the bite of a mosquito, so measures directed against this pest receive an additional argument.

\section{Yellow Fever}

Thanks to the late and deeply lamented Major Walter Reed of our Army Medical Corps, who demonstrated the fact that yellow fever is transmitted by the bite of a certain mosquito only, we have succeeded absolutely in eradicating this terrible disease from Cuba and Panama, where for centuries it had been prevalent. This has been accomplished by antimosquito measures alone. The insect concerned in the transmission of this disease is known as the stegomyia calopus or "tiger mosquito," the latter name 
resulting from its striped appearance, by which it may be recognized. It is peculiar in the fact that it bites chiefly in the afternoon. It is a house mosquito, residing in or near dwellings, and, since it finds favorable breeding conditions in water-tanks of ships, it is often carried about the world in this way. This fact gives rise to concern lest, when the Panama Canal is opened, yellow fever may be carried from points in Mexico, Central and South America, where it persists, to the Philippines and other parts of Asia. Its larva, like that of the culex, floats head downward in the water. (See Fig. 5.)

\section{Cholera}

Cholera, whose normal home is the tropics, is by no means confined to warm climates, but is frequently brought to our own shores. Since we know its cause (the "comma" bacillus) and the fact that the measures for its control are similar to those for typhoid fever, we do not fear that it will effect a lodgment in the United States. Cholera has given us much trouble in the Philippines, but even there, where sanitary measures are carried out with greater difficulty, its invasions have been met and checked.

\section{Plague}

Plague, the "black death" of the Middle Ages, establishes itself independently of climate wherever it finds favorable conditions. It has been demonstrated that rats are even more liable to this disease than man, and it is well established that infection is usually incurred through the bite of the rat flea, which, after the death of its normal host, forsakes the 
latter and attacks man. Rats should, therefore, he relentlessly pursued, their haunts made inaccessible to them, and opportunities for obtaining food cut off. Cousins of the ratsuch as the prairie dog of our western plains and the ground squirrel (tarbagan) of Manchuria - are subject to the disease and may be agents in its transmission. In some epidemics a very deadly form ("pneumonic" plague) attacks the lungs. Here the germ is transmitted by breathing and the flea is not a factor.

\section{Beriberi}

Beriberi is of interest and importance for the reason that it has attacked many of our Filipino scouts. No perfectly authenticated instance of its occurrence in an American soldier is on record. This does not mean that they are immune, but rather that their food contains the essential preventive substances. Rice-eating peoples are most often affected, and it has been found that some necessary food substance resident in the husk of the grain has been removed in the polishing process to which the higher grades of rice has been subjected. By substituting an "undermilled" rice for the polished varieties, this disease has been entirely controlled among the scouts, and its incidence much lessened among the Filipinos generally. This is the latest instance of the beneficent effects, upon the health of the native populations, of the occupation of tropical lands by the American Army.

\section{Scurvy}

Scurvy is a disease resulting from scant or improper diet and was formerly common among armies and navies. It is 
now but seldom encountered, although beleagured garrisons (as the Russians in Port Arthur) and remote detachments (as in Alaska) are sometimes affected. Its chief causative factor is the absence from the diat of organic acids contained in fresh meats and vegetables. Potatoes, onions, tomatoes (raw or canned), vinegar, the juices of rare meats, lemon and lime juice are preventive and curative.

\section{Leprosy}

Leprosy is mentioned because of the popular interest in this affection and not because of the risks of contact. Its germ is feebly contagious and no apprehension need be felt if its victims are encountered.

\section{Effects of Heat}

The effects of heat are frequently noted on the march in hot weather. These effects are of two kinds, notably differing in symptoms. In the severer type (heatstroke) the sick man is unconscious, his face is scarlet, his pulses throb violently, and his skin feels burning hot. In the other condition (heat exhaustion) the consciousness is retained, but the man feels exhausted, his face is pale, his heart beats feebly, and his skin is cold and clammy. Heatstroke is most apt to occur when the air is not only very warm, but is surcharged with moisture as well. Evaporation from the skin is interfered with, and as such evaporation is an important means whereby excess heat is withdrawn from the body, the temperature may rise to a dangerous degree. These heat effects can largely be avoided by timing the march, when possible, to take place 
during the relatively cooler parts of the day. The head covering should have a roomy air space and the crown should contain some light, moist object, as a wet sponge or handkerchief or green leaves. Water should be sparingly drunk on the march; the man who empties his canteen between halts is most often the man who is overcome by heat.

\section{Alcoholic Excess}

Alcoholic excess is a potent source of disability, not only in its immediate effects, but by opening the way to the onset of many other disease conditions through the lessening of vitality. This subject will be discussed more at length in a later chapter.

\section{Skin Eruptions}

Skin eruptions are very common in campaign, for the reason that men cannot or do not keep their persons and clothing in a sufficiently cleanly state. The affections which occur most often are those due to the presence of small animal parasites. Of these, lice are the most objectionable. The hirsute parts of the head and body should be inspected for the eggs of these insects, which are readily seen as little masses attached to the individual hairs. When insects or their eggs are found, the man's underclothing should be boiled and the affected parts of his body shaved or freely anointed with mercurial ointment.

\section{Biting Insects, Etc.}

Itch mites and chiggers (red bugs) cause much discomfort by burrowing beneath the skin. Ticks and leeches 
fasten themselves upon the body. Fleas, mosquitoes, and biting flies abound in certain localities. Some of these insects-as lice, ticks, fleas, and mosquitoes-are known to be concerned in the transmission of serious diseases. In regions where they are common, men should be taught to recognize them, with a view to their avoidance and the prompt relief of injuries induced by them. An acute inflammation of the skin results from contact with the leaves of the so-called poison-oak or ivy in susceptible people. Men should learn to know these plants too.

\section{Blistered Feet}

Large numbers of men are incapacitated-particularly at the onset of a campaign-by blistered feet. The two chief causes of blisters on the feet of the marching soldier are bad fitting shoes and uncleanliness. The feet should be kept dry if possible; shoes, when wet, wrinkle and lose their shape. To insure keeping the feet in good condition, their daily washing, after getting into camp, is absolutely necessary. If sufficient water is not at hand, wipe the feet carefully - especially between the toes -with a wet rag.

Shoes.-The shoe is, at least for the infantryman, the most important article of clothing. It is only after many years of experiment that a rational marching shoe has been developed for our service, and the urgent necessity for exactness in the fitting of each soldier with these articles and for their proper care, appreciated. Company commanders are now held responsible for undue injuries to the 
feet of their men from ill-fitting footwear. Each man should have at least one pair, well broken in, for marching use. Men should be instructed in the care of shoes and of feet, and frequent inspections of both should be made.

Socks.-An infantry soldier should carry two or three pairs of socks, which ought to be soft, smooth, and undarned. Those worn on the day's march should be washed at the same time as the feet; clean, dry socks are then put on and the wet ones hung up to dry. In this way a clean pair may always be had. A woolen sock (light or heavy) is more comfortable when marching than a cotton one because it is softer and more yielding, while it absorbs the perspiration better. If perspiration of feet is excessive, a thin cotton sock under one of light wool does well.

Prevention of Blisters.-To prevent blisters, foot baths of strong brine or alum or alcohol, used for a week or more before the march, are of great service in hardening the skin. Many experienced soldiers of our army soap the feet before putting on their socks. In the German Army, socks (or rags, which many wear for economy's sake) are soaked in grease. An excellent powder, made up of starch, soapstone, and salicylic acid, is supplied by our medical department to sift into the socks. These measures are used to diminish the friction of the foot against the sock. The French have found that a small strap buckled about the instep, over the shoe, diminishes friction and lessens the tendency to the formation of blisters. (See Fig. 9.) If such form in spite of our care, they must be opened to allow the serum to escape. 
Treatment.-The opening is made at the lowest point of the blister, with a clean needle, after the feet have been washed. The raised skin must not be disturbed, but is to be dressed with vaselin or other ointment and protected from pressure by adhesive plaster. Men afflicted with bunions or corns should be required to report promptly to the surgeon for appropriate treatment. 


\section{CHAPTER VI}

\section{CLOTHING}

Purposes.-Clothing protects the body against the changing conditions of the weather, such as cold, heat, wind, and rain; shields in a measure from blows and bruises; and serves to adorn the person. The materials used for this purpose are derived from a variety of sources, animal and vegetable. The chief substances taken from the animal world are wool, fur, leather, and silk; from the vegetable kingdom we obtain cotton, linen, and rubber, as well as a number of less important materials. A good material for clothing purposes must meet the following requirements:

1. It must afford proper protection against the weather.

2. It must not interfere with the natural functions of the skin.

3. It must exert no irritating effect upon the skin.

The characteristics and merits of the more important substances will be considered briefly.

Wool is undoubtedly the most valuable of these substances used by us. It has the merits $(a)$ of being a poor heat conductor, thus retarding escape of warmth from the body and preventing the thermic rays of the sun from passing freely. Through its heat conservation it is much warmer than cotton, and when loosely woven, so that much air is entangled in the meshes of the fabric, its warmth is markedly in90 
creased. This property makes it most valuable in cold climates, and even in hot ones it is not altogether undesirable. The olive drab flannel overshirt has been found to be a very valuable garment in tropical field service. By day it keeps out heat and chemical rays, and by night it prevents chilling. (b) Wool is a great absorber of water, a very important quality, as evaporation from the body's surface during free perspiration is checked and the danger of chill lessened. Perspiration passes through linen and cotton freely and loss of heat is rapid. (c) It does not absorb odors readily. A disadvantage of wool is that its fibers become smaller and harder after washing, so that garments of which it is composed undergo marked shrinking and stiffening. This tendency is minimized by washing as follows: Plunge garments, one at a time, in hot soapsuds and use gentle friction to cleanse from dirt. Remove and rinse out all soap carefully with cold water. Hang up to dry without wringing. Stretch into shape while drying if a tendency to shrink is observed.

Cotton is next to wool in value for purposes of clothing. It has these merits: (a) Good wearing qualities; $(b)$ cheapness; $(c)$ non-shrinkage in washing; $(d)$ coolness. Its demerits are: (a) Rapid heat conductivity; $(b)$ poor water absorption; $(c)$ free absorption and release of odors.

Merino (a mixture of cotton and wool) is much used for underwear.

Linen (flax fiber) conducts heat even more rapidly than cotton and is also a poor ahsorbent of moisture, besides being much more expensive than cotton. 
Paper.-It is useful to know that paper is of value in conserving warmth, and the Japanese have utilized it in military clothing. A paper vest affords marked protection against cold winds, while a newspaper between blankets adds much to comfort on a cold night.

Warmth and Coolness.- The warmth or coolness of clothing depends upon several factors: these are material, texture, and coior. We have seen that, according to heat conductivity, the materials named, in order of warmth, are wool, cotton, linen. Conversely, linen is coolest. With respect to texture, the more loosely woven the material, the warmer the garment. Thus, a cotton or linen loose mesh undershirt is much superior to one that is closely woven. The same effect of warmth may be produced by wearing two or more thin undergarments, one over the other, the advantage resulting not so much from the increased thickness as from the layers of warmed air. Color is of importance in this connection, in accordance with its relative heat-absorbing properties. Thus, white absorbs least heat; black, the most. Black clothes are, therefore, warmest; white, coolest; blue is next to black for warmth; olive drab and khaki are cooler than blue. Olive drab, being darker, is markedly warmer than khaki.

Waterproofing.-Clothing may be waterproofed in several ways. The best known of these is a coating of rubber. Rubber-coated materials are impermeable to moisture from within as well as without. Thus, perspiration is fostered and evaporation minimized, with much resultant discomfort. This objection applies, with somewhat less force, 
to raincoats and slickers made waterproof by a varnishing or oiling process. But woolen and other materials may be waterproofed without losing their porosity by impregnating them (a) with aluminum acetate or $(b)$ with a solution, in benzine, of sheep's wool fat (lanolin). These processes may be readily carried out in the field, if found to be necessary or desirable.

Military Attire.-There are certain requirements in clothing designed for the military service which are not necessary for civilian attire. The outer dress should be such as to maintain the soldier's pride in his calling and to indicate his place in the service, while the color of that designed for field use must, in its relation to visibility at a distance and against varying backgrounds, be inconspicuous. Most of the great military nations have adopted a special color looking to this end, the British being the leaders, with their "khaki" (A Hindoo word meaning "brown"). The Germans, Italians, Spanish, French, and Russians have chosen gray shades, some with a greenish admixture. Much experiment indicates that our so-called "olive drab" approximates the ideal shade for this purpose more nearly even than gray. The olive drab has but little advantage over khaki in this particular.

Having in mind the principles discussed, the chief points to be considered in the selection of clothing for the military service are: (1) Good quality; (2) durability; (3) moderate cost; (4) permeability to air; (5) heat conduction and absorption; (6) color, with respect to warmth and visibility; (7) distinctiveness. 
In our service all necessary articles are supplied by the government: these are usually of good quality, reasonably well made, and satisfactorily adapted to the uses for which they are designed. Unfortunately, we have been for years and still are in a transition period, during which changes of outer clothing have been frequent. The result has been that a company frequently appears in motley rather than in uniform. The total weight of the clothing proper varies from $6 \frac{1}{2}$ to $11 \frac{1}{2}$ pounds, in accordance with climate and season.

Headgear.- Until very recent years, most inappropriate headgear was worn in field service. Cortez, in Mexico, and Magellan; in the Philippines, wore brass helmets. The huge shako of the British Grenadier in the Crimea and the absurdly inadequate cap of the Federal soldier in our Civil War are fairly modern examples, at opposite ends of the scale of size. Some nations still send their troops to war in head coverings illy adapted for protection. Of these, the German helmet ("pickelhaube"), the French cap ("képi”), and the Turkish "fez" are conspicuous types.

The headdress is intended to afford protection from cold and heat and to shield the eyes and the back of the neck from solar rays. The style of garrison hat or cap is relatively unimportant. That for field service should be light in weight and color, broad brimmed, well ventilated, and not easily dislodged. Our service hat is perhaps best adapted of all military headgear in current use, but is by no means perfect. The "Montana peak" which has recently supplanted the crease in the crown is a step in the right direc- 
tion, as it improves the ventilation. 'To better the circulation of air still more, a fluted strip should be inserted between the hat and its sweatband. The brim is now stiff, but the question as to whether this stiffening should be removed is still under discussion. The stiff brim is understood to have been adopted in deference to the view that a military garment, even in the field, should be neat. But dear to the hearts of those who wore it. in active service is its soft-brimmed predecessor, the "campaign" hat.

For tropical wear a khaki-covered cork or pith helmet is undoubtedly cooler than the service hat. On the other hand, it is very bulky and sets so insecurely upon the head as to cause much annoyance by frequent dislodgment. For cold weather two types of cap are issued, the one of muskrat fur, the other of canvas. Both are blanket lined and have turn-down flaps for covering the ears. The fur cap is much the better in warmth and appearance.

Military Coats.- There is a great variety of taste in military coats worn by modern armies. Those for garrison use are still designed more for display than for comfort. Here the dictum that the circulation, respiration, and free muscular movements should not be interfered with is quite cast aside and the nearest approximation to "a perfect fit" possible is often sought. Comfort is entirely secondary to appearance. Still, we must no doubt sacrifice something to the principle that the soldier's pride in his calling should be fostered, and it is well known that a handsome uniform is a good stimulus to recruiting. For campaign wear the loose-fitting olive drab blouse with large patch pockets is 
an excellent garment. In hot weather this coat is discarded and the olive drab flannel shirt is worn as the outer garment; this is an admirable concession to comfort and good sense. In cold weather the blouse will usually be replaced by a heavy wool sweater.

Overcoat.-Two kinds of overcoats are used in our service. That ordinarily issued and worn is of drab woolen cloth, thinly lined. It was formerly equipped with a hood, which, for reasons not understood, is no longer authorized. In weather of moderate severity this is a fairly satisfactory garment. By recent regulation it does not become the property of the soldier, but its continued ownership is vested in the United States. The frequent issue of a long overcoat to a short man and the reverse is a common observation. The front corners of the skirts are provided with buttons and flap, that they may be turned back in marching. But even with this provision, marching of foot troops is decidedly hampered by the overcoat. This garment is much too thin to afford protection against extreme cold. For such weather an overcoat made of brown canvas and lined with blanket is an occasional issue. This is a superior article and affords excellent protection against cold winds, as well as rain.

Mackinaw Coat.-For Alaskan service a short Mackinaw coat of heavy blue woolen material is furnished, since the overcoat would too much impede free movements in deep snow. And with the view that it may, after due trial, supersede the overcoat and render this garment unnecessary for field service, a heavy sweater, knitted of wool and cotton and olive drab in color, is now supplied. The merits of 
such a garment are obvious, but whether it will sufficiently conserve the heat of the body in extreme cold remains to be proved. At any rate, it is possible to wear the overcoat with the sweater.

The poncho is an outer garment designed to protect the wearer from rain. This is a sort of waterproof blanket, whose distinctive feature is a slit through which the head passes. The idea is borrowed from our Latin-American neighbors. A light varnished cotton, olive drab in color, now replaces the heavy rubber poncho for the use of foot troops in our army. Attempts have been made to perfect a garment of this type which shall perform an additional function as a shelter tent half. Such double use has an advantage and a disadvantage. In the first place, the weight of the soldier's pack would be reduced by about $2 \frac{1}{2}$ pounds. On the other hand, one of the most important uses of the poncho is as a ground cloth at night, to keep the body and clothing from direct contact with wet soil. With the poncho forming part of a tent, this use must be abandoned unless, on occasions when such protection is especially necessary, three men shall occupy the shelter, the poncho of the third forming the floor. The new style poncho may be folded and buttoned to form a sleeping bag.

The slicker, a long and voluminous outer coat of oiled cotton cloth, is worn by mounted troops in place of the poncho.

For garrison wear, trousers are supplied as part of the dress, the white and the fatigue uniforms. Suspenders or a belt may be worn for their support, according to individual 
preference. With the service uniform, breeches are worn with leggings. For field wear, breeches are far more satisfactory than trousers, as the latter are bulky at their lower ends, which, too, may become heavy with mud or water. Breeches are apt to compress the legs behind the knees, especially in the seated or squatting attitudes. The service uniform is now required for daily wear in garrison, and, as thus used, the breeches become open to certain objection. While undoubtedly neater and more distinctive than trousers, their constant use in garrison, particularly by those whose duties are sedentary, is undesirable. The close fit of the breeches and leggings, at and below the knees, may produce a degree of constriction which markedly interferes with the circulation of the legs and feet, thus favoring muscular cramps and varicose veins. Breeches should fit snugly about the waist and upper part of the pelvis, but from the hips to a point below the knees they' should be quite loose, even baggy. They should have ample pockets at sides and back and should be laced (not buttoned) at their lower ends.

Service Uniform.-The service uniform is provided in two materials, wool and cotton, both olive drab in color. The former is designed for cold, the latter for warm, weather. The olive drab cotton goods thus far supplied are distinctly inferior to the khaki previously issued in several particulars. The color fades and "runs" in washing, the uniform is not so neat in appearance, and the darker shade is notably warmer.

Leggings are worn with breeches, since the latter end above the ankles, leaving a space otherwise unprotected 
except by the stocking. They protect the legs from bruising, shield the breeches, socks, and shoe uppers from mud and burrs, and afford support to the leg muscles. Many types have been tried out in our service and found wanting. The new issue, of stout canvas, without a foot strap and secured (at three points only) by a cord, promises well. Its main defect is that, being laced and reinforced in front, it may exert uncomfortable pressure upon the shin bone. Leggings of leather, fastened by a strap, are worn by mounted men. Another form of legging, much used in the British Army and authorized for officers' field wear in our service, is the "puttee," a long woolen bandage which is applied spirally about the leg. The fit and resultant pressure on the leg are more uniform than with other leggings, and the appearance is neat, but the adjustment takes considerable time. This question of time required to clothe one's self when on campaign is a serious one. The lacing of breeches and leggings is slow work. It would seem that a heavy woolen sock leg, drawn up over the breeches, would fulfil all the purposes of a legging (except neatness), save much time in dressing, and be more comfortable. This style of dress is much worn by guides and hunters in our northern woods.

Gloves are at present authorized and issued in great variety, in the endeavor to suit these articles to all climates, seasons, and conditions of service. Many of these are intended for parade and social uses. Mention may be made of mittens for very cold stations; of woolen gloves in olive drab for ordinary wear; of leather ones to protect the hands of those handling heavy guns and machinery; and of gaunt- 
lets (gloves with a large, flaring cuff) for mounted service. A useful provision to prevent loss in winter field service is to fasten the gloves together by a long cord which passes through the coat sleeves and across the shoulders.

Underwear.-From the standpoint of ordinary hygiene, the most important part of the clothing is the underwear, since it comes in direct contact with the person, and must, therefore, be frequently changed and cleansed. The underclothing should vary in weight and material with season and climate. Wool of varying thickness suits many, winter and summer, and, when well borne by the skin, is the best material. But wool often produces cutaneous irritation, and individuals thus affected naturally prefer other materials. Efficient cold-resisting substitutes are: (a) Merino; $(b)$ a woolen or merino garment over a thin cotton one; $(c)$ two garments of cotton. Underclothing should be light in color, for the reason that dark shades absorb odors (as of perspiration) more readily.

Undershirts are now regularly issued to our troops in three weights-light cotton, light and heavy merino. A fleece-lined shirt is also provided for posts where cold is extreme. Those who are subject to sharp diarrheal attacks not explainable by dietetic errors will do well to wear a small, apron-shaped additional covering for the protection of the abdominal organs, especially at night.

The olive drab overshirt has already been mentioned as a garment of exceptional merit. It has a turn-down collar and breast pockets, which give it a neat appearance when it is worn without the blouse or sweater. 
Drawers are provided in weights and materials similar to those of the undershirts. They should be roomy, for greater warmth and freedom of movement. The band should not be tight, as constriction by a narrow girdle may displace the internal organs. Drawers should reach to the ankles and be fitted snugly there by an elastic webbing. Strings in that situation are objectionable by reason of breakage and pressure of the knots, while buttons cause pressure and are easily lost. The knee-length drawers which have lately become fashionable do not afford adequate protection against dust and contact with dirty outer clothing.

Socks are furnished in cotton and in light and heavy wool. Those of cotton are suitable for garrison wear, but not for marching. Those of light wool (which are really 50 per cent. cotton) are used by the majority of our men on field service. The heavy socks, of pure wool, are quite bulky, but are superior for marching wear, except in the rare cases in which they cause skin irritation. Wool absorbs perspiration better, stretches better, and fits more uniformly, so it is less likely to form creases and produce blisters, calluses, and corns. Socks should have a seamless foot, with reinforced toes and heels. They should fit well and have no rough thread ends. It is of interest to note that only two armies other than our own issue socks to their soldiers. These are Great Britain and Japan. The great military nations of the European Continent expect their men to provide themselves somehow with these articles, which by us are deemed of such importance. From motives of economy many German soldiers wrap oil-soaked cloths 
about their feet in lieu of socks. A British military sanitarian (Colonel Melville) estimates the life of a sock to be only 60 to 70 road miles. This is probably a fair. mileage for our light wool sock, but it is believed that the heavy woolen article will do considerably better. Comfort and cleanliness as well as regulations require that socks shall be changed and washed daily on the march. It is well to remember that a piece of soft cloth a foot square (wool or part wool) will make a better foot covering than a worn out or poorly darned sock.

Garters are useful, but care should be taken to avoid undue constriction, which interferes with the normal circulation of parts below.

Shoes.-No one article of the soldier's clothing plays so large a part in his efficiency as the shoe. Although army commanders and sanitarians of the past century have emphasized the importance of good footwear, it is but very recently that the military shoe has received scientific study. The marching ability of armies is second to no other military factor, yet, while enormous percentages of troops in campaign have been incapacitated by injuries to the feet due to shoes badly made, shaped or fitted, it has but lately been realized that the conditions were preventable. A board of officers convened for the purpose by our War Department has recently (1912) rendered its report in the form of a truly admirable study of the foot and the shoe. A number of important recommendations are made in this report, among which are: (a) The adoption of shoes made on a rational last (one developed by the board); (b) careful fitting 
by company officers personally; (c) full series of sizes carried in stock at posts; $(d)$ frequent inspections of feet by company and medical officers. The War Department has adopted these recommendations and has published them in the form of an order, in which occurs the following sentence: "Hereafter an undue amount of injury and disability from shoes will be regarded as evidence of inefficiency on the part of the officers concerned and as cause for investigation." This places the responsibility where it belongs, and officers will do well to study most carefully the foot and its coverings. This may best be done by consulting the work "The Soldier's Foot and the Military Shoe," by Major Munson, Medical Corps, United States Army, president of the army shoe board above referred to. Major Munson lays down the following requirements for a good military shoe:

(a) It must be of good materials and well made.

(b) It must be fairly flexible, with pliable and porous uppers.

(c) The interior should be perfectly smooth, the heel broad and low, the sole but moderately thick.

(d) The arch should be flexible and without metal shank or other stiffening.

(e) It should have eyelets (not hooks) for fastening, and the tongue should lie smooth under the laces.

(f) The shoe should reach only a little above the ankle; it should be wide across the ball of the foot and should have a high toe cap.

(g) It must be comfortable, neat looking, and light in weight.

(h) It must be easily put on and removed. 
Civilian Models.-The styles of shoes purchasable in the shops are practically all defective in shape and unsuitable for marching. 'The "toothpick" type and even broadtoed models produce a forced outward angling at the junc-
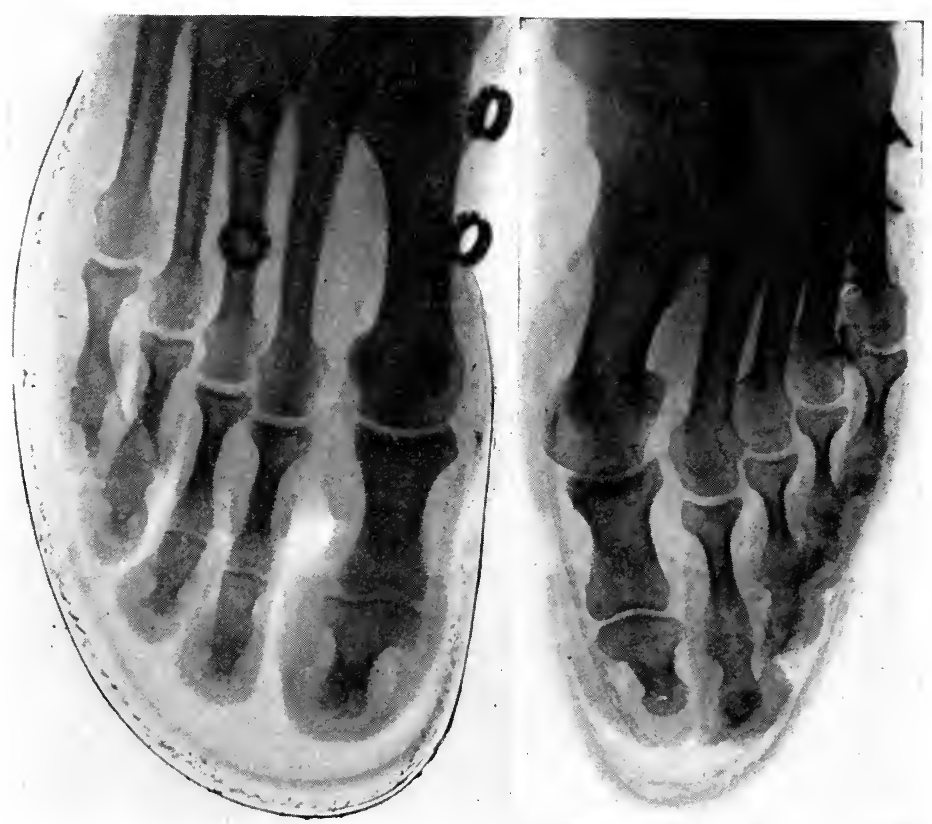

Fig. 7.-Skiagrams ( $x$-ray pictures) of feet: Left, well-shaped foot in new model army shoe. Right, deformed foot in type of shoe responsible for the deformity.

tion of the great toe with the main portion of the foot. This shifts the axis of the foot, which normally should be directly to the front in marching. Shoes as ordinarily purchased are too small for the wearer, either in length, in breadth, or in both these dimensions. It must be re- 
membered that the soldier is obliged to carry a load of clothing and equipment amounting to at least 40 pounds. Under such a weight the foot, if unconfined, lengthens and broadens to a surprising degree. This may amount to more than $\frac{1}{2}$ inch from heel to toe and nearly as much across the ball. The lengthening is more pronounced in a high-arched foot. It is thus evident that, to avoid injury in marching, the shoe must be roomy enough to allow all or a major part of this normal expansion.

Supervision in Fitting.-Soldiers cannot be trusted to fit themselves with marching shoes, as, through ignorance or vanity (or, perhaps, lack of proper sizes), tight-fitting footwear will usually be chosen or accepted. Thus the supervision of officers becomes necessary.

How to Fit Shoes.-Feet are measured and shoes fitted by company commanders in the following manner: The soldier stands with bared foot upon a small, graduated measuring board, resting his entire weight (augmented by a 40pound burden on his back) upon that foot. The length of the expanded foot is read off from the board and the circumference around the ball is taken by means of a tape applied at the base of the toes (Fig. 8). An approximation to the correct shoe length is then determined by adding 2 to the scale reading. For width, the table of sizes given in the annual price list of clothing, issued by the Quartermaster General, should be consulted. For example, let us assume that a foot measures $6 \frac{1}{2}$ on the scale and has a circumference of $9 \frac{1}{4}$ at the ball. Size $8 \frac{1}{2} \mathrm{D}$ is found to be the shoe which should approximate a fit; if this is not quite correct, 
others will be tried on until a satisfactory fit is had. With each trial the shoe should be snugly laced and the soldier will throw his augmented weight upon the shod foot. The company commander personally verifies the fit, assuring himself especially, by pressure with his hand, that not less than $\frac{2}{3}$ inch of vacant space exists in front of the great toe and that no undue pressure or wrinkling exists over the ball of the foot.

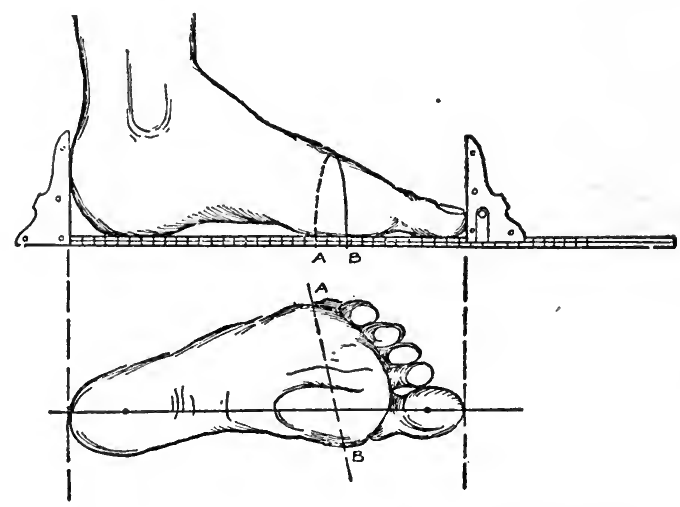

Fig. 8.-Foot measuring diagram (Munson).

Breaking in.-New shoes should be adapted to the contours of the feet by gradual wear and should on no occasion be used for marching until broken in. If there is need for haste in the process, this may be accomplished by having the soldier stand in water for a few minutes until the leather is sodden. He should then walk about for an hour or so on a level surface, letting the shoes dry on his feet. On removal, a little neat's-foot oil should be rubbed into the leather to prevent hardening and cracking. Shoes 
may be waterproofed by rubbing a considerable amount of this oil into the dry leather.

It is believed that with the adoption of the new shoe and its complete supply to the army, to the exclusion of other styles, our service will have footwear much superior to that of any other nation. The average American has a foot rendered abnormal by long wear of shoes of bad shape or improper size. But, taken in conjunction with the oversight in fitting and care of the feet now rendered obligatory, we should have a minimum of foot troubles. The high boots worn by German and Russian foot troops furnish a striking contrast to our own shoes in appearance, comfort, and efficiency. That men can march at all in such clumsy, misshapen footwear as that of the foreign nations cited is sur-

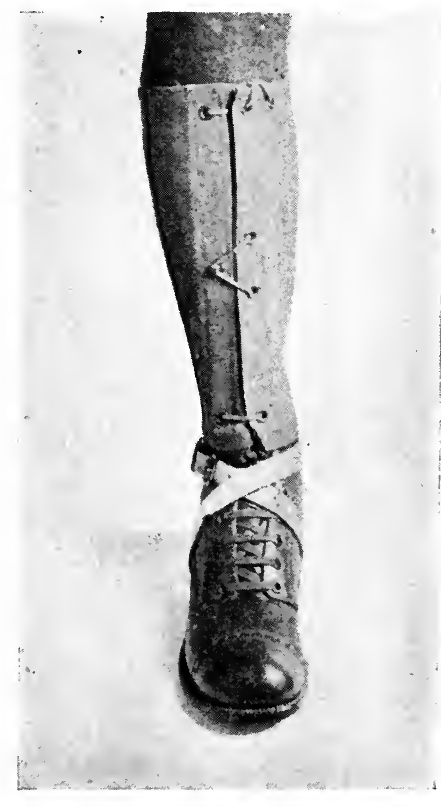

Fig. 9.-New army shoe, legging, and marching strap.

prising. The weight of such boots is 4 pounds, which is twice that of our shoes. (See Fig. 11.)

Overshoes are desirable for garrison wear, but not usually practicable in field service. The "arctic" type is the only one officially supplied. 


\section{CHAPTER VII}

\section{EQUIPMENT}

Definition.-The equipment of a soldier (or equipage, as it is sometimes termed) includes all articles, other than his clothing, which are essential to the performance of his duties. To some extent clothing and equipage overlap, since such articles as overcoats, ponchos, slickers, and sweaters, already described under the former head, are sometimes listed as the latter. It is obvious that a fighting man must carry the tools of his trade, with certain other articles necessary to his comfort and health. But it is equally obvious that such articles have decided limitations with respect to weight, bulk, shape, and number. A man of average size and strength can carry but a limited burden with the expectation that, at the end of a march, he will be fit for his prime function, that of battle. It has been found that, for our service at least, the weight carried by the infantry soldier should not exceed 50 pounds.

The actual weight of the full equipment is 40 pounds, 6 ounces, which, with the service clothing (7 pounds, 13 ounces), makes a total burden of 48 pounds, 3 ounces. This is made up as follows: 
Table of Articles of Equipage, with Weight of Each

Clothing (one extra pair of socks) . . . . . . Pounds

Ounces.

Rifle and sling. .................. 9

13

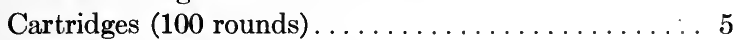

Cartridge belt. . . . . . . . . . . . . . . . . 1

15.88

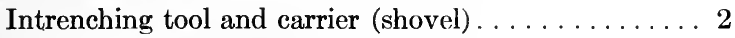

6.10

2.04

Bayonet and scabbard ................ 1

5.48

First aid packet and pouch................ 5.59

Canteen (filled) with cup and cover. . . . . . . . . $3 \quad 10.03$

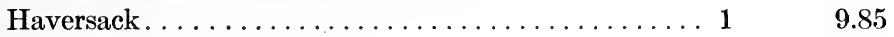

Pack carricr. ..................... 7.32

Blanket......................... $3 \quad 1$

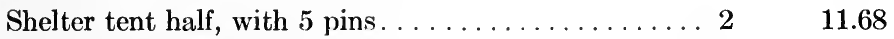

Poncho........................ 3

Meat can, knife, fork, and spoon........... 1

Rations (2 reserve) with containers (1 bacon can,

1 condiment can).................4 4.72

Table of Weights Carried by Foot Soldiers (Canteen Filled)

American (new equipment) . . . . . . . . . . . . . . . 48

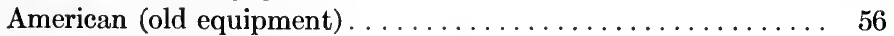

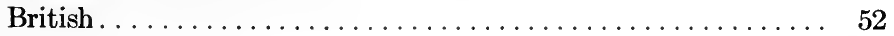

Japanese. . . .......................... 55

French............................. 56

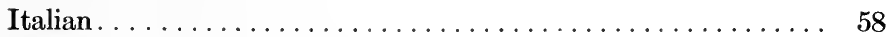

German. ............................ 60

Russian............................... 60

Austrian. .......................... 63

Note.-The weights given are approximate and may vary somewhat in either direction, according to whether special articles (as overcoats and intrenching tools) are carried or others (as shelter tents and ponchos) are discarded temporarily.

The burden borne by our soldiers is considerably less than that carried by the men of foreign armies. Other things being equal, this fact should make our men more efficient. But certain races are accustomed to burden bear- 
ing. The Japanese coolie is capable of carrying a load amounting to more than half his own weight, while the American soldier cannot be expected to do better than onethird.
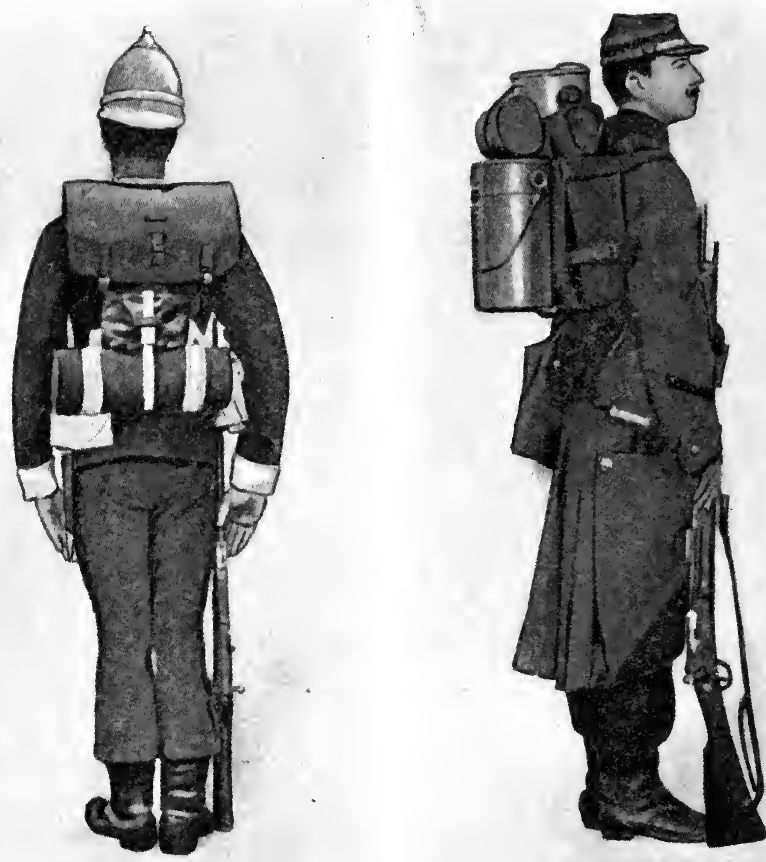

Fig. 10.-Infantrymen of foreign armies, with field equipment. Left, British; neat pack and good arrangement of components. Right, French; note the inadequate cap and the top-heavy pack (after Lavisse).

Articles Making Up the Load.-The articles composing the load (or pack, as it is often termed) fall under several heads with respect to their nature. These are: (a) Clothing; (b) armament (including rifle, bayonet, ammunition, and 
intrenching tool); (c) food (rations, water, mess equipment); (d) accoutrements (haversack, pack carrier, belt, first aid packet, identification tag); $(e)$ shelter (overcoat, poncho, blanket, shelter tent); $(f)$ personal necessaries (toilet requisites, tobacco, etc.).

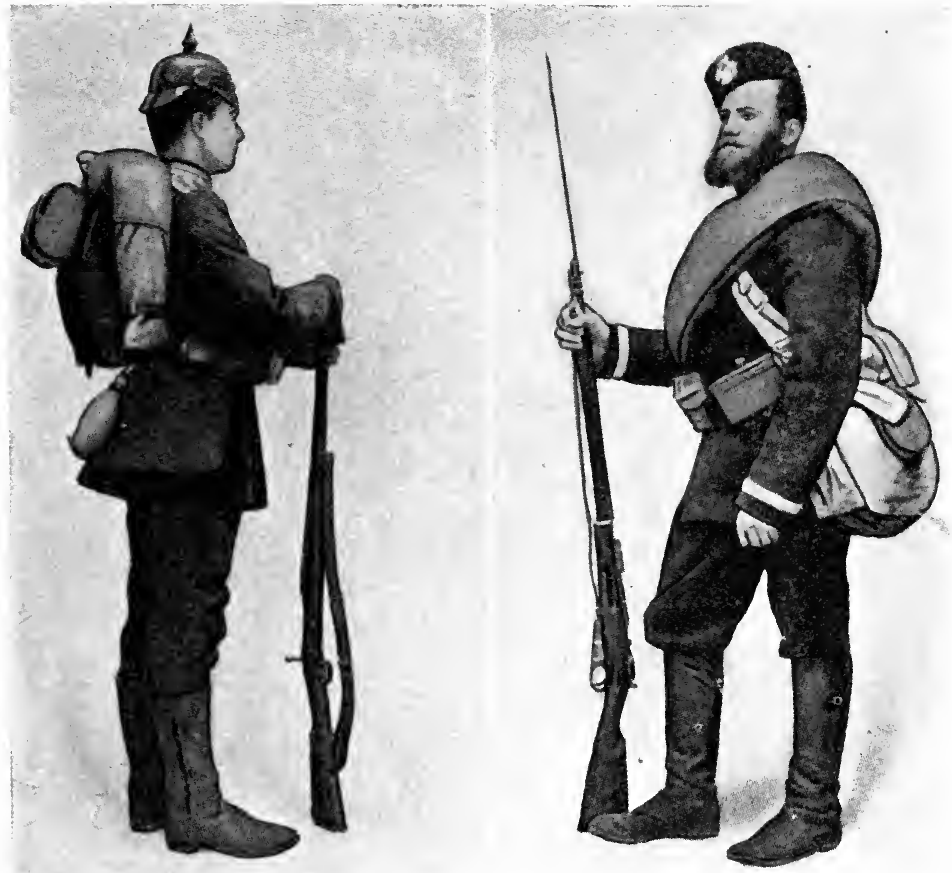

Fig. 11.-Infantrymen of foreign armies, with field equipment. Left, German; note headgear and footwear. Right, Russian; note blanket roll and boots (after Lavisse).

Forms of Packs. - The arrangement of the several components of the load upon the person of the soldier varies as greatly among armies as does the style of pack. France, Germany, Austria, and Italy employ some form of knapsack, 
in and about which the equipments are placed. Russia makes use of a blanket roll, a form of pack recently discarded by us. Japan has a knapsack, which is replaced by a roll over each shoulder when action impends. England and the United States use a combined haversack and pack carrier. In shape, appearance, material, internal arrangement, and contents, no two of these devices are alike, thus clearly indicating that the pack even approximating the ideal is still to be found.

The Ideal Pack.-In its report, the Infantry Equipment Board which devised the outfit recently adopted by the United States Army well describes the needs in this particular as follows: "The ideal load would be one as light as possible consistent with containing all of the articles essential to the soldier's purpose, health, and comfort; one whose distribution upon the framework of the body is such that its center of gravity coincides with that of the bearer and whose weight is transmitted to the medium of locomotion, the legs, with the minimum effort and fatigue to the medium of transmission, the body; and one which may be borne without interference with the vital organs and limbs."

United States Army Pack (New Model).-Our own contrivance, recently adopted, but not yet (1914) fully issued to the army, is a radical departure from former types, and is believed to be a marked improvement over all others in the matters of lightness, method of carriage, arrangement of parts, and convenience of access. The whole is supported by broad braces passing round each shoulder from front to rear and is steadied below by straps attached to the belt. 
The equipage is divided into two portions in such manner that the non-essentials (chiefly shelter articles) may be rapidly

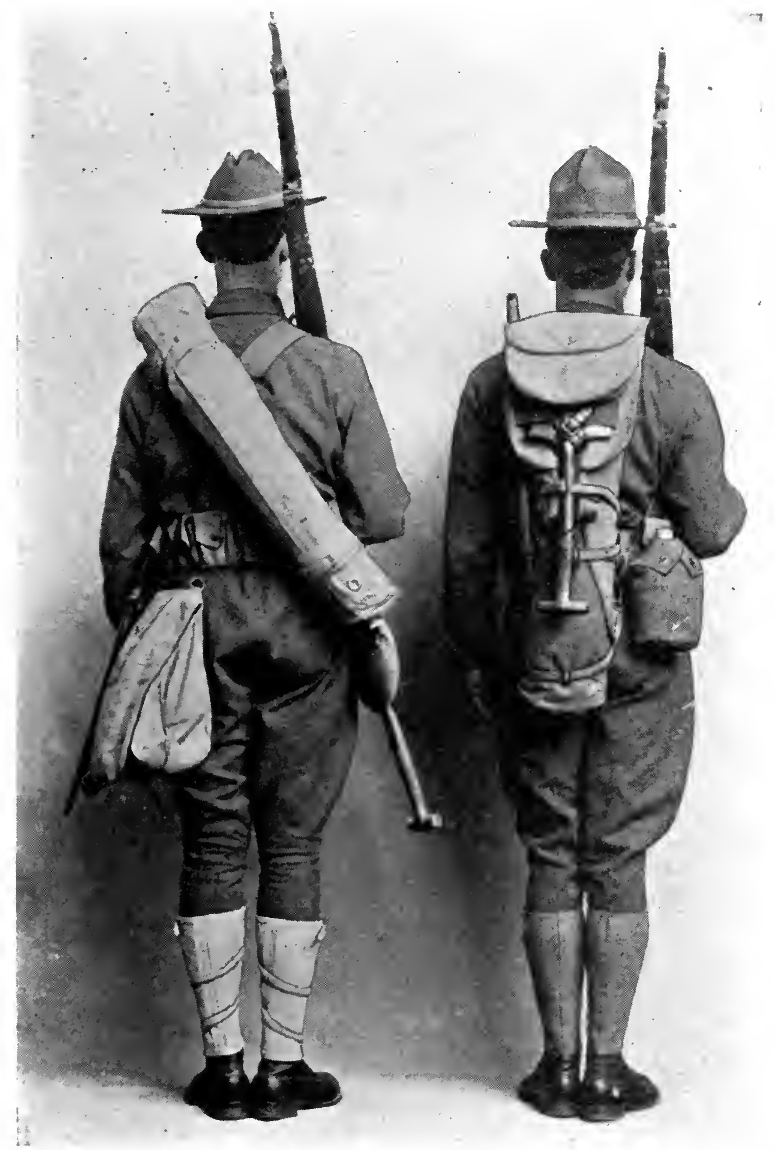

Fig. 12.-United States infantrymen, with old and new packs contrasted. detached for carriage by wheeled transportation or before going into battle. Thus the soldier, when transportation is available, carries the so-called "normal" equipment, com- 
prising the clothing actually worn, his armament, and his food (with the necessary mess kit), from any of which it is not possible to separate him without sacrificing his quality of self-support. It is thus evident that there is an irreducible minimum, which with us amounts to about $31 \frac{1}{4}$ pounds on the march (normal equipment) and 39 pounds in combat (fighting equipment) The increase of the latter over the former is due to the addition of two bandoleers (120 rounds) of cartridges, the rest of the equipment remaining identical. The new equipments effect a saving in weight of more than 8 pounds.

The Carriage of the Load.--The position of a load upon the back is very important. If high, it tends to raise the center of gravity, to require greater effort in maintaining the erect posture, and to constrict the blood-vessels and nerves of the armpits. The main load should, therefore, be carried well down the back. Also, it should not lie in close contact with the body, but should tend to fall away therefrom, that interference with perspiration in this situation be minimized. The United States Army equipment lies with its greater diameter along the spine, in the normal line of gravity, and, the points of origin and insertion of its supporting braces being far apart, it produces but little pressure upon the back or constriction of the axillary contents. The play of the chest is only slightly interfered with, as no straps cross it.

Transportation for packs should be provided whenever possible, in order to conserve the soldier's strength. When so carried a grave disadvantage may result on active service, in that the equipment may not be available when needed. 
This objection applies also to removal of part of the equipment before going into battle, as packs. may never be seen again, whether on advance or retreat. There are many historic instances of such loss. Raw troops especially would suffer from the lack of shelter and of little comforts.

The Blanket Roll.-It is not altogether improbable that our infantry in war time will discard the new pack and again resort to the blanket roll, as they did in the Civil War. The disadvantages of the latter are recognized and led to its replacement in our service, but it has advantages to the heavily laden soldier. Its principal disadvantage lies in the pressure it exerts upon the chest, thus interfering with breathing.

\section{Articles of Equipage}

Haversack and Pack Carrier.-The container-known as the haversack. and pack carrier-consists of an irregularly triangular piece of stout canvas, provided with flaps, straps, and buckles, the whole being designed to fold about and enclose the smaller items of equipment. There is but one pocket and the entire device may be spread out flat for ready cleansing. The haversack pocket holds the meat can, inside of which the knife, fork, and spoon are carried. The components of the haversack ration, in their special containers; are laid upon the middle of the canvas, together with the toilet articles, and there secured by flaps and straps. If carried, the shelter articles (tent, blanket, and poncho) are tightly rolled and fastened below the haversack contents by means of that part of the device known as the "pack carrier," which forms the apex of the canvas triangle. 
The carrier, with its roll, is known as the "pack"; this is readily detached from the haversack by the withdrawal of a coupling strap.

The blanket is an excellent article of wool, and now weighs but 3 pounds instead of $5 \frac{1}{8}$, as previously issued. This blanket is warm enough for most seasons; if two must be carried, they are much warmer than the heavy single one because of the non-conducting layer of warmed air between them.

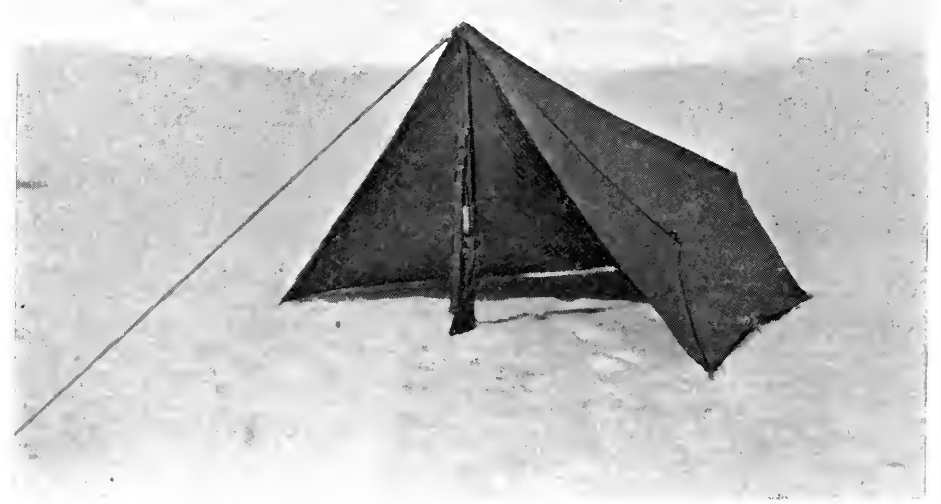

Fig. 13.-United States Army shelter tent, new model.

The shelter tent protects two men, each of whom carries a half. These halves may be buttoned together and set up in a few minutes. A rifle supports the higher (front) end, a bayonet or intrenching tool the rear. The tent is of light, waterproofed cotton material resembling that from which the poncho is marle.

The cartridge belt is of stout cotton webbing, has pockets for cartridges in front, and is adjusted for size at the back. 
A valuable feature of this belt is that its weight is supported from the shoulders by means of three straps attached to the haversack. This takes the pressure off the lower part of the abdomen and disposes of the objection that a heavy belt tends to produce hernia or contusion of internal organs. Moreover, the weight of the belt and cartridges in front acts as a partial counterbalance for the knapsack and its load.

The bandoleer is a broad cartridge belt, worn over the shoulder and across the body. This is a convenient method of carrying ammunition, but is decidedly objectionable for the reason that its great weight upon the chest interferes seriously with the respiration, as well as with evaporation of perspiration from the area which it covers. In our service it is used only for the carriage of additional ammunition in battle, and soldiers are instructed to use cartridges therefrom before depleting the supply in the cartridge belt proper.

The rifle is the heaviest of all the equipments. Since this essential component of the load must usually be carried in the hand or upon the shoulder, and constitutes a weight which is shifted from time to time, it tends to make the whole load asymmetric. It is, therefore, found to make a demand upon the energies of the soldier which is much greater than that of a fixed weight. With the new equipments the bayonet, in its scabbard of webbing, is attached to the pack.

Intrenching tools are of two kinds: one is a shovel, the other a combined pick and mattock. Less than half the men carry these, and they may be shifted to other men on alternate days of a march. They are carried on the lower part of the pack, from which they may be detached readily. 
Canteen and Cup.-The canteen, whose capacity is one quart, is of seamless aluminum and has a wide mouth closed by a screw cap. The kidney-shaped pint cup, also of aluminum, has a folding handle and fits over the lower part of the canteen. Both these vessels may be utilized as cooking utensils in the preparation of food or the boiling of suspicious waters.

The first aid packet, since its adoption by armies, has contributed greatly (in fact, more than any one cause or sum of causes) to the saving of lives of those wounded in battle. Surgery has made wonderful advances in the last generation, but a great merit of the first aid packet lies in making operative surgery superfluous in a large number of cases. The infection of wounds by the bacteria which find therein the conditions best suited for their activities is usually prevented by the prompt application of the contents of the packet. The bandages and compresses of cheese-cloth (absorbent cotton gauze) are treated with bichlorid of mercury, a powerful germicide. A tight metal case protects the packet from contamination. This is easily opened and the contents readily applied, in accordance with simple directions enclosed with the packet. Soldiers in war quickly learn to value and to preserve their packets. In our service it is carried in a small pouch of webbing which is attached to the belt and is quite accessible. It is variously carried in foreign armies, sometimes in the coat pocket or sewer in the coat lining. As the coat is likely to be discarded in the heat of action, the packet may be missing when most needed. 
Surplus Kit Bag.-Certain additional articles required by the soldier in campaign are carried in a canvas sack known as the surplus kit bag. One of these is assigned to each squad of 8 men, and its contents comprise the

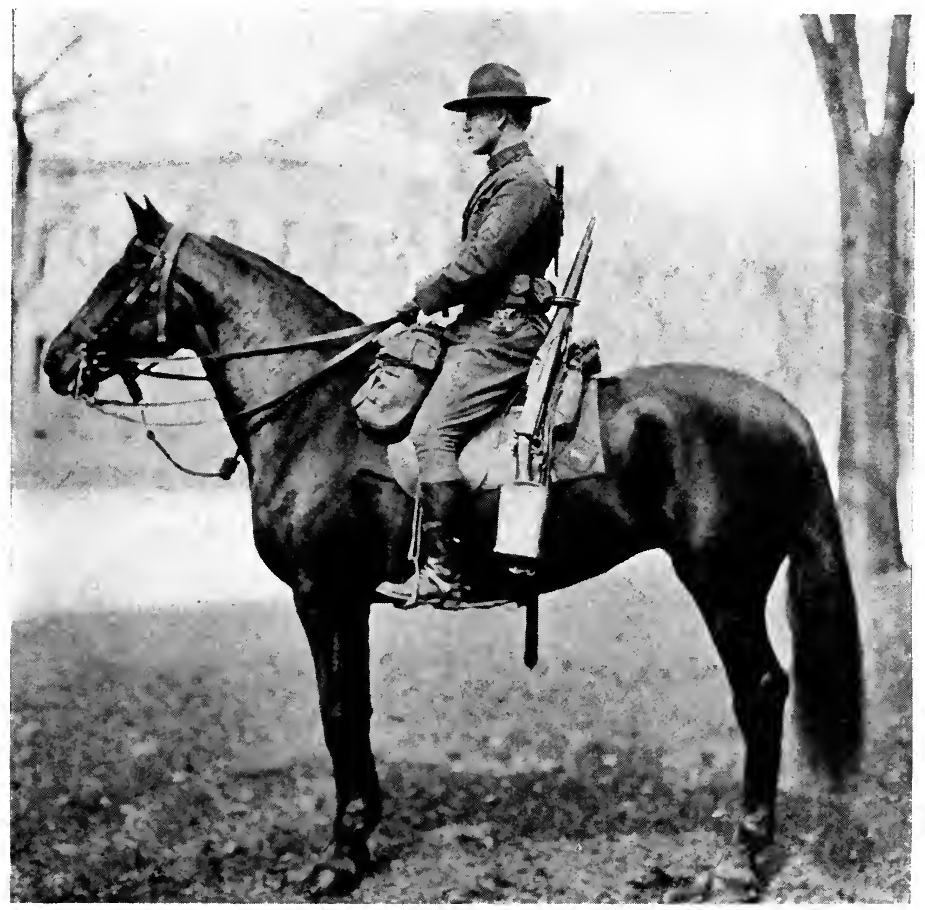

Fig. 14.-United States cavalryman, mounted; normal equipment, new model (Cavalry Equipment Board).

sweater (if not worn), with a change of shoes and underclothing for each man.

Cavalry Equipments.-In the mounted branches of the service the weight of the equipments is borne by the horse. It is as important to the cavalry not to overload their mounts, 
as it is to the infantry to avoid undue weighting of the individual soldier. A cavalry equipment board has recently

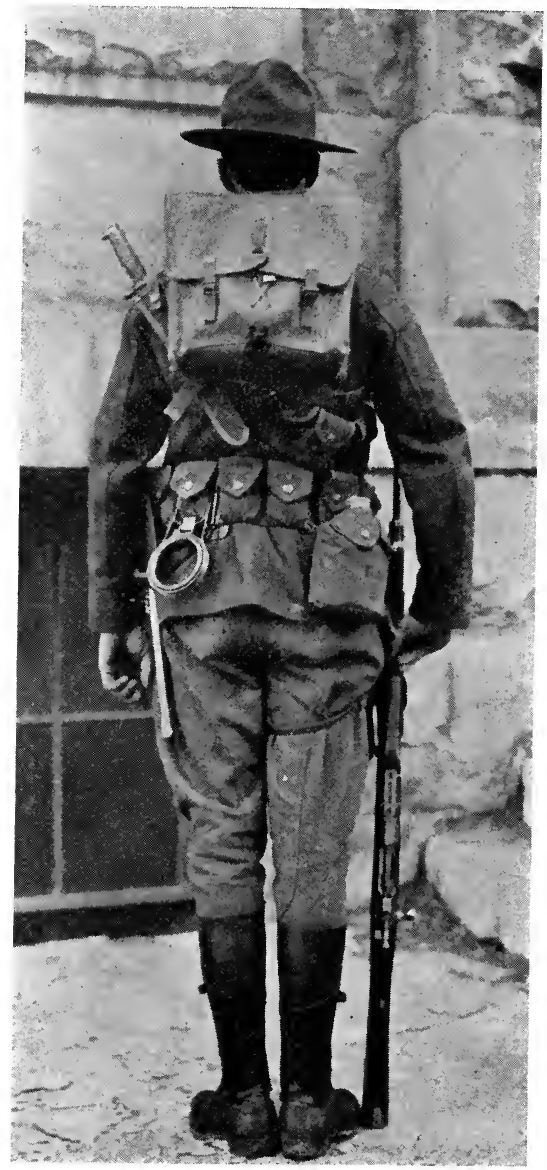

Fig. 15.-United States cavalryman, dismounted to fight on foot; new model equipment (Cavalry Equipment Board).

(1913) succeeded in reducing the weight of equipage by 17 pounds. As the actual weight carried by the horse was not 
believed to be excessive, the board found it possible by this reduction to add extra ammunition, extra rations, and grain to the load. Assuming a weight of 150 pounds for the trooper, the average animal must sustain a burden of at least 245 pounds (Fig. 14). This may be increased to 282 pounds by the necessity for additional clothing, ammunition, or special equipment, or it may be reduced materially if wagon transport is available. The articles of the new equipment are now in process of manufacture and, it is anticipated, will soon be issued. Our cavalry is trained to fight on foot as well as on horseback, and the new equipment is devised with the idea that, though separated from his mount, the man is still self-supporting and in condition to perform his battle functions. The accompanying illustration (Fig. 15) shows the dismounted trooper, equipped with his armament, food, and mess kit. 


\section{CHAP'TER VIII}

\section{WATER-SUPPLY}

Necessity.-Water is absolutely essential to the existence of all forms of life, whether animal or vegetable. Man can exist without food for many days, but can bear deprivation of water for a very much shorter time. Means for its supply in adequate quantities and sufficient purity must be arranged for by all communities, civil or military, permanent or temporary. Water constitutes over 60 per cent. of the weight of human tissues, and, as it is constantly being given off from the body through the lungs, skin, kidneys, and intestines, it must as constantly be replaced. It forms a part, also, of all substances used as food, solid as well as liquid. Bread; for example, contains 33 per cent. of water, and green vegetables as much as 90 per cent.

Functions.-It is obvious, from the fact of its constant presence in such quantities, that water must serve important functions in the human economy. These functions are: (a) To give fluidity to the liquids of the body; (b) to soften and render pliable the various tissues in which these qualities are necessary; $(c)$ to take part in the chemical and physical changes peruliar to normal bodily processes; $(d)$ it plays a large part in the regulation of the temperature.

Man makes use of water for ordinary domestic purposes as follows: (1) drinking; (2) cooking; (3) cleansing; 
removal of wastes (sewerage). A relatively small amount is required for drinking purposes, but a large reserve must always be available for cleansing, flushing, and emergency use, as well as to provide against times of drought and conflagration. Where the supply of drinking-water is scanty, it is sometimes necessary to install a double system (as of sea and distilled water on shipboard). A system of supply implies a supplementary system for the disposal of waste water.

Quantity.-In field service each man requires daily at least $2 \frac{1}{2}$ quarts for drinking and cooking, and as much more for washing his person and clothing. In the tropics this amount must be increased by at least one-third. In camps of some permanency he should have not less than 5 gallons. In garrison, a much larger quantity is desirable and, indeed, necessary. Including that required for sewerage and adding the practically inevitable wastage, a minimum of 30 gallons per head should be provided. A horse will drink about 8 gallons per day. In estimating needs, 10 per cent. should be added for fire purposes.

Sources.-Water is ordinarily derived from natural deposits on or near the earth's surface, as streams, lakes, springs, and wells, and the supply is maintained by the rainfall. Rainwater itself is sometimes collected from house roofs and stored in cisterns for domestic use. The British fortress ${ }^{\cdot}$ of Gibraltar derives its entire supply from this source. It is especially useful for washing and cooking on account of its softness, that is, its freedom from mineral salts (chiefly calcium and magnesium) in solution. Cisterns 
must be carefully screened in order that they may not serve as breeding-places for mosquitoes.

Hardness is of two kinds, temporary and permanent. The former results from the presence of chalk (calcium carbonate) held in solution by carbon dioxid also present in the water. When the gas is driven off by boiling, the chalk is precipitated. If water contains more than 10 grains of mineral salts to the gallon, it is classed as hard. Extreme examples of this type are found in the alkali waters of our western states. Hardness of water has certain disadvantages. It deposits a chalky material upon boilers and pipes; it hinders the cooking of meats and vegetables (notably that army staple, beans); and it causes great waste of soap in washing.

Impurities.-With respect to the source of drinking-water, that derived from springs or deep wells is most apt to be wholesome. Next to these is upland surface water (mountain streams and lakes). Shallow wells and streams subject to contamination are dangerous sources, and water derived therefrom generally requires purification before it is fit to drink. The physical characteristics of good drinking-water are: appearance, clear, colorless, brilliant; odor, none, even after warming and shaking in a closed vessel; taste, palatable. But the presence of all these by no means insures purity, and a water exhibiting such characteristics may be dangerously contaminated, even with sewage. Impurities prejudicial to health may be derived from mineral, vegetable, or animal sources, of which the last named is by far the most serious. Under the first head may be cited: 
(a) Lead, derived by solution from pipes of that metal; (b) copper, iron, and other metals washed into streams as wastes from manufactories; $(c)$ insoluble earthy particles in a finely divided state, held in suspension. Minute vegetable growths (algæ) not infrequently impart an unpleasant fishy taste and odor to stored waters, and decaying vegetation may add products of organic decomposition. Bacteria are microscopic vegetable organisms, but since the diseaseproducing varieties are parasites upon man and invariably derived from him, they are properly considered under the third head. Such bacteria constitute the chief danger in drinking-water and the principal diseases to which they may give rise are typhoid fever, cholera, and bacillary dysentery. Still other diseases, due to minute animal parasites, are transmitted in exactly the same way, that is, as the result of contamination with discharges from the bowels of infected human beings. Amebic dysentery is the most important member of this group. It should be remembered that while the fouling of the water-supply is not the only method of transmission of these diseases, such method is extremely common and is apt to affect large numbers of individuals at one time.

Pollution of Water-supply.-As already suggested, the contamination of the water-supply by sewage (the term here particularly referring to human excretions) is the most serious kind of pollution. Opportunities for such fouling are constantly being afforded. Men are prone to void their excrement on the margins of streams or even directly into the water. The insanitary methods of disposal of such material from railway trains is a constant menace to the purity of 
bodies of water along the right of way. Privies and wells exist in close proximity in our rural districts. Furthermore, the sewage of inland towns and cities usually discharges into streams. It must not be inferred, however, that because sewage has entered a water-supply, such supply is certain to induce disease, for this is not necessarily the case. It may not contain the germs of the diseases thus conveyed. Nevertheless, it is not pleasant to contemplate the drinking of diluted sewage, and the risk that water so tainted is infected is very great. It is highly important, therefore, to obtain a supply as pure as possible and to protect it from pollution. The outflow from sewerage systems, house wastes, refuse from factories, garbage, dead animals, and other foul materials must not be placed in or near streams, lakes, and reservoirs which form part of the system of supply. Horses and cattle must be kept out of water sources. Privies and stables must not be allowed upon their banks. Bathing and washing of clothing in their waters must be prohibited. Picnic parties, if permitted, must be supervised. Finally, an effective system of inspection of the entire drainage area must be instituted.

Determination of Sewage Pollution.-The determination of the presence of sewage in a suspected water is not easy. The findings of a chemical examination merely indicate probabilities, which must be confirmed by a study of the local conditions and, more particularly, by a bacteriologic examination. The index of pollution in this latter case is the presence of the colon bacillus, so called from the fact that its normal home is the large intestine. Even when 
found, this bacillus does not necessarily indicate contamination with human excrement, for it may be derived from cattle. But, for practical purposes, its presence absolutely negatives the use of such water for drinking unless first purified.

Purification.-We come now to the consideration of practical matters which especially concern us as military sanitarians, that is, to methods of purification of unsafe waters. The questions as to the exact quality and composition of waters must be left to the experts of the Medical Department, but all in the military service should have some knowledge as to the methods whereby an unsafe water may be rendered potable. Moreover, it must be emphasized that, once purified, it must be so maintained. The discussion of these methods naturally falls under two heads, namely, whether the supply must be treated on a large scale (as in a permanent post) or on a small one (as in the field or on board a transport).

\section{Methods of Purification of Water on a Large Scale}

(A) Sedimentation.-This consists merely in affording opportunity for suspended solids to settle to the bottom of large tanks, from the upper parts of which the clear water flows or is piped. Ordinary reservoirs utilize this principle in addition to that of mere storage.

(B) Precipitation.- The addition to the water, in settling tanks, of a minute amount of certain chemicals (notably alum) causes the formation of a peculiar gelatinous precipitate, which, sinking slowly, entangles small floating earthy parti- 
cles and even bacteria, and carries these to the bottom. As in sedimentation, the clear water is then drawn from the top of the tank.

(C) Filtration.-(1) Slow Sand: This is carried out through beds of clean fine sand and gravel 3 or more feet thick. Every few weeks the slimy film of mud and vegetable growth which forms on the surface of the beds must be scraped off, as it interferes, to a rapidly increasing degree, with the rate of filtration. On the other hand, this film is of considerable value, for the reason that harmless germs which form part of it assist in the destruction of the disease germs. On this account the film should not be disturbed except when it becomes so dense as to interfere with a reasonable rate of filtration. If the water is very turbid, sedimentation is practised beforehand. (2) A mechanical filter is the same as a slow sand one, except that precipitation is employed at the same time. Alum ( $\frac{1}{2}$ to 1 grain per gallon) is added to the water as it flows upon the sand bed. Iron with lime may be substituted for alum. This form of filter requires a daily cleansing. Both slow sand and mechanical filters are very effective, as, if properly constructed and operated, they strain out about 98 per cent. of the bacteria contained in the raw water.

(D) Addition of Copper Sulphate.-This is especially applicable where the minute vegetable growths known as algæ have to be dealt with in tanks and reservoirs. One part of the chemical to the million parts of water is effective in checking the growth of these plants and thus removing the fishy taste imparted to the water by them. 
(E) Chlorin gas has the property of destroying bacteria in water. The best apparatus for its use is that devised by Major Darnall, Medical Corps, United States Army. In this the gas, compressed in steel drums, is mixed with the water to be treated as it flows through the supply-pipe. The apparatus is easily operated, effective, and economical. The cost is about 40 cents per million gallons.

(F) Ozone.-This allotropic modification of oxygen, produced in the usual manner by non-luminous electric discharges in dried air, is a very efficient germ destroyer. When mixed with the water as this passes through gravel filters, it quickly and thoroughly destroys dangerous bacteria.

(G) Ultraviolet Light. - The chemical rays of the solar spectrum have been found to be destructive to germ life, and their application to contaminated water-supplies is effective in rendering these safe for drinking and other purposes.

\section{Methods for the Purification of Water on a Small Scale}

Removal of Objectionable Substances.-This means, for our purposes, the supply of a safe drinking-water on field service. The source of supply may be pure, in which case it becomes our duty so to maintain it. Certain constituents, while perhaps not such as to induce disease, may still be objectionable and, therefore, require removal or alteration. For example, the water may be very hard, muddy, or unpleasant in taste. If, as is likely, a part of the hardness is temporary, such part may be removed by boiling. A muddy water may be clarified by sedimentation, precipi- 
tation, filtration, or a combination of these procedures. In this connection it is useful to know that the prickly pear cactus, which grows over a large part of our country, will, if bruised and thrown into a vessel of muddy water, aid in its clarification. Its action is like that of alum, in that its juice entangles the floating solid particles and sinks with them to the bottom. An unpleasant taste may sometimes be driven off by boiling; if due to algæ, a little citric acid will dispel it.

Removal of Disease Germs.-Disease germs are removed or destroyed by certain of the measures previously outlined or by others to be described. Thus, sedimentation and precipitation will remove many germs along with other floating particles which settle to the bottom of the containing vessel. Apparatus has been devised for the field use of chlorin, of ozone, and even of ultraviolet rays, but these up-to-date methods have not yet assumed a practical field form, and it is not likely that they will hereafter, for the reason that they require bulky machinery and impose an additional strain upon an already excessive transport. And this criticism applies to water carts and wagons, found to some extent in foreign armies and sometimes recommended for our own. These vehicles are wheeled filters or heat sterilizers. While undoubtedly desirable, the increase in transportation units (one or more to a regiment) renders their use in war unlikely.

Purification in the Field.- There are three methods of purification which may be employed in the field. These are chemical treatment, filtration, and the use of heat. 
Chemical.-A large variety of substances have been used at different times for the rapid chemical disinfection of water by individual soldiers on field service. Some of these-as iodin and bromin - are perfectly efficient when conditions are entirely favorable, but, owing to difficulties of supply and handling or lack of intelligente in their use, they cannot be relied upon. Permanganate of potassium is slow in action and uncertain in results. The bisulphate of sodium is efficient, but not suitable for prolonged use. Chlorin and chlorids impart an unpleasant taste to the water. And thus it is evident that chemical sterilization in the field, while excellent in theory, fails in practice. We are, therefore, in the present state of our knowledge of this subject reduced to the employment of two measures, namely, filtration and the use of heat.

Filtration.-Filtering material and methods differ in armies. In the British, German, and French services hollow "candles" composed of unglazed porcelain or infusorial earth are employed. The water is driven through these by means of a small force pump. Such filters are fragile, require trained care, and clog quickly. The Japanese employ the Ishiji filter (Fig. 16), an inverted cone of canvas, whose two spouts are plugged with sponge and powdered charcoal, which constitute the filtering agents. The water in the cone is given a preliminary chemical treatment with permanganate of potash before filtration commences.

Darnall Filter.-Our own device, but little more complex than the Ishiji and decidedly more efficient, is the Darnall siphon filter (Fig. 17). Like the Japanese filter, it em- 
ploys precipitation in conjunction with the filtration. The chemical agent in this 'case is alum, combined with sodium

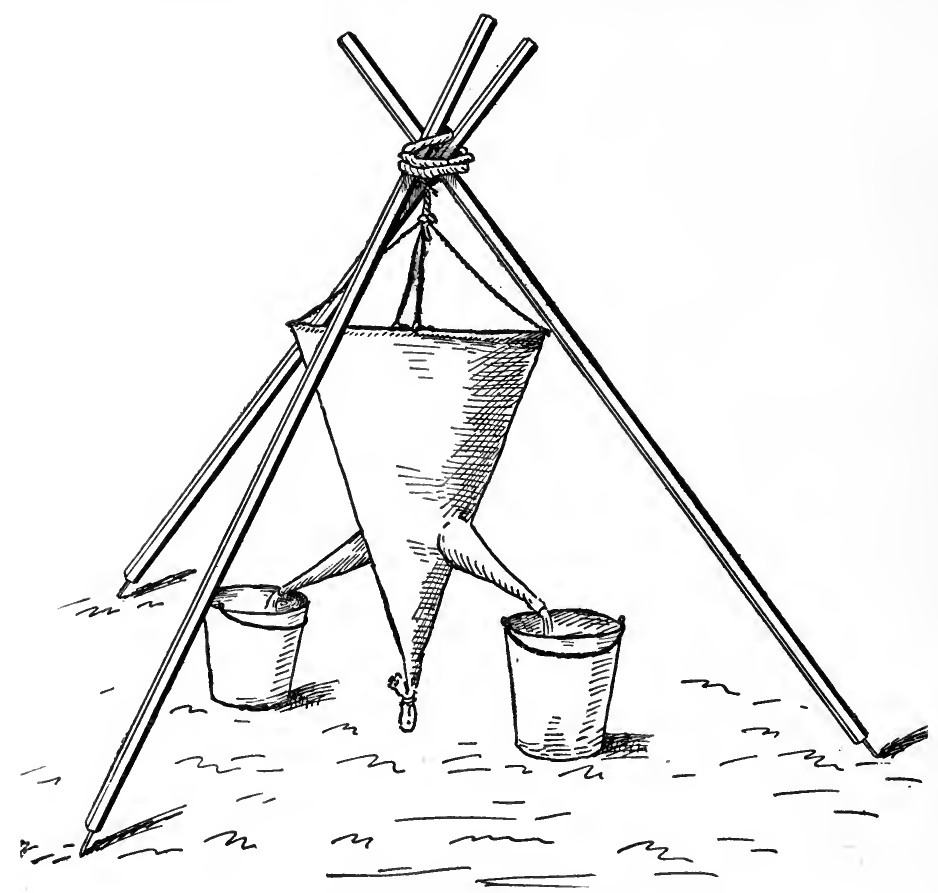

Fig. 16.-Ishiji filter (Japanese model).

bicarbonate. The complete apparatus weighs 52 pounds and consists of the following parts:

(A) One filter tank, galvanized iron.

(B) Two water cans, galvanized iron.

(C) One siphon filter, bent perforated pipe.

(D) Four filter cloths, of outing flannel.

In addition, the apparatus is supplied with a small hand pump, to serve as a siphon primer; a brush for cleansing cloth when clogged; and a measure for the chemical. 
All other parts pack inside the tank. To operate the filter proceed as follows: (1) Wrap a filter cloth around the wires of the siphon.

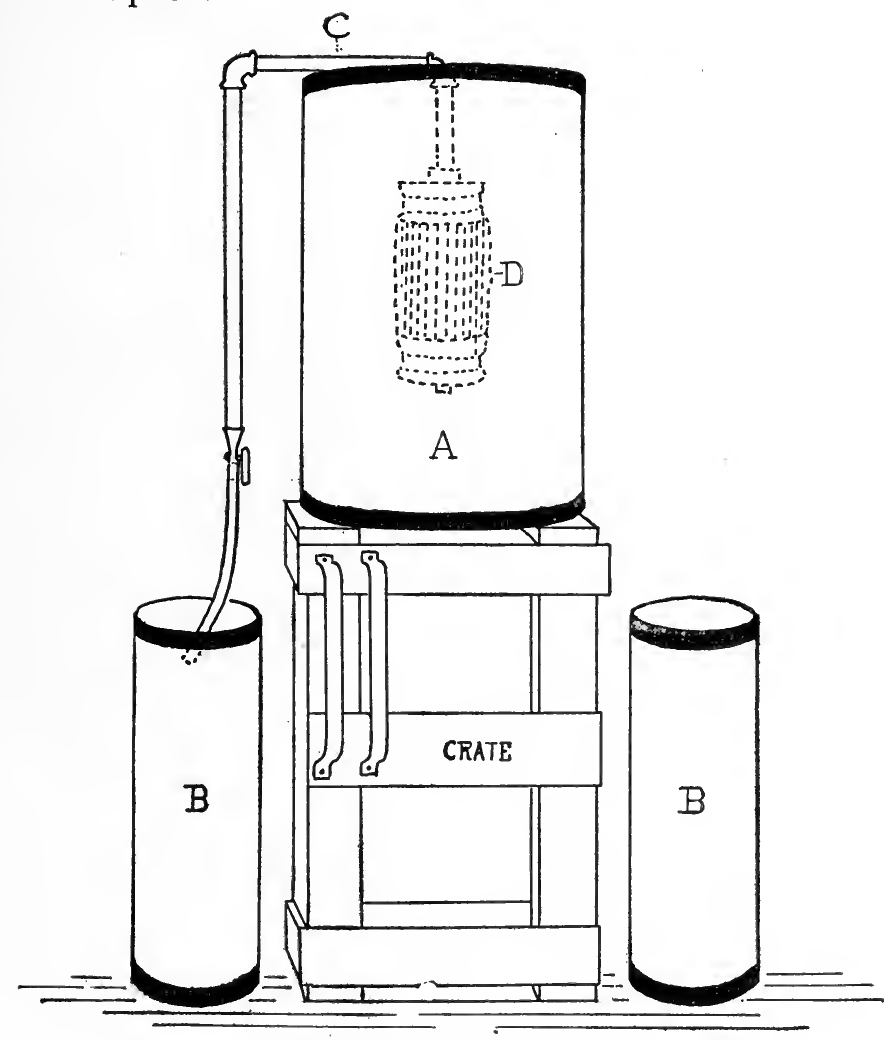

Fig. 17.-Darnall filter, showing method of operation.

(2) Sterilize the siphon by putting it in one of the cans, filling the latter with boiling water, and drawing off the water by starting the siphon.

(3) Fill the other can with the water to be treated, stir in a measure of the alum-soda powder, and empty the can 
into the tank. Repeat until the tank is full, then transfer the siphon to the tank and start it with the pump. Lift the siphon and brush off its cloth whenever it becomes clogged with sediment. With clear water the filter will furnish 50 gallons of the purified product per hour, a quantity sufficient to fill 200 canteens. If the water is muddy, the amount is considerably reduced.

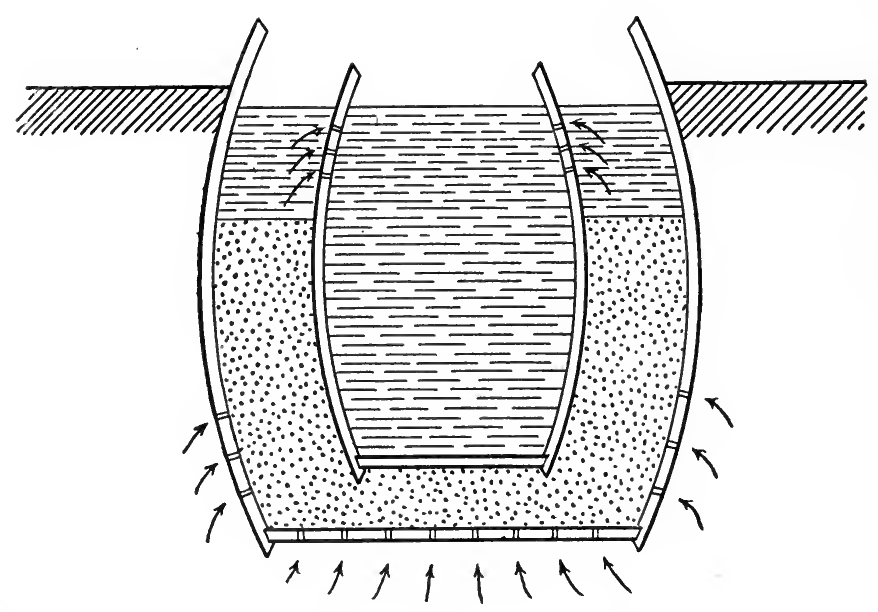

Fig. 18.-Barrel filter sunk in spring.

Improvised Filter.-A filter may be improvised by sinking a barrel or box in the source of field supply (spring or margin of stream), placing a smaller cask or box within, and filling the intervening space with sand. The outer barrel should be pierced at or near the bottom, the inner one near the top, with a number of small holes (Fig. 18).

Success by filtration methods is relative rather than absolute. 
The destruction of bacteria in water (sterilization) by heat is accomplished: (a) By distillation; $(b)$ by boiling; or (c) by raising the temperature to a point, short of $212^{\circ} \mathrm{F}$., which is fatal to the germs. Distillation is employed for small communities-as on shipboard and at certain Philippine stations-but is not practicable in the field. A temperature of $176^{\circ} \mathrm{F}$., maintained for a few seconds, is sufficient to kill the germs of diseases transmitted by drinkingwater. This principle is utilized in the Forbes sterilizer, of which many have been supplied to our service. These have been much used in the past and have filled an important place, but it is doubtful if they will be issued in the future, at least for field service. Their defects are: weight; comparative fragility; easy derangement; necessity for skilled attendance; risk of imperfect sterilization. The fuel ordinarily used is kerosene, and the difficulty in the supply of this material constitutes a further defect. This objection has been met by the invention of a wood-burning attachment, thus adapting it to the local fuel supply. The weight of the apparatus, with this attachment and two nested barrels, is nearly 180 pounds, and at least three of the sterilizers are required for the needs of a regiment. The apparatus is of value in the supply of a safe drinking-water for permanent camps and outlying stations. By reference to Fig. 19, which shows the United States Army type with woodburning attachment, the sterilizer is seen to be a slender upright machine of copper and brass. The base is a kerosene reservoir with a small compression pump to feed the "Primus" burner. By an ingenious arrangement, whereby 
the raw and sterilized waters are separated merely by a thin metal partition, the former is gradually heated and the latter cooled by their interaction. Thus the water when it

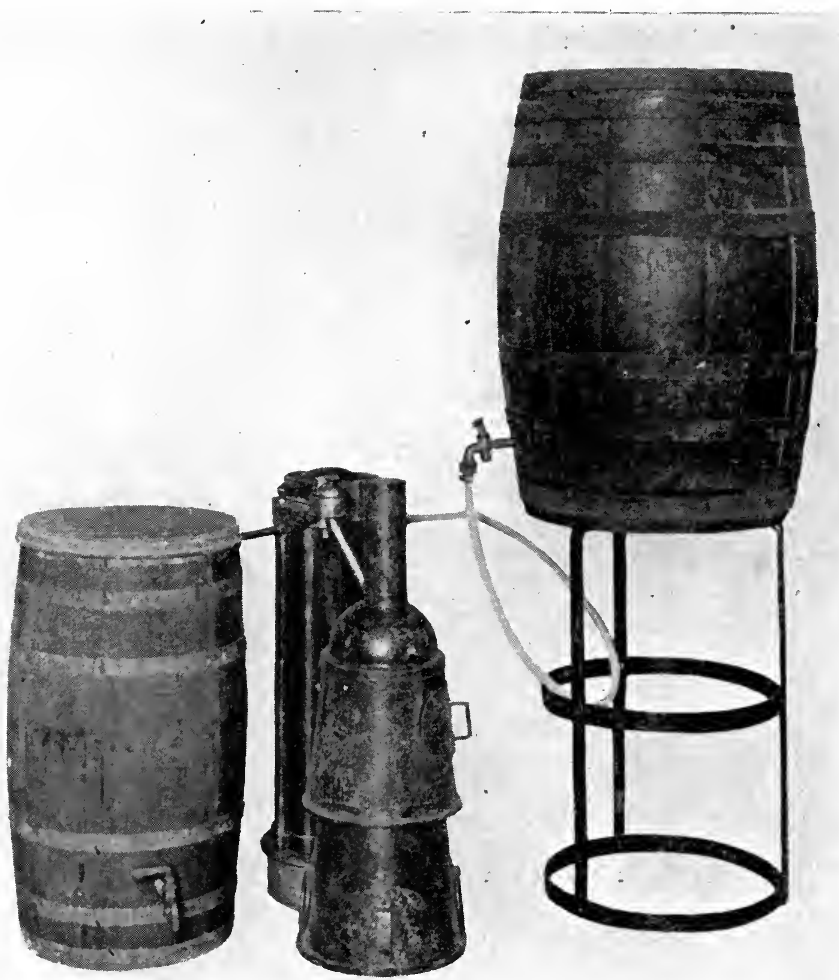

Fig. 19.-Forbes' sterilizer with "wood-burning attachment" and "barrel accessory."

leaves the sterilizer is but 4 degrees warmer than when it entered.

The Forbes company has devised a large sterilizer, capable of yielding 400 gallons per hour, and mounted on the running 
gear of an escort wagon. If such a wagon actually accompanied a moving command, it should be able to supply a brigade. The Germans, French, and British have experimented with large portable sterilizers operating on the heat exchange principle utilized by the Forbes, but have not found them practicable for field service, for reasons already cited.

Boiling.-The safest, simplest, and most uniformly available method of water sterilization is boiling. This can be done in the company kettles at night after supper, and the water is cooled and ready for the canteens by morning. Or, if the kettles are not available, each soldier may boil his own supply in cup or new model canteen. Even this procedure has certain disadvantages, which, fortunately, are minor ones. It is an inconvenience; the water cannot be used until it cools; the dissolved air is driven off and the taste thereby made insipid. As for the last objection, the water may be re-aërated by pouring it from one vessel to another a few times:

Ice taken from an impure source may contain dormant disease germs. Freezing does not always kill them and they may become active when the ice is melted, but a greater danger results from the careless handling of this substance, contact with dirty hands or other infected objects often adding to a pure ice the dangerous micro-organisms. Unless one is sure of source and handling, it is wise not to place ice in the beverage, but to cool the latter by applying the chilling agent to the outside of the container.

If in Doubt, Purify.-It is possible that antityphoid vac- 
cination may be found to confer such immunity as to render the sterilization of water superfluous, at least so far as that disease is concerned. If such proves to be the case, a great source of anxiety would be removed, as well as the necessity for bulky apparatus and expenditure of time and trouble. But, pending such finding, it must be remembered that no sure and rapid test as to purity exists. So the word-pictures drawn by certain correspondents during the Russo-Japanese War, of medical officers hurrying in front of marching commands, armed with microscopes and chemical sets for examination of waters prior to the arrival of troops, are absurdities. A careful inspection of the source and surroundings of the water-supply, with a view to determining probable contamination, is our best guide. The rule to be followed is: If in doubt, purify. 


\section{CHAPTER IX}

\section{FOODS AND THEIR PREPARATION}

Cells.-Man, in common with all complex living organisms, is made up of a vast assemblage of minute structural units, which, for lack of a better name, are called cells. In order that these cells may possess certain properties which are necessary to the well-being of the body, they must have food.

Properties of Cells.--The properties incident to healthy cells are: (a) growth; $(b)$ repair; $(c)$ reproduction; $(d)$ the storage of materials which are capable of being utilized as producers of heat or other forms of energy (i.e., fuel); $(e)$ the actual production of energy by the burning up (oxidation) of such fuel.

Definition of Food.-In its general sense, food may be taken to mean anything which nourishes the body. Such a broad definition would include the oxygen derived from the air we breathe. In its ordinary usage the term refers to materials voluntarily introduced into the body to support life.

Bodily Processes.-In the normal processes of the body tissues must be grown or rebuilt; waste must be repaired; energy must be created; heat must be supplied. Woodhull says: "Life is essentially a form of motion. It is maintained by the rejection of old and wornout particles and by the 
assimilation of new particles to replace these or to develop the body still further." The new particles, introduced as food in a certain form and altered by the chemistry of the body according to its needs, are utilized thus: (a) To form tissues; (b) to make repairs; $(c)$ to use as fuel; $(d)$ to develop the activity of muscles and other structures; $(e)$ to store up as food for future use.

Chemical Composition of Body.-Four elements-oxygen, hydrogen, carbon, and nitrogen-are necessary ingredients of all the tissues of the body. Nitrogen is essentially a tissue builder, acting under heads $(a)$ and $(b)$ above. The other three elements are force producers and serve the purposes of the body as represented by $(c),(d)$, and $(e)$. It is obvious, therefore, that food must likewise contain these elements in proportions at least approximating the needs of the body. Certain other elements are found in varying quantities in the tissues, but for the purposes of this discussion they need not be considered here.

The great bulk of our food consists of substances containing carbon, hydrogen, and oxygen; in other words, the force producers. These substances are completely oxidized in the system, their end-products being carbon dioxid and water.

Nitrogenous Foods.-The nitrogen-containing foodsthat is, the tissue builders-leave a residue of waste material in the form of urea and like substances. As Hutchinson expresses it, "The body does not reduce all its fuel to ashes. Some of it is only charred." Certain physiologists maintain that a large excess of such nitrogenous foods is ordinarily taken and that these impose undue strain upon the organ- 
ism. On the other hand, men engaged in severe exertion draw upon their reserve stores, especially of nitrogen, unless this is amply provided in the food. It is at least certain that we cannot accept as final, laboratory experiments which are greatly opposed to the experience of centuries.

Classes of Foods.-Substances used as food by mankind naturally fall under three groups, in accordance with their chemical characteristics. These groups are proteins, carbohydrates, and fats. The proteins are the nitrogenous foods, being made up of carbon, hydrogen, oxygen, and nitrogen. Carbohydrates and fats contain the first three of these elements only. In addition to the true foods just mentioned, there are other substances equally vital to the life of the cells, notably water and mineral salts. Foods are thus seen to be derived from animal, vegetable, and mineral sources, and may be classified as follows:

Classification of Materials Used as Foods

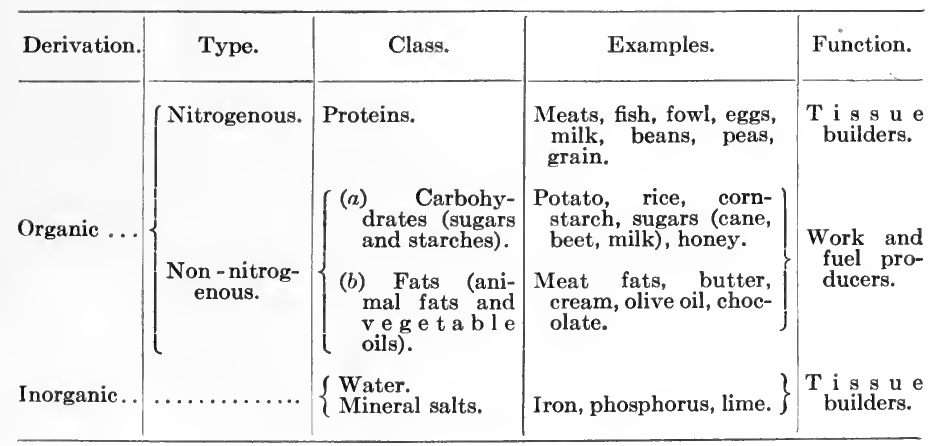

Materials Accessory to Foods. - While the above furnishes a complete classification of foods, man makes use of cer- 
tain accessory materials which, though they do not yield energy, are valuable in association with foods proper. Such are condiments, flavoring extracts, bakers' chemicals, and stimulants like tea and coffee. For, in diet, nutritive values are not the only consideration; flavor and variety also are important.

Functions of Different Classes.-The chief function of the proteins in the food is to nourish the muscles. Carbohydrates furnish heat and muscular activity and, in addition, are stored up as reserve fuel. This reserve occurs in two forms: first, as glycogen or "animal starch"; second, as fat. Glycogen is contained in the liver and the muscles, and there may be enough of it to supply energy for four or five days in the absence of all food. Fats, like carbohydrates, are work and heat producers, but, oddly enough, they do not form fats in the human body. As their functions are nearly identical, carbohydrates and fats are capable of replacing one another in the diet to a considerable extent, though the body burns carbohydrates by preference. Thus, Arctic dwellers derive their energy chiefly from fatty foods; Tropic inhabitants, from starchy ones. There is a great difference in peoples as to character and preparation of foods. This is the result of training and habit as well as of necessity, but seems of minor importance so long as the nutritious principles are present in proper amounts and proportions. A marked military advantage inheres in this fact, as a nation whose food is of little variety and small bulk can dispense with much transportation and is less dependent thereupon. 
Calories.- The potential energy contained in any food substance is expressed in calories. A calorie is a heat unit: it is the amount of heat required to raise one kilogram of water from zero to $1^{\circ} \mathrm{C}$. Thus,

1 gram of protein yields 4 calories.

1 gram of carbohydrate yields 4 calories.

1 gram of fat yields 9.4 calories.

Fat, though economical in bulk and cost, cannot ordinarily be freely used to replace carbohydrate because of digestive limitations, so foods of the latter class are the ones chiefly called upon to furnish energy. They constitute the bulky part of the diet.

Salts.-The inorganic salts needed in the diet are contained in sufficient amounts in ordinary food. The only one which must be specially supplied is sodium chlorid (common salt).

Water.-The body is mainly water, which makes up nearly two-thirds of the total weight. The food must, therefore, contain a large amount of water to replace constant losses.

Ration.-A ration is the food allowance for the subsistence of one person for one day. The term "balanced ration," often heard nowadays, means one by which perfect nutrition is secured, without excess of any kind of food. Certain standards have been arrived at by experts, fixing the quantity, expressed in calories, of each class of a ration for individuals in different environments and under varying circumstances of muscular work and other occupations. Such standards are but approximate and of little concern to 
us here. It may be of use to us to know that a garrison ration should have an energy-yielding value of about 3000 calories and a field ration of not less than 4000 calories.

Diet in General.- The relative digestibility of food stuffs differs markedly, but the ordinary meal is usually completely digested in four to five hours. In general, meats are more readily assimilated than vegetables. It is probably true that too much meat is taken by many individuals, and that the protein excess tends to produce irritant waste matters which are likely to cause gout, Bright's disease, and arterial changes, but civilized man has accustomed himself to meats, and their moderate use is believed to be to his advantage. Except by a few extremists, it is generally admitted that a mixed diet is the rational one. Man is extraordinarily adaptable in matters of food, just as he is in other particulars (as climate). With respect to the quantity of food taken, we know that moderate amounts in excess of a balanced ration are stored up in the body as a reserve. Militarily, this is likely to be of the utmost value at times when the soldier, lacking food, must subsist in whole or in part upon his own tissues.

Milk.-Certain forms of the commoner foods deserve separate mention. Milk is perhaps the most important of all foods, since it is the only one capable of supporting life by itself. It is not a perfect food, but approximates one more nearly than any other substance. In the absence of cows, the milk of goats, mares, and domesticated buffaloes - as the Philippine carabao-is useful and fairly nutritious. Condensed cream and milk are valuable when the fresh 
product is not obtainable. Milk is often adulterated in one or both of two ways: by the removal of cream or the addition of water. It may transmit the germs of disease, such as typhoid fever and tuberculosis. It absorbs odors readily and should not be placed in a refrigerator with strongsmelling substances, such as onions, stale cheese, and tainted meat. Its products are numerous and valuable and include butter, cheese, buttermilk, koumiss, soured milk, and whey. Cheese is a highly nutritious food and might advantageously be substituted for bacon as an occasional issue. Milk artificially soured by the addition of a lactic-acid-forming bacillus is not now thought to prolong human life, though it is a nutritious and useful beverage.

Eggs contain all the ingredients necessary to support life, though not in proper proportions. The fresher they are, the more digestible. Cold-storage eggs preserve their freshness fairly well for a month or two. After that they acquire a taste and odor which distinguishes them from the fresh article, though they are still useful for baking purposes. They are sometimes preserved by desiccation, in which form they are readily portable and serviceable for cooking.

Beef.-Meats furnish us with our chief supply of nitrogen. They are popularly classified as flesh, fowl, and fish. Of all foods under this head, beef is the most important. Since it constitutes so essential a part of the ration, ability to judge of its freshness and freedom from disease is of great practical value. The appearance of fresh cuts cannot be accurately described and a knowledge of their characteristics should be gained by study of the meats themselves. Good 
beef is bright red in color. A dark purplish hue suggests that the animal has died from disease or has been imperfectly bled; this latter is objectionable, as it predisposes to decomposition. The odor should not be disagreeable, although refrigerated beef, especially when the sacking has just been removed, often has a cadaveric smell. Undue softness and stickiness of the freshly cut surface, or the presence of pus, indicates decay. An early evidence. of decomposition is furnished by thrusting a knife or skewer deeply into the meat and smelling it on withdrawal. If decay has commenced, a putrid odor is observable.

The bones make up about 20 per cent. of the weight of the carcass and 5 per cent. more is wasted in trimming the cuts. Cattle on the hoof accompanying a marching army are poor in flesh and their meat is tough and stringy. In these days of refrigeration it is unusual to obtain a supply of freshly slaughtered beef.

Refrigeration.-Actual freezing of beef causes some deterioration, and its temperature in cold storage should preferably be maintained at a point just above freezing. Fresh beef issues in the United States have usually been in cold storage for about a month; those in the Philippines at least two or three times that long.

Preserved Meats.-Aside from cold storage, there are four methods used in preserving meats. These are: (a) curing; $(b)$ sterilizing by heat and then canning; $(c)$ drying; (d) treatment with chemicals. Meats are cured with salt, wood smoke, vinegar, or sugar. A pound of canned beef 
has a nutritive value about one-third greater than an equal weight of the fresh meat. Canned beef is supplied in two forms for our ration, to be used when fresh meat is not obtainable. These forms are roast beef and corned beef hash. The latter is much liked; the former, though wholesome, is made from the inferior cuts and is rather tough and flavorless. Chemical preservatives (commonly borax and sodium sulphite) are objectionable, and the use of meats so treated should be discouraged.

Bacon, the cured side of the hog, is an even better food for the military ration than beef. Its palatability, digestibility, portability, and keeping qualities all combine to render it our chief reliance in the field. Its fat is peculiarly assimilable and yields more energy than any other food.

Meat Juices, Extracts, and Powders.-The juices of fresh meats possess much nutritive value; on the other hand, meat extracts are nearly valueless as food, though they are useful as stimulants, like coffee and tea. Meat may be dried and powdered, and, if well prepared, is fairly nutritious in this form. Having the advantage of small bulk, this may be found suitable for military use.

Unusual Meats.-The objection to horseflesh and other unusual meats is chiefly sentimental. It is well known that certain peoples find such animals as dogs and rats a valuable addition to their diet. Meat from diseased animals is ordinarily objectionable, but in time of siege or other extremity it is better to use it than to go hungry. In preparing such meat for food, the animal should be thoroughly 
bled and the internal organs, together with all obviously diseased parts, rejected. Cooking should be thorough.

Flour.-Of food stuffs derived from vegetable sources, wheat flour is undoubtedly most important to us, as from it "the staff of life" is made. There is a great difference in flours, according to the quality of the grains from which they are made, the excellence of the milling, the age of the product, and the method of storage. If (as a result of age, dampness, or general inferiority) chemical changes ensue, flour is invaded by minute insects (mites and weevils). Flour absorbs strong odors readily, wherefore such substances as kerosene, tobacco, and onions should not be stored near by.

Bread.-The baking of bread is so important a part of the rationing of soldiers that all officers should have a knowledge of its principles. Briefly, the process consists of the following steps: First, making a dough by the mixture, with the flour, of water, salt, and yeast. Yeast is a ferment which produces carbon dioxid. Second, allowing the ferment to work upon the dough for some hours, during which time a considerable increase in bulk takes place as a result of the development of the $\mathrm{CO}_{2}$. Third, baking the dough into loaves. The changes induced in the flour by these means are: (a) Uniform diffusion of the gas, thus forming bubbles throughout the bread and making it light; $(b)$ the coagulation of the gluten (the protein component of the flour), which binds the loaf; $(c)$ the conversion of some of the starch into sugar and other readily digestible substances. Bread may also be made by generating the necessary carbon dioxid with a baking powder or by forcing the pure gas 
into the dough. Bread which has become sour or stale may be made palatable by serving as toast.

Beans contain a considerable proportion of nitrogen, and are, therefore, capable of replacing meats to some extent. They are nutritious and constitute one of the staples of the field ration. They are, however, hard to cook and difficult of digestion. The old army saying, "Beans kill more than bullets,". is a tribute to their power for evil when they are imperfectly prepared. The dry, issue beans must be soaked in warm, soft water for twelve hours and then cooked for several hours more. The trained army cook knows how to prepare them properly. A plate of beans has the approximate food value of one of meat and potatoes.

Potatoes are valuable, as the large amount of starch which they contain is readily digestible, and the modes of preparation are so variable that one does not tire of this vegetable. The outer layers of the potato are the most nutritious, and it is, therefore, desirable to scrape away, rather than cut, the peel.

Rice constitutes the staple food of a majority of the earth's inhabitants. But though the teeming millions of tropical and subtropical lands find it a necessity, it has never become very popular with dwellers in temperate climes. Nevertheless, it is a valuable starchy food and deserves our better acquaintance.

Sugar is of especial value, because it is so readily available for use by the system. It needs but little change in the chemistry of the body before it becomes capable of absorption and utilization. 
Fruits are useful for their content of vegetable acids, sugar, and salts. The acids supply a bodily need, as shown by the fact that, when they are lacking, scurvy develops. The most common acids of this class are citric (from lemons, oranges, and limes); acetic (from vinegar); tartaric (from grapes); malic (from apples, tomatoes, and pears). Bananas, dates, and figs contain much nutriment, and are widely used as food staples wherever they are native to the soil. Green vegetables are of value for much the same reasons as fruits. Though most of them contain but small amounts of nutritive principles, their acids and salts, their appetizing flavors, and the variety they impart to the diet make them a very important part of the ration. The essential food principle in staple vegetables is starch.

Coffee.-The American soldier is very fond of coffee, and though, as already explained, it does not yield energy, its agreeable flavor and its ability to sustain flagging powers make it of much worth. Such being the case, company officers should insist that it be properly made, for, as a rule, it is spoiled by carelessness or ignorance. The coffee bean, after roasting and grinding, soon loses the delicacy of its flavor unless kept in an airtight container. It is, therefore, desirable to use freshly roasted and ground coffee in garrison. In the field, where it is usually impracticable thus to prepare the raw bean, care should be taken to keep the ground coffee in a tin with tightly fitting top.

The average cook makes the coffee too weak and drives off the fine aroma by prolonged boiling. Such cooks often prepare the beverage hours before it is to be used. By 
insisting that it shall be freshly made, of fresh materials, in a clean vessel and boiled but a minute, its best qualities of flàvor, odor, and activity are preserved.

Tea.-Oddly enough, though our Anglo-Saxon relatives, the English, are extremely fond of tea, the average American soldier does not care for it. Its effect upon the body is practically identical with that of coffee, and as its bulk and weight are much less, its military value is superior. Weak, cold tea is very palatable and makes an excellent beverage with which to fill the (aluminum) canteen. The Japanese and the Russians drink tea almost to the exclusion of water, which fact is said to explain the relative exemption of their armies from water-borne diseases in the Manchurian campaign of 1904 . Tea should never be boiled. The leaves are dropped into freshly boiled water, and, after a minute or two, the beverage is (preferably) poured from the leaves into another vessel. Utensils employed in making tea should be of some material which is resistant to tannin (such as silver, china, agateware, or aluminum), for the leaves contain a large proportion of this acid, which promptly attacks tin or iron. If allowed to stand on the leaves for some time, much of the tannic acid will be extracted, making the beverage black and bitter.

Although not strictly necessary, it is desirable that cooks should have some knowledge of the processes of nutrition and of food values. Raw materials of the best quality are often ruined in the cooking. On the other hand, a skilled cook may prepare inferior food stuffs so that they are savory as well as nutritious. 
Cooking of Meats.-The effects of cooking meats are to render them more palatable and to destroy germs, though the process does not always increase digestibility. The principal methods of preparation of such foods are:

(A) Soups and Broths.--These are made by soaking the meat, cut up into inch cubes, in cold water for an hour, then cooking slowly. The object here is to extract the nutritious juices from the meat. Bones should be broken up and cooked in soup for the sake of the marrow, which is very rich.

(B) Stewing is like soup making, except that the meat is not soaked before cooking, very little water is used, and vegetables are usually added.

(C) In boiling, the entire piece of meat is plunged at once into boiling water, in order to coagulate the surface and thus prevent the juices from escaping. Thereafter the cooking should be continued at a lower temperature.

(D) The principle of roasting is the same as that of boiling, that is, the meat is first exposed to a high temperature, to cause prompt coagulation of the surface and to keep the juices within. After this is accomplished the temperature of the oven is reduced and the meat frequently "basted" with the pan juices.

(E) In broiling, the same effect of retention of juices is produced by exposing the meat to an open fire. This method produces especially agreeable flavors.

(F) Last and least desirable comes frying. This is accomplished by dropping the meat into hot fat, which promptly seals the surface. But, unless the fat is very hot and the 
work skilfully done, the fat will penetrate the meat, making it greasy and hard to digest.

Cooking of Vegetables.-Most vegetable foods require cooking, because the cellulose which encloses their starch granules is practically incapable of digestion by man. The raw starch, too, must be softened. Cooking breaks up the cellulose and enables the digestive fluids to act upon the starch.

Temperature in Cooking.-In all forms of cooking the temperature should be kept fairly low-below $170^{\circ} \mathrm{F}$ - except for the short preliminary treatment, where necessary, to seal the exterior. Company cooks must be frequently cautioned and inspected concerning this point.

The United States Army ration is generous and elastic, and savings therefrom, with provision for a company fund, make it still more so. The average soldier in our service gets food of higher quality, greater variety, and superior preparation than he has been accustomed to in civil life. This, combined with his military exercises, regular habits, and general hygienic conditions, causes marked gains in the weight and strength of recruits. The British military sanitarian, Melville, strongly endorses a regimental or battalion system of messing as being more cleanly, causing less waste, and simplifying the removal of refuse. Our service has tried out this system and has become thoroughly convinced that the company mess is much superior. The chief reason for our decision is that, when a command moves into the field, company messes are imperative, and, therefore, company cooks must be trained and mess equipment ready. An 
organization of 100 men in garrison will require a mess staff consisting of one non-commissioned officer, one first and one second cook, one or two cook's police, and a dining room orderly. Captain Holbrook and Sergeant Dunne, in their excellent manual "Handling the Straight Army Ration," epitomize the requisite factors of a successful mess as follows: "Variety in bills of fare, careful preparation of food, palatable seasoning, prevention of waste, and good dining room service." The average cook, unless carefully taught and supervised, wastes an enormous amount of good food in its preparation and in throwing away any excess. Cooks are prone to fall into a rut with respect to variety. The man who habitually serves his excess of prepared food in the form of a thin stew (called "slum" by the soldiers) will provoke much discontent. Left overs may be served in a great diversity of appetizing forms. Meats can be made up into pies, stews, hashes, cold loaf, croquettes, etc. Vegetables can be used in puddings, soups, salads, hashes, and stews. Corn and cereals can be made into cakes and fried, while potatoes may be utilized in many ways. The uses for stale bread are many and varied. If care is taken to place a minimum of food upon each plate, replenishing only when desired, the total wastes from the tables after a meal should not exceed a half-bucketful.

Mess Supervision.-Company officers should know the principles of handling, cooking, and serving the ration, ifor of all measures in the military service promoting contentment, a good company mess is the greatest. Many militia and volunteer companies owe the physical breakdowns 
which are so common in such organizations to the lack of a trained field cook and intelligent mess supervision. Perhaps the most important lesson to be learned by a newly commissioned and inexperienced company officer is the method of preparing ration returns and of drawing the food necessary for the subsistence of his men.

Field and Reserve Rations.-Rations for campaign are of two kinds, field and reserve, whose names suggest their use. The former, consisting chiefly of bacon or canned meat, fresh or hard bread, beans; coffee, and sugar, constitutes the main reliance of a field force, but is supplemented by such other food as it is possible to obtain. The reserve ration is made up of bacon, hard bread, coffee, sugar, and salt, and is to be used when the field ration is not obtainable and then only upon the order of the commander. In other words, it is intended for emergency use. Each man habitually carries at least two reserve rations. The field trains convey two field and one reserve ration, and the supply train has two more field rations for each man. Thus, unless the troops cut loose from their transport or the latter fails, a command can subsist for at least seven days on its own supplies. And, unless the exertions of the troops are unusually severe, two reserve rations will maintain the health and vigor of the men for four days should emergency demand. However, this half ration should not be continued longer than is absolutely necessary, as the body tissues are being called upon for their stores of reserve food.

The Quartermaster Corps will usually succeed in furnishing food stuffs supplementary to the field ration. Most 
important of these is fresh bread, made by the division field bakeries. The hard bread is intended for use only when soft bread is not available. And even should the bakeries fail, a good field cook will usually manage to have a supply of fresh yeast or baking powder with which to make bread or biscuit. Our hard bread is a good issue, though the pain de guerre of the French is said to be its superior in palatability, digestibility, and keeping qualities. The War Department has recently adopted a so-called field bread, which has not yet been tested in campaign. It is palatable and, owing to a very thick crust, resists drying for two or three weeks.

Fresh and Canned Vegetables.-The only fresh vegetables which keep well are potatoes and onions; others, therefore, must usually be supplied in dried or canned form. Of cannerl vegetables, our reliance is chiefly on tomatoes, which are much liked by our men. In using canned goods we must assure ourselves, by noting that the ends of the containers are concave, that no fermentation has ensued. Bulging of the ends indicates gases of decomposition.

Cooking in the Field.-This procedure naturally differs considerably from that in garrison. In a permanent camp it may be carried on much as in garrison, but with a moving command facilities are more or less scant. When the regimental train is at hand, a field range may be available (Fig. 20). This range may be carried on a pack animal, or its utensils so transported and the range itself left behind. Failing these, a simple trench or fire pit must serve, with cooking in the individual mess kits. It is advisable, when 
starting on a campaign, to take along some fresh bread and canned goods in order to help out until cooks become habituated to the changed conditions. Most armies are now supplied, at least in part, with "rolling kitchens" (Fig. 21), which, accompanying troops on the march, furnish a hot soup or stew as soon as camp is reached. This method will

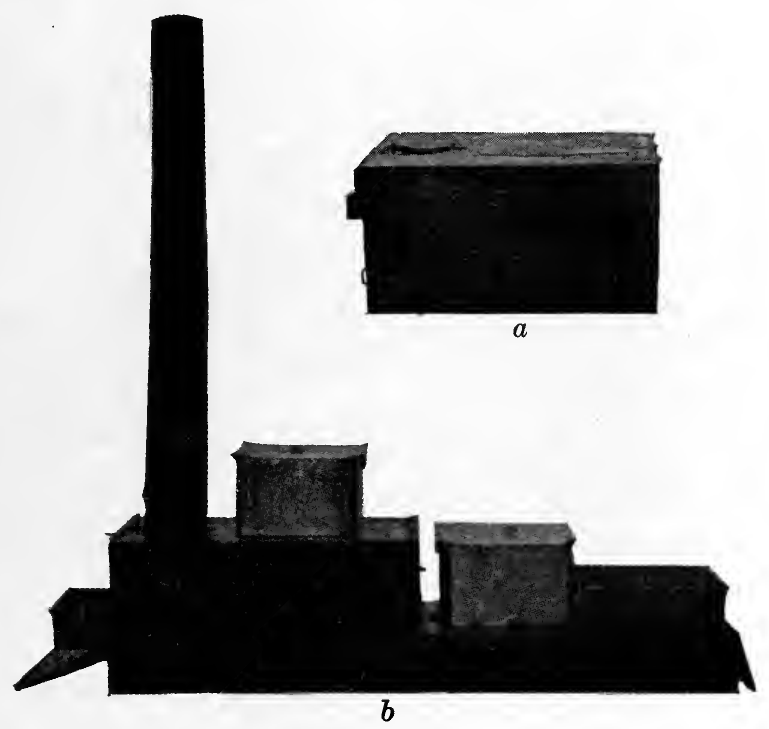

Fig. 20.-United States Army field range: $a$, Packed for transportation; $b$, set up ready for use.

be given a trial in our service, though our rough roads and the fondness of our men for variety render its success problematic. Soldiers of the mobile forces should be individually taught how to prepare the field and reserve rations. 
Concentrated Foods. - We read of concentrated and tabloid foods possessing in small bulk all the elements necessary to sustain life. This is fallacious; the only way to condense a food is to drive off its contained water. Its more valuable principles cannot be extracted by any known process. All so-called emergency rations, therefore, possess considerable bulk and weight, while they are at the same

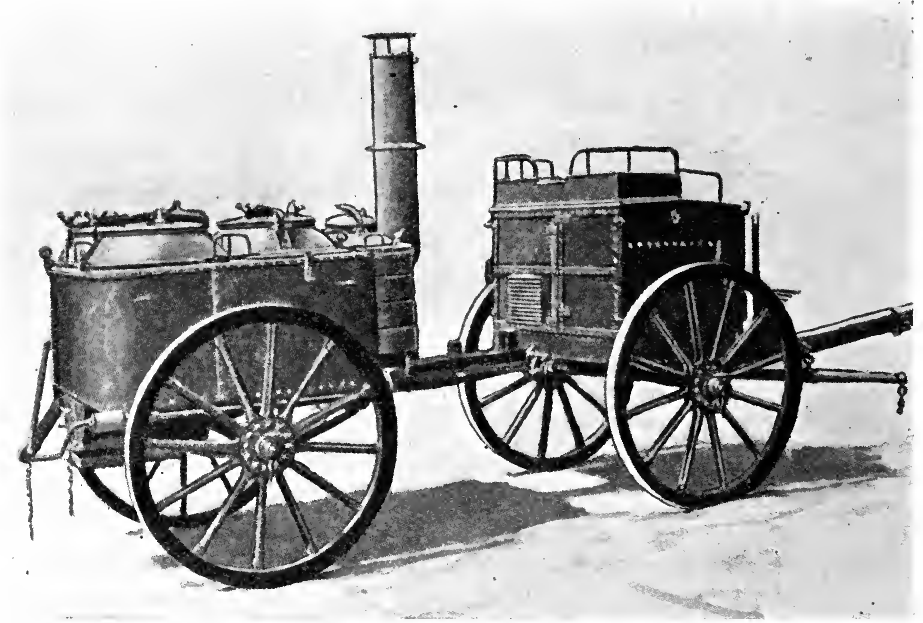

Fig. 21.-Rolling kitchen, Austrian model (Dunbar, in Journal Royal Army Medical Corps).

time deficient in fuel value. The British have one of chocolate and "plasmon," the latter being a milk product. The German "iron ration" is composed of biscuit, preserved meat, preserved vegetables, and coffee, and weighs $1 \frac{1}{2}$ pounds. Our army has experimented largely with emergency rations, but has not found a satisfactory one. The 
German "erbswurst" (pea sausage), made up of pea flour, fat pork, and salt, is a valuable food in small bulk. Another useful article of this class is "pemmican," a food of American origin, which consists of dried lean beef, tallow, currants, and sugar, compressed into cakes.

Arctic and Tropical Rations. - In preparing a ration for tropical or arctic service, departures from the ordinary ration are not so great as might be surmised. Briefly, Americans serving in the tropics desire a little less meat and fat and considerably more sugar. In Alaska an increase in meats and particularly in fats is craved.

Diseases Resulting from Faulty Diet.-There are certain diseases which result from (I) the lack of proper food or (II) the use of infected materials. Under the first head we have: (a) Scurvy. This disease, though formerly greatly dreaded by field armies and ships' crews, is now but rarely encountered. It is due to faulty diet and especially to the absence from the diet of organic acids existing in fresh meats and vegetables. (b) Beriberi caused many deaths and much disability among our Philippine scouts until it was learned that, in the milling of the rice which forms their chief food, some necessary substance was removed with the hull. The exact nature of this substance has not yet been determined, but the use of "undermilled" rice has produced a complete disappearance of the disease from that command.

Diseases Due to Infected Food.- -Under the second head we find that such communicable diseases as typhoid fever and tuberculosis may be transmitted by infected milk and other raw foods. Imperfectly cooked meats-especially of 
swine-may convey tapeworms and trichinosis. This latter disease is characterized by the lodgment, in the muscles, of a great number of small spiral worms. Glanders may be contracted by man through contact with the pus from an infected animal. The disease of this class most commonly encountered in our military service is ptomain-poisoning. Ptomains are chemical compounds resulting from the decomposition of organic substances; in food-poisoning they are developed most often in warmed-over hash, canned fish, and sausage. The symptoms are violent vomiting, colic, and diarrhea, attended by great prostration. Often a large number of men belonging to one company are affected at the same time. Fortunately, though alarming, ptomainpoisoning is not usually fatal. 


\section{CHAPTER X}

THE SANITATION OF POSTS, BARRACKS, AND TRANSPORTS

\section{The Sanitation of Posts}

Sites.-Naturally, the first matter to interest us in this connection is the site of the post. This may be unhealthful by reason of certain factors neglected in its selection or ignored on account of military expediency. A healthful site depends primarily upon the character of the soil, especially with reference to the amount of moisture therein. Granite, limestone, metamorphic and trap rocks, sandstones, well-cultivated soils, deep gravels, and sands furnish dry and salubrious sites. Made grounds are usually objectionable because of the contained organic matters. Clays, alluvial soils, and spots illy drained make the atmosphere damp and favor the development of tuberculosis, rheumatism, and colds. The ground water should not rise above 8 or 10 feet from the surface. If it be higher, underdrainage with open joint tiling should be installed, the lines of pipe being laid some 10 to 20 feet apart. Care must be taken that the slope of fall shall be even and the piping not liable to settle into occasional depressions. Aside from soils and soil moisture, slopes having a northern exposure, enclosed valleys, and ravines are undesirable sites on account of unsatisfactory conditions as to sunlight and air stagnation or air currents. 
Barrack Construction.-Building sites in moist soils should have foundation drains, damp-proof wall courses (Fig. 22), and thick concrete cellar floorings. If the building has no cellar, it should be set up on brick, stone, or concrete piers, that there may be free circulation of air beneath. Other than dryness, the necessary conditions to be met in the

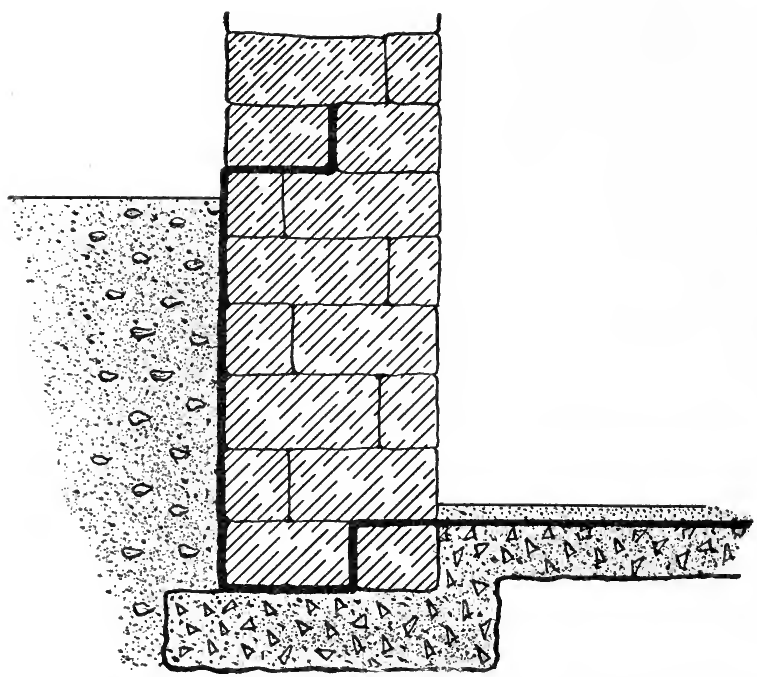

Fig. 22.-Damp-proof course for foundations of buildings (indicated by the heavy line).

construction of a barrack building are lighting, ventilation, heating, water-supply, and sewerage.

Exposure.-If barracks are large, it is desirable to face them so that their squad rooms may receive a maximum of light and air. When their long axes are north and south the sun will flood their rooms from both sides, and if this arrangement brings them broadside to the prevailing winds, 
so much the better. For smaller quarters a southern exposure is most satisfactory, being warmer in winter and, very likely, cooler in summer. Sunlight is a famous purifier, being inimical to many kinds of disease germs.

For the lighting of dwellings, electricity only should be considered, if available. Failing this, acetylene, ordinary illuminating gas, or mineral oil may be employed, in the order named as to desirability. These latter agents vitiate the atmosphere by using up oxygen and giving off products of combustion. If gas is used, Argand or Welsbach burners should be provided.

Ventilation.-The ventilation of buildings should be arranged for by natural means, that is, dependent upon the movement of the outer air. Artificial ventilation, accomplished by forcing air in or out with fans, is but a poor substitute for perflation, which means the passage of natural air currents through a room. The essential factors in efficient ventilation are: proper temperature (not too warm), dryness, and a certain amount of movement of the air. A simple and excellent system of ventilation may be installed as follows: (1) Place transoms over hall doors of all rooms. (2) Install ventilator openings in lower window sashes of rooms. (3) Put heating radiators under windows so ventilated (Fig. 23). (4) Provide good-sized openings above the windows or doors at ends of halls, with large radiators below these. (5) Where necessary (as in toilet rooms) this system may be reinforced by air ducts from basement to roof, with a radiator at the foot of each.

Air inlets through walls, terminating beneath radiators, 
are in common use and are satisfactory when well kept. But they are liable to become dust receptacles, and are often choked up with an old garment by some fresh-air coward. The simplest method of improving the ventilation of a room

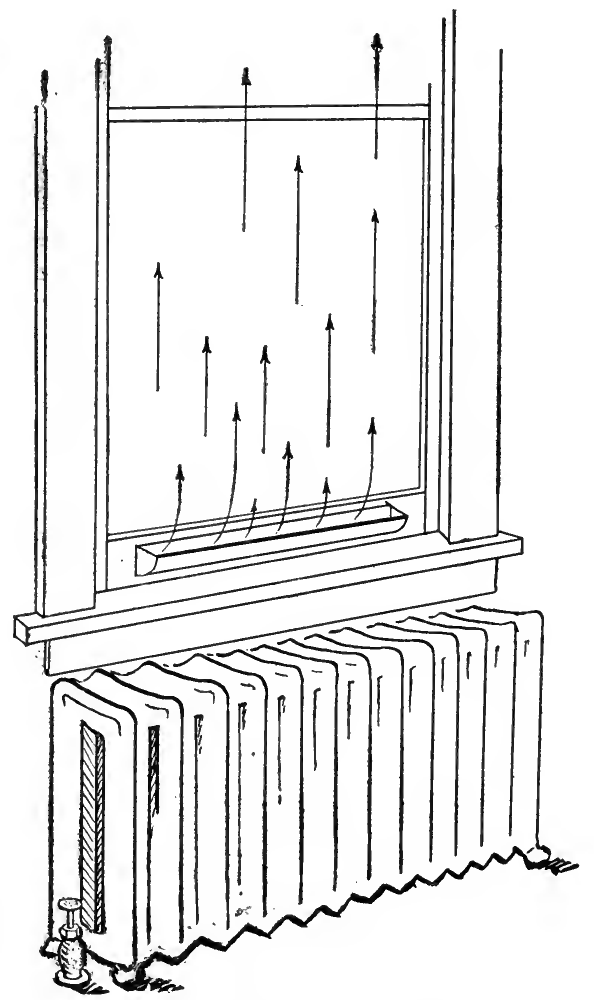

Fig. 23.-Ventilation system.

without producing drafts is to raise the lower window sash a few inches and fill the opening with a board. Air then enters between the sashes and is directed upward toward the ceiling, where it spreads out and is warmed some- 


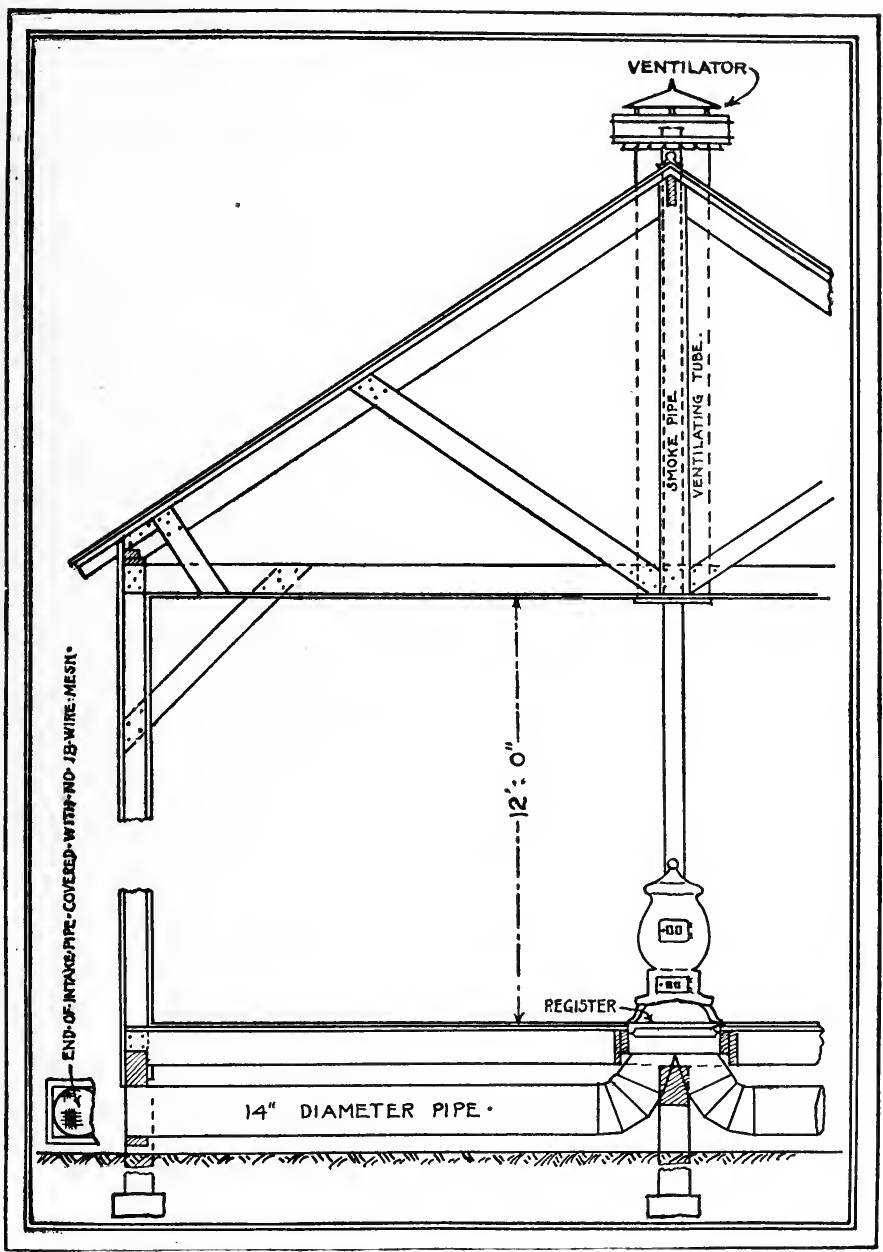

Fig. 24.-Ventilation system for temporary buildings by means of freshair ducts beneath floors, opening under stoves.

what before coming in contact with the occupants of the room. In temporary structures the best system is to bring the air in by ducts beneath the floor; these discharge through 
a grating directly under the stoves by which (presumably) the building is heated (Fig. 24). 'The fresh air is thus drawn in and warmed. Vent outlets are provided in the ceiling and through these the stovepipes pass. If the rooms are heated by open fires, natural ventilation will be adequate. In any case, perflation should be practised daily by opening the windows for a time.

Floor and Air Space.-In connection with the subject of ventilation, the consideration of floor and cubic space per occupant is vital. Experience has demonstrated that not less than 60 square feet of floor space and 600 cubic feet of air space per man in squad rooms is essential to preserve the health of troops. But these figures are really lower than is consonant with safety; medical authorities are of the opinion that the minimum in floor space should be 70 square feet, and in air space, 800 cubic feet. This assumes the usual ceiling height of 12 feet. The capacity of each squad room should be estimated on the basis of the latter figures, the number proper to each painted on the door thereof, and such number never exceeded. If a temporary increase occurs in a company, it is better to utilize the halls of barracks for additional cots rather than to diminish floor and air space in squad rooms.

Heating of buildings is accomplished by one of three systems, namely, direct, indirect, and direct-indirect. The first named is where the source of heat is in the room itself and not directly connected with ventilation. Under this head are stoves, grates, and steam or hot-water radiators without air inlets. "Indirect" is the term applied to methods 
in which the air is heated before entering the room, this air being used both for heating and ventilation. Of such are hot-air furnaces, and steam-coils over which air is passed. The third system comprises measures where the source of heat is in the room and the air supply is brought in contact with it there. Hot-water and steam radiators connected with air inlets, or stoves with air ducts opening beneath them, are examples of this class. Of all the methods indicated, the low-pressure hot-water system of direct type is perhaps the best for barracks, when conjoined with the system of ventilation recommended above. Room temperature should not ordinarily exceed $70^{\circ} \mathrm{F}$.

Plumbing.-Water-supply in general is discussed elsewhere. A system of supply implies means for the removal and disposal of waste water, that is, a system of sewerage. Plumbing should be as simple, compact, direct, and plain as possible. Its various parts should be exposed, so that they may be readily accessible and kept clean. Closets of the "siphon jet" type, in which the bowl and trap are molded in one piece, are the best form (Fig. 25). Showerbaths are preferable to tubs for barrack use, being economical in water used and less likely to transmit skin and venereal diseases. Every separate fixture (closet bowl, bathtub, shower, basin, urinal, kitchen or slop sink) should have a trap as near to it as possible. A trap is a bend or partition in a pipe or other plumbing fixture, so arranged that the liquid contents form a seal which prevents the passage of air, but permits the flow of liquids. The seal of "running" traps is easily forced by the back pressure of gases, by siphon- 
age, or by evaporation; non-siphonage traps, such as the "Sanito," are, therefore, desirable (Fig. 26). If a nonsiphoning trap is not used, each fixture must have a vent pipe to protect the seals of traps and to carry off offensive odors. All vent pipes pertaining to a set of fixtures connect with a main vent at a point higher than the fixture. The main vent joins the soil-pipe above the top fixture or is carried up through the roof separately.

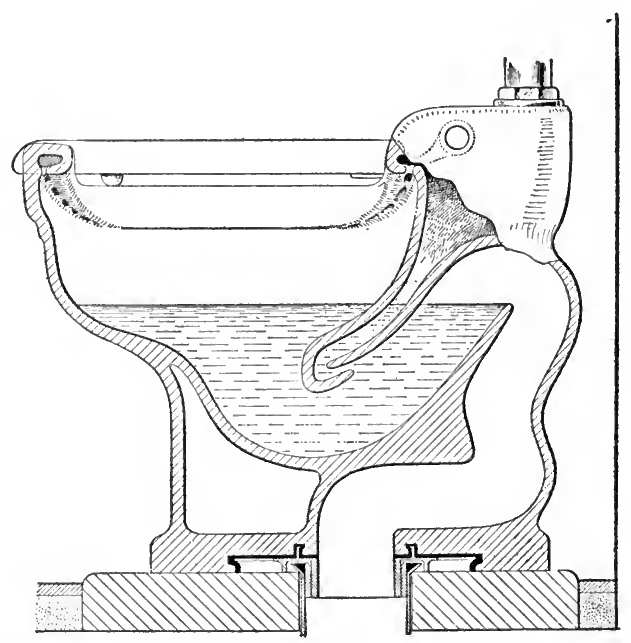

Fig. 25.-Siphon jet closet, "West Point" model (J. L. Mott Co.).

Soil-pipe.-Waste-pipes draining fixtures should be of iron (not lead) and discharge into the soil-pipe. This is an upright pipe of 4-inch extra-heavy cast iron, whose lower end rests on a concrete pier in the cellar and whose open upper extremity is extended through the roof. $Y$ branches at proper points receive the waste-pipes, and a bend in the cellar effects a junction with the branch sewer. It is desir- 
able to test plumbing after installation and when there is suspicion of defects. This may be accomplished by one of several methods, of which the peppermint test is perhaps the simplest. In this test, vents are closed and traps filled, after which 2 ounces of oil of peppermint are poured into the top of the soil-pipe, followed by two quarts of hot water.

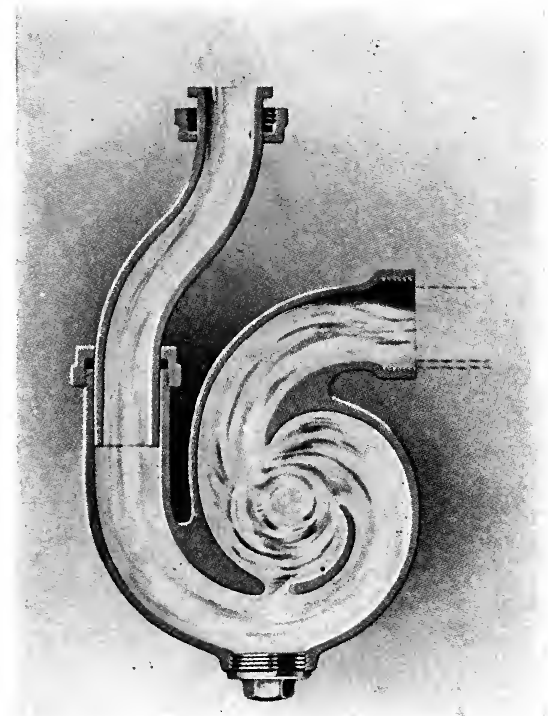

Fig. 26.-Non-siphoning trap vent, "Sanito" model (J. L. Mott Co.).

The top of the soil-pipe is then stopped up, and, if a leak exists, the pungent smell of the oil may be detected near the defective fixture. When house plumbing is in temporary disuse (as by reason of absence of occupants) it should be flushed once a week to prevent breakage of seals by evaporation, as well as the breeding of mosquitoes in open tanks and bowls. 
Stables must be kept in a sanitary state, not only for the sake of the animals, but to prevent the propagation of flies and rats, which are justly regarded as foes of mankind. Flies breed by preference in horse manure, though they may develop in other decaying animal and vegetable material, such as garbage. They will also breed in earth soaked with horse urine. Stable floors should, therefore, be of brick or concrete, and the bare ground outside, where horses stand, should be sprinkled once a week with crude mineral oil, which is offensive to the insects. Manure should be removed daily. Rats are responsible for the spread of the deadly epidemic disease known as bubonic plague. 'These pests find conditions favorable for their continued existence in an insanitary stable. Such conditions are: $(a)$ food and (b) places suitable for nesting and breeding. Eliminate either of these, and the animals are driven away. A campaign against rats should embrace five measures, viz., trapping; poisoning; shooting; cutting off the food supply; destroying existing nests and preventing the formation of new ones. Metal-lined feed bins and the plentiful use of cement in their runways and other haunts are effective measures.

Police of Grounds.-The police of the grounds in and adjoining the post is of great importance from an esthetic standpoint as well as that of sanitation. Wastes must be removed and disposed of. Walks and roads must be cleaned, kept free from dust, and properly maintained. Weeds and tall grass should be cut because they furnish hiding-places for mosquitoes and are evidences of neglect. A consistent scheme for the beautification of the grounds ought to be 
carried out. Privies, earth closets, and cesspools are abominations and not to be tolerated in a permanent garrison. Dumps should be inconspicuous and no putrescible materials permitted thereon.

Mosquitoes.-Collections of standing water which may serve as breeding-places for mosquitoes are to be sought for

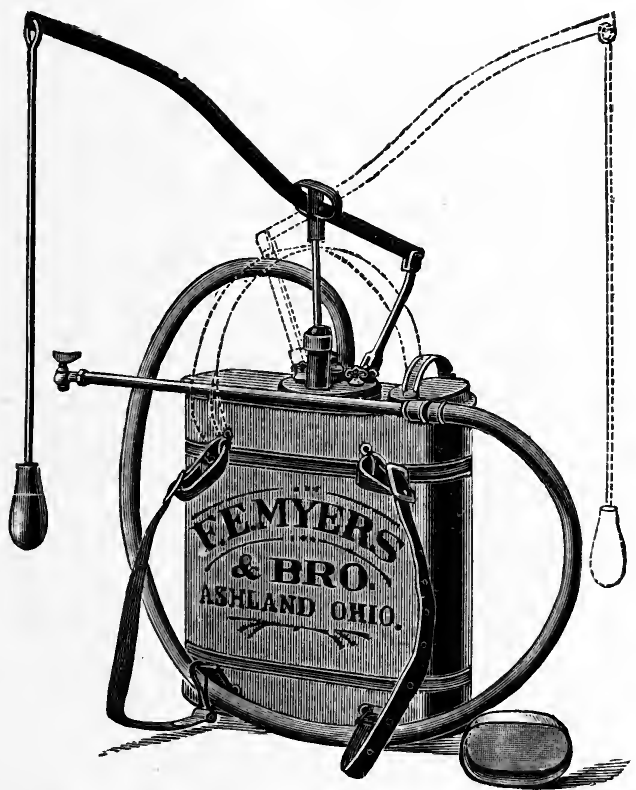

Fig. 27.- "Knapsack" spray pump for oiling standing water (F. E. Myers \& Bro.).

and filled in, drained, oiled, or screened. Hundreds of these insects may develop in a little rain water contained in an old tin can, a broken bottle, the crotch of a tree, or a slight depression in rock or clay soil. Cisterns, water troughs, excavations, fire buckets, pans in chicken yards, 
boats on the riverside, water pitchers, open plumbing traps, and the like may contain myriads of "wigglers." Sagging or choked rain gutters offer favorable conditions for their propagation. Gold fish may be placed in ornamental ponds and fountain basins to devour larvæ. Adult mosquitoes often survive throughout the winter by hiding in sheltered places, such as cellars. Fumigation with sulphur or pyrethrum, followed by sweeping up and burning the temporarily stupefied insects, will dispose of these and materially lessen next season's crop. Crude oil, kerosene, and a mixture known as "larvacide," are efficient for oiling standing water. These are conveniently spread by spraying them from a watering pot or other sprinkling apparatus. As mosquitoes develop from the egg in about ten days, oiling should be repeated weekly.

\section{The Sanitation of Barracks}

Care of Quarters.-The proper care of their quarters is vital to the health of the men. Bunks should be moved out from the wall for at least a foot, that the spaces behind them may be kept clean and the heads of the occupants be out of the stagnating air which clings to the walls. Beds and bedding are to be inspected as to cleanliness, the presence of bugs, and the tendency to secrete dirty clothing under pillows or mattresses. Bedding should be aired once a week. Cuspidors, if used, must be cleansed and scalded out daily. Wall and trunk lockers should be clean and orderly. Soiled clothing must not be put in barrack bags while wet. Wooden floors should not be flushed for cleansing purposes; 
as little water as possible is to be used, since very wet floors dry slowly and the liquid carries filth into the wood fiber. The use of a wood filler, followed by wax polishing for squadroom floors, amply repays the initial labor by the improved appearance, prevention of fouling, and ease in cleansing. Sweeping and dusting, as commonly practised, raise clouds of dust particles which settle elsewhere. A little wet sawdust strewn on the floor is of value in preventing this. If waxing is not practicable, the use of an oily floor dressing such as the "Standard" may be considered. All moldings and ledges upon which dust may settle should be wiped with a damp cloth. Vacuum cleaning is excellent in results and may replace other methods. Lavatories, latrines, store-rooms, and basement should be maintained in a neat and orderly state. Especial attention is to be paid to corners and crevices where dirt may collect. Take care of the corners and the middle of the floor will take care of itself. In the police of sinks no disinfectants are necessary and their routine use is prohibited by army regulations.

Care of Plumbing.-Daily and thorough scrubbing of the plumbing fixtures will prevent the urinous odor noted about a dirty closet. This odor is due to the deposition, on the surface of the urinal or closet bowl, of ammoniacal salts. These will not form if an old broom or a brush is used frequently and vigorously. The men should be protected from mosquitoes by screens for windows and bars for beds. Spaces under non-cellared buildings and under porches are apt to be dirty and crowded with junk. Immediate repairs 
should be made by the company artificer, of all defects which he is competent to correct.

Messing.-Foods and their preparation are discussed in a separate chapter, but there are other matters relating to the messing of troops in barracks which deserve special mention here. First and foremost of these matters is the scrupulous cleanliness of everything connected with the mess. Cooks should be required to be clean and neat in person and clothing. They should have a daily bath and should wear white clothing, the latter to be furnished from the company fund. Bake pans, boilers, kettles, griddles, and lesser utensils must be kept scoured within and free from soot and grease without. When not in use these articles should be in a designated place-preferably suspended from a rackwhere they are out of the way and may be inspected readily. The range is to be kept polished or greased as to surface, its ovens clean and free from dust and charred fragments of food. The pantry, table drawers, and shelves require especial attention to keep them free from vermin and from stocking up with trash of all kinds. The tables in kitchen and dining room are to be scrubbed with hot water and soap after each meal. Refrigerators need much care to preserve them sweet and clean. Their waste-pipes must not be allowed to discharge on the ground, thus fouling the earth and forming a pool for mosquito breeding. Dish cloths must be thoroughly scalded out after use and hung up to dry.

Fly Destruction.-Flies are to be treated as enemies, and constant efforts made to exclude and to destroy them. 
Doors and windows of kitchen and dining room must be efficiently screened. The following measures are useful as destructive agents: (1) Sticky fly paper; (2) saucers containing 1 per cent. formalin with a little sugar; (3) arsenic paper in water (bought in the shops and very effective); (4) fly traps, which should be freshly baited every day (Fig. 28); (5) Persian insect powder (pyrethrum), the burning of which

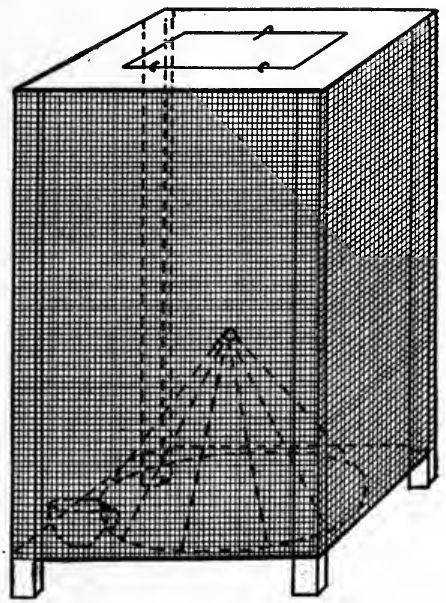

Fig. 28.-Fly trap, as made by company artificer.

produces fumes which stupefy the insects; these fall to the floor and may be swept up and burned before they revive.

Roaches.-Another type of kitchen pest is the roach family, of which the so-called Croton bug is the commonest variety. In fluorid of sodium, a cheap white powder innocuous to man, we fortunately possess an agent which is deadly to this insect. 
Mess Supervision.-Cooks should be familiar with the official publications "Handling the Straight Army Ration" and "Manual for Army Cooks." Everyone not on duty there is to be excluded from the kitchen. The men are required to wash their hands before meals and to wear proper uniform at table. Daily inspections covering the quality of food stuffs, their variety and their modes of preparation, as well as all other details under this head, are necessary for the maintenance of satisfactory conditions.

Bakery.-The post bakery requires careful supervision. Because of the nature of their work, bakers should have a daily bath and make a complete change of underclothing. They should be provided with an ample number of white aprons and caps, the same to be furnished and laundered from the bakery fund. Building, grounds, equipment, and utensils must be kept scrupulously clean. War is to be made against rats, mice, and roaches. Flour is to be kept in a cool, dry, well-ventilated room, remote from decaying vegetables, kerosene, and other strong-smelling substances, whose odors it readily absorbs. All flour should be sifted before using to remove foreign substances, such as weevils and mouse droppings. Sourness in bread is often due to the lodgment, along cracks in wooden mixing troughs, of particles of old dough. Bread should not be issued before it is twenty-four hours old. During issue to and transportation by organizations, it should be kept covered and not handled with dirty fingers.

Guard-house.-At the average post insanitary conditions are found at the guard-house more often than in any other 
building. These are usually: overcrowding; insufficient ventilation; lack of proper cleanliness; overheating; presence of bedbugs. Such defects result largely from divided responsibility, a new guard being mounted every twentyfour hours. To prevent infestation by bugs, walls and floors should be of impervious material. Where the insects have effected a lodgment, live steam from a portable boiler, turned into the closed room, is more effective than any other agent, since it destroys the eggs as well as the bugs. A guard-house should have its own water-closets and showerbaths, which require careful supervision.

Inspections.-Finally, the system of inspection should be thorough and complete. It is not necessary to cover daily every point discussed in this chapter, but visits should be sufficiently frequent, irregular and unheralded, to keep those directly concerned upon the alert.

\section{The Sanitation of Transports}

The Transport.-The troopship, which is known in our service as a transport, is a vessel used for the conveyance of soldiers by water. As the ship is a floating habitation, its sanitation is considered here. A transport ought to be suited to and fitted up for its special purpose, but, as war may come suddenly, vessels illy adapted for such use may have to be utilized, as was the case in 1898. Roughly considered, the capacity of a ship may be computed at the rate of $2 \frac{1}{2}$ tons net per man, or 7 tons per animal. To reduce gross tonnage to net, multiply by .65 .

Ventilation.-The most important problem relating to 
the sanitation of a transport is the ventilation thereof. 'Troops are so crowded on the berth decks' (sleeping quarters) that the bunks are in two tiers and the individual soldier has but 20 square feet of floor space and 200 cubic feet of air space. Such conditions are favorable to the transmission of communicable diseases. Air must, therefore, be changed much more frequently than in barracks and an artificial system of ventilation is a necessity. In the operation of such a system, the chief difficulty lies in the avoidance of drafts, which produce discomfort and may cause sickness. Berth decks are best supplied with fresh air by forcing it in from without by motor-driven fans. In cold weather the incoming air should be warmed. Where objectionable odors or excess heat are present (as in latrines, kitchens, and boiler rooms), an evacuating system is installed separately in addition to the other. Aids to natural ventilation, such as windsails, louvers, and open ports, should supplement the artificial methods. To avoid atmospheric vitiation, smoking is prohibited on berth decks, and, to enable the air to be completely changed and freshened, these decks are vacated (weather permitting) from 8 A. M. until after morning inspection.

Messing.-A mess officer, detailed from the troops, is assigned to see that the men are properly fed and to supervise all matters relating to kitchen (galley) management. No food is allowed in the men's sleeping. quarters. A cold-storage compartment, a butcher shop, and a bakery are necessary parts of the messing equipment of a transport. 
Sanitary Rules.-On boarding a transport, the men should be instructed concerning the location, use, and sanitation of water-closets, urinals, shower-baths, lavatory bowls, laundry tubs, and drinking-water supply. Sanitary rules should be printed and posted conspicuously.

Water-supply.-Drinking-water containers should have "bubbling" taps; if these are not available, the common cup is to be. kept in a weak antiseptic solution. As the supply of fresh water (which is ordinarily derived from a distilling apparatus) is not sufficient for all purposes, sea water must be used for baths and laundry tubs, but as clothing washed with sea water does not dry readily, garments should be rinsed with fresh water after laundering. Water tanks are covered or screened to prevent mosquito propagation.

General Police.- Since the men are so closely aggregated, cleanliness of their persons, of their clothing, and of the ship itself is of great importance. Much seasickness is to be anticipated early in the voyage and during heavy weather, so special arrangements must be made at such times to cope with this condition. Large details of men not so affected should be made to care for the sick and to maintain cleanliness. If this is not done the berth decks are soon rendered virtually uninhabitable. A police officer and a police sergeant are designated to maintain order and cleanliness in all parts of the ship occupied by troops. A non-commissioned officer is assigned in charge of each wash-room, watercloset, and the like, and enough privates are detailed to keep these clean. Rifles are kept in racks; packs, in designated places. Sentinels are posted at all important points to see 
that orders are carried out, that gangways are kept clear, and that no disturbances arise. Sweepings, remnants of food, etc., must not be thrown from ports. Bedding is to be aired on deck every clear day. Bedbugs are frequently found on shipboard. They must be carefully searched for and destroyed. Scrubbing or spraying crevices in bunks with kerosene or a carbolized solution will destroy the insects; boiling water will dispose of eggs as well as of bugs. As the tendency to dampness is so great, this should not be enhanced by flushing floors of berth decks; these are to be cleansed with a minimum of water, soiled areas being wiped up rather than scrubbed. Spitting on floors is prohibited. Unusual odors are traced to their source with a view to their abatement. A careful inspection is made daily at $10 \mathrm{~A}$. M. by the commanding officer of troops, the police officer, and the surgeon.

Personal hygiene is insisted upon. Vigorous exercise is taken, by drills or calisthenics, for at least twenty minutes each day. Bathing is enforced and facilities given for laundering of clothing. Men are encouraged to keep in the open air as much as possible. A weekly examination of enlisted men, in their underwear, is held to determine cleanliness as well as to detect cases of disease, such as venereal affections, lice, and the itch. Drinking and gambling are prohibited, while athletic contests and various amusements are encouraged. 


\section{CHAPTER XI}

\section{THE HYGIENE AND SANITATION OF MARCHES, CAMPS, AND BATTLEFIELDS \\ Marches}

Principles.-To quote from the Field Service Regulations, "Good marching is secured by careful preparation, strict discipline, and the due observance of march sanitation." The attainment of the last-named requirement is dependent in great part upon the other two, for ill-trained and poorly disciplined troops violate all the laws of health.

Preparation.-Sanitation on the march implies a watchful attention to all conditions which relate to the care of troops. The "careful preparation" of the Regulations includes the training of soldiers, in advance of a campaign, in hygienic and sanitary principles and observances. The sick must be left behind, and such weak individuals as may be discovered by preliminary observation eliminated. Venereal diseases and foot abnormalities are especially conducive to early breakdown. Protection against special diseases, notably typhoid fever and small-pox, must be provided by vaccinations. Troops should be trained in marching. Short marches gradually extended, first without, then with, field equipments, are necessary to harden the muscles, to toughen the feet, and to inure the men to minor discomforts which at first seem real hardships. After a seasoning of ten to four- 
teen days, good infantry can march indefinitely and wear down the animals of the mounted branches. In such training men should be instructed to walk with their toes directed forward, so that the weight is borne by the line of greatest strength of the foot. Men with weak arches invariably toe out. The flexion step of the French (in which the knees and hips are slightly bent, the body inclined forward, the feet raised very little and planted flat) is worthy of our serious study. Anyone who has seen this method of progression is sure to be impressed by its results on the rate and length of the march, as well as by the good condition of the troops at the end thereof.

March Order.--In order that subordinates may know the hour for the start, their place in column, etc., the commander issues a march order, which is usually published the evening before. The start is made early, but not so early that the men are turned out before daybreak. Nor should they be required to don their equipment nor to get into column before the time set. As marching at the tail of a column is more fatiguing than at the head, it is customary to rotate organizations in these situations on successive days. Thus, each company of a battalion, each battalion of a regiment, each regiment of a brigade, and each brigade of a division takes its place in turn. Route step is habitually employed, except perhaps in passing through towns. Halts are made at intervals, to rest the men and animals and to enable the former to attend to the calls of nature.

Halts. - The first halt is usually of fifteen minutes' duration and is made when the column has been on the road for 
one-half or three-quarters of an hour. The place should be selected with a view to reasonable privacy, and spots are designated where the men of each company (or battalion) may void their excrement. A police party from each of these organizations is detailed to dig a few individual shallow trenches, which are covered in before the command moves on. Indiscriminate fouling of the ground is thus avoided and the interests of the inhabitants and of following organizations are protected. Subsequent halts of ten minutes' duration are ordinarily made at hourly intervals. At such times the men are allowed to fall out of ranks and are encouraged to remove their packs and to rest upon the ground, preferably at full length.

Factors Affecting March.-The length of the march is largely governed by the size of the command. Other factors are the character of troops, their seascning anc discipline, the kind of road (dusty, muddy, sandy, snowy), the weather conditions (rain, heavy wind, etc), It is important to remember that though the head of the column may have a good road, the rear is probably marching through mud or dust. And if the men at the head of a long column are allowed to pick their way around puddles, etc., such column will soon be much extended, causing many irritating stops and hurried efforts to close up to proper distances. It is very fatiguing to support the heavy pack while at a standstill, uncertainly awaiting a resumption of the forward movement. There is a tendency to lag in the later stages of a march. At such times the slowing results from a shortening of the step rather than from a less number of steps 
per minute. Where possible and desirable the men may be relieved of a part of their packs, but it is usually inadvisable to separate the soldier from any part of his equipment. If the men become dependent upon aid for its carriage they will abandon a part of their load, or break down, or grow discontented, when transport is not available. The commander plans to have a march end early enough to enable the wagons to come up, so that the men may make camp before dark. In hot weather the march is usually conducted in the cooler part of the day. If a forced march is necessary, there must be adequate halts for rest and food. Probably two periods a day, of three or four hours each, will be found essential for this purpose. Night marching is only to be required for tactical reasons, since loss of sleep and nervous strain are apt to induce a large percentage of physical breakdowns.

Marching Aids.-Singing, the playing of music in march time by regimental bands, and good-natured chaffing among the men help to keep up the spirits. It is often practicable to make up a lunch sandwich from the food served at breakfast. On the march it is desirable to breathe only through the nose, in order not to draw dust into the lungs. Some relief from heat rays is afforded by carrying a wet handkerchief or some green leaves in the hat. Avoidance of rapid chilling, if wet or overheated, is imperative.

Thirst and Beverages.- Since the diseases which cause the. greatest amount of sickness in campaign proceed largely from drinking impure water, the best course is to regard all water (except such as has been examined and approved by 
a medical officer) as unsafe until it has been boiled or otherwise purified. Canteens should be carried filled. Recruits are prone to empty their canteens between halts, refilling and redrinking at every opportunity. As a result, they perspire excessively and tire out more easily, while they suffer much if the supply is cut down. Old soldiers learn to drink heartily before the start and sparingly on the march. A certain amount of water is, of course, needed to replace that lost from the blood by perspiration, but.mere dryness of the throat is apt to be mistaken for thirst. This feeling is relieved by carrying a leaden bullet or small pebble in the mouth, which acts by increasing the flow of saliva. Weak, unsweetened coffee may often be had from the excess in the company pot; it appears to quench thirst better than plain water and is an excellent beverage with which to fill the canteen, as it has been sterilized by boiling.

The care of the feet of the marching soldier is dwelt upon elsewhere, but the importance of the subject cannot be too much emphasized. The preliminary toughening of the skin, the use of foot powder or soap in the socks, the application of adhesive plaster to threatened areas, daily cleansing, and the prompt report of actual lesions to a medical officer, constitute the essentials.

Days of Rest.-A rest every Sunday and at such other times as required for recuperation, repairs of kits, etc., helps to keep the command fit. A marching command is a healthy one, but only when reasonable care is taken to so maintain it.

Sickness. - The regulations require that no man shall leave the ranks without permission. If a soldier wishes to 
fall out on account of sickness, he must ask permission of his company commander. If this officer thinks the case a proper one, he gives a written permit, and the man (accompanied by a non-commissioned officer, if thought desirable) waits by the roadside till the first medical officer comes up. This officer examines him and either directs him to rejoin his company or gives him a diagnosis tag authorizing him to be taken on or to accompany the regimental ambulance. His permit is endorsed with the action taken and is returned to the company commander at the next halt. Should the company commander think best, he may have the man relieved of a part or all of his pack and direct him to continue the march thus unencumbered.

Railroad Journeys.-In the movement of troops by rail, due provision must be made for their accommodations; water and ice supply; messing facilities; closets and toilet paper; measures for cleanliness; lighting and heating; police of cars, and disposal of refuse. Inspections should be made frequently with reference to the sanitary conditions. As the officers usually travel on a car separate from their organizations, the duty of enforcing order, cleanliness, and decency falls to the senior non-commissioned officer in each car. Men are apt to be very careless at such times, and must be prevented from spitting on floors, defacing cars, gambling, and acting in an unseemly manner. Food is prepared either by a kitchen car for the entire train or by a special heater for each car. The latter may be operated by the gas supplied for car lighting and is thought to be the better plan, as meals are furnished more promptly and with far less con- 
fusion. Mess kits must be cleansed and inspected after each meal.

\section{Camps}

Types of Camps.-There are different types of military camps, having respect to length of occupation and kinds of shelter. Sanitation in each varies with the conditions encountered, but certain principles are common to all. Types of camp which are uncommon to our service will merely be

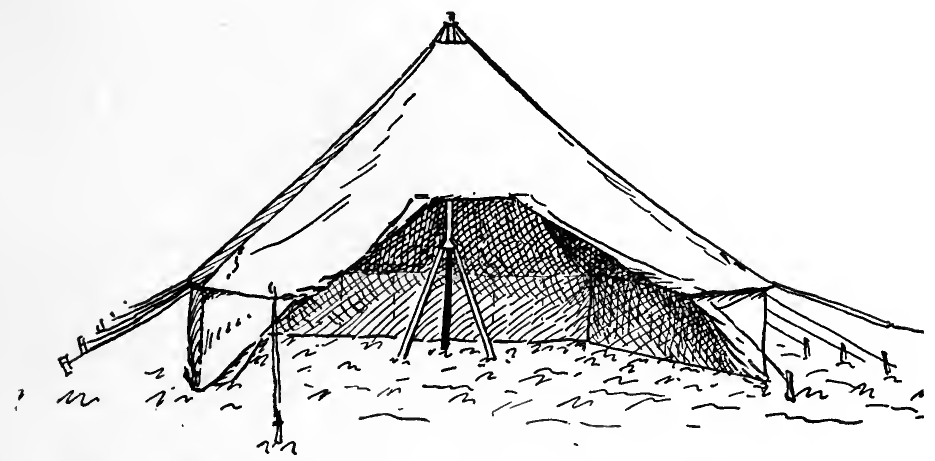

Fig. 29.-Pyramidal tent, with tripod support (United States Army standard model for fixed camps).

cited. Thus a bivouac, which is a camp without shelter, does very well for short periods in fine weather, but is conducive to physical inefficiency when the season is inclement. Cantonments, in which the troops are sheltered in huts or other temporary buildings, are exceptional, and billeting is still more so. Our troops are ordinarily sheltered under canvas, and camps having this provision are referred to as temporary or fixed in accordance with their duration. Other names used for the latter are: camps of position; canton- 
ment camps; standing camps. Camps occupied by a marching command are temporary; those used for maneuver and mobilization purposes belong to the latter class.

The risk of disease increases with length of occupation of a camp site, owing chiefly to fouling of the ground or of the water-supply. Where the site is occupied for but a single night, our sanitary arrangements are less elaborate and many of our procedures simpler. For this reason the following discussion will apply-where not otherwise specified-more particularly to fixed camps.

Camp Sites.-Areas intended for camping should be selected with care. The requirements of a good camp site are high, dry ground, with availability of wood for fires, of water for general purposes, and of grass for horse feed. Military necessity may force the utilization of an unhealthy site, but the commander must be prepared for probable physical detriment to men or animals resulting therefrom. Sites previously occupied within the year should be avoided because of the risk of infection. Our regulations require that the area shall be inspected, previous to its occupancy, by officers designated for the purpose. Such inspection should include an inquiry as to the presence of contaminated wells, springs, and creeks; probably infected privies; recent cases of communicable diseases among the inhabitants; habits as to the disposal of wastes in the vicinity; manure piles and mosquito-breeding areas on and near the camp site; dirty dairies; any other matters which may relate to disease prevention. Sites for fixed camps should be prepared in advance by clearing, grading, draining, and the 
installation of general sanitary appliances. Care must be taken to prevent fouling of the soil by workmen and to avoid cutting it into dust or mire by vehicles. The Quartermaster Corps should have the necessary equipment and supplies on hand in ample time. These may include any or all of the following articles, viz., excavator wagons; garbage carts; water-carts; galvanized iron water-tanks; incinerators; garbage and urinal cans; water-cans with faucets; wire and gauze netting for food covers; straw for bedsacks; stoves or spiders for laundry fires; clothes boilers; fuel; crude oil; lime; lumber; extra valves for pumps. Civilian scavengers should be on hand and instructed in their duties. The first day or two should be devoted to settling the troops comfortably in camp and making the sanitary arrangements of the separate organizations. On arrival, the camp commander issues an order giving detailed instructions as to matters of general import, including sanitation.

Halt Order.-The commander of a marching column issues a "halt order," in persuance of which certain staff officers precede the command by several hours. They select the camp site and designate places for obtaining drinking and cooking water, for watering animals, for bathing and laundry purposes, in the order named, from up stream down. Upon the arrival of the troops, guards are immediately set at these places to insure their proper use. As the various organizations reach camp, each commander at once details a party to dig a small sink till time permits more permanent arrangements. If picks and shovels are not available, a retired spot is selected where the men may relieve themselves, and a 
guard is placed there. These measures obviate the dangerous and disgusting fouling of the camp site by feces and urine.

Disposal of Wastes. - The most essential feature of camp sanitation is the efficient disposal of wastes. If it is necessary to remove refuse substances in civil communities, it is even more so where a multitude of men are closely aggregated within the cramped limits of a camp. Of such wastes, the discharges from the bodies of the men themselves are most important, since they are offensive to sight and smell and are likely to contain and to convey the germs of the most serious of the camp diseases. But other refuse matter, such as kitchen wastes-wet and dry-horse manure, camp sweepings, and rubbish of all kinds, tends to accumulate and must be removed. Provision must also be made for the adequate disposal of fouled water from basins, baths, and laundry places, as well as of excess flow from taps and of storm waters.

Disposal of Excreta.-Where camps are located near posts or cities, it may be possible to use water-closets connected with an existing sewer system, for the disposal of excreta and liquid wastes. Our service has, since the war with Spain, made extended trials of two methods of treatment of body discharges. One is their complete destruction by fire (which is the greatest of all cleansers) in one or other of the incinerators described in the chapter on "The Disposal of Wastes." Prompt and thorough incineration is the ideal treatment, but in practice certain impediments have been experienced, of which the principal are: $(a)$ It has been found difficult to hire scavengers willing and competent enough to care 
for the incinerators properly; $(b)$ when not well tended, foul odors are developed, to the general discomfort; $(c)$ these devices are expensive in cost and upkeep. The other method is that known as the Reed trough or "odorless excavator" system. In this system the excreta are received in a long trough partly filled with water, from which the contents are transferred daily to a tank wagon by means of a hand-

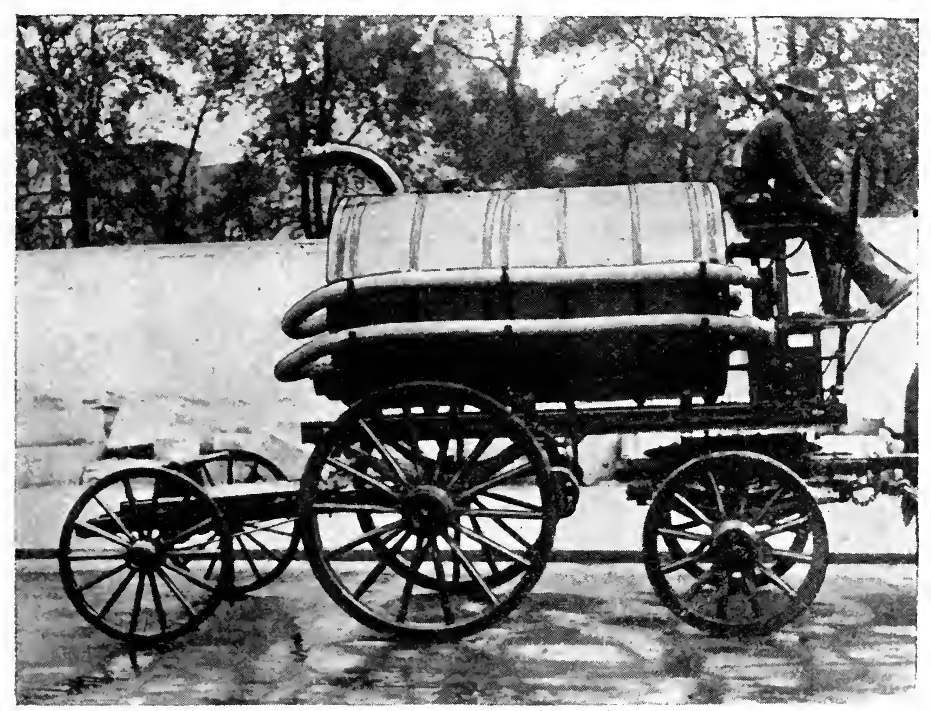

Fig. 30.- "Odorless excavator" tank wagon, with pump as a trailer.

pump (Figs. 30, 31). Although lime is sometimes recommended for use in the troughs as a deodorant and fly deterrent, it is not to be compared in value for this purpose with crude oil. The only disadvantage of the oil is that it rots the rubber valve of the pump. Defects in this method are: (a) Frequent breaking down of pump; (b) fouling the ground by leakage; $(c)$ difficulty in final disposition of the material. 
These methods, when well managed, are excellent in their results, but, though suitable for fixed camps, they are not practicable for troops on the march. Since temporary camps are those normal to campaign, and as soldiers must learn to care for themselves in the field, our sanitarians have reverted to the use of a pit in the ground as the only practicable means of disposal so far devised for the excreta of

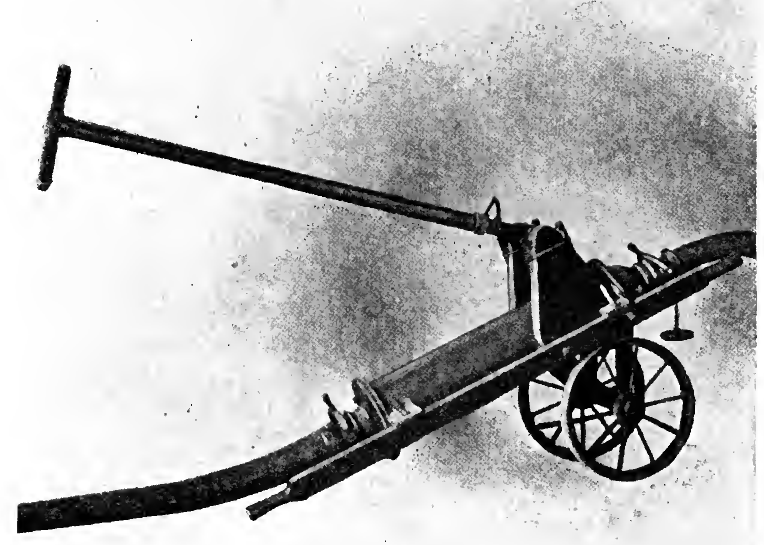

Fig. 31.-Hand-pump for use with "odorless excavator" apparatus.

marching commands. Pits for this purpose are usually designated as sinks or latrines and are of two kinds-the short, shallow individual type intended for very brief periods, and the larger, deeper company ones. These must be placed on the flank opposite the kitchens to minimize the danger from flies. They should be screened for privacy, lantern lighted by night, and have an orderly to maintain them in a cleanly state. The fecal deposits of a marching 
command are immediately covered with earth. Deep pits used in a fixed camp are (except in winter) made fly-proof by boards or sacking over the top and have seats with selfclosing covers. Urinal cans, marked by lanterns, are placed in the company streets at night. One of the most decided evidences of a poorly disciplined command is the presence, around the edges of a camp, of fecal deposits. Men urinating or defecating upon the ground within or close to the camp limits should receive sharp penalties. Toilet paper is provided by the quartermaster; it should be in rolls, as loose sheets blow away. The last duty of a moving command is to fill in the sinks before the day's march is commenced.

Water-supply.-The supply of water must be carefully guarded, frequently inspected as to pollution, and purified by special means when necessary. Sources of supply not considered safely potable are to be marked "Bad," and men drinking from such sources should be brought before a summary court-martial. When the supply is from a stream, immediate protection is necessary to prevent fouling and muddying by men and animals, especially if other commands are camped lower down. The various points designated for obtaining drinking-water, for watering animals, for bathing, and for laundry purposes are to be suitably marked and the sentries placed there are given specific instructions. The formation of a bucket brigade, the digging out and lining of small springs, or the diversion of a part of the stream into sunken barrels or boxes will obviate the necessity for men to enter the stream. Animals may be watered 
from buckets or troughs. Bathing can be adequately performed by the men pouring water over one another from buckets. The washing of clothing should be conducted far enough from the stream so that the soiled water will not flow back into it. Men must be prevented from urinating or defecating along the banks. Drinking-water containers should have a cover and a tap, to prevent contamination by some one ladling the water out with a dirty vessel. Each man brings his own cup, for a common cup is soon filthy. Canteens should be scalded out occasionally and care exercised to avoid contamination of water while filling these vessels. If the drinking-water must be boiled, this duty is assigned to a carefully instructed and reliable soldier. Bathing is to be insisted upon whenever practicable. If bath-houses exist, an orderly is detailed to keep the place clean, the taps turned off, and the ditches and pits for waste water clear. Where streams are utilized, bathing places must be below those where drinking-water for men and animals is obtained. In fixed camps each company should have a bench, with a sufficient number of basins, placed near the water source for lavatory purposes. Laundry facilities are desirable: the simplest of these takes the form of a fire over which a large boiler is placed, with a bench or table for scrubbing near by. In wet weather, a drying tent is a necessary adjunct.

Messing.-Cooks are required to maintain scrupulous cleanliness in everything pertaining to the operations of the mess. The men should be made to wash their hands before eating. They will not ordinarily be permitted to 
eat in their tents. Food is protected from flies by covering or screening. Milk, fruit, bread, and foods after cooking are subject to contamination by flies or by careless handling. The food served to the men must be carefully watched and the use of any from unauthorized sources prevented. Cooks should prepare a sufficiency of hot soapy water for use of the men in cleansing their mess kits after meals. Garbage of marching commands is usually buried; that of fixed camps is burned.

Sutlers.-Peddlers and sutlers are a nuisance. Being imperfectly under control, they furnish inferior or even infected foods, while they are constantly appealing for extra privileges or running "boot legs" and secret gambling places. 'The men are better off without them, as the quartermaster and the exchange officer supply all reasonable needs.

. Ice-box.-If ice is available, a satisfactory container may be made for it by burying a large box in an excavation. Stones are placed in the bottom to take up the water and shelves are arranged for the ice and food stuffs.

Care of Tents.-As rain may occur at any season, tents should usually be ditched to prevent wetting of the ground forming the tent floor. To avoid soil moisture, men must be kept off the ground, by use of the ponchos in one-night camps, by cots or raised platforms in camps of longer duration. The tent walls are to be raised every day, weather permitting, so that sunlight and fresh air may reach every part of the interior. Ventilation must be ensured by leaving the door flaps, or the hood, or both, open. Canvas is not pervious to air when it is wet. If the soil is dusty, 
tent floors should be sprinkled. The crowding of tents with equipments may be relieved by placing certain of these (such as horse equipage) on racks outside. Neatness and order should be maintained. Bedding and extra clothing should be frequently sunned, and in camps of some permanence tents should be moved laterally, to the spaces intervening between them, every week or so, to obtain the purifying effects of the sun and air on the old sites. If shelter tents are used, the men must not be permitted to close their fronts. A poncho may be extended forward to cut off rain and wind, or a fire built in front. Overcrowding is seldom necessary. In fixed camps, 8 men to a conical wall or pyramidal tent make the proper complement. If tents are floored, the boards should be loose or the floor in sections, to facilitate cleansing and searching for contraband articles. In very hot weather, light coverings of tree branches over tents, messing places, sinks, and picket lines form a grateful shade. In winter camps, huts should be constructed or tents lined and floored.

Police of Camp.-For police purposes the ground within and bordering on the camp should be equitably divided. The daily cleansing of camp is to be inspected by the proper officers before the police details are dismissed. Special attention must be given to the edges of the camp area proper, for it is in these situations that piles of excrement, human and equine, are most apt to be deposited and to remain undetected. Picket lines should be kept swept all day, the manure removed each morning, and the ground occasionally sprinkled with crude oil (or even burned over) to pre- 
vent fly propagation. Dust is to be abated by sprinkling the roads. Flies are discouraged by destroying the garbage and excrement on which they feed and breed. Mosquitobreeding areas are carefully searched for and drained or oiled. If malaria exists or is feared, troops in fixed camps should be supplied with mosquito bars. Those in marching commands will probably have to depend on the daily use of quinin for the prevention of this disease.

Personal hygiene must be carefully looked to. Cleanliness of person and clothing is to be required, avoidance of alcoholic and sexual excesses preached and practised. Ennui should be combated by plenty of military work, and if idleness is enforced-as by winter storms-cheerfulness is promoted by entertainments of various sorts, such as minstrels, lectures, athletics, music, and moving pictures. The sick should be promptly separated from the well, and when their ailments are of a contagious nature their clothing and bedding must be disinfected. For this purpose Major Munson has devised a light and compact apparatus which generates formaldehyd gas by the addition of potassium permanganate to a solution of the gas (Fig. 32). Sick call for a marching command is usually held immediately after arrival in camp. For a fixed camp the hour is ordinarily 5 P. M. If much sickness exists, it should be held twice a day.

Responsibility and Inspections.-The system of inspection and responsibility for camp sanitation must be thorough and complete. It will often be found advisable, in conformity with Paragraphs 291 and 292, Field Service Regulations, 
1913, to place the entire sanitary service under the control of the chief surgeon, and to authorize the sanitary inspector to direct the abolition of conditions prejudicial to health. Next to the company commander, the most important link

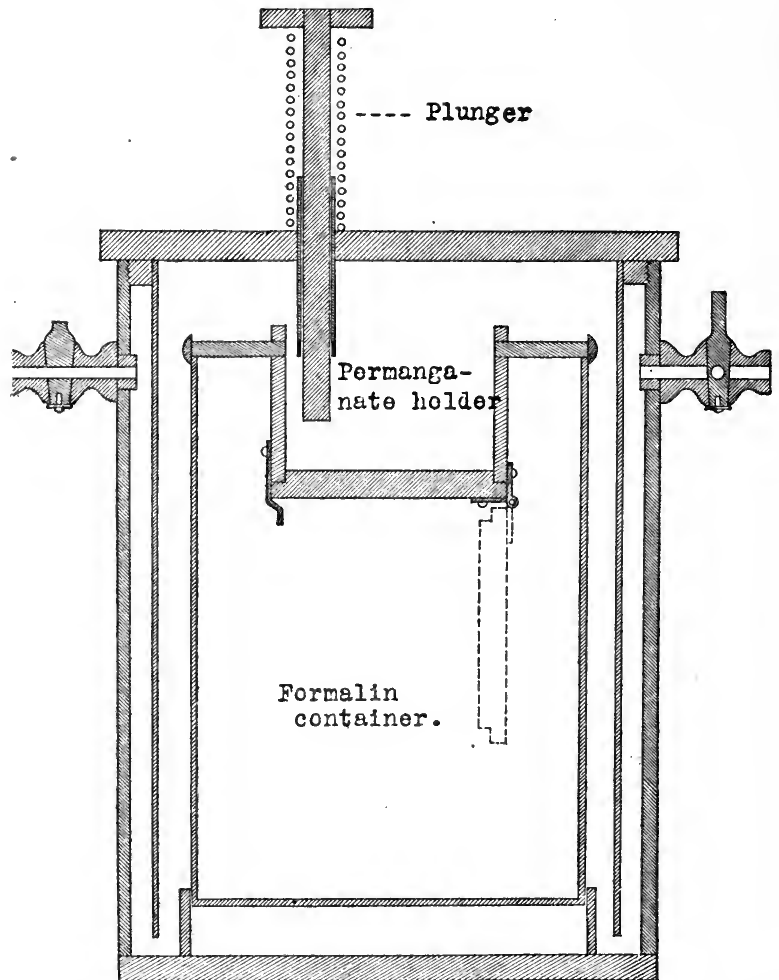

Fig. 32.-Gas generator, for disinfection in the field. Height, 8 inches; diameter, 6 inches; weight, 5 pounds (Munson).

in the sanitary chain is the regimental surgeon. It is his duty to organize the personnel assigned to such functions into a sanitary detachment and to direct it in the performance of all work looking to disease prevention. When 
necessary the sanitary detachment may be augmented by civilians employed under competent authority, or by details from line troops.

\section{Battlefields}

Evacuation of the Sick.-The great changes in battle tactics necessitated by increased range and rapidity of fire have largely altered the conditions to be met by sanitary troops, as well as by those of the line. During and immediately subsequent to a battle the efforts of all concerned are put forth to achieve victory and to maintain the forces in a mobile state. And since the wounded and the sick embarrass the army and hamper its movements, the prompt evacuation of those disabled individuals to the rear is of vastly greater importance from a military standpoint than is their care. The sanitary troops of modern armies are, therefore, organized and trained more with a view to the removal of helpless men from the scene of action than to their care, although the latter is absolutely essential from political as well as humanitarian considerations.

Sanitary Preparations.-Preparations for a battle include the evacuation of all encumbering sick; the tentative selection of locations for dressing stations, field hospitals, and other sanitary formations; the collection of extra wagons, motor cars, and litter bearers by requisition on the inhabitants; the designation of lines of evacuation for the wounded; the arrangement of a system of interrelation between the many sanitary units, to the end that no undue strain be placed on any part of the line while other parts are relatively idle. 
Sanitary Troops.-The regulations prescribe that a total of nearly 1000 officers and men of the Medical Department shall be assigned to each division. These are organized into regimental detachments, three field hospitals, four ambulance companies, and a reserve depot for sanitary supplies. On the line of communications there are nearly 700 more sanitary troops per division. And as these numbers are notoriously insufficient to handle battle casualties, the regulations further authorize the employment of bandsmen and impressed or hired civilians as litter bearers at the front, as well as of members of the Red Cross Society in evacuation hospitals and in other units of the sanitary column.

Lines of Sanitary Aid.-Sanitary aid from front to rear is as follows: (1) The firing line, where regimental medical officers and Hospital Corps men are placed at intervals if shelter exists; (2) aid stations, one to each regiment, established by its sanitary personnel as close as conditions of terrain will permit; (3) dressing stations, one per brigade usually, formed by ambulance companies; (4) stations for slightly wounded (one for a division); (5) field hospitals; (6) sanitary column. At night all sanitary stations are marked by green lanterns.

Care of Wounded.-The regimental sanitary personnel is, as a matter of course, first to have work. The wounded begin to trickle back, many with injuries already dressed with the contents of a first aid packet, which soldiers in campaign quickly learn to value and to apply. Diagnosis tags are affixed by the first medical officer who handles the cases. During lulls in the enemy's fire or where the ground 


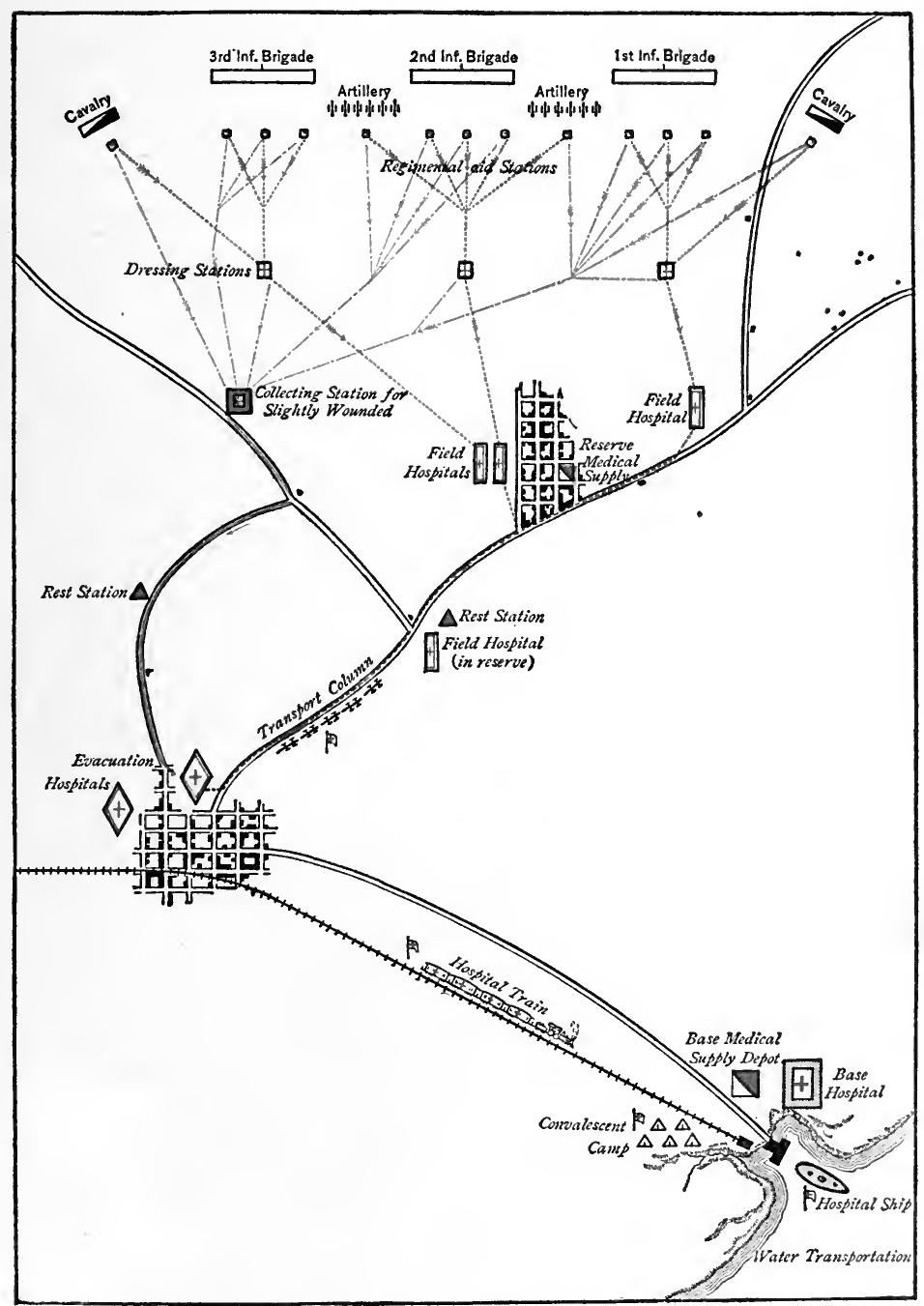

Fig. 33.- Sanitary aid stations and lines of evacuation (Straub). 
affords sufficient protection, litter squads of two men each are pushed forward from the dressing stations to find and carry back helpless wounded. Meanwhile, those among the less severely injured who are able to walk, are availing themselves of every opportunity to obey that powerful impulse which urges a wounded man to seek the rear. Lines of sanitary aid are marked by ambulance guidons or other easily understood symbols visible from the front, and the streams of wounded are thus led to the various stations. The dressing stations are established as close to the firing line as the necessary conditions of comparative protection from rifle and cannon fire, with water-supply and access by road, will permit. Wounded men are sent back from these stations by ambulances, emptied ammunition and supply wagons and litter bearers, to the next line of aid, namely, the field hospitals, from which they are evacuated by the sanitary transport column pertaining to the line of communications. At the conclusion of the battle the successful commander is required to organize a thorough search of the field for the collection of the wounded and the dead.

Water-supply.-Wounded men are always tormented by thirst, chiefly because of their loss of blood. The violent exertions required of troops in battle induce a rapid loss of water from their bodies through the perspiration. These reasons render it imperative that arrangements shall be made for a supply of drinking-water at such times. When water is not readily available from streams, a system of distribution should be arranged, regulated, and supervised. Under the stress of battle conditions it is likely that we may 
be obliged to ignore questions of purity and to allow the men to drink from any available source. On the other hand, it will often be possible to form regimental sanitary water detachments, whose duty shall be to provide a supply for troops in action. This duty might be carried out by details from the reserves. If possible to purify the water before issue, this may be done by Darnall filters, of which three ordinarily suffice for a regiment. These may be transported on a pack mule. A capable Hospital Corps man should be in charge of the filters and their operation. For food we may have to rely on the reserve ration alone.

Casualties.-The average percentage of casualties for one day of battle (based on modern wars and including the sick as well as the enemy's wounded who may fall into our hands) may be considered roughly as 12 per cent. This percentage may not be reached for the whole army, but is likely to be exceeded in some organizations. The ratio of killed to wounded is about 1 to 4 . Of $100 \mathrm{men}$ hit, it is estimated that:

20 will be killed.

15 will require transport lying down.

35 will require transport sitting up.

5 will be too desperately wounded to bear transportation.

25 will be able to walk.

The location of the wounds will be about as follows:

Per cent.

Head and neck. ........................ 16

Trunk............................. 30

Upper extremities. . . . . . . . . . . . . . . 26

Lower extremities.................... 28 
Wounds will be caused by:

Per cent.

Rifle missiles. . . . . . . . . . . . . . . . . . . . . 84

Shell fire (mostly shrapnel) . . . . . . . . . . . 14

Bayonet........................ 1

Saber, lance, etc................... 1

Note.-The figures in the foregoing tables are, necessarily, mere approximations.

Identification of Dead.- The identification of the dead is required by regulations, and is facilitated by the fact that officers and men wear round aluminum tags (on which their names and organizations are stamped) suspended from their necks. By the terms of the International Red Cross Convention, the commander left in possession of the field after a battle is charged with the duty of identifying the enemy's dead and of transmitting their identification tags, with such valuables as may be found upon them, to the proper authorities for return to their own country.

Disposal of the Dead.- The melancholy duty of disposal of the dead falls to the Quartermaster Corps, whose officers employ captives, neighboring inhabitants, or troops detailed for this purpose. Public sentiment prefers burial, although cremation is far more desirable. Captured trenches may be utilized for either method. If cremation is used, it is aided by crude oil, coal-tar, or such other high inflammables as may be available. In case of burial the clothing is removed, for the reason that it delays decomposition, and is burned to prevent possible contagion. The identification tag is fastened to the body by copper wire, for the sake of subsequent recognition in case of disinterment. The burial trench 

should be 9 or 10 feet deep and 7 feet wide. 'Tree branches or rocks are placed in the bottom to facilitate drainage and the bodies are placed in several layers, with lime between, if this substance can be obtained. Dead animals must likewise be burned or buried. 


\section{CHAPTER XII}

\section{THE DISPOSAL OF WASTES}

Wastes.-Substances of various kinds which are no longer of value to man, but which, on the other hand, may be detrimental to him, must be disposed of in one way or another. Broadly speaking, such substances, or waste matters, may be solid or liquid. The term "refuse" is often applied to all solid wastes not carried away by sewers, to distinguish these from "sewage" proper. The quantity of refuse which requires disposal may be very great. In New York City it is estimated that these solids amount to one ton per capita for the year.

Classification.-Wastes may be conveniently classed as follows, having due regard to their importance with relation to the public health:

1. Human excrement (feces and urine).

2. Solid kitchen refuse (garbage).

3. Liquid, non-excrementitious house wastes (from kitchen sinks, laundry tubs, baths, basins, etc.).

4. Manure (horses, cattle, swine).

5. Street sweepings.

6. Rubbish (house trash, waste paper, brush, grass, leaves, etc.).

7. Storm waters.

8. Ashes. 
For our purposes, the topic under discussion must be treated with respect to the widely differing conditions of garrison and camp life.

\section{The Disposal of Wastes in Garrison}

The Ideal Method.-As previously intimated, the ideal method of disposal for all kinds of waste matters is their destruction by fire, which leaves a single unobjectionable residue, namely, ashes. But as this method is usually inapplicable, at least in part, other methods must be considered as well.

Human Excrement.-Experience has demonstrated that human excrement is not only a public nuisance, but it is a public danger. It must, therefore, be destroyed or removed as promptly as possible. Methods for its disposal are as follows:

(A) The old-fashioned privy, with its pestilential odors, its ground and water pollution, and its feces-food-flies relation, should no longer have a place in any garrisoned post. Privy pits are better than indiscriminate droppings, and must perhaps still be employed in rural districts, although it is possible to substitute better measures for them. If, for any reason, privies must be used in a military community, their vaults should be waterproofed by a tight cement lining and their contents adequately protected from flies and rats.

(B) The dry earth system (Fig. 34), which is employed by us in some Philippine stations, is much superior to the ordinary privy pit. This consists of pails or pans placed beneath 
closet seats to receive the discharges, which latter are promptly covered by dry, powdered earth, ashes, or lime. To be successful, the following points are to be observed: (a) The pail must fit close up to the seat, that urine may be voided into and not outside of it. (b) Flies must be excluded by making the closet box fly-tight and providing the seat with a self-closing cover. (c) Enough earth must be used to absorb the liquids and to act as a deodorant. ( $d$ ) The fecal

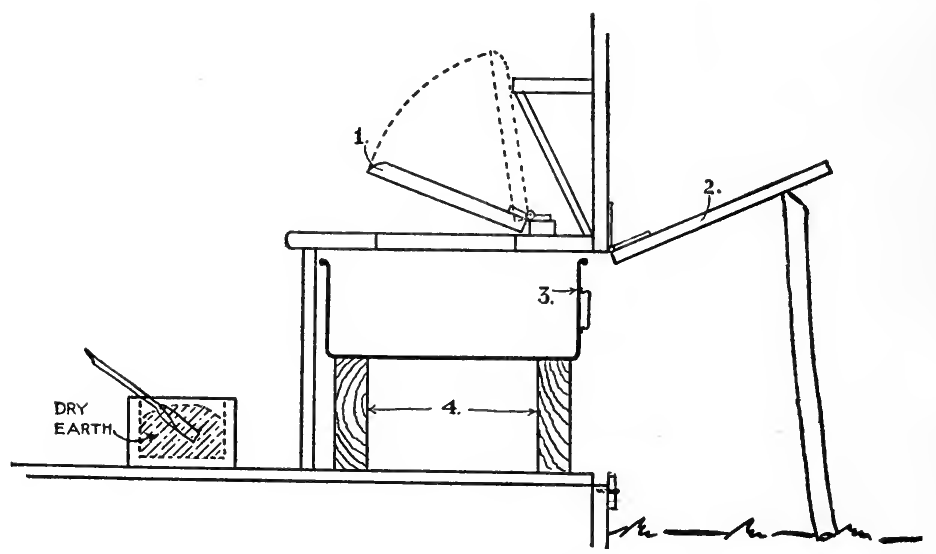

Fig. 34.-Dry earth closet: 1, Self-closing śeat cover; 2, fly-tight trapdoor; 3 , pan; 4, supports for pan.

matter must be removed daily (or nightly) and properly disposed of (as by burial, incineration, or dumping into the sea). The pail may be removed and replaced by a clean one, or its soiled areas may be sprinkled with crude petroleum or some other disinfectant.

(C) Public Health Service Latrine-Officers of the United States Public Health Service have devised a simple apparatus consisting of two barrels or tanks, upon the 
larger of which a closet seat is superimposed. The larger receptacle is partly filled with water, up to a point where a pipe connection with the smaller one takes care of any overflow (Fig. 35). Flies and mosquitoes are repelled by

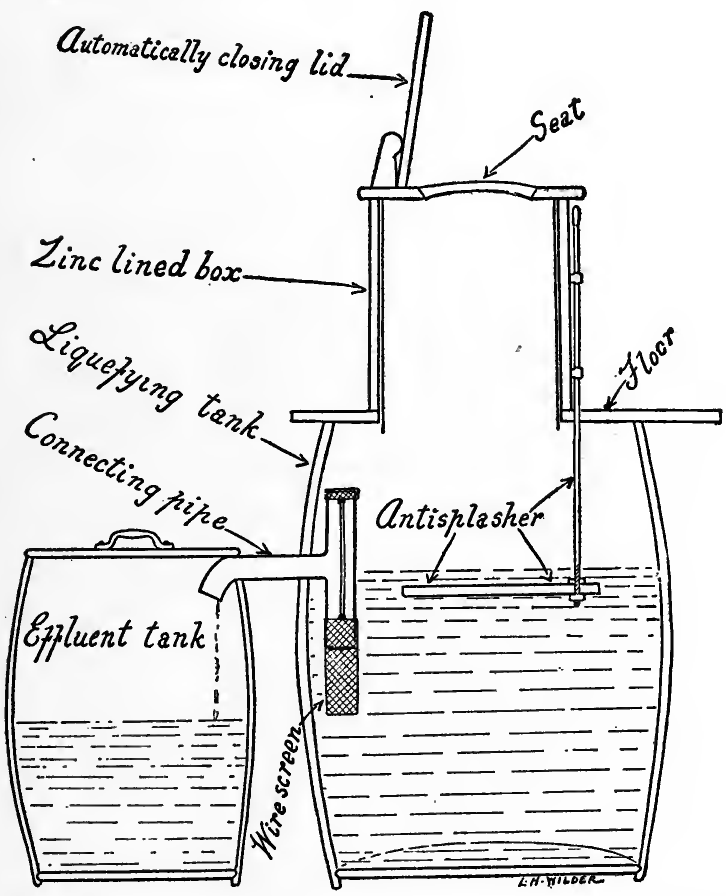

Fig. 35.-Closet devised by officers of the United States Public Health Service (Lumsden, Roberts, and Stiles).

screening, a self-closing seat cover, and a little oil on the water's surface. This apparatus liquifies the fecal matter, reduces its volume, and diminishes its odor. The tanks need emptying but seldom, when the removed material may be disposed of by any approved method. 
(D) Destruction by Fire.-Excreta may be incinerated by any one of the numerous destructors which have been devised for this purpose. Some of these are neat in design, correct in

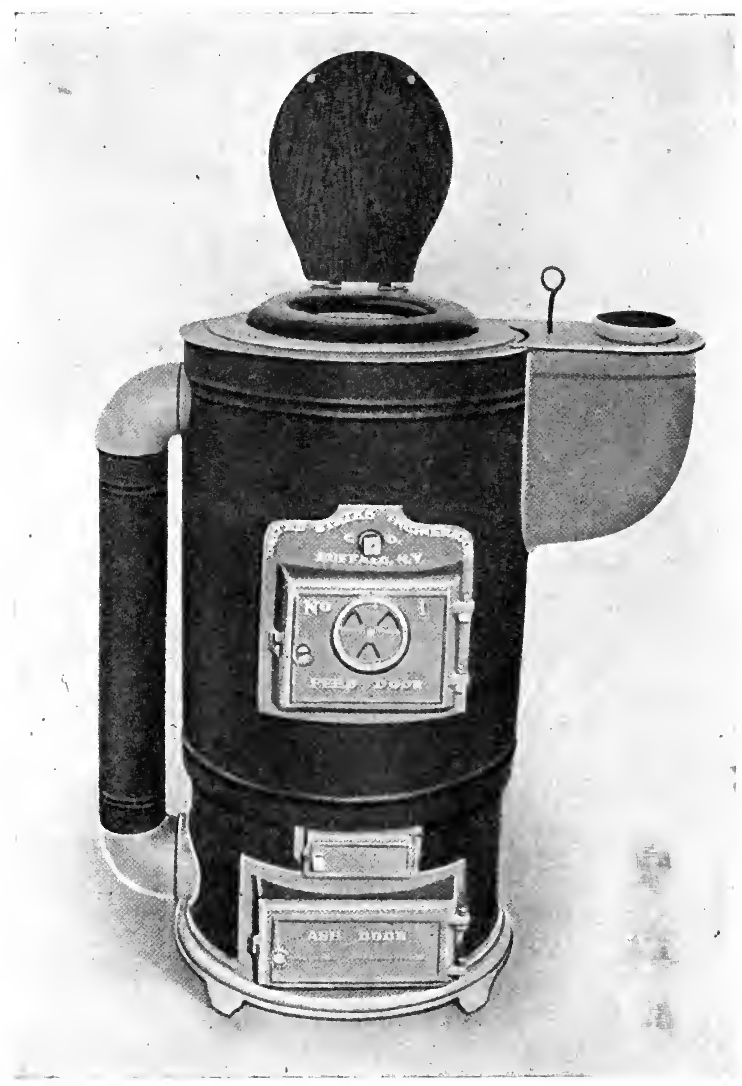

Fig. 36.-Incinerator for excreta; United States Incinerator Co. type.

principle, and effective in application. The operation of any type must be in charge of a careful and conscientious man, lest the excreta be carelessly handled or a nuisance 
develop as a result of imperfectly combusted gases. Figure 36 shows one form.

(E) Cesspools.-For isolated buildings, cesspools (covered pits) are sometimes utilized for the reception of fecal matter, together with liquid house wastes. The buildings are supplied with plumbing, the sewage from which has its outfall into the cesspool instead of a stream. Cesspools should be made water-tight by concreting them. Their contents must be removed by an "odorless excavator" wagon or the liquid overflow (effluent) disposed of by absorption in plowed land.

(F) Sewerage System.-The method now preferably employed by modern communities is removal by water carriage, that is, sewerage. Even this has its disadvantages, as, though the filth is removed from dwellings, its discharge into streams may give rise to offensive or dangerous conditions. Nevertheless, it is the method of election.

Sewers.-Sewage collected from houses must be carried away and disposed of in some manner that will not create a nuisance nor constitute a menace to health. In the construction of sewers for the conveyance of liquid and semisolid wastes, the first point is the estimation of the expected quantity. The amount of water used equals the amount of sewage, and the size of main and branch sewers is based thereon. In general, a minimum of 8 inches in diameter is used for mains, of 6 inches for branches. If the amount of sewage is small, circular pipes are satisfactory. If very inconstant in volume (as when storm waters are admitted), ovate pipes, with the narrower part below, are best. Sewers 
of less than 24 inches diameter are generally made of vitrified earthenware; if over 24 inches, they are best constructed of concrete, or brick set in cement and lined therewith. The direction of a sewer should be as straight as possible and the fall equable, without sudden changes of level. Small sewers require a greater gradient than large ones. Manholes should be provided for ventilation and cleansing. Sewer air-or "gas," as it is sometimes mistakenly termedmay be offensive, but is not liable to transmit disease.

Sewage Disposal.- Sewage may be disposed of in a variety of ways; these are:

(1) Discharge into the sea or other waters.

(2) Chemical treatment.

(3) Irrigation (sewage farming).

(4) Biologic methods.

(a) "Contact" filtration.

(b) "Percolating" filtration.

(c) Septic tank.

Of these, the first is simplest and cheapest, but cannot always be employed because of the fouling of harbors and water-courses. Chemical treatment is too expensive. The use of sewage as a farming irrigant does very well when the quantity is small, and, if the method is properly carried out, the risk of transmitting disease thereby is but slight.

Biologic Methods.-The term "biologic," as used in this connection, means that the sewage is acted upon by certain forms of life, in this case some of the microscopic vegetable germs known as nitrifying bacteria. These attack the organic solids and largely liquefy them, while they destroy 
most of the disease germs which may be present. Contact filtraiion is performed by large beds of broken stone, from 3 to 5 feet deep. These are rapidly filled with the sewage, which is allowed to stand for several hours, during which the harmless bacteria referred to are active. Percolating filters are beds similar to, but deeper than, contact ones, over the surface of which the sewage is sprinkled automatically. A septic tank is, practically, a scientifically constructed cesspool. The present consensus of expert opinion is that a combination of biologic methods produces the best results in the purification of sewage. For example, septic tank treatment, followed by percolating filtration, produces an effluent sufficiently purified to be safely discharged into some water-course.

Drainage, as distinguished from sewerage, means the removal of surface water as well as the surplus moisture of the soil. 'It is desirable to have a separate system of drains for this purpose rather than to trust to the sewers, which latter may be choked or damaged by storm waters.

Garbage.-With careful and interested attendants it is possible to dispose satisfactorily of garbage in kitchen ranges or basement furnaces, thus obviating the need for cans and slop wagons. As yet, however, the first condition is rarely met, and it is usually necessary to collect such refuse in cans and to convey it to some point sufficiently remote, where a general incinerator (such as the Morse-Boulger destructor, Fig. 37) is located. Such an apparatus can readily cremate a dead horse.

Small incinerators designed for institutional use may now 
be obtained and installed in barracks, hospitals, and the like. These are capable of caring for the house rubbish as well as for the garbage (Fig. 38). In the absence of house apparatus, garbage is placed in cans until such time as the cart makes its daily rounds.

Separation of Components.-It is important to keep garbage proper in cans separate from ashes and other indestructible materials, as the former is to be incinerated,

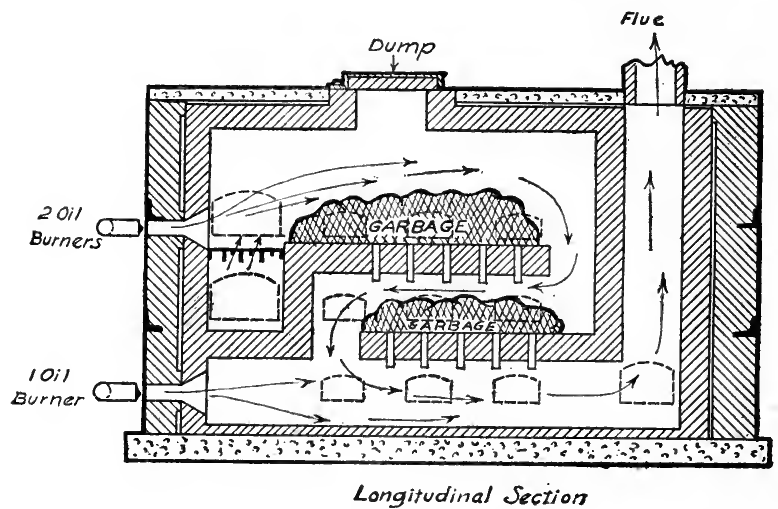

Fig. 37.-Morse-Boulger destructor, longitudinal section.

with which action the latter interferes. An exception to this rule is in the disposition of emptied food cans, which should be treated as garbage for the reason that much organic matter remains in their interiors. An even more important consideration for such separation is that ashes must be deposited on a dump, or used for filling up some ground depression, or even employed on roads and paths, in any of which situations decomposing organic refuse would be highly objectionable. Liquids should be strained out and dis- 
posed of in the kitchen sink; thus, only the solid garbage need be placed in the cans.

Cans, Stands, and Covers.-Garbage cans should be elevated on stands a foot or so above the ground in order that fouling of the latter may be promptly detected and remedied (Fig. 39). Cans and stands should be kept whitewashed

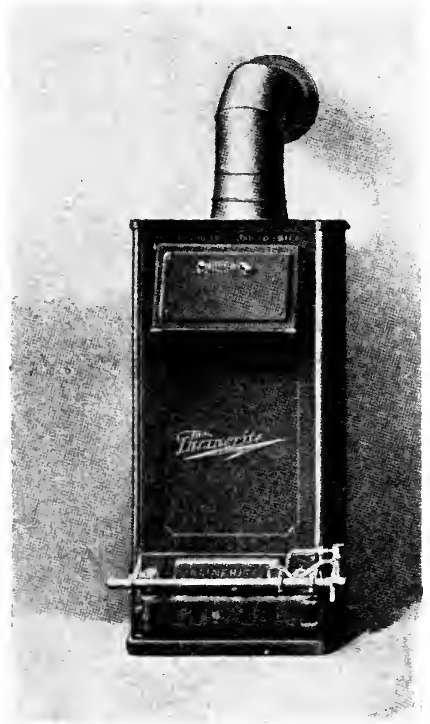

Fig. 38.-Incinerator for house wastes (Incinerite Co.).

for the sake of neatness and cleanliness. That flies and rats may not be attracted and fed, it is important to have well-fitting covers for the cans and to require these to be properly used. When covers warp so that they no longer fit, they may be replaced by others of wood, made broad enough to overlap the sides a few inches and furnished with. 
a handle. Several cleats nailed on the under side will prevent the wooden covers from being dislodged by the wind.

Liquid house wastes from kitchen sinks, bathtubs, and the like are cared for by the sewerage system, if one exists. In the rare event of its absence in a military community, such wastes must be carried away in open drains or removed by garbage carts. A large amount of grease passes through

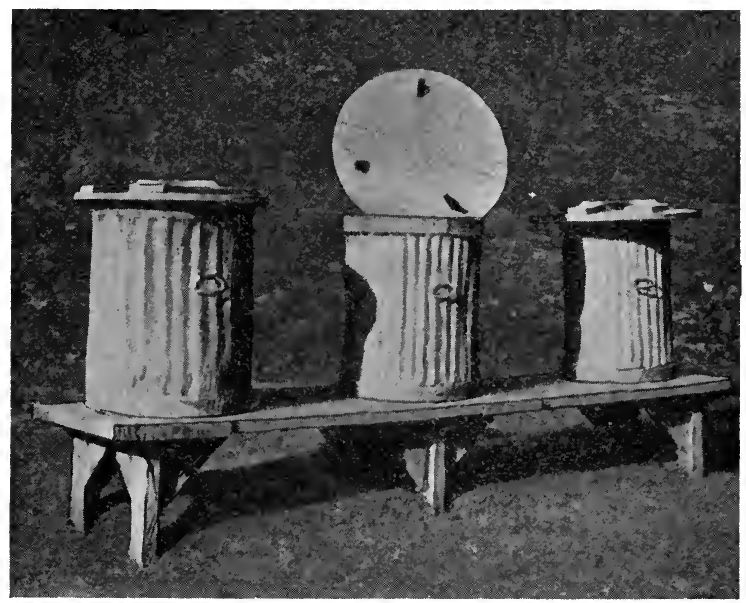

Fig. 39.-Garbage cans, with wooden covers, on stand.

pipes from kitchen sinks and may choke them. An open "grease trap," from which the material may be skimmed, is sometimes installed. Failing this, a strong hot solution of lye should be flushed through the sink occasionally.

Manure.-The disposal of manure is a question which may have to be handled differently at each station. As this material is chiefly responsible for the propagation of house flies, its complete destruction by fire is desirable. 
But, on the other hand, manure is of considerable economic value as a land fertilizer, and it will usually be found that a compromise must be effected between sanitation and utility. Some officers of mounted troops seem to regard horse manure as a purely beneficent substance and, therefore, ignore its objectionable qualities. The number of eggs laid by a single fly is very large, and one horse will supply enough manure to furnish flies for an extended neighborhood. A period of ten to fourteen days is required for the evolution of the adult fly from the egg, through the larval stage of the common maggot.

Manure Disposal.-Manure should not be allowed to accumulate, but should be removed from stables daily to a dumping ground fairly remote from habitations and in the direction of the prevailing summer winds. Only enough of this substance should be accumulated for fertilizing purposes and all excess should be burned. Where the smoke will not prove annoying, the heaps of manure may be allowed to smolder, and the fumes blowing over the fertilizer supply (if this is properly placed with reference to the wind) will aid in keeping flies away. If more rapid destruction is desirable, this may be accomplished in a destructor, or a crematory pit, or upon a rough gridiron of old rails, or piping. When used as a fertilizer during fly season the manure should be promptly spread and worked into the soil. If it is not possible to remove the manure every day, a fly-proof vault should be built at the stable for its temporary storage.

Sweepings and Rubbish.- Street sweepings generally contain so much soil that it is difficult to dispose of them by 
incineration. If their content of organic matter is relatively small, they may be deposited on the dump or used as filling. If the sweepings are chiefly horse manure, they should be handled with that substance. Rubbish collected from houses is placed in cans or other proper receptacles, whence it is removed to the incinerator. Dead grass, leaves, and the like are carted away or burned in any convenient situation.

Dump.-It is generally necessary to have some place set apart as a dumping-ground for solid wastes which cannot be burned. The location of the dump should be well removed from habitations and inconspicuous. No organic materials should find a place there. A caretaker should be assigned to keep it in a proper state of police.

\section{The Disposal of Wastes in Camps}

Excreta.-Incineration.-As previously emphasized, the complete destruction of excreta by fire is the ideal method for the disposal of these unpleasant and dangerous wastes. Nany kinds of incinerators, fixed, portable, and ambulant, have been devised for this purpose, and some of these have been found highly efficient. The essentials for success with any type are plenty of fuel and efficient attendants. When carelessly performed, incineration may be more offensive than any other means of disposal. A slow fire, wet wood as fuel, or failure to utilize the auxiliary combustion grate (which some types need for the destruction of the offensive gases) will drive off heavy urinous odors which hang over all parts of the camp. The shallow urinal pans sometimes overflow and foul the ground. Some types become so hot 
that the device cannot be used for several hours after burning out.

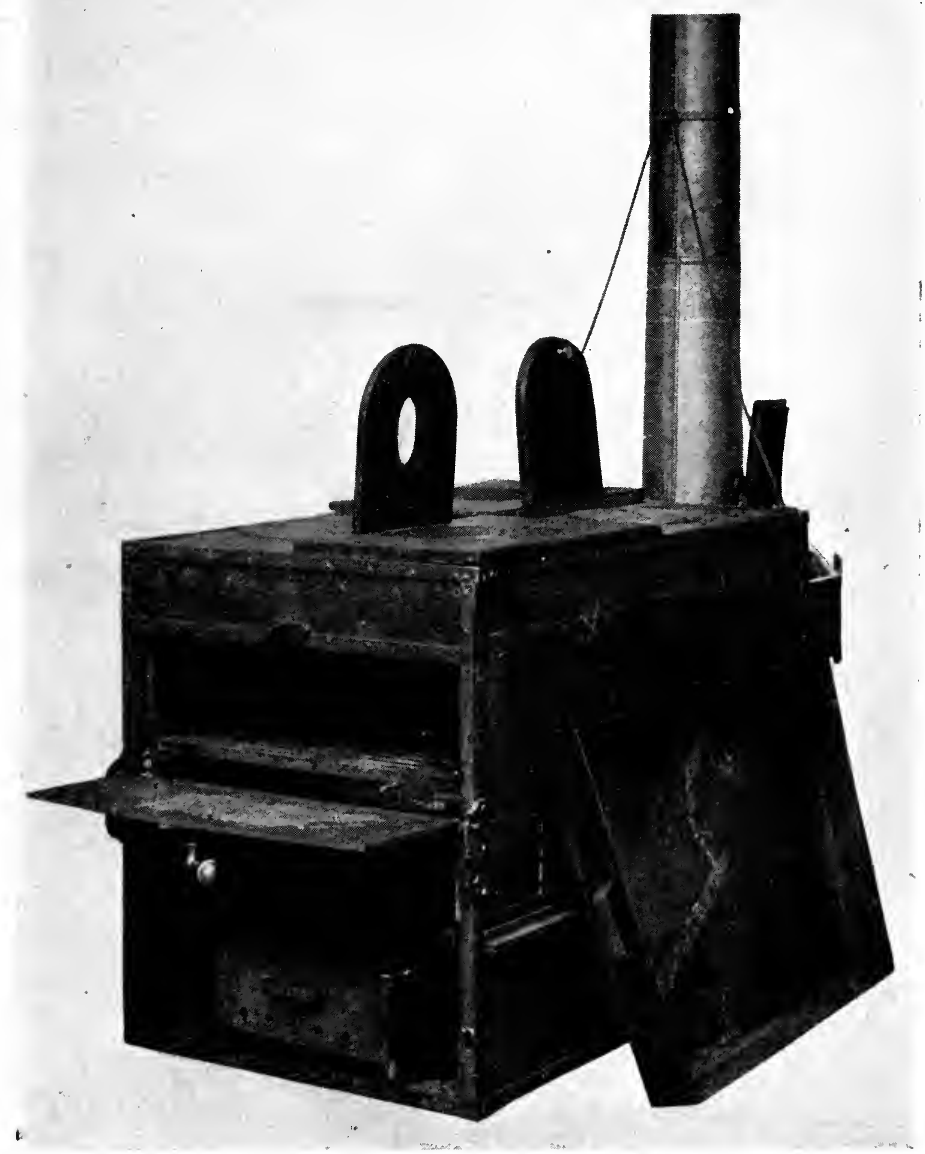

Fig. 40.-Incinerator for excreta, Quartermaster Corps type.

Types of Incinerators.-The Bissell and the Lewis and Kitchen patents are mounted on wheels, with the idea that 
they may accompany moving commands; they are efficient as incinerators, but not practicable as to mobility. The Quartermaster Corps has devised and issued a type (Fig. 40) which closely resembles the patented models of $\mathrm{McCall}$ and Conley. Harris, of the Medical Reserve Corps, has invented one which is simpler and more portable than most others, while perhaps equalling the best in efficiency (Fig. 41).

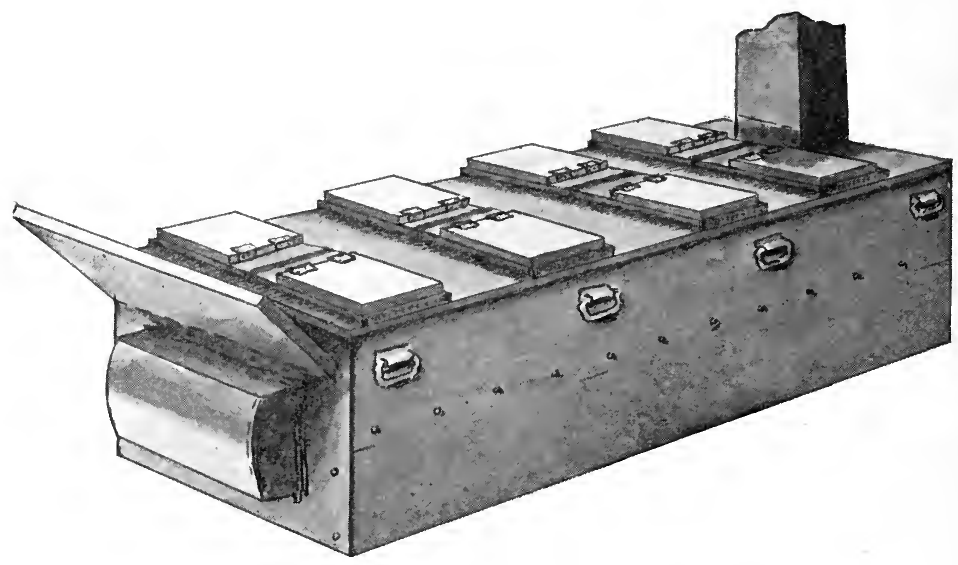

Fig. 41.-Incinerator for excreta, Harris type.

Reed Trough.-This is made of galvanized iron, curved to facilitate cleansing, and deeper at one end for ready emptying. It is long enough to accommodate seven seats, which latter have self-closing covers. The covers are made to fall shut of their own weight by nailing a board longitudinally above the seat at a point which allows them to be raised less than 90 degrees. This board also performs the valuable function of preventing men from standing on the seat. In Artillery Reserve camps and other 
favorable situations, it may be possible to place their outlets directly over sewer manholes. Usually their contents must be pumped by hand into a tank wagon and removed to the place of final disposal. This latter may be a sewer, a stream, the sea, an incinerator, or a burial pit. If crude oil is used to cover the surface of the liquid in the trough, the tank wagon may even discharge its contents upon the ground, as the oil keeps flies away and acts as a deodorizer.

Sinks or Latrines. - Company sinks (called also latrines) are ordinarily 15 feet long, 2 feet wide, and 6 feet deep; with large organizations they may have to be somewhat longer. They are placed in line on that flank of the camp which is opposite the kitchens and in a situation sufficiently elevated so that storm waters will not flow into them. If any such risk exists, drainage ditches should be dug around them. Moreover, they must be far enough from the water-supply to obviate any danger of polluting the latter.

Box Seats.-In fly season, seats with lids should be provided, and the open space beneath the seats is to be boxed in (or covered to the ground with muslin or sacking). In the preparation of these box seats it is desirable to pay attention to the following points: (1) Make seat holes oval instead of round; (2) leave $\frac{1}{4}$ inch space at hinges of seat covers to allow for swelling of wood when wet by rains or cleansing solutions; (3) nail a piece of galvanized iron or tin below and in front of each seat to direct urine into the pit; (4) slope back of box well to rear, to avoid soiling with feces; (5) if the soil crumbles, rest the box on wooden sleepers and place a foot board at the pit edge. The boxing should 
be removed every day and the pit burned out. This will require about 5 pounds of hay or straw, with 1 or 2 gallons of oil. The oil should be sprinkeld on the pit walls as well as upon the discharges.

If, for any reason, pit covers cannot be had, crude oil, kerosene, or chlorid of lime, well distributed over the sides

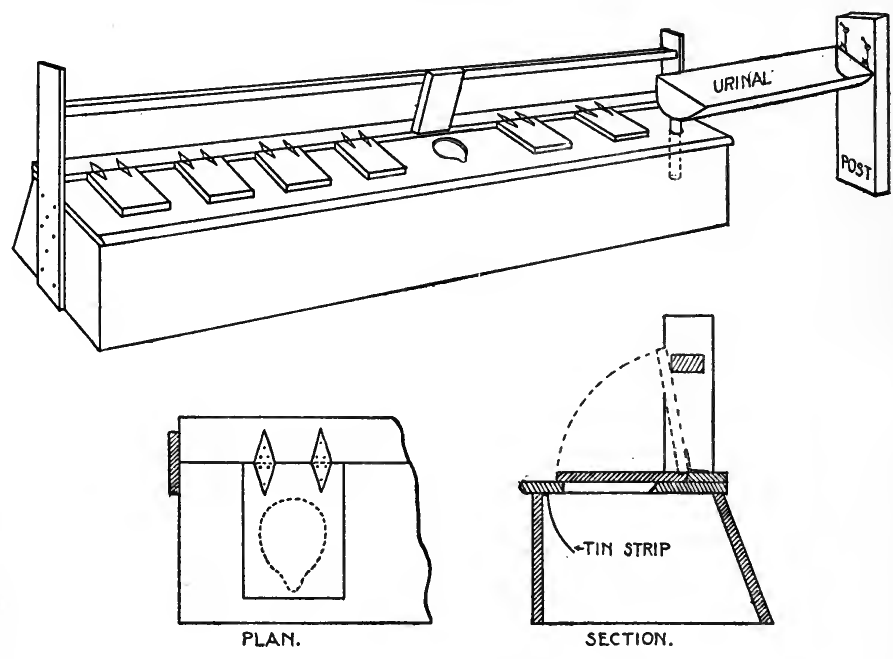

Fig. 42.-Box seat cover and urine trough for company sink. Note shape of seat, self-closing cover, slope of back, and tin strip. (After Straub and Miller.)

and bottoms of sinks, will greatly discourage the approach of flies. Ordinary lime - unless freshly slaking and activeis not particularly objectionable to the insects. In the absence of the chemical agents mentioned, a supply of dry, powdered earth, which is a good deodorizer, is maintained, 
and a shovel or scoop is provided for handling it. Each soldier is required to cover his discharges at once.

Pole Seat.-When a board seat is not available, one must be improvised out of a straight, smooth pole resting on supports of crossed timbers (Fig. 43).

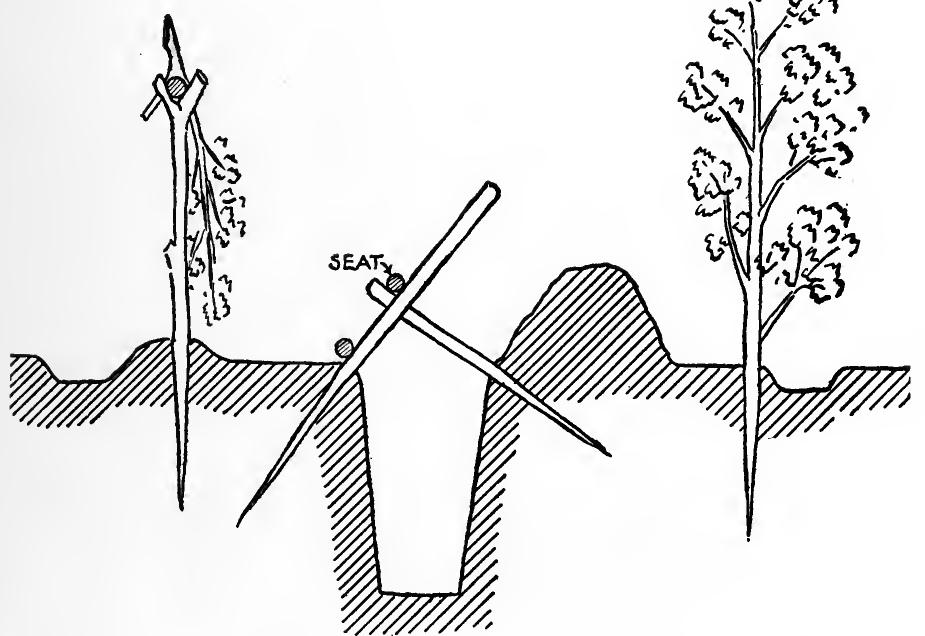

Fig. 43.-Company sink, cross-section, showing pole seat, brush screening, and ditching.

In some situations a rocky site or high ground water may not permit of deep pits. In such case shallow sinks will do, if the pits are oiled and burned out regularly. Shelter is to be provided by tentage, boards or brush, and privacy ensured by screens of canvas, tree branches, or burlap. Where brush is used for roofing, there is danger of fire when the pit is burned out. Sinks should be filled in when their contents approach within 2 feet of the surface. 
Disposal of Urine.-If men are allowed to urinate directly into the sink, they will soil the seats of a closed pit or foul the edge of an open one. It is, therefore, highly desirable to make separate provision for the urine, and this is done by constructing a trough at one end or in rear of the sink and draining into the latter. The trough may be made of lumber, galvanized iron, tin from empty cans, tarred paper, or even of muslin stiffened and rendered impervious with paint or tar. It is important to scrub this daily with an old broom (to prevent the deposition of ammoniacal salts) and to keep it well sprinkled with oil. A less satisfactory device for the disposal of the urine is a shallow trench, about 3 feet long and 1 foot wide, dug at the edge of the sink and sloping rapidly to the latter. The trench is partly filled with straw or brush to prevent spattering, and such materials are raked into the pit and burned regularly. The men using the trench, bestride it. Petroleum is used to keep the trench sweet and free from flies.

Urinal Cans.-Men awakened from sleep at night by a desire to urinate will simply step outside their tents to relieve themselves upon the ground unless it is made easy for them to be cleanly in this respect. Urinal cans or tubs should, therefore, be placed in the company streets at dusk, set up at a convenient height and their location marked by lanterns. This procedure constitutes one of the duties of a latrine orderly, who is responsible for the cleanliness and care of the receptacles. In the morning the cans are emptied into the sink, after which they are rinsed out with milk of lime or crude oil in water. Officers will find the use of a tin 
or bottle for night urine to be a comfort. Such a vessel may be emptied into the sink and washed out in the morning.

Latrine Orderlies. - It is necessary to have an orderly assigned to each latrine, whose duties will be: (a) To be present at all times during the day while troops are in camp; (b) to see that deposits are promptly covered; $(c)$ to have seats clean and covers down; $(d)$ to keep the urinal trough or trench in proper condition; (e) to set out the urinal cans at evening and to remove and cleanse them after reveille; $(f)$ to maintain the surroundings in efficient police; $(g)$ to fill, light, and set up the lanterns at latrine and urinal cans; (h) to report any infractions of the rules of sanitation and decency. The men must be made to realize that the duties of a sanitary orderly are highly honorable, and that, involving (as they do) the care of the health of all, they are in the highest degree important. If officers discredit this work, the men will slight it.

Marching commands will ordinarily find the shallow, individual "straddle trench" satisfactory. A series of these is dug side by side and 3 feet apart. Each trench is 3 feet long, 1 foot deep, and merely as wide as the spade. A man using such a trench squats astride of it and covers his excreta with earth as soon as they are voided (Fig. 44).

Washing of Hands. - It is desirable that the men should be trained to wash their hands after defecation; this procedure becomes necessary when intestinal disease of an infectious nature is present in camp. At such times a lavatory bench with a supply of basins, soap, water, and some disinfectant solution should be maintained at each latrine. 
Disposal of Garbage.-Extended trial has been made by us of methods for the disposal of garbage, wet and dry. Most of these methods have involved removal in wagons or carts to incinerators of various types located at convenient points in the camp area. The incineration has been satisfactorily performed, but the "slops" have emphasized their character by leaving trails through camp, where the cans carried on escort wagons have spilled over. 'The necessity

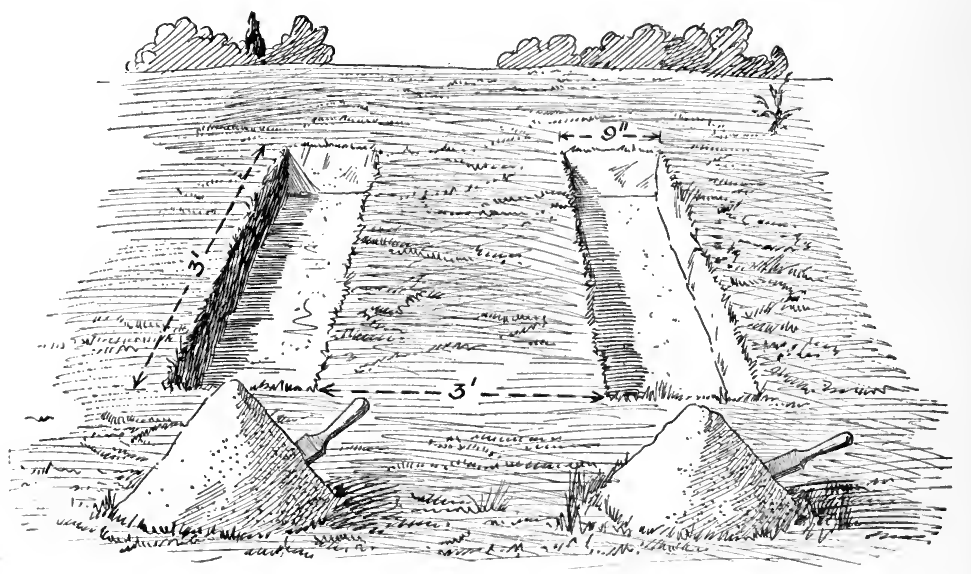

Fig. 44.-Shallow "straddle" trenches for excreta.

for cans and the attraction to flies in the accumulation of garbage therein are other objectionable features. A system has, therefore, been evolved whereby each mess incinerates its own garbage promptly. This is performed in pits prepared in the following manner: (a) Sites are selected close to the company kitchen-mess shelter and, preferably, in one line for each regiment. (b) A pit is dug, approximately $4 \frac{1}{2}$ feet long, 3 feet wide, and 1 foot deep, which is filled with 
large rocks. The pit is purposely made shallow, so that the rock lining may be thoroughly heated. Deeper pits become mere cesspools unless the soil is very porous. (c) A rock wall, $1 \frac{1}{2}$ feet high and reinforced with earth, is built up around

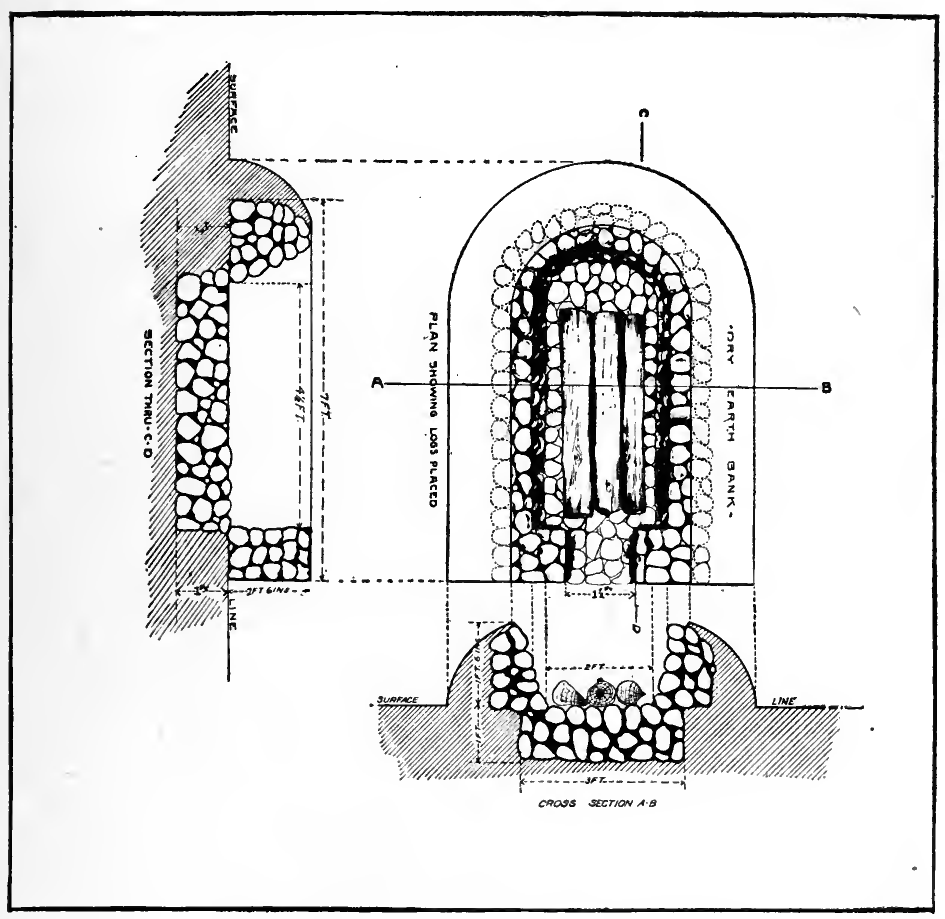

Fig. 45.-Company mess incinerator (Straub).

two sides and one end of the pit; the other end is left open to assist the draft and to facilitate the removal of ashes. Cooks are required to dispose of all kitchen wastes (liquid as well as solid) in this incinerator, and, as the former is the more difficult, they soon learn to be economical in their use 
of water. Solids are placed directly upon the fire and liquids are carefully poured upon the heated rocks of the side walls. About one-sixth of a cord of wood per day is required for each incinerator. If the command has no field ranges, the incinerator fire is well adapted for the preparation of food. If rocks are not available, a horseshoe of clay (or bricks and cement) may be constructed, to form a sort of fire-box having the general dimensions of the rock pit described above. The open end is toward the prevailing wind; a Sibley stove or other contrivance is set up for a chimney and a large pan is placed over the top. Solids are burned on the fire and liquids are evaporated from the pan. A marked saving of fuel results from this device.

Pits for Liquid Garbage.-Liquid garbage may be disposed of in pits measuring about 3 feet in the various dimensions. The soil must be porous or the pits will soon fill up. In the latter case their contents might be removed by an odorless excavator. Liquids poured into pits should always be screened through a wire mesh or a piece of sacking and the solid refuse burned. Pits must be covered to exclude flies. This method is not regarded favorably, for the reason that total destruction is practicable and so much preferable.

Care of Cans and Stands.-Where garbage is collected in cans, these should be cared for as in garrison. They are to be elevated on stands (which in the absence of lumber may be constructed of saplings or split cordwood). Cans and stands should be whitewashed. The former must be kept covered, emptied daily, and cleansed by rinsing with milk 
of lime or by burning out with straw, paper, or oil. If the ground beneath the stands be soiled, lime solution is thrown upon it. When the solids are burned and the liquids otherwise disposed of, these two components of the garbage must be kept in separate cans. .

Marching Commands.-With marching commands, garbage disposal is much simpler. A hole 1 or 2 feet in diameter and at least 2 feet deep is dug near the company kitchen and solids and liquids thrown therein. Such holes are carefully filled in before the march is resumed. In case it is anticipated that other troops will soon occupy the same site, burial must be deeper or the solids of the garbage burned in the kitchen fire.

Disposal of Manure.-Manure should be removed daily to the dumping-ground or incinerator. Picket lines should be swept frequently and the ground occupied by them sprinkled with crude oil occasionally. If this substance proves harmful to the hoofs of the horses, it may be covered over with a little earth; or, the ground may be burned over with the aid of straw. These measures are for the discouragement of flies and their breeding. In case the manure at the dump cannot be rapidly burned by special means, the piles should be set on fire and kept burning, with the aid of oil if necessary. The dumping-place should; of course, be to leeward of the camp. An efficient and economical device for the incineration of manure is easily made by setting up a gridiron of old rails or pipes on stones a foot or so above the ground. The manure is thrown on the grid and a fire started beneath, after which the drying refuse will 
serve as fuel for its own destruction. The method is thus economical in fuel and tending.

Camp Sweepings.-A surprising amount of rubbish needs removal from the camp area each day. This consists of waste paper, leaves, twigs, grass, sweepings from tents, old clothing, and the like. A convenient method of collection for the bits of waste paper which blow about a camp is to furnish each of several members of the police party with a sharpened stick and a gunny sack; the paper is picked up with the stick

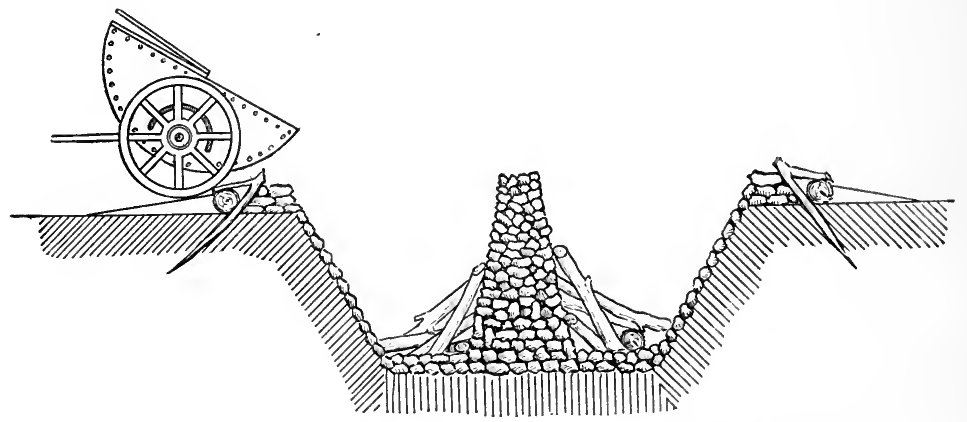

Fig. 46.-Circular pit (rock pile) crematory (after Wilson).

and the sack serves as a place of deposit. Rubbish is to be burned, preferably in the incinerator.

Circular Pit Incinerator.-The type of improvised field incinerator which has been found most useful in our service for general purposes is a circular pit. This type is variously known as the pit crematory, the rock pile crematory, or the circular pit incinerator. As ordinarily constructed, a circular pit having sloping sides is dug in a suitable situation. A cone of rocks, whose apex is 1 or 2 feet higher than the ground level, is next built at the pit's center, to serve as a 
sort of chimney. The entire pit, bottom and sides, is then lined with large stones. Finally, a ramp of logs, earth, or rocks is laid at the margin. The dimensions of the pit are: diameter at ground level, 15 feet; diameter at pit floor, 10 feet; depth, 3 feet; base of rock cone, 3 feet. 'The crematory is operated in the following manner: a fire of cordwood is built in a quadrant of the pit and is allowed to burn for an hour or more, until the mass is thoroughly ignited and the adjacent rock lining of the pit is well heated. Solid wastes are then carefully fed upon the fire, where they soon dry and are consumed. Liquid wastes are poured upon the heated stones, which evaporate them promptly. The next day the fire is started in another quadrant and that used previously is allowed to cool, when the ashes and other incombustible refuse are raked out and removed to the nearby dump. This crematory is wasteful in fuel, but if plenty of wood is available, and caution is exercised not to drown out the fire with liquids carelessly applied, it will consume about two tons of organic refuse per cord. The pit is capable of incinerating dead animals, and, when well tended, may be used for the destruction of excreta. One attendant is necessary to build the fire, feed the wastes properly, and keep the pit and its surroundings in a cleanly state.

Sod Crematory.-If fuel is scarce, another kind of crematory may be improvised, which is efficient for a limited amount of solids and a less proportion of liquids. It consists of two stone-lined trenches crossing one another at right angles, with a round chimney of clay or sod over the point of intersection. The trenches should be about 6 feet 
long and $1 \frac{1}{2}$ feet wide; their common center is 1 foot deep, but thence they slope upward to the surface level. Their purpose is to provide apertures for draft and for the removal of ashes. The chimney is to be built about 3 feet high (Fig.

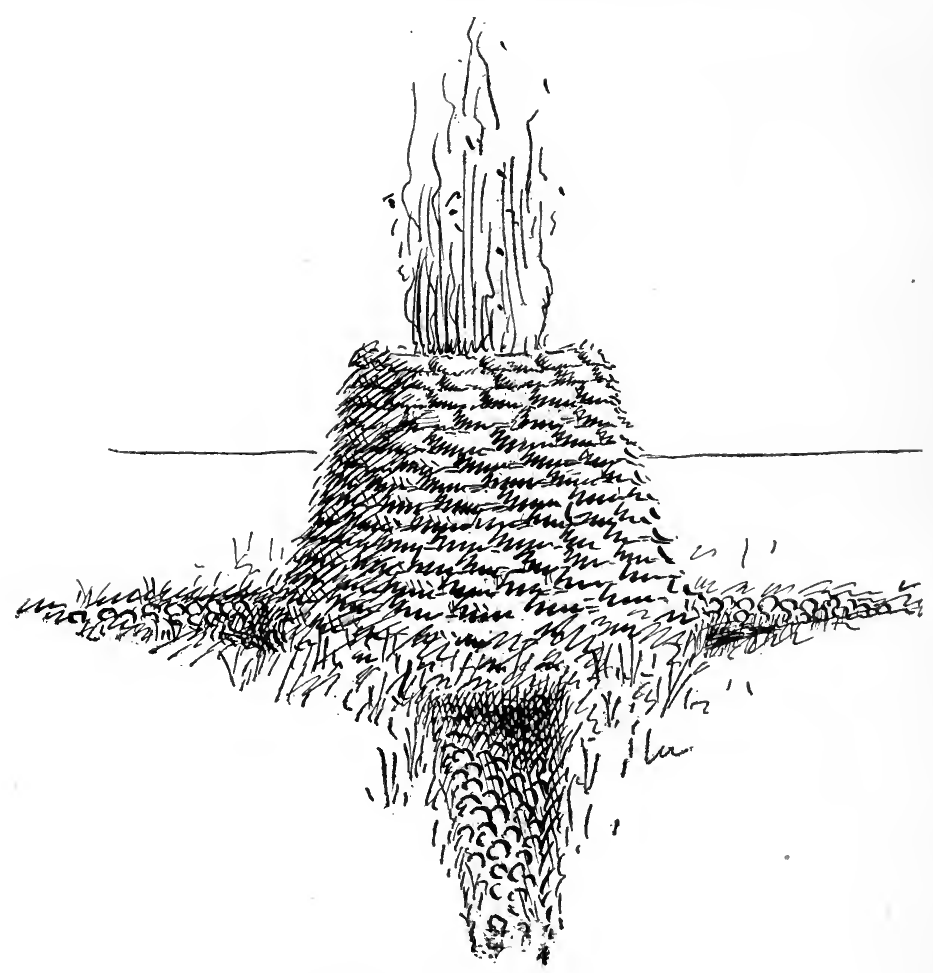

Fig. 47. - Sod crematory.

47). A strong fire is started at the bottom of the chimney and the draft is regulated by closing up those trench openings which are out of line with the wind. Solids are thrown down the chimney directly upon the fire and liquids are poured upon the heated stones of the trench linings. If 
iron bars of any sort are available, the efficiency of this crematory is much increased by laying them at the bottom of the chimney as a grate. Several pieces of corrugated iron, bent round, wired together, and with holes cut at the lower edge for draft, will make a crematory which operates similarly to the one just described. Other types resemble a bee-hive or a horseshoe in form.

Wash Water.-Fouled water resulting from the washing of the persons and clothing of the men must be adequately cared for or it will be thrown upon the ground, producing muddy areas which will contain a considerable percentage of decomposable organic material that will attract flies and may give off offensive odors. The simplest way to provide for these waste liquids is to dig pits directly beneath the washbasin benches, the laundry tables, and the bath-house drains, into which the soiled water flows or is poured. If the soil is permeable, the pits are filled with stones. If, on the other hand, the soil will not permit the water to drain away, pits must not be stone-filled, but should be covered with boards (or brush and earth) and emptied when necessary by means of the excavator pump and wagon.

Waste from Taps.-Excess flow from water taps is taken up by stone-filled box frames sunk in the ground under the taps. Overflow from watering troughs must likewise be cared for. Vigilance must be exercised to keep down the wastage of water to the lowest possible limit, so that the quantity to be disposed of shall not be too great for us to handle. To this end, self-closing cocks should be placed on the hydrants, the keys to taps over latrine troughs should 
be removed and troughs filled only by the sanitary squad; a bath-house orderly should be charged with the duty of keeping shower taps turned off when not in use; and a plumber is to be employed to correct leaky fixtures.

Camp Drainage.-Camp areas may be inundated by sudden rains; therefore company streets, picket lines, sinks, incinerators, and (most important of all) tents, should be protected by a system of ditches. These should be united into a well-thought-out drainage system, that storm waters may be carried away as fast as they fall. 


\section{CHAP'TER XIII}

\section{TROPICAL AND ARCTIC SERVICE}

\section{Tropical Service}

Tropical Climate.-It is popularly supposed that in changing from a temperate to a tropical climate the principal difference noted is an increase of heat. This difference is not striking, however, and, in point of fact, there are days in our North American summers which are much hotter than any noted in our tropics. $92^{\circ}$ in the shade is hot for the Philippines, while $102^{\circ}$ is not uncommon in some parts of the United States. But the warmth of the climate is continuous, within very moderate range, throughout the year, and there is no marked succession of seasons with relation to temperature. It is this continuous high temperature, unrelieved by periods of cold and associated as it is with a high degree of humidity, which proves so trying to our people and is chiefly responsible for the loss of energy, initiative, and memory, and, in fact, the general physical and mental deterioration which is frequently observed after two or three years' residence. The factor of atmospheric moisture is important. Man can bear high atmospheric temperature easily provided the air is dry, but when that air is charged with moisture, evaporation from the surface of the body (so necessary to the maintenance of the normal bodily temperature) is considerably diminished. If, however, there is a 
breeze, high humidity (as. well as heat) is much more bearable. This conjunction of meteorologic conditions exists in our tropics, for at most seasons of the year the heat and moisture of the atmosphere are rendered more bearable by the persistence of winds. In the Philippines these are known as the northeast and southwest monsoons. Another atmospheric factor which plays some part in producing departures from a state of health is tropical sunlight. Observers in Manila have concluded that the light rays proper are not harmful, except for the glare on sensitive retinas. They are further of the opinion that the ultra-violet (chemical) rays of the solar spectrum do no injury so long as the bodv is covered, but that the infra-red (heat) rays have hurtful potentialities. The theory that blondes are more likely to break down in the tropics than brunettes, by reason of the alleged fact that their skins are more readily penetrated by some of the rays mentioned, has not been substantiated.

Effects of Tropics.-After a somewhat prolonged exposure to tropical conditions-say from one year upward-the average American experiences a certain loss of energy, initiative, and memory. Many persons grow irritable, morose, and homesick. Fits of passion may be caused by trivial incidents. There is often, at the same time, an enfeeblement of constitution or, at least, a diminished power of resistance to disease. Individuals vary greatly in this regard, some seeming to thrive. It is believed to be a fact, however, that even these are usually constitutionally undermined by prolonged residence, so that, when attacked by acute 
illness, they frequently succumb with astonishing ease. Women are, as a rule, more promptly affected by the climate than men. Children born in the tropics are usually fragile, and require a sojourn in a colder climate to give them a reserve of strength. „Older children-of school age-do well for two or three years. Enlisted men have no social opportunities, and furloughs (involving a chance to visit the home or foreign lands for recuperation), such as may be enjoyed by officers, are practically out of the question for the former.

Causes of Disease.-But climatic conditions by themselves are perhaps not so much responsible for sickness as is the presence of many kinds of preventable disease, associated with ignorance and carelessness; in other words, defective hygiene. Men are apt to continue habits formed in temperate climes which are unsuitable for the tropics. It is not unusual for a vigorous individual to experience a sense of exhilaration during the first few weeks of his tropical service; this may lead him. into habits of carelessness or excess. At the same time, opportunities for dissipation are frequent, while ordinary restraints and normal outlets for energies are less than at home. Under such circumstances, alcoholic and sexual excesses are common. Later on, a want of buoyancy, a weariness of mind and body, a feeling of depression, may tend to alcoholic indulgence. There are, then, many factors contributory to disease in the tropics, though but few of these are peculiar to hot climates. In addition to those already cited (heat; humidity, habits, idiosyncrasy, prevalence of infectious diseases), other factors 
may be operative. Such are: the location of the individual (city or country life, remoteness, isolation); occupation; monotony; insanitary surroundings.

Acclimatization, that is, the adaptation of the body processes to the new conditions imposed by tropical residence, may and does take place in some individuals, but in most cases the deterioration referred to heretofore is apparent, though proper sanitary and personal measures against disease undoubtedly diminish the tendency (as so splendidly shown in Panama). The consensus of medical opinion in our army as to the length of tropical service is very largely to the effect that more than two years is likely to result in physical deterioration in the average man.

The individual measures to be adopted for the prevention of disease in the tropics are adaptations of the principles laid down in the chapter on Personal Hygiene. Certain measures under this head will be briefly discussed.

Baths.-Since perspiration is excessive, frequent baths are a necessity for comfort as well as cleanliness. A bathtub can seldom be found, but as a shower is so readily improvised and is more grateful anyway, this plan fulfils all requirements. If nothing else is available, an empty 5-gallon kerosene can is always to be had, which, when perforated, placed on a support overhead, and partly filled with a bucket of water, proves fairly satisfactory. The question of the source of the bath water is important, for the ordinary surface water in the tropics teems with germs, often of a dangerous sort. In the absence of an approved supply, rainwater can be caught and utilized for a large part of the year, 
and in the dry season the water may easily be boiled and cooled.

Laundry.-The question of laundering the body linen. is always a serious one, for the native method is to stand in a pool of water or a stream, wet the garment therein, lay it on a flat rock, and pound it with a club. This is hard on buttons, but does not harm the germs, and, as soap is rarely used, the degree of cleanliness is problematic. Wet linen, though washed in clean water, may be spread out to dry on infected ground. The only way to be sure that the clothes are soaped, boiled, and otherwise properly handled is to provide the facilities and have the work done, under supervision, at one's quarters.

Diet.-Our Quartermaster Department is generous in its provision for variety in staples. Tropical fruits are readily obtainable, but fresh vegetables-other than potatoes and onions-are seldom to be had. When obtained from local sources they are very apt to convey disease, since irrigating waters are infected, while the oriental gardener uses human excrement as a fertilizer. Therefore, all native vegetables should be cooked. The local fruits, handled by unclean natives, should be plunged for an instant in boiling water before peeling and eating. This does not injure the ordinary thick-skinned varieties and greatly diminishes the risk of disease from this source.

Abdominal Congestion.-The digestive organs have an undue strain placed upon them in the tropics by reason of a tendency to chronic congestion. Excesses in diet are, therefore, especially to be avoided, and digestive irregularities 
(constipation, diarrhea, dyspepsia) should be corrected promptly. Beverages containing alcohol are generally undesirable because they increase congestion; if taken at all, they should not be used before the evening. The enlisted men must be instructed concerning the dangers of drinking "Vino," a native Philippine spirit, crudely distilled from the young tips of the nipa palm. This liquor contains very poisonous principles, which give rise to sudden blindness, acute mania, and other mental aberrations.

Water-CAll sources of drinking-water in the tropics should be presumed to be infected and likely to transmit disease, unless proof to the contrary has been established. Our dependence for its purification must rest, in the main, upon boiling, although at certain stations it may be possible to obtain a supply which has been rendered safely potable by distillation, or the use of some appliance such as the Forbes sterilizer. The precautions mentioned must be extended to include all water used for washing table and kitchen ware, for brushing the teeth, and for any other purpose where articles which we handle may thus convey infection to the mouth. The source of aërated waters should be investigated, for serious errors have been found in their manufacture.

Clothing.-The outer garments are, of course, definitely fixed by the War Department, but consideration of the principles involved may be useful. Our interest in this matter covers two points. The first is coolness; the second, protection from the sun's rays. White absorbs the least heat, and is, therefore, coolest. Khaki intercepts a large 
portion of the chemical rays and may be useful for that reason. Olive drab has the same advantage, but is distinctly warmer than khaki. On the other hand, it should be remembered that when the garments are starched (and they are commonly so worn), the normal cooling of the body (by radiation, together with evaporation of the perspiration) is interfered with, and heightened temperature results. The headgear should have an airspace between sweatband and brim to permit free circulation of air within the crown. For underclothing, the preference of the wearer may be indulged to some extent. There is no doubt that a wool undershirt is less likely to permit rapid chilling of the surface when overheated, and a garment of this material is, therefore, to be preferred for field service when it is well borne by the skin. Linen mesh and cotton mesh are worn by many, and when the circulation is active these fabrics are, perhaps, more comfortable than the wool. Silk is preferred by some and is suitable for tropical wear. Underwear of orange-red color, designed to exclude the chemical rays of the sun, has been carefully studied in the Philippines and found undesirable, for the reason that it is decidedly hotter than white, thus inviting, rather than repelling, disease. An important accessory garment is an abdominal covering of wool to be used during sleep. At this time chilling of the surface is especially likely to occur, and the abdomen is most sensitive in this regard. Therefore a broad circular band or, better, a small apron-shaped flannel pad should be worn; failing this, the corner of a thin blanket should be drawn across the abdomen. These precautions 
should be taken even in the hottest weather. The most important points in this connection may be summed up in the maxim "Keep the head cool and the abdomen warm."

Exercise is just as necessary and beneficial as at home. The sun does not prove a deterrent to open-air work, though common sense dictates that the midday hours should not be chosen for this purpose.

Habitations should be constructed of heat-repelling materials (preferably concrete) and raised from the ground on piers. Walls, inside and out, should be of soft, non-reflecting color. Interiors should be shaded and cooled by wide verandas. Rooms should be large and ceilings high. Double roofs, with intervening air space and ridge ventilation, are desirable. Windows and doors ought to be made mosquito-proof. In the absence of this latter provision, the use of mosquito-bars on beds must be enforced. Neighboring vegetation should be thinned out and mosquitobreeding areas controlled. Other vermin-rats, roaches, ants, flies, bedbugs-must be warred against. General police must be thorough.

Special Diseases.-There are many diseases peculiar to hot climates, and nearly all are due to minute animal or bacterial parasites. Other diseases (of which malaria is the chief example) are found in higher latitudes, but flourish more actively in the tropics. The reason is simple, and lies in the fact that tropical conditions of heat and moisture are most favorable to the growth and multiplication of the parasites mentioned, or to the lives of their intermediate hosts. And by "intermediate hosts" is meant that many 
such parasites require, in addition to man, some lesser animal in which to complete the cycle of their existence. In the case of malaria the mosquito is necessary; in sleeping sickness, a biting fly and a crocodile are intermediate hosts; the rat and his attendant flea are the media of transference of bubonic plague; a tick conveys relapsing fever, and so on. To many of these diseases the natives of the country are more or less immune, while newcomers-particularly those from temperate lands-are especially liable to be attacked. The native immunity results from racial resistance, which is handed down by inheritance from centuries of ancestors in whom a survival of the fittest with respect to the disease has occurred. Racial immunity has a notable example in the case of yellow fever among the native Cubans.

Malaria is very common and often more serious in type than that encountered in this country. Every year it is responsible for a very large proportion of all the cases of sickness among our people. Therefore the measures alluded to in earlier chapters, especially protection from the bites of mosquitoes and destruction of their breeding-places, are of great importance. One of the difficulties which confronts us in our efforts to reduce the incidence of malaria is that a very large percentage-perhaps one-half-of the natives of tropical countries are affected with a chronic form of this disease. Servants, laborers, clerks, etc., are thus likely to transmit it. Mosquitoes may breed in unusual situations, such as bamboo joints and pitcher plants.

Intestinal Diseases.-Dysentery is a grave source of trouble, particularly in the Philippines. Victims of this affection 
are apt not to make complete recoveries, but even after return to the United States may suffer for years or die of sharp acute attacks or some complication. The risk of cholera exists because, as with dysentery, it is likely that certain natives habitually harbor the germs, even in the apparent absence of the malady. Intestinal parasites other than those mentioned are very common. More than half the natives of the Philippines seem to be infected with worms, great and small. They occur very commonly in the white man, and are due to the neglect of the precautions so constantly insisted upon herein, that native vegetables must be cooked and water sterilized.

Small-pox is very prevalent in tropical lands, and the likelihood of contact with it is greater than at home. It behooves us, therefore, to be sure that we are efficiently vaccinated.

Skin Diseases.-Few Americans escape the dhobie itch, a species of ringworm which attacks the groins and armpits, and is believed to be generally transmitted through imperfectly washed underclothing. The name, in fact, is derived from this association of ideas, since "dhobie" is a Hindoo term meaning "washerman." Prickly heat torments many who have a tendency to perspire excessively. This affection is combated by frequent baths, alkaline sponging, and the use of talcum powder.

Venereal diseases are more common and virulent than they are in higher latitudes. It is important that the military personnel shall be made aware of, and kept alive to, the dangers of illicit intercourse. At the same time, the 
measures of prophylaxis and punishment provided for by our regulations should be enforced.

Homesickness. - Finally, there is an affection due to the remoteness of our tropical possessions from "home and mother" and the lack of social amusements to which the soldier may have been accustomed. This is nostalgia, more familiar to us as homesickness, which often becomes a very real disability. Its indications must be watched for among the men and steps taken to promote cheerfulness and contentment.

Field Service.-If war is to be waged in a hot climate, the campaign should be planned for the most favorable season, if this is possible. It is to be expected that disease in war time will be largely in excess of that incident to field service in temperate zones. Care must, therefore, be taken to observe march and camp sanitation. Fatigue is to be obviated by light packs and frequent halts. Marches should be made in the cooler parts of the day. Crowding is prevented and ventilation ensured by an open order - as by using both sides of the road, leaving the middle clear. Advantage is taken of shade and the water-supply is carefully arranged for. Chilling is to be guarded against, chiefly because latent malaria is made active thereby. Quinin is given daily as a routine measure for the prevention of malaria, when this, disease is to be feared.

When debilitated by climatic conditions or illness, convalescence is apt to be protracted and imperfect. Under such circumstances it is desirable or even necessary to have a sojourn in some hill station (as Baguio, in Northern Luzon), 
or to obtain a leave of absence and spend it in a cooler clime like North China, Japan, Australia, or the homeland. Neurasthenia and recurrent attacks of dysentery, pernicious malaria, or heatstroke usually necessitate a prolonged period of convalescence in the United States. Our experience indicates that removal to a winter climate invigorates those returned from tropical service most promptly.

\section{Arctic Service}

Cold Climates Healthy. - Not so much need be said under this head, for cold regions are very salubrious. Alaska is by far the healthiest place in which our troops are stationed. This is probably due chiefly to the fact that the germs responsible for infectious diseases exist with difficulty in a low temperature. Man is able to endure extremes of cold which would be fatal to most animals, because of his ability to clothe himself adequately and to produce shelter and fire when needful. Moderate cold is exhilarating, and even great cold is well borne when vigorous men are prepared for it. When such cold is "dry" and still, a much lower temperature may be endured than when the atmosphere is humid or in active motion. It is in "blizzards" that men are usually overcome by the effects of cold.

Effects.--Exposure may result in varying degrees of injury to the body, from temporary discomfort to death. Chilblains, with their puffy, purplish appearance and tingling, burning sensation (all of which are aggravated by heat), may recur at intervals for years. Frost-bite at times necessitates amputation of the extremities. When a man begins to freeze, 
his vision is dimmed, his body feels numb, he staggers along like a drunken man, and he experiences an overpowering desire to sleep. To restore a frozen part, it is important that the circulation be brought back gradually. If warmth is applied, reaction is excessive and the part may mortify. Rubbing with the hand, a piece of fur or wool, or with cold water (while the victim remains in the open air) until the normal color returns, is the appropriate treatment. It is a fallacy to use ice or snow for this purpose. Freezing occurs most readily when the parts are wet, as the loss of heat from the surface of the body is rendered more rapid thereby. A minor form of disability is that known in Alaska as the chechawker (tenderfoot) knee, which is a name applied to pain and stiffness of that joint resulting from exposure to a cold wind. Snow-blindness is a distressing condition, due to the effect on the eyes of the sun's reflection from snow surfaces. It may be prevented by wearing amber-colored or smoked glasses or blinders of horsehair or wood. The glare is mitigated by blackening the eyelids with a mixture of charcoal and grease. Men cooped together during the long winters, with no sunlight, insufficient exercise, overcrowding, monotony, and probable uncleanliness show signs of nervous strain, such as irritability and quarrelsomeness. Scurvy must be guarded against. If, under the conditions cited, some of the men begin to complain of muscular stiffness, rheumatism, night-blindness, or sore gums, the company mess should be carefully investigated.

Food.-The quantity of food consumed is considerably greater than in lower latitudes, as much fuel must be utilized 
in keeping up the bodily fires. An approximation to the character of the native diet (in which a large excess of fats is the distinctive feature) is desirable. The use of alcohol is more deleterious here than elsewhere on account of the lowering of body temperature produced by this substance. The eating of snow to allay thirst causes stomach irritation. In field service the use of fireless cookers, oil or alcohol stoves, and "Thermos" bottles will be found of great value.

Clothing. - The practical point about clothing is, not that a large amount shall be habitually worn, but that additional external garments may be readily donned or doffed as occasion requires. The Quartermaster Corps supplies a number of special articles for Alaskan service. These include Mackinaw coats, pea-jackets, trousers lined with kersey or blanketing, felt shoes, German socks, fleece-lined drawers and undershirts, fur caps, moccasins, and mittens of fur or buckskin. An excellent garment, not officially supplied, is the so-called parka. This is a loose coat of canvas or drill, which excludes the wind; it has a fur-edged hood and should be long enough to fall below the knees. German socks worn with moccasins are perhaps the most comfortable footwear in very cold weather. Felt shoes are more durable, but are big and clumsy. The objection to all these is that they do not exclude moisture. Leather shoes stiffen and rub the feet, while they slip on frozen surfaces. The best covering for the hands is a woolen glove worn inside of a large, fleecelined mitten of fur. Mittens should have the index-finger separated (as well as the thumb), in order that the rifle may be handled, and should be insured against loss by attaching 
them to a cord which passes through the coat sleeves and across the shoulders. When men are housed under canvas, the tents should be sheltered by wind breaks of brush or snow. Steel tent pins, or erowbars to prepare holes for wooden pins, are necessary. For bedding, the sleeping bag of canvas, lined with blanket or sheepskin, is highly valued. This article should be laced or buckled, so that it may be readily taken apart for cleansing and drying or to remove the blankets.

Disposal of Refuse.-Organic refuse should be deposited at designated places. During the winter these substances are rendered innocuous by freezing. On the approach of spring the frozen masses should be removed and properly disposed of.

Personal hygiene is of much importance. The men should be well instructed in measures for taking care of themselves. In permanent stations there should be facilities for bathing; the Russian bath, with its steam and hot-air rooms and cold shower, is much appreciated. Systematic exercise is necessary. Measures of general interest, such as games, hunting parties, and entertainments, must be instituted to overcome monotony. Bedbugs and lice find favorable conditions in Arctic life and must be vigorously combated. Unnecessary exposure is to be minimized; when, for instance, a storm makes exposure particularly severe, sentries should be changed every half-hour or so. 


\section{CHAP'TER XIV}

\section{VENEREAL DISEASES}

Importance of the Subject.-A special chapter is given to this subject because of its great and growing importance. The American people have, until recently, shunned public discussion of venereal matters through what many now feel to have been mistaken prudery. A great movement has lately been instituted, through the American Association for Sex Hygiene and allied societies, looking to the awakening -of the public conscience and the moral education of the youth of the land.

Prevalence in the Army.-Venereal infections are responsible for an enormous amount of sickness in the armyvastly more than any other cause-and constitute the most important health problem with which we have to deal. There are constantly on the sick report from this cause a number of men which more than equals the strength of a regiment of infantry. Our army has the unenviable distinction of having a much greater amount of sickness of this nature than any foreign army. Moreover, since the SpanishAmerican War the ratio of such cases has rapidly increased, until it is now twice as much as in 1898. The situation must, therefore, be fairly faced and every effort put forth to determine the causes for the prevalence of venereal diseases and to devise measures for their prevention. 
That the army has a greater percentage of such disease than has an equal number of vigorous young unmarried men drawn from like source in civil life is not believed. Such infections cause the largest proportion of rejections of applicants for enlistment. They honeycomb our social structure. In point of prevalence they vastly outnumber all other infectious diseases, both acute and chronic, combined.

Causes.-These are not far to seek. In the first place, sexual desire is implanted in man as a compelling factor for the perpetuation of the race. This desire is strong, especially when, by previous exercise of the function, the habit has been formed. Next, the demand for partners in the sexual relation has always created a supply, and prostitution is as ancient as history. Of late this supply has been elevated to the dignity (?) of a business, and a hideous traffic, with an intricate system for procuring young girls and suborning those who legally should prevent such traffic, is now strongly entrenched.

Preventive Measures.-How, then, shall we set about to minimize, as far as possible, the incidence and effects of these loathsome diseases, largely dependent, as they are, upon causes inherent in the nature of mankind? From a sanitary standpoint it is plain that we must apply the ordinary principles of sanitation. That is, we must recognize their contagious character and apply such preventive measures as are effective in other transmissible diseases. The most important measure of this character is the isolation of infected individuals until the danger of transmission is past. In the army we can and do control our infected soldiers, but the 
women from whom their disabilities were derived, as well as infected male civilians, are still at large to spread the contagion further. It is obvious, therefore, that, if we hope for success, sentimentalism and prudery must give way, and that diseased public women must be admitted to hospitals or otherwise placed under restraint till the infectious stage of the disease is over. For the diseased male, it should be made a crime knowingly to spread a venereal disease.

Education.-The measures above outlined do not conform with the yet uneducated public feeling that it is immoral openly to recognize diseases of this class and their chief transmitter, the prostitute. On the other hand, the measures themselves are certainly not immoral, while they are practical. On the moral side, the campaign of education already begun should be extended and a flood of light poured upon the subject, that all may clearly understand sex matters, the dangers as well as the immorality of illicit intercourse and the methods of spread of diseases transmitted thereby. With such education, the veil of ignorance, misinformation, and prudery will be lifted and the tendency to secret vices among children will be lessened. Havard says truly, "It is in the conscience of the young man that prophylaxis should begin." The knowledge of sexual matters acquired by a child is from bad sources and of a perverted kind. Such knowledge, secretly acquired and brooded over in secret, hastens the awakening of sexual feeling and leads to vice.

Action by the War Department.-Our War Department has acted with courage and vigor in attacking this problem. Orders were issued in 1912 directing procedures as follows: 
I. That physical inspections of enlisted men should be made twice in each month for the detection of venereal disease.

II. That any soldier who exposes himself to infection shall report for cleansing and preventive treatment immediately upon return to camp or garrison.

III. That any soldier who fails to so report, if found to be suffering from a venereal infection, shall be brought to trial by court martial for neglect of duty.

IV. That men so diseased shall be confined strictly to the limits of the post during the infectious stages of the disease.

V. That all officers serving with troops shall do their utmost to encourage healthful exercises and physical recreation, and to supply opportunities for cleanly social and interesting mental occupations for the men under their command.

VI. That company and medical officers shall take advantage of favorable opportunities to point out the misery and disaster which follow upon moral uncleanliness and the fact that venereal disease is never a trivial affair.

Action by Congress.-Congress, too, has taken a decided stand, by an enactment providing that no officer or enlisted man who shall be absent from duty on account of disease resulting from his own intemperate use of drugs, or alcoholic liquors, or other misconduct, shall receive pay for the period of such absence.

It will be seen from the foregoing that the army now has an excellent plan for the discouragement of vice and the control of disease resulting therefrom. To add to the effectiveness of this plan, efforts are being made to induce 
Congress to repeal the anti-canteen legislation, thus again permitting the sale of beer and light wines in the soldiers' clubs and co-operative stores officially known as post exchanges. It is not here argued that the canteen is an unmixed good nor that drinking should be encouraged. It is, however, in the highest degree desirable to keep the men away from more evil influences, and it is notorious that the saloon, prostitution, and professional gambling go hand in hand. The close relation between alcoholic excess and sexual indulgence is an interesting fact. A man's passions are inflamed by liquor, his will power and his judgment are alike weakenerl, and he vields to conditions which in his sober moments might be positively offensive to him.

Syphilis.-There are three kinds of venereal disease. The most serious to man is, perhaps, syphilis (sometimes called the "pox," and referred to in the newspaper advertisements of charlatans as "blood disease"). This is due to a very active, corkscrew-shaped protozoal germ. Its first apparent result is an open sore at the point of infection. This sore, known as a hard chancre, does not appear for several weeks after exposure, but is then very resistant to treatment and remains for a month or more. The body is soon infected throughout, and symptoms of this condition appear most often in the form of skin eruptions and glandular swellings.

Syphilis is an infection of the entire system and its manifestations are practically innumerable. We may expect it to appear in any conceivable form, and where a chronic case of disease is obscure, tests often reveal its presence. Certain 
of these manifestation may (and do) appear many years after the disease was contracted. Among these are paresis (softening of the brain) and locomotor ataxia.

Syphilis is extremely difficult to cure, and, in a certain proportion of cases, never is cured. The new remedy" 606 " or salvarsan-is still in the experimental stage, but it is at least certain that its use is not followed by permanent recovery, and that the older and more prolonged forms of treatment must still be employed. Syphilis is the disease which is so often transmitted to the children - "even unto the third and fourth generation," as the Good Book informs us-as well as to the wife. It may be transmitted to others not only by sexual contact, but also by means of articles (such as towels, eating and drinking utensils, a comrade's pipe) used in common. Cases also are frequently met which have been innocently acquired through kissing, surgical or dental operations, the ministrations of a nurse, and numerous other blameless ways.

The danger of transmission of the disease from father to child (hereditary syphilis) is very considerable. Many children are born dead; others die soon after birth; still others (who, though diseased, may survive) show characteristic deformities or unmistakable syphilitic lesions.

Marriage.- "Marriage of a syphilitic is permissible only after five years, during the last two of which he has been without symptoms and without treatment" (Keres).

Gonorrhea, or "clap," is the result of infection with the bacterial germ known as the gonococcus, and is characterized by a profuse purulent discharge from the affected part. 
This is usually the canal of the penis (the urethra) in the male, although any mucous or serous membrane may be involved. Thus if, by carelessness or misfortune, a little of the pus is transferred to the eye, a most violent inflammation ensues and the sight is in grave danger of destruction. Gonorrheal rheumatism is a common and intractable affection. Heart disease is an occasional sequel.

Gonorrhea is even more frequently conveyed to the wife than syphilis, and with most serious results, as thousands of deaths and tens of thousands of chronic invalids attest; 60 to 80 per cent. of pelvic suppurations in women are due to this affection. The eyes of babies become infected during birth. It is estimated that 25 per cent. of blind people owe their infirmity to this cause.

Gonorrhea is popularly regarded as something of a joke, an affection but little more harmful than a cold in the head; but many surgeons look upon it as more serious than syphilis in its results, for the infection has a way of traveling along the various routes to the bladder, kidneys, and testicles, leaving a man permanently injured and often greatly shortening his life. Gonorrhea is transmitted to innocent people -wife, child, comrade - with extreme ease, so, if thus affected, one cannot be too careful to make sure that none of the discharge is brought in contact with a healthy individual. Cotton or other material soiled with the discharge should be burned or otherwise safely disposed of.

Chancroid.-The third venereal disease-chancroid or soft chancre-is a contagious ulcer. It is always local, never constitutional, and has no relation to syphilis (although it is 
frequently necessary to wait for weeks before one can be sure it is not the latter). Its cause is a special bacillus. While it may occur elsewhere, it is practically always found about the genitals. Though less serious than the other diseases of this class, it is a painful and repulsive affection. In about one-third of the cases it is accompanied by an abscess in the groin known as a bubo.

Personal Prophylaxis.-Reference has been made earlier in this chapter to the War Department requirement that enlisted men who have exposed themselves to venereal infection shall report at hospital or dispensary for cleansing and preventive treatment immediately upon return to camp or garrison. It is not necessary nor proper to enter here into the details of such treatment, but it may be said that the procedures used are very successful in the prevention of infection. Objection has been made that such prevention, by making licentiousness safe, encourages the latter. As already shown, our problem is to keep our soldiers physically fit, and purely sentimental considerations are of secondary importance. Moreover, our navy has given the system a fair trial, and finds an actual diminution in percentage of exposures as the result of the campaign of education.

In the absence of legitimate intercourse (that is, married life), nature will relieve the situation by an occasional nocturnal emission, which is in no sense harmful. The cultivation of pure thoughts, the avoidance of temptation, cold baths, simple, non-stimulating diet, vigorous physical exercise, and alcoholic abstinence will prove efficacious in overcoming desire. 


\section{CHAPTER XV}

\section{ALCOHOL AND OTHER NARCOTICS}

\section{The Nature of Alcohol}

Alcohol is the generic name for a class of chemical compounds which are formed from hydrocarbons by the replacement of one or more hydrogen atoms by hydroxyl $(\mathrm{OH})$. When, however, the term is used without qualification, it refers to ethyl alcohol, whose formula is $\mathrm{C}_{2} \mathrm{H}_{6} \mathrm{O}\left(\mathrm{CH}_{3}, \mathrm{CH}_{2}, \mathrm{OH}\right)$. This substance is not found in nature in a free state, but commercially is derived from the spirituous fermentation of saccharine juices. The air-borne microscopic fungus known as the yeast plant produces a ferment which, acting on sugars, splits them up into carbon dioxid and alcohol. Such sugars are found in nature in many substances, notably in certain grains and tubers.

Strength.- The alcoholic strength of fermented sugar solutions is never over 14 per cent., for the reason that above this point yeast ceases to act, but by successive condensations and vaporizations an alcoholic content of 91 per cent. may be had, and this is the strength of the commercial product. By further treatment of this substance with charcoal and then rectifying it in a special still over some dehydrating agent, the so-called absolute alcohol-which contains not more than 1 per cent. of water-is obtained. 
Physical Properties.-Alcohol is a colorless liquid which is highly inflammable, has a strong affinity for water, and congeals at a very low temperature (about $200^{\circ} \mathrm{F}$. below zero).

Ethyl alcohol is the essential principle of all intoxicating drinks. While alcohol itself is sometimes employed in diluted form as such a drink, it is commonly taken in the more agreeably flavored preparations made for man's consumption.

Classification.-These preparations are classified as follows:

1. Wines.

2. Malt liquors.

3. Distilled liquors.

4. Patent medicines-tonics, bitters, nerve stimulants, etc.

1. Wines, properly speaking, consist of the fermented juices of the grape, but substances called wines are often made by the addition to alcohol of materials to make the product resemble the genuine article. Wines have an alcoholic content of 9 to 22 per cent., the stronger ones being "fortified" by the addition of an extra amount of alcohol. Home-made wines-hard cider, currant wine, and the likecontain 5 to 10 per cent. of alcohol.

2. Malt liquors are produced by the fermentation of malted grain, to which a bitter substance-usually hopsis added to impart the characteristic flavor. Beer, ale, and porter are the most commonly used beverages of this class. These contain $2 \frac{1}{2}$ to 8 per cent. of alcohol. One pint of beer has about 1 ounce of alcohol. Beer prepared 
for export is frequently adulterated with salicylic acid to ensure its keeping qualities. This substance is objectionable because it interferes with digestion.

3. Distilled liquors, or spirits, as the name implies, result from the distillation of saccharine or starchy substances. Besides ethyl alcohol, spirits contain small quantities of the higher alcohols (propyl, butyl, amyl) as well as other aromatic principles, to whose derivatives the flavor of old whiskies and brandies is due. These are highly poisonous, but are present in amounts so minute as to be negligible toxicologically. We may, therefore, consider that the effects of liquors are in direct proportion to their content of ethyl alcohol.

Liquors occur in the following forms:

(a) Brandy.

(b) Whisky.

(c) Gin.

(d) Rum.

(e) Liqueurs.

(f) Vino.

(a) Brandy is distilled from grapes and fruit and has a high alcoholic percentage (50 to 56 per cent.).

(b) Whisky is the spirit most commonly used in this country. Various forms of this beverage are distilled from different substances; for example, Bourbon whisky is made from corn; Scotch whisky, from barley; Irish whisky, from potatoes; rye, from the grain of that name; while baser grades are produced from oats, beets, refuse molasses, and even sawdust. So-called "blended" whisky is merely a mixture of a "straight" whisky with varying proportions of alcohol, and, 
finally, whisky may legally be made by the addition to alcohol of coloring-matter and flavoring agents. Doctor Wylie reports that " 85 per cent. of whisky sold in this country is nothing less than a cheap imitation." Many adulterants are employed and much whisky is made from refuse substances. However, such adulterants are not usually harmful and consist most often of caramel and water. Whisky has about 50 per cent. of alcohol in its composition.

(c) Gin is made in the same manner and from the same materials as whisky, with the exception that juniper berries are added as a flavoring agent. It is popularly supposed to exert a favorable influence upon the action of the kidneys, but it is highly probable that this liquor has done more harm than good to the organs mentioned. Gin contains 40 to 50 per cent. of alcohol.

(d) Rum is derived from molasses, and has an even higher alcoholic content than the spirits heretofore mentioned, namely, 60 per cent.

(e) Liqueurs are sweetened spirits, flavored with some aromatic substance. Absinthe, benedictine, and chartreuse are examples of this class. Absinthe contains 70 to 80 per cent. of alcohol, and its use is believed to lead to evil effects out of proportion even to this great percentage.

Cordials are liqueurs prepared with fresh fruit juices.

(f) Vino is a crudely distilled spirit made in the Philippines from the young shoots of the nipa palm. It is potent for evil, as it contains a large amount of methyl alcohol. Indulgence by Americans has frequently resulted in blindness or acute insanity. 
4. Patent Medicines Containing Alcohol.--Since some of these have been known as "temperance drinks" (at least prior to the enforcement of the Food and Drugs Act), large quantities are sold to people ignorant of the fact that they are alcoholic beverages. Many such alleged medicines contain a greater percentage of alcohol than ordinary wine and beer. They seem to be popular in proportion to their alcoholic content, and have undoubtedly been responsible for the formation of the habit in many persons. A few of those most advertised are named below, with a statement of their alcoholic percentages:

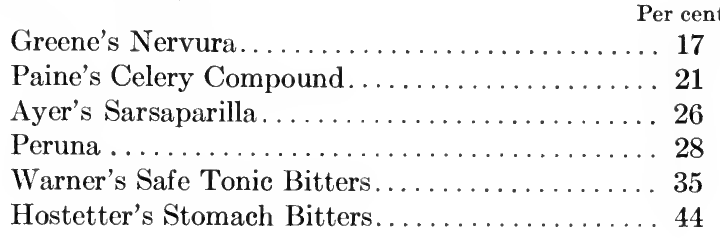

"Denatured" alcohol is the ordinary product, to which methyl alcohol and benzine or naphtha have been added in order to render it undrinkable. It is used in the arts and manufactures.

Wood Alcohol.-Methyl (wood) alcohol is capable of producing intoxication and is sometimes employed for that purpose. Such use must be unqualifiedly condemned, for wood alcohol is highly poisonous and has frequently caused mania, blindness, or death after a single indulgence.

\section{The Effects of Alcohol on the Tissues and Vital Processes of the Human Body}

On the Cells.-The human body, like other complex living organisms, is made up of units which we term cells. The 
substance composing the cells is called protoplasm. Perhaps the most common and characteristic action of alcohol on the body is its effect upon the cells thereof, particularly those of the nervous system. Alcohol is a protoplasmic poison, in that it inhibits the activity of the individual cell, especially by interfering with its capacity for taking up oxygen-what may be called the "breathing function" of the cell. Changes in nerve-cells may be recognized after a single indulgence, though such changes disappear rapidly and completely if no more alcohol be taken. Continued overuse results in chronic degeneration of nerve-cells, with an increase in the intercellular connective tissue.

On the Nervous System.-Alcohol exerts a specific action on nerve-centers. The special affinity possessed by the nervous system for this drug is shown by the fact that when all traces of its use have disappeared elsewhere, it can still be detected in the cerebrospinal fluid. Curiously enough, the highest and last-formed faculties of the brain-namely, the consciousness of right and wrong, ethical conceptions of duty and responsibility, reasoning power, memory, judgment, self-control, will, and the sense of proportion-are the first to feel the narcotic action of the drug. While this is occurring the individual is apt to be deceived into thinking that all the above qualities are quickened; that he is witty and giving pleasure to others by his fluent conversation; that he is putting forth great strength; that all is going well. Such drug deception is similar to that which occurs with other narcotics, as chloroform and opium.

While it is true that there is a primary increase of mental 
activity, this is more than counterbalanced by the fact that all reactions requiring nicety of judgment are dulled, even by small amounts of alcohol. This increase is soon followed by a lowering in output as well as in quality of intellectual work, the early excitation giving place to nervous depression and weakness.

Continued overindulgence frequently produces mental aberrations. A careful observer (Hirsch'l) has estimated that nearly 21 per cent. of lunatics suffer from alcoholic insanity.

Coming down the scale of nervous functions, we find that chronic alcoholism tends to produce disease in the mechanism presiding over voluntary movements. Such disease may be entirely or principally manifested either in the brain cortex (which originates the nervous impulse), in the cerebellum (where the mechanism of muscular co-ordination resides), in the spinal cord (which transmits and relays the impulse), or in the terminal nerves carrying that impulse to the muscles themselves.

On the Circulatory System.-The circulatory system comprises the heart, the blood-vessels, and the blood, all of which may be injuriously affected by habitual alcoholic indulgence.

Heart.-There is a marked difference of opinion among investigators as to whether alcohol stimulates the heart. Those who have most recently studied this phase of the subject find it is not a true circulatory stimulant, and that moderate or large doses, by acting directly on the heart muscle, cause weakening and a tendency to dilatation of that 
organ. A brief rise of the pressure within the blood-vessels does, however, occur and the pulse feels fuller and stronger. The capillaries on the surface of the body are dilated, thus giving a sensation of warmth and causing flushing of the face. As radiation of heat from the skin is increased, however, the temperature of the body is actually lowered. In a debauch such lowering may amount to several degrees, which explains why drunken men are so prone to pneumonia and freezing. Long-continued use of spirits tends to infiltration and degeneration of the heart muscle. Beer drinkers acquire a characteristic cardiac enlargement due to the deposition of quantities of fat.

The effect of continued use of alcohol upon the bloodvessels is that of a chronic irritant in the circulating medium; stiffness and loss of elasticity in the arteries, with dilatation of the veins, results. Such vessels are liable to rupture under the strain, and this tendency is especially noticeable in the minute arteries of the brain, producing the condition known as apoplexy. As for the blood itself, alcohol appears to narcotize the white cells, diminishing their activity; to interfere with the most important function of the red cells, that is, their oxygen-yielding capacity; and to impair the bactericidal power of the serum.

On the Digestive System.-Small amounts, taken before a meal, increase the flow of gastric juice, but diminish the normal movements of the stomach. Unless employed in high dilutions alcohol exerts a decidedly irritant effect upon the stomach. Dyspepsia, catarrh, and gastritis due to this substance are quite common, the character of these condi- 
tions - whether mild or severe, acute or chronic-depending upon the quantity and the concentration of the ingested irritant and the duration of the overindulgence. But it is upon the liver, of all the digestive organs, that alcohol exerts its most marked and characteristic action. Here we find the condition known as "gin-drinker's" or "hob-nailed" liver, the latter term being well descriptive of the external appearance of the organ. As with the heart, beer is more likely to cause hepatic fatty degeneration and infiltration than cirrhosis.

On the Kidneys. - It is the function of the kidneys to take from the body a large part of the waste materials engendered by the activity thereof. Anything that interferes with their work will in time cause retention of poisonous waste products within the body, to the detriment of the entire economy. Alcohol, persistently taken, has such an effect upon the kidneys and is frequently responsible for the pathologic changes included under the name of chronic Bright's disease. The process is commonly a hardening, as in many other parts of the body.

On the Visual Apparatus. - Steady drinking is not infrequently responsible for a serious impairment of vision and even blindness, due to degeneration of the optic nerve.

On the Generative Function.-Alcohol increases sexual desire and, by destroying natural caution, is indirectly responsible for a great amount of venereal disease. Children of hard drinkers are peculiarly prone to be born weakminded, epileptic, and physically feeble.

General Effects.-Recent investigators are very generally 
agreed that the continued use of alcohol produces a diminution of bodily vitality and of resisting power to disease. Experimental work and clinical experience coincide in this finding. In experiments recently concluded it was found that animals which for a few weeks or months had received amounts of alcohol too small to cause any symptoms of intoxication, succumbed to poison administered in doses so minute as to produce no effect upon other animals which had not received alcohol. The natural resistance of red bloodcorpuscles is lessened, the phagocytic action of white bloodcells is inhibited, and the germ-destroying properties of normal blood-serum are impaired. The oxygen which is carried in combination with the hemoglobin of the red corpuscles is retained in such combination instead of being yielded up to the tissues, while the excretion of waste materials is checked. Thus the defenses of the body are lowered, the liability to disease is intensified, the capacity for recovery lessened. Senile changes are accelerated; the prognosis after injuries or surgical operations is graver and more uncertain; the tendency to obesity and to gouty affections is marked; the mortality in pneumonia, tuberculosis, fevers, and inflammations is much higher.

The advocates of a regular and moderate use of alcohol have based their arguments largely upon its value as a food and as a medicine. Let us, therefore, examine into its merits in these particulars.

Alcohol as a Food.-The question as to the nutritive properties of alcohol, as used by individuals in a state of health, has been debated more earnestly than any other, 
and the range of views is still wide. Such range is contracting, and the advocates of its use in moderate quantities - especially in the medical profession-are lessening yearly. On the one hand, certain physiologists maintain that alcohol can be burned in the body; that it may be a source of heat and energy; and that, like fats and carbohydrates, it acts as a protein-sparer, that is, a preventer of undue waste of this important constituent of the body tissues. In persons accustomed to its use 98 per cent. of moderate doses (not more than 3 tablespoonfuls per day) are consumed in the body. If more than that amount is taken, the excess is excreted, unchanged, by the lungs and kidneys. It is but fair to conclude that such moderate amounts are utilized for the purposes of the body in the manufacture of heat and certain forms of energy. Although alcohol may furnish energy, it is not yet determined whence the body derives such energy - whether from the alcohol itself or from fats or carbohydrates which are metabolized by it. As for the tissue-sparing properties of this substance, it seems certain that these are more apparent than real, the conditions noted being due to its narcotic effect, which, by decreasing activity, diminishes oxidation. It is manifest that it is not a practicable food (comparable with carbohydrates for instance), as it disturbs the metabolism of foods proper and throws waste materials, which are inimical to health, into the circulation.

From the foregoing it may be seen that while the energy produced by alcohol in small quantities may be utilized by the body for its purposes, its beneficial action in this par- 
ticular is but slight and is more than neutralized by undesirable effects produced elsewhere. Such is the conclusion that has been reached by most men who have studied this problem.

Alcohol as a Medicine.-(a) The medicinal qualities of alcohol as an aid to digestion have long been urged. Such use is without the support of clinical or laboratory evidence, however, for while small amounts in dilute solutions (1 to 2 per cent.) increase the flow of gastric juice, the digestive powers of the stomach are rapidly depressed, with increase of alcoholic percentage. The retardation of digestion is commensurate with the two factors - strength of digestive agent and percentage of alcohol; 2 to 3 per cent. is enough to interfere with pancreatic as well as gastric digestion. So, the results of the inquiry into this phase of the question may be stated thus: Strong digestions do not need it and weak ones are disturbed by it.

(b) Alcohol is generally regarded as a stimulant, that is, an agent which produces a temporary increase of vital activity. It has appeared in the foregoing discussion, however, that this substance does not produce a true stimulation. The observed effects are chiefly, if not wholly, due to its narcotic effect on the nerve-centers, lessening the sense of pain, fatigue, or other discomfort. When employed for such purpose, in conditions of exhaustion, in the prostration of severe acute fevers, and in general infections, especially at times when food cannot be administered, it undoubtedly has a certain value. Yet even here its beneficial action is apt to be impaired by its objectionable quali- 
ties; furthermore, there are real stimulants of greater utility and less risk.

(c) It was long thought by the medical profession that alcohol was of great value in tuberculosis. Exact observations and statistics have proved, however, that far more people with this disease have been injured by its use than benefited. In heart disease, surgical shock, and snake-bite-conditions of cardiac and nervous depression in which it was formerly much employed-it is harmful, since, in the large doses necessary for such cases, it is depressant to the circulatory and nervous systems.

(d) An alcoholic drink may at times be useful as a restorative in fatigue following hard labor. It is useless in combating the effects of exposure to cold. If employed before or during work (physical or intellectual) it usually lowers the output of such work, both as to quantity and quality. It will enable a brief muscular spurt to be made, but will not give sustained power. On the contrary, its use is soon followed by a reduction of energy below the normal.

Summary and Discussion with Regard to the Use of Alcohol as a Beverage

The effects of alcohol, useful and deleterious, as set forth in the preceding pages, may be summarized as follows:

\begin{tabular}{l|l|l}
\hline & For. & \multicolumn{1}{c}{ Agarsst. } \\
\hline $\begin{array}{l}\text { Cells of body. } \\
\text { (a) Cells. }\end{array}$ & $\begin{array}{l}\text { Diminishes activity. } \\
\text { Is a poison to all cells; } \\
\text { possesses a special and in- } \\
\text { jurious affinity for nerve- } \\
\text { cells. }\end{array}$ \\
\hline
\end{tabular}




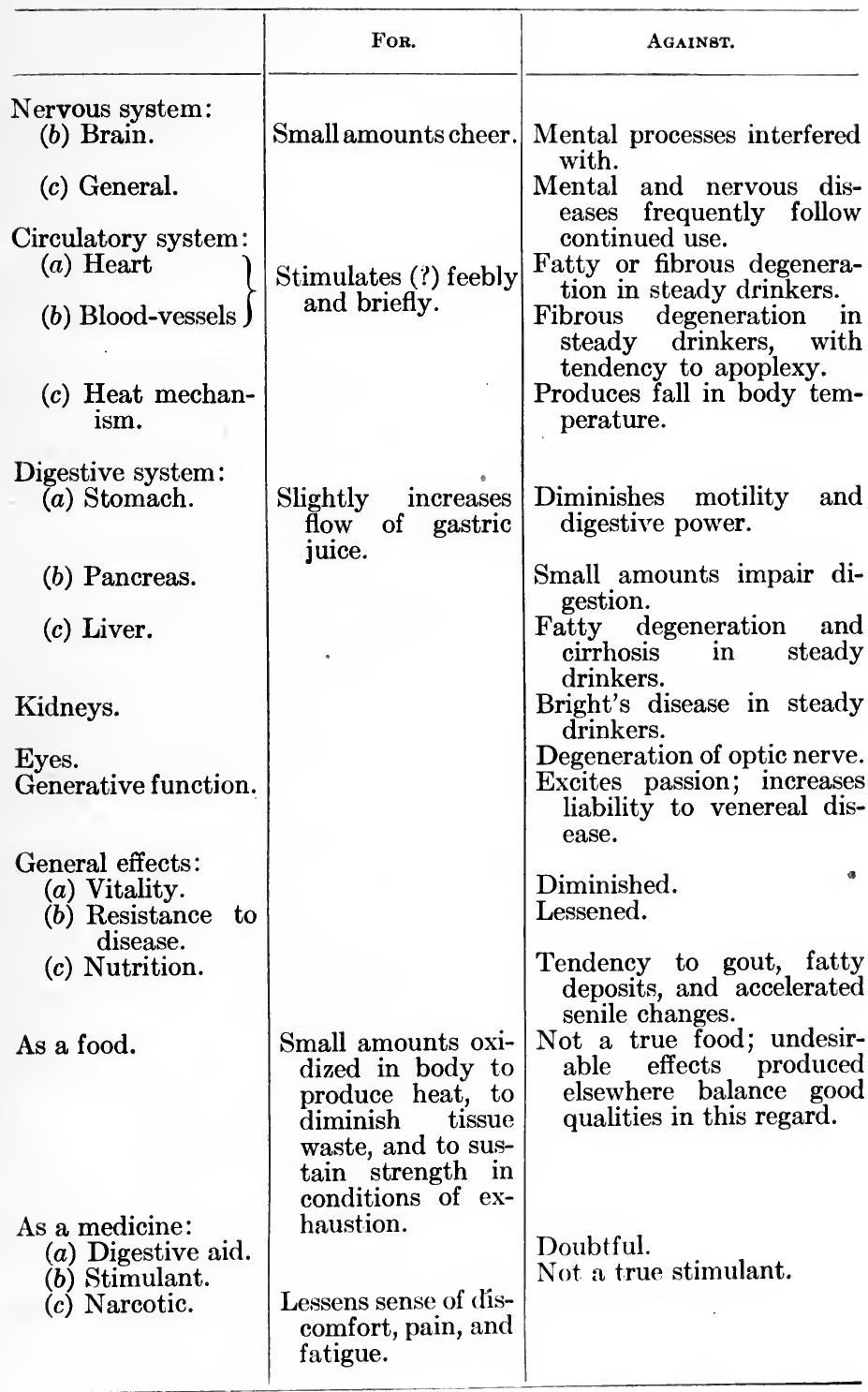


The foregoing summary indicates how difficult it is to make a favorable showing for alcohol. As a stimulant it is uncertain and risky, while there are much richer available sources of food.

Poisonous Effects.-It follows, from the evidence submitted, that alcohol is a narcotic poison-to protoplasm, nervecell, and, in fact, when in sufficient dose, to all the tissues of the body. The term poison is a relative one and means any substance which kills living tissue or impairs its function. So sensitive is the nervous system to the action of alcohol, even when taken in amounts so small that no effects can be recognized by the persons under observation, that it uniformly causes measurable changes in acuteness of the senses, mental processes, muscular power and endurance, and these effects last for many hours. On other tissues and in different persons it acts in varying degree, according to individual susceptibility. Idiosyncrasy plays a most important part. There is no constant and definite relation between the amount of alcohol consumed and its pathologic effects. In one person the brain may be the organ chiefly damaged; in another, the kidney; in a third, the heart. It must not be assumed that all or any of the disease processes mentioned inevitably follow the use of alcohol, since many persons show a marked resistance to its irritant and narcotic effects. On the other hand, such effects are by no means limited to persons recognized as intemperate, but are often encountered in those whose use of alcohol has been regarded as "moderate." It is generally agreed that the mortality from diseases of the heart, blood-vessels, nervous system, kid- 
ney, and liver is much higher in drinking men than in abstainers.

Effect on Longevity.-British life insurance companies that but a generation or so ago regarded "teetotallers" as extra-hazardous risks, now report that the expectation of life is shortened nearly 20 per cent. in habitual users of alcohol. To put this in another form, an English actuary states that of every 100,000 moderate drinkers, 44,000 reach seventy years, and of every 100,000 abstainers, 55,000 attain that age.

Change in Sentiment.-The alteration of policy just mentioned affords a striking example of the change in sentiment upon this vital subject which has occurred within the last few years. An entire agreement of medical opinion has by no means been attained. It is significant, however, that a large percentage of physicians have ceased to employ it in their practice, and that most of those who still utilize it, do so in greatly diminished quantities. As in the evolution of all medical practice, former beliefs concerning the effects of alcohol were founded on experience and observationwhich in this case were very likely helped out by inclination. Thus, results so attained were often wrongly interpreted. Of late years the subject has shared in the general scientific investigation of matters imperfectly understood, and a great advance has been made in our knowledge. Consequently, earlier views as to the usefulness and beneficence of alcoholic drinks have been greatly amended. The majority of scientists who have studied the subject have become opponents of its use. It was not so long ago that the "grog 
ration" was a regular issue in our army, and for years after its abolition we adhered to the custom (borrowed from the British military law) of adjourning courts-martial at 3 P. M., "since no gentleman was expected to be sober after that hour." At the present time the use of alcohol by officers is steadily lessening, and the general sentiment is strongly adverse to those who at any time show its effects.

Moderation.-Assuming, for the sake of argument, that the habitual and moderate ingestion of alcohol is in some sort beneficial to the body, it is now pertinent to inquire if there is such a thing as moderation in the use of this substance. The term moderation is misleading and hard to define. What is moderate for one is immoderate for another. A century ago our "3-bottle" ancestors were considered to be moderate drinkers. Now less than 1 ounce is found to be harmful to many. Physiologically, a moderate amount of alcohol may be defined as that quantity which may be completely burnt up in the body. Scientific investigation has shown that such quantity, for the average individual, does not exceed $1 \frac{1}{2}$ ounces per day, and that oxidation is then accomplished only when the alcohol is taken in small, highly diluted doses. If, therefore, there $i s$ a moderate permissible quantity, it is at least certain that this is represented by 1 to 2 glasses of wine or a pint of beer in twenty-four hours. This is best taken at meals and especially with the last meal of the day.

Formation of the Habit.-Since the dawn of history men have felt a desire for some agent which would widen the range of emotional life; something to heighten their pleasures 
or to dull their miseries. This need has been supplied by alcohol, opium, hashish, and certain other narcotics. The widespread use of alcohol is due to its effect in this direction, together with its recognized properties as an aid to the social side of life. The habit of alcoholic indulgence is easily formed, since many factors besides those just mentioned are contributory. Heredity, an unstable nervous system, force of example, fear of ridicule, environment, mental strain, idleness, fatigue, a craving for excitement, are some of these factors. When taken as a daily drink, alcohol causes sensations and effects which in time are imagined to be a necessary part of life. The stomach, for instance, becomes dependent upon the regular dose and disinclined to work without it.

Military Considerations.-Opinion among military experts all over the world is now general to the effect that the use of alcohol results in much inefficiency. It is well understood by all who control large bodies of men that alcohol and effective work are incompatible. Abundant liquor means a full guard-house and many court-martial cases. In the matter of target shooting, careful experiments conducted in Sweden showed an average of 40 per cent. fewer hits by marksmen after one drink of brandy. Since alcohol markedly interferes with the mental processes, it is plain that decisions in military crises are apt to be faulty. Alcoholism and venereal disease are closely allied, and the admission rates for both of these conditions are higher in the United States Army than in any other.

There is one consideration, however, which at present 
qualifies the objections to the use of alcohol as a beverage in our service. Many men enter the army who in civil life have accustomed themselves to its use. Moreover, saloon men take advantage of the close alliance which exists between gambling, venery, and alcoholism. Such being the case, the "canteen" feature of the post exchange has proved valuable by enabling the soldier to obtain drinks having a small alcoholic content, at home and free from the temptations of the saloon. The canteen is thus the friend of decency and . of discipline.

Solution of the Liquor Problem.-Against the general misuse of alcohol, legislative measures-prohibition, local option, high license, state dispensaries, and the like-have proved ineffective. The solution of the liquor problem rests in the gradual education of the public as to the harmful effects following the use of alcohol.

Conclusions.-Under normal physical conditions alcohol is never necessary and is usually undesirable. It does not give power nor capacity. It does not prevent fatigue nor ward off the effects of cold. It interferes with the higher mental faculties and is thus responsible for many errors and accidents. It lessens the sense of proportion, responsibility, and restraining impulses, and leads to the formation of the habit, with resultant evils to the individual and to society.

\section{Nature and Effects of Narcotics Other than Alcohol}

Drugs used habitually for their special effect upon the nervous system are employed for one of two purposes: first, to produce a general sense of well-being; second, to 
allay a discomfort. Some of the substances here discussed (as alcohol, opium, cocain) are used at times for either of these effects. Others (as coffee, tobacco, chloral) fulfil but one of these conditions.

(a) Opium and its Derivatives.-Nature--Opium is the dried juice obtained by incising the unripe seed capsules of the white poppy; commercially it occurs in brownish, irregular lumps. It has many derivatives, all of which, broadly speaking, act upon the body similarly to the crude drug; chief of these is the alkaloid morphin; others are codein and heroin, which sometimes replace morphin in the formation of the habit.

Effects.-Opium is a narcotic poison, whose final action is depressant to the tissues and more especially to the nervous system. In many persons the drug, while a true sedative, relieving pain and discomfort, may at the same time produce a temporary stimulant effect, conferring a feeling of comfort and of increased mental and physical vigor. It is the association of these results which constitutes its attractiveness and often leads to the formation of the habit. Later, the chronic user takes the drug less for the effects cited than for the relief of the craving, which is described as "a horrible sensation."

Habit.-Opium is taken in various ways by its habitués. The crude drug is inhaled by smoking; its preparations may be swallowed; while morphin is most often injected beneath the skin by means of a hypodermic syringe. Its victims become pale, irritable, unsociable, unreliable, and mentally and physically depressed. They have, however, following 
a fresh dose, periods of exaltation during which they seem normal or even excited.

Craving.-This drug, perhaps more than any other, has the property of creating a craving and leading to the formation of a habit which imperiously dominates the will. The course and termination of such a case is typical. The victim requires increasingly larger doses to solace the craving. Distressing functional disturbances occur, as palpitation of the heart, oppressed breathing, colic, insomnia or nightmares, with such mental aberrations as irresolution, melancholy, and perversion of the moral sense.

Overdose.-The characteristic symptoms of an overdose of an opiate are contracted pupils and a rate of breathing much below the normal.

Alcohol and Opium.-A comparison between the general effects of opium and alcohol discloses striking differences. Opiumism is a solitary habit; alcoholism, a convivial one. Opium does not usually produce tissue degeneration, while alcohol causes extensive pathologic changes. The one quiets the passions, the other inflames them. Habitués of the first are not excited to crime by its use as those of the second often are, although one craving the drug may resort to any means, however desperate, to obtain it.

The use of this substance is increasing rapidly among our people and importations far exceed the therapeutic needs. The recent enforcement of the Food and Drugs Law, requiring that the ingredients of nostrums be given on the label, disclosed the fact that cough and soothing syrups generally contained an opiate. These have been responsible 
for the formation of the habit in many innocent persons, including infants.

(b) Cocain.-Nature.-Cocain is an alkaloid obtained from the dried leaves of a South American plant, the erythroxylon coca. When used in susceptible situations, it is a local anesthetic of marked power. Absorbed into the blood in sufficient dose, it is a narcotic poison, which, like those previously discussed, has a special effect upon the nervous system and tends to the formation of a habit. Taken at first to relieve pain or discomfort, the pleasure derived from it persuades its victim to continue its use.

Effects.-The main effect for which the drug is taken is a sense of exhilaration and refreshment. A buoyant feeling replaces weariness; the subject is active, talks freely, and enjoys everything. Later, hallucinations and delusions appear; voices are heard and vague fears are felt.

Habit.-The habit produces a train of ill effects which supervene more promptly than with alcohol and opium addictions. The dose tends to increase rapidly. The cocainist becomes a pallid, nervous, emaciated dyspeptic, and suffers also from loss of memory, impaired quality of work, and diminished ethical sense. Insanity is a common sequel. Cocainism, like the opium habit, is a solitary vice. A peculiarity of its habitués is that they will take any other narcotic to replace the cocain, if that is not obtainable, or to conceal its effects. The drug is most commonly taken by snuffing the powder or a solution up the nostrils. It forms a part of many catarrh snuffs, which, therefore, should be avoided unless properly prescribed. 
(c) Tobacco.-Nature.-Tobacco depends for its influence on the body upon the contained nicotin. This is an exceedingly poisonous alkaloid which is found in small quantities in the leaf of the plant.

The use of tobacco is more widely spread than that of any other narcotic. The "divine weed" has many devotees who claim it possesses no unwholesome qualities. By others it is denounced as wholly pernicious. The truth, no doubt, lies between these extremes.

Effects.-Tobacco is a narcotic, whose use, like that of alcohol, opium, and cocain, induces a habit. It exerts a depressant influence upon the nervous system and the circulation, and its continued employment by susceptible individuals causes throat irritation, nervous dyspepsia, cardiac palpitation, shortness of breath, disturbed sleep, and failure of vision.

It seems well established that the habit retards the growth of adolescents; also much evidence has accumulated to show that its use by college students is closely associated with idleness, lack of ambition, and low scholarship. There is no doubt that its employment by youths who have not reached maturity is distinctly prejudicial.

It must be admitted, on the other hand, that in many individuals its use is followed by certain benefits; these are mental calm, dulling of physical discomfort, a feeling of contentment, and the ability to concentrate thought. The comfort derived from a pipe, in the trenches or during severe weather, is frequently noted in the military service. Unlike the drugs heretofore discussed, tobacco, 
while it may do physical damage, does not disturb the moral sense.

IIabit.-Despite its occasional good qualities, the fact remains that tobacco is a poison whose tendency is to interfere with certain normal functions. When the habit is confirmed, many become as dependent upon it to steady their nerves as alcohol or opium habitués are upon their favorite drugs. It is apparent, therefore, that even the moderate use of tobacco is not without possibilities of evil, and that it cannot be indulged in habitually except at some risk. Cigarette smoking as commonly practised is perhaps most likely to be prejudicial to health because of two factors; these are: first, inhalation into the lungs (where absorption of the nicotin is most complete); second, the cheapness and availability of the cigarette tend to immoderate use.

(d) Other Narcotic Drugs.-There are certain other narcotic drugs whose use sometimes degenerates into a vicious habit. Since such habit is not very common in this country, these drugs will be mentioned merely. The more important ones fall under two classes in accordance with their predominant physiologic action. Class I comprises sleep-producers, as chloral, ether, chloroform, and Indian hemp (hashish). Those of Class II are pain-dispellers, of which the coal-tar products, antipyrin, phenacetin, aspirin, and acetanilid, are the most common. The drugs of the latter class have the additional disadvantage of being dangerous cardiac depressants. They are usually found in the "headache powders" so widely advertised and extensively used. Such remedies 
should, therefore, be viewed with suspicion and taken with caution.

(e) Caffein.-'The discussion of this subject would not be complete without the consideration of another class of substances, namely, those dependent for their activity upon the alkaloid caffein. Caffein is not a true narcotic, and tea and coffee, the principal substances which contain it, are stimulating in their effects. They have, however, a certain tendency to habit formation and to the production of functional disturbances of the nervous, circulatory, and digestive systems. Intemperance in their use causes nervousness, insomnia, depression, indigestion, and palpitations. On the other hand, when properly prepared and used they are refreshing, cheering, and stimulating. They dull the sensation of hunger and assist the user to withstand cold and fatigue. They are, therefore, of decided military value. 


\section{GLOSSARY}

Abscess. A collection of pus.

Adolescent. A youth prior to maturity.

Alkaloid. An active medicinal principle of vegetable origin having the chemical properties of a base.

Alluvial. Relating to soil deposits made by flowing water.

Anesthetic. A drug that produces loss of feeling or sensation.

Antibodies. Substances in the body which are antagonistic to disease.

Antidotal. Counteracting poison.

Antitoxin. A substance prepared from the blood of one animal for injection into another to resist some infectious disease. Literal meaning, Against poison.

Apoplexy. The disease conditions produced by the rupture of a blood-vessel, commonly in the brain.

Bactericidal. Destructive to bacteria.

Bacteriology. The science which treats of bacteria.

Bright's disease. Inflammation of the kidney.

Cadaveric. Pertaining to a dead body.

Capillaries. The smallest blood-vessels.

Carbohydrates. Sugars and starches used as foods.

Cardiac. Pertaining to the heart.

Catarrh. Inflammation of a mucous membrane, with free discharge.

Cell. One of the minute elementary structures which combine to form a living body.

Cerebellum. That division of the brain which presides over the co-ordination of muscular action.

Cerebrospinal. Pertaining to the brain and spinal cord.

Circulating medium. The blood.

Cirrhosis. Chronic inflammation of, with increase in, the fibrous framework of an organ.

Cirrhotic. Pertaining to cirrhosis.

Clinical. Pertaining to the observation of the sick.

Colon. The large intestine.

Condiment. Something used to give relish to food. 
Congestion. An excess of blood in a part.

Connective tissue. The fibrous matcrial which binds together the various structures of the body.

Constitutional. Affecting the whole body.

Co-ordination. The harmonious working together of different parts.

Corpuscles. Small cells which form part of the blood.

Cortex. The outer layers of an organ.

Defecation. Evacuation of the bowels.

Degeneration. Deterioration of a tissue.

Dehydrate. To deprive of water.

Delusion. A false mental impression as to things perceived by the senses.

Depressant. A drug which reduces vital energies.

Desiccation. Drying.

Digestive system. The organs of food digestion, made up of the alimentary canal (mouth to anus), liver, and pancreas.

Economy. A name for the human body considered as a whole.

Epidemic. Attacking many people at one time.

Excrement. The natural discharges of the body, especially feces and urine.

Excrementitious. Pertaining to excrement.

Excreta. Same as Excrement.

Excretion. The discharge of waste matter from the body, or the material so discharged.

Fecal. Pertaining to feces.

Feces. The discharges from the bowel.

Ferment. A substance which produces fermentation.

Flexor. A muscle which bends a joint.

Fumigation. The production of smoke or vapor for disinfection or for stupefying insects.

Functional. Affecting the functions of the body.

Gastric. Pertaining to the stomach.

Gastritis. Inflammation of the stomach.

Genitals. The sexual organs.

Germ. Any microscopic form of life.

Germ plasm. The reproductive substance of living organisms.

Germicide. A germ killer.

Glycogen. A carbohydrate found in the liver and muscles.

Groin. The depression between the abdomen and the thigh. 
Hallucination. The fancied perception of objects or sensations which have no reality.

Hemoglobin. The red coloring-matter of the blood.

Hirsute. Hairy.

Hypodermic. Under the skin.

Idiosyncrasy. A peculiarity by which one person differs from others.

Illicit. Unlawful.

Immunity. Security against any particular disease.

Incubation period. Time elapsing between exposure to a disease and its manifestation.

Infection. The communication of disease from one person to another.

Infectious. Liable to be communicated by infection.

Infiltration. The accumulation, in a tissue, of substances not normal to it.

Infusorial earth. Composed of the shells of microscopic marine animals.

Ingestion. The act of taking food, medicines, etc., into the body.

Inhibit. To check or suppress.

Intercellular. Among or between cells.

Kidneys. The two organs which excrete the urine.

Koumiss. A fermented drink prepared from milk.

Larva. The worm-like stage in the development of an insect from the egg.

Larvacide. Larva killer.

Lesion. Any change in a part of the body resulting from disease or injury.

Local. Restricted to one spot.

Louver. A ventilating device.

Malt. Grain (usually barley) artificially germinated.

Meningitis. Inflammation of the coverings of the brain or spinal cord.

Metabolism. The power possessed by cells to use up and to renew the matter composing the body.

Metabolize. To transform by means of metabolism.

Microbe. Any microscopic form of life.

Mucous membrane. The continuation of the skin lining those cavities of the body which communicate with the external air. 
Narcotic. Any drug which produces a condition of partial unconsciousness.

Narcotize. To put under the influence of a nareotic.

Nervous system. All collections of nerve tissue (brain, spinal cord, sympathetic system, and nerves) considered as a whole.

Nostrum. A quack, patent, or secret remedy.

Organ. Any part of the body having a special function.

Organic. Pertaining to substances derived from living organisms.

Organism. A name applied to the assemblage of organs constituting a living being.

Ovate. Egg shaped.

Ovum. An egg; in this case, the female reproductive cell of the human species.

Pancreas. One of the digestive organs.

Pancreatic. Pertaining to the pancreas.

Pathologic. Referring to the phenomena of disease.

Pelvic. Pertaining to the lower part of the trunk of the human body, which is known as the pelvis.

Pernicious. Of very injurious or deadly type.

Phagocytic. Pertaining to certain cells which have the power to destroy germs or other cells.

Physiologic. Pertaining to the functions of the body in health.

Pneumonic. Pertaining to the lungs.

Potable. Fit to drink.

Prognosis. The prospect as to recovery from a disease.

Prophylactic. A remedy or measure which tends to prevent disease.

Prophylaxis. The prevention of disease.

Proteins. (a) Nitrogenous compounds which form a large part of the body tissues; $(b)$ a class of foods.

Protoplasm. The essential constituent of living cells.

Pulmonary. Pertaining to the lungs.

Purulent. Containing pus.

Pus. The creamy looking liquid resulting from suppuration.

Putrescible. Capable of offensive decomposition.

Pyrethrum. Certain powdered plants used to destroy insects.

Salivary glands. The organs in the mouth which manufacture the saliva from the blood.

Serous. Pertaining to the lining of those cavities of the body which are closed and do not communicate with the external air. 
Serum. (a) The liquid part of the blood; $(b)$ specially prepared blood-serum of animals, used in the treatment of disease.

Specific action. Exerting a peculiar influence over any special part of the body.

Sputum. The spittle ejected (expectorated) from the mouth.

Suppuration. Advanced inflammation, resulting in the formation of pus.

System. A set of parts or organs which unite in a common function.

Tabloid. Medicines or other substances compressed in the form of a lozenge.

Therapeutic. Pertaining to the treatment of disease.

Thermic rays. The heat rays of the sun.

Thorax. The chest.

Tissue. Any collection of similar cells united to form some structural part of the body.

Toxic. Pertaining to poisons.

Toxicologic. Pertaining to the study of poisons.

Toxin. A poison produced by the action of disease germs.

Ulceration. The formation of an open sore.

Urea. A waste product of the body found in the urine.

Vaccine. Any material used for preventive inoculation (as antityphoid vacciné).

Vasomotor. Presiding over the contraction and expansion of bloodvessels.

Venery. Sexual intercourse.

Virus. Any animal poison. 



\section{INDEX}

Abdominal congestion in tropics, 239

covering of wool in tropics, 241

Absinthe, 261

Acclimatization, tropical, 238

Acetanilid habit, 281

Ague, 74

Air space, 166

Alcohol, 35, 258

and opium, comparison, 278

apoplexy from, 265

as aid to digestion, 269

as food, 267

as medicine, 269

as narcotic, 272

as restorative, 270

as stimulant, 269

blindness from, 266

Bright's disease from, 266

change in sentiment in regard to, 273

classification, 259

conclusions in regard to, 276

denatured, 262

effects, general, 266

on blood, 265

on blood-vessels, 265

on brain, 263

on cells, 262

on circulatory system, .264

on digestive system, 265, 269

on eyes, 266

on gastric juice, 265

on generative function, 266
Alcohol, effects on heart, 264 on kidneys, 266

on liver, 266

on longevity, 273

on nervous system, 263

on resistance to disease, 267

on stomach, 265

on tissues and vital processes, 262

on visual apparatus, 266

on vitality, 267

poisonous, 272

ethyl, 258

formation of habit, 274

general effects, 266

habit, formation, 274

heat mechanism, 265

in aortic service, 248

in heart disease, 270

in patent medicines, 262

in shock, 270

in snake-bite, 270

in surgical shock, 270

in tuberculosis, 270

methyl, 262

military considerations, 275

moderate use, 274

nature, 258

nutritive properties, 267

physical properties, 259

poisonous effects, 272

problem, solution, 276

strength, 258

wood, 262 
Alcoholic excess, 86

Ale, 259

Ameba, 72

Amebic dysentery, 72

American Army, antityphoid vaccination in, 69

Anatomy, 32

Animal starch, 142

Anopheles mosquitoes, 74

Antibodies, 68

Antimeningitic serum, 80

Antipyrin habit, 281

Antiseptic, 62

Antitoxin, diphtheria, 81

Antityphoid vaccination, 67 . See also Vaccination, antityphoid.

Apoplexy from alcohol, 265

Aretic ration, 159

Aretic service, 246

diseases, 246,247

disposal of refuse, 249

effects, 246

personal hygiene, 249

Arteries, 38

Aspirin habit, 281

Athletics, 53

BaCILlary dysentery, 72

Bacillus, 60

comma, 83

of dysentery, 61,72

of influenza, 79

tubercle, 77

typhoid, 65

Bacon, 147

Bacteria, 60

in ice, 137

in water, 125

destruction, 135

removal, 130

Bakery, 176

Baking of bread, 148

Balanced ration, 143
Bandoleer, 117

Barracks, construction, 162

exposure, 162

inspection, 177

messing in, 174

supervision, 176

plumbing of, 173

sanitation of, 172

Baths, 32

cold, 32

hot, 32

in camp, 193, 194

in tropics, 238

shower-, 167

Battlefields, 199

care of wounded, 200

casualties, 203

disposal of dead, 204

evacuation of sick, 199

identification of dead, 204

lines of sanitary aid, 200

sanitary preparations, 199

troops, 200

water-supply, 202

Bayonet, 117

Beans, 149

Bedbugs on transports, 180

Bedding, care of, 172

Beds, care of, 172

Beef, 145

canned, 147

refrigeration of, 146

Beer, 259

Belt, cartridge, 116

Benedictine, 261

Beriberi, 84, 159

Beverages on marches, 184

Biliousness, 37

Billeting, 187

Biologic disposal of sewage, 212

Bites of insects, 86

Biting flies, 87

Bivouac, 187 
Black death, 83

Blanket, 116 roll, 115

Blindness from alcohol, 266 snow-, 247

Blistered feet, 87 prevention, 88 treatment, 89

Blood, effects of alcohol on, 265

Blood-vessels, effect of, alcohol on, 265

Blouse, 95

Blues, fits of, 39

Bodily activity, necessity for, 41 processes, 139

Boer War, typhoid fever in, 63

Boiling of meats, 152 of water, 137

Bowels, care of, 37

Box seats for sinks, 221

Brain, effects of alcohol on, 263

Brandy, 260

Bread, 148

baking of, 148

care of, 176

field, 156

hard, 155

Breakbone fever, 82

Breathing functions of cells, 263

Breathlessness, 57

Breeches, 98

Bright's disease from alcohol, 266

British Army, antityphoid vaccination in, 68

Broiling of meats, 152

Broths, cooking of, 152

Buildings, sanitation of, 161

Bunks, care of, 172

Burial of dead, 204

Cafferen habit, 282

Calories, 143

Campaign hat, 95
Camps, 187

bathing, 193, 194

cantonment, 187

care of food, 195

circular pit incinerator, 230

diarrhea, 73

prevention, 73

disposal of excreta, 190, 218

incineration, 218

straddle trench, 225

of garbage, 226

of manure, 229

of rubbish, 230

of sweepings, 230

of urine, 224

of wash water, 233

of waste from taps, 233

of wastes, 190, 218

drainage, 234

drinking-water, 193

equipment and supplies, 189

fixed, 187

garbage cans in, care of, 228

stands in, care of, 228

guards, 189

halt order, 189

ice-box, 195

inspections and responsibility, 197

latrines, 192, 221

laundry water, 193, 194

messing in, 194

peddlers, 195

personal hygiene, 197

pits for liquid garbage in, 228

police, 196

preliminary inspection, 188

preparation, 188

sanitation of, 187

sinks, 189, 192, 221

sites, 188

sod crematory, 231

standing, 188 
Camps, sutlers, 195

temporary, 187

types, 187

watering animals, 193

water-supply, 193

Canned beef, 147 vegetables, 156

Cans, garbage, in camps, care, 228 in garrison, 215 urinal, 224

Canteen, 276 and cup, 118

Cantonments, 187

Caps, 94

Carbohydrates, 141 functions, 142

Carbon, 140 dioxid, 37

Care of troops, 17

Carriers, typhoid, 65, 66

Cartridge belt, 116

Cavalry equipment, 119

Cells, breathing functions, 263 definition, 139 effects of alcohol on, 262 properties, 139

Cerebrospinal fever, 80

Cesspools for excreta, 211

Chancre, hard, 254 soft, 256

Chancroid, 256

Changres fever, 74

Chartreuse, 261

Chechawker knee, 247

Cheese, 145

Chemical composition of body, 140 purification of water in field, 131

Chest measurement of recruits, 28

Chiggers, 86

Chilblains, 246

Chill, avoidance of, 58

Chills and fever, 74

Chloral habit, 281
Chlorin gas purification of water by, 129

Chloroform habit, 281

Chocolate, 158

Cholera, 83 in tropics, 244

Circular pit incinerator for camps, 230

Circulatory system, effects of alcohol on, 264

Civil communities, typhoid fever in, 64

War, typhoid fever in, 63

Clap, 255

Cleanliness of surroundings, 39 personal, 32

Climate and diet, 34 cold, 246 effects of, 246

tropical, 235

Climbing, 52

Clothing, 33, 36, 90

color, 92

coolness, 92

cotton, 91

in aretic service, 248

in tropics, 240

khaki, 92, 93

merino, 91

military, 93

olive drab, 92,93

paper, 92

purposes, 90

requirements, 90

source, 90

warmth, 92

waterproofing, 92

wool, 90

Coats, Mackinaw, 96

military, 95

Mackinaw, 96

overcoat, 96

Cocain, 279 
Cocain, effects, 279 habit, 279 nature, 279

Codein, 277

Coffee, 150 habit, 282

Cold bath, 32 climate, 246 effects, 246

Colds, 37 common, 79 catching, 79

Comma bacillus, 83

Concentrated foods, 157

Congestion, abdominal, in tropics, 239

Conscripts, 25, 26

Constipation, 37

Consumption, 77

Contact filtration for sewage disposal, 213

Cooking in field, 156

of broths, 152

of meats, 152

of soups, 152

of vegetables, 153

temperature in, 153

Copper sulphate, purification of water by addition of, 128

Cordials, 261

Cotton clothing, 91

Coughing in tuberculosis, 77

Crematory, sod, for camps, 231

Crude oil, 191

Culex mosquitoes, 74

Cuspidors, care of, 172

Darnall filter, 131

for water purification in field, 131

Dead, disposal of, 204 identification of, 204

Death-rate, 19
Denatured alcohol, 262

Dengue, 82

Depots, recruit, 29

Dhobie itch in tropics, 244

Diarrhea, camp, 73 prevention of, 73

Diet, 34

and climate, 34

faulty, diseases from, 159

in arctic service, 247

in general, 144

in tropics, 239

Dietary don'ts, 35

Digestion, alcohol as aid to, 269

Digestive system, effects of alcohol on, 265,269

Diphtheria, 81 antitoxin, 81

Diseases due to infected food, 159 from faulty diet, 159 in arctic service, 246,247 in tropics, 242 military failure due to, 18 prevention of, 20 preventable, 18

Disinfectant, 62

Disinfection in field, apparatus for, 198

Distilled liquors, 260

Double time marches, 51

Drainage, camp, 234 in garrison, 213

Drawers, 101

Drinking, excess in, 35

Drinking-water in tropics, 240

Dry earth water-closet, 207

Dump for garrison, 218

Dust in transmission of typhoid fever, 67

Dusting, 173

Dysentery, 72 amebic, 72

bacillary, 72 
Dysentery bacillus, 61, 72 in tropies, 243

prevention of, 73

Eating, excess in, 35

Education, hygienic, 42 physical, 41

Eggs, 145

Emergeney rations, 155

Energy, potential, of food, 143

Enterie fever, 63. See also $T y$ phoid fever.

Entertainments, 39

Environment, 42

Epidemies, typhoid, 65

Equipage, 108. See also Equipment.

Equipment, 108 articles, 108

cavalry, 119

components, 110

definition, 108

fighting, 114

forms of pack, 111

normal, 113, 114

table of artieles, 109, 110

of weights, 109

weights, 108

Erbswurst, 159

Esprit, 21

Ether habit, 281

Ethyl aleohol, 258

Excess in drinking, 35

in eating, 35

Excreta, disposal of, in camps, 190, 218

incineration, 218

straddle trench, 225

in garrison, 207

eesspools, 211

dry earth system, 207

fire, 210

incineration, 210
Excreta, disposal of, in garrison, privy, 207

Publie Health Service Latrine, 208

sewerage system, 211

Excretory functions, 36

Exereise, 38

effect of, on heart and lungs, 38, 47

in tropics, 242

setting-up, 50

Exhaustion, heat, 85

Eyes, effeets of alcohol on, 266

Farming, sewage, 212

Fatigue, 57

Fats, 141

functions, 142

Feces. See Excreta.

Feet, blistered, 87

prevention of, 88

treatment of, 89

care of, on marches, 185

Fez, 94

Field bread, 156

range, 157

service in tropies, 245

Filter, Darnall, 131

for water purification in field, 131

improvised, for purification of water in field, 134

Ishiji, 132

Filtration, eontact, for sewage disposal, 213

of water, 128

in field, 131

percolating, for sewage disposal, 213

First-aid paeket, 118

Flax fiber, 91

Flea, rat, in transmission of plague, 83 
Fleas, 87

Fletcherizing, 34

Flexion step, 182

Flies, biting, 87

destruction of, 170, 174

in transmission of dysentery, 72 of typhoid fever, 66,67

propagation of, 170

trap for, 175

Floor space, 166

Floors, wooden, care of, 172

Flour, 148 care of, 176

Food, 34, 139

alcohol as, 267

calorie, 143

care of, in camp, 195

classes, 141

concentrated, 157

definition, 139

functions, 142

in arctic service, 247

infected, diseases due to, 159

materials accessory to, 141

nitrogenous, 140

potential energy, 143

preparation, 139

Forbes' sterilizer, 135, 136

Forced march, 184

Franco-Prussian War, typhoid fever in, 63

Freezing, 246

Frost-bite, 246

Fruits, 150

Frying of meats, 152

Functions of medical officers, 18

Garbage cans in camps, care, 228 in garrison, 215

covers in garrison, 215

disposal of, in camps, 226

in garrison, 213

in marching commands, 229
Garbage incinerator, 213, 214, 215 liquid, in camps, pits for, 228 stands in camps, care, 228

in garrison, 215

Garrison, disposal of excreta, 207 cesspools, 211

dry earth system, 207

fire, 210

incineration, 210

privy, 207

Public Health Service Latrine, 208

sewerage system, 211

of garbage, 213

of liquid house wastes, 216

of manure, 216, 217

of rubbish, 217

of sewage, 212

biologic methods, 212

chemical treatment, 212

contact filtration, 213

discharge into sea or other waters, 212

irrigation, 212

percolating filtration, 213

septic tank, 213

of sweepings, 217

of wastes, 207

separation of components, 214

sewers, 211

drainage, 213

dump, 218

garbage cans, 215

stands, 215

Garters, 102

Gas, chlorin, purification of water by, 129

generator for disinfection in field, 198

Gastric juice, effects of alcohol on, 265

General order No. 66, 30 
Generative function, effects of alcohol on, 266

German Army, antityphoid vaccination in, 68

Germs, 60

Gin, 261

Gin-drinker's liver, 266

Glanders, 160

Glossary, 283

Gloves, 99

Glycogen, 142

Gonococcus, 255

Gonorrhea, 255

transmission of, 256

Grog ration, 273

Guard-house, 176

Gymnastic contests, 53

Gymnastics, applied, 53

HaBIT, acetanilid, 281

alcohol, formation of, 274

antipyrin, 281

aspirin, 281

caffein, 282

chloral, 281

chloroform, 281

cocain, 279

coffee, 282

correct, formation of, 31

ether, 281

hashish, 281

opium, 277

phenacetin, 281

tea, 282

tobacco, 281

Habitations in tropics, 242

Hands in transmission of typhoid fever, 66

washing of, after defecation, 225

Hard bread, 155

chancre, 254

Hardness of water, 124

Harrington, quotation, 59
Harris incinerator, 220

Hashish habit, 281

Hat in tropies, 241

Hats, 94

Havard, (quoted), 252

Haversack, 115 rations, 155

Headache powders, 281

Headgear, 94

in tropics, 241

Health, public, 17

Heart disease, alcohol in, 270 effects of alcohol on, 264 of exercise on, 38,47

Heat, effects of, 85 exhaustion, 85 mechanism of alcohol, 265 prickly in tropics, 244

Heating, 166 direct, 166 direct-indirect, 166 indirect, 166

Heatstroke, 85

Height of recruits, 28

Helmet, 94, 95

Heroin, 277

Hob-nailed liver, 266

Homesickness in tropics, 244

Hookworm disease, 82

Horseflesh as food, 147

Hot bath, 32

Houses in tropies, 242

Hutchinson, 140

Hydrogen, 140

Hygiene, definition of, 17

military, scope of, 17

personal, 31

in arctic, 249

Hygienic education, 42

ICE, bacteria in, 137

Ice-box in camps, 195

Identification of dead, 204 
Identification tag, 204

Immunity, 60 after antityphoid vaccination, 71

Impotence, 36

Improvidence of soldiers, 22

Incineration, 190 of excreta, 210 in camps, 218

Incinerator, circular pit, for camps, 230

for excreta, 210

for garbage, 213, 214, 215

Harris, 220

types of, 190, 191

Incinerators for excreta, types, 219,220

Infected food, diseases due to, 159

Infection, 60

prime source, 62

Influenza, 79

bacillus, 79

Insects, bites of, 86

Inspection of barracks and posts, 177

Intellectual and physical functions, interrelation, 44

Intermittent fever, 74

Intestinal diseases in tropics, 243 parasites in tropics, 244

Intrenching tools, 117

Iron ration, 158

Ishiji filter, 132

Itch, dhobie, in tropics, 244 mites, 34,86

Ivy, poison-, 87

JUMPING, 52

KÉPI, 94

Khaki clothing, 92, 93

Kidneys, care of, 37

effects of alcohol on, 266
Kit bag, surplus, 119

Kitchens, rolling, 157

Knapsack spray pump, 171

Knee, checkhawker, 247

tenderfoot, 247

LARVACIDE, 172

Larvæ of mosquitoes, 74, 75

Latrine orderlies, 225

Public Health Service, 208

Latrines, camp, 192, 221

Laundry in camp, 193, 194

in tropics, 239

Leeches, 86

Leggings, 98

Leprosy, 85

Lice, 34, 86

Life, length of, 19

Lighting, 163

Lime, 191

Line officers, duties of, 20

Linen, clothing, 91

Liqueurs, 261

Liquor problem, solution, 276

Liquors, distilled, 260 malt, 259

Liver, effects of alcohol on, 266 gin-drinker's, 266

hob-nailed, 266

Load, soldier's, 110. See also Pack, soldier's.

Longevity, effect of alcohol on, 273

Lungs, 37

effect of exercise on, 38,47

MaCkinaw coat, 96

Malaria, 74

in tropics, 243

mosquitoes and, 74

pernicious, 74

prevention of, 76

transmission of, 75 
Malt liquors, 259

Manure, disposal of, in camps, 229 in garrison, 216, 217

Marches, 181 aids, 184 beverages, 184 care of feet, 185 days of rest, 185 disposal of excreta, 225 of garbage, 229 double time 51 factors affecting, 183 forced, 184 halts, 182 length, 183 night, 184 order, 176 preparation, 181 principles, 181 quick time, 50 sanitation, 182 sickness, 185 thirst, 184

Marriage of syphilitic, 255

Masturbation, 36

Measles, 79

Meats, 145

boiling of, 152

broiling of, 152

cooking of, 152

extracts, 147

frying of, 152

juices, 147

powders, 147

preserved, 146

refrigeration of, 146

roasting of, 152

stewing of, 152

unusual, 147

Medical officers, functions of, 18

Medicines, patent, alcohol in, 262

Melville, 153

Meningitis, cerebrospinal, 80
Mental condition of recruits, 27 overwork, 39

Merino, 91

Mess, 153 supervision, 154

Messing in barracks, 174 supervision, 176 in camps, 194 on transports, 178

Methyl alcohol, 262

Micrococci, 60

Micro-organisms, 60

Military hygiene, 18

Militia, 25

Milk, 144

Mites, itch, 34, 86

Monsoons, 236

Morphin, 277

Morse-Boulger destructor, 213

Mosquitoes, 87, 171

anopheles, 74

culex, 74

destruction of, 171, 172

larval forms, 74

malaria and, 74

stegomyia, 75

yellow fever and, 82

Mumps, 80

Munson on shoes, 103

Munson's field disinfection apparatus, 197

NARCotics, 258,276

National Guard, 25

Nervous condition of recruits, 27 strain in aretic service, 247 system, effects of alcohol on, 263

Neurasthenia, 39

Nicotin, 280

Night marches, 184

Nitrogen, 140

Nitrogenous foods, 140 
Nostalgia in tropics, 245

Nutritive properties of alcohol, 267

OAK, poison-, 87

Odorless excavator system, 191

Officers, line, duties of, 20 medical, functions of, 18

Oil, crude, 191

Opium, 277

and alcohol, comparison, 278

craving for, 278

effects, 277

habit, 277

nature, 277

overdose, 278

Order No. 66, 30

Orderlies, latrine, 225

Overcoat, 96

Overshirt, olive drab, 100

Overshoes, 107

Overwork, mental, 39

Oxygen, 140

Ozone, purification of water by, 129

PACK, carriage of, 114

carrier, 115

soldier's, 110

articles in, 110

forms of, 111

ideal, 112

transportation for, 114

U. S. A., new model, 112

Packet, first-aid, 118

Pain de guerre, 156

Paper as clothing, 92

Parasites, intestinal, in tropics, 244

Parka, 248

Parotitis, 80

Patent medicines, alcohol in, 262

Pea sausage, 159

Peddlers, 195

Pemmican, 159

Peppermint test of plumbing, 169
Percolating filtration for sewage disposal, 213

Perflation, 163

Pernicious malaria, 74

Personal cleanliness, 32

hygiene, 31

in arctic, 249

Phenacetin habit, 281

Physical education, 41

training, 41

aptitude, 55

condition, 55

facilities, 55

factors to be considered, 55

for military purposes, 45

importance to state, 43

instruction material, 49

methods, 48

military methods, 49

modern tendency, 45

necessity, 41

object, 44

racial attributes to be considered, 48

requirements for military service, 46

time, 55

use of material, 56

Physiology, 32

Pickelhaube, 94

Pits for liquid garbage in camps, 228

privy, 207

Plague, 83

pneumonic, 84

Plasmon, 158

Plumbing of barracks, 173

of posts, 167

peppermint test of, 169

testing of, 169

Pneumonic plague, 84

Poisoning, ptomain-, 160

Poison-ivy, 87 
Poison-oak, 87

Poisonous effects of alcohol, 272

Pole seat for sink, 223

Police, 40, 170

of camp, 189

of transports, 179

Poncho, 97

Porter, 259

Posts, inspection, 177

plumbing of, 167

sanitation of, 161

sites for, 161

Potatoes, 149

Pox, 254

Precipitation of water, 127

Preserved meats, 146

Preventable diseases, 18, 59

Prickly heat in tropics 244

Privy pits, 207

Prophylaxis, results of, 19

Proteins, 141

functions, 142

Protoplasm, 263

Protozoa, 61

Ptomain-poisoning, 160

Public health, 17 service latrine, 208

Puttee, 99

QUARTERs, care of, 172

Quick time marching, 50

Pacial attributes in physical training, 48

Railroad journeys, 186

Rainwater, 123

Range, field, 157

Ration, 143

arctic, 159

balanced, 143

emergency, 155

haversack, 155

iron, 158
Ration, tropical, 159

U. S. A., 153

Rats, breeding of, 170

destruction of, 170

in transmission of plague, 83,84

Reading rooms, 39

Recreation, 39

Recruiting, 23

Recruits, 23

age, 28

character, 27

chest measurement, 28

defects, 26

depots, 29

examination, 26

height, 28

high motives, 24

lowered standards, 24

mental condition, 27

nervous condition, 27

percentage qualified, 23

records, 29

special abilities, 24

vaccination, 30

weight, 28

Red bugs, 86

Reed trough, 191, 220

Reed, Walter, and yellow fever, 82

Refrigeration of meat, 146

Refuse, 206

disposal of, in arctic, 249

Regulars, 25

Regulations, sanitary, enforcement of, 21

Remittent fever, 74

Rest, 39

Rice, 149

polished, 84

undermilled, 84, 159

Rifle, 117

exercises, 52

Roaches, 175

Roasting of meats, 152 
Rolling kitchens, 157

Rubbish, disposal of, in camps, 230 in garrison, 217

Rum, 261

Running, 51

SABRE exercises, 52

Saliva in transmission of typhoid fever, 66

Salts, 143

Salvarsan in syphilis, 255

Sand filtration of water, 128

Sanitary aid stations and lines of evacuation, 201

regulations, enforcement of, 21

rules on transports, 179

troops, 17, 200

Sanitation, definition of, 17

of barracks, 172

of battlefields, 199

of camps, 187

of marches, 181

of posts, 161

of transports, 177

Sausage, pea, 159

Scarlatina, 81

Scarlet fever, 81

Scurvy, 84, 159

in arctic service, 247

Seasickness on transports, 179

Seats for sinks, box, 221 pole, 223

Sedimentation of water, 127

Septic tank for sewage disposal, 213

Serum, antimeningitic, 80

Setting-up exercises, 50

Sewage, disposal of, in garrison, 212

biologic methods, 212

chemical treatment, 212

contact filtration, 213

discharge into sea or other waters, 212

irrigation, 212
Sewage, disposal of, in garrison, percolating filtration, 213 septic tank, 213

farming, 212

pollution of water-supply, 125 determination, 126

Sewer air, 212

Sewerage, system of, 167

for removal of excreta, 211

Sexual indulgence, 36

Shelter tent, 116

Shock, surgical, alcohol in, 270

Shoes, 87, 102

breaking in, 106

civilian models, 104

how to fit, 105

requirements for good, 103

soiled, in transmission of typhoid fever, 66

supervision in fitting, 105

waterproofing, 107

Shower-baths, 167

Sick call for marching command, 197

evacuation of, on battlefields, 199

Sinks, care of, 173

in camps, 189, 192, 221

seats for, box, 221

pole, 223

Siphon closet, 168

Siphonage, 167

Skin diseases, 34

in tropics, 244

eruptions, 86

Sleep, 39

Sleeping bag, 249

Slicker, 97

Small-pox, 81

in tropics, 244

vaccination against, 81

Snake-bite, alcohol in, 270

Snow-blindness, 247 
Socks, 88, 101

Sod crematory for camps, 231

Soft chancre, 256

Soil-pipes, 168

Soldiers and disease prevention, 20

dependency of, 59

inexperienced, 60

Soups, cooking of, 152

Spanish-American War, typhoid fever in, 64

Spirilla, 60

Spirits, 260

Spitting in tuberculosis, 77

Spray pump, 171

Stables, sanitation of, 170

Starch, animal, 142

State, importance of physical training to, 43

Stegomyia calopus, 82 mosquitoes, 75

Sterilization, 62 of water, 135

Sterilizer, Forbes', 135, 136

Stewing of meats, 152

Stomach, effects of alcohol on, 265

Straddle trench, 225

Sugar, 149

Surgical shock, alcohol in, 270

Surplus kit bag, 119

Sutlers, 195

Sweater, 96

Sweeping, 173

Sweepings, disposal of, in camps, 230

in garrison, 217

Swimming, 54

Syphilis, 254

hereditary, 255

marriage in, 255

salvarsan in, 255

transmission of, 255
TAPeworms, 160

Taps, waste from, disposal of, in camps, 233

Tea, 151

habit, 282

Teeth, care of, 33

Temperature in cooking, 153

Tenderfoot knee, 247

Tent, care of, 195

pyramidal, 187

shelter, 116

Test, peppermint, of plumbing, 169

Thirst on marches, 184

Throat affections, 78

Ticks, 86

Tiger mosquito, 82

Tissues, effects of alcohol on, 262

Tobacco, 280

effects, 280

habit, 281

nature, 280

Tonsillitis, 78

Training, physical, 41. See also Physical training.

Transports, messing on, 178 personal hygiene on, 176

police of, 179

sanitary rules on, 179

sanitation of, 177

seasickness on, 179

ventilation of, 177

water-supply of, 179

Trap, 167

fly, 175

Trichinosis, 160

Troops, care of, 17

sanitary, 17

Troopships, sanitation, 177

Tropical climate, 235

ration, 159

service, 235

Tropics, 235

abdominal congestion in, 239 
Tropics, abdominal covering of wool in, 241

acclimatization, 238

baths in, 238

causes of disease in, 237

cholera in, 244

clothing in, 240

dhobie itch in, 244

diet in, 239

diseases in, 242

drinking-water in, 240

dysentery in, 243

effects of, 236

exercise in, 241

field service in, 245

habitations in, 242

hat in, 241

headgear in, 241

homesickness in, 245

houses in, 242

intestinal diseases in, 243

parasites in, 244

laundry in, 239

malaria in, 243

nostalgia in, 245

prickly heat in, 244

skin diseases in, 244

small-pox in, 244

underclothing in, 241

venereal diseases in, 244

water in, 240

Trousers, 97

Tubercle bacillus, 77

Tuberculosis, 77

alcohol in, 270

bacillus of, 77

coughing and spitting, 77

from infected food, 159

prevention of, 78

Typhoid bacillus, 65

fever, 63 •

army epidemics, 65

carriers, 65,66
Typhoid fever, cause, 64 dust in transmission of, 67 flies in transmission of, 66, 67 from infected food, 159

hands in transmission of, 66 immunity from, 71

in Boer War, 63

in civil communities, 64

War, 63

in Franco-Prussian War, 63

in Spanish-American War, 64

method of spread, 65

prevention, 67

saliva in transmission of, 66

scourge of armies, 63

soiled shoes in transmission of, 66

vaccination against, 67. See alsoVaccination, antityphoid.

UltRAVIOLET rays, purification of water by, 129

Underclothing in tropics, 241

Undershirts, 100

Underwear, 33, 100

Uniform, service, 98

Urinal cans, 224

Urine, disposal of, in camps, 224

Vaccination against small-pox, 81 antityphoid, 67

history of, 67

immunity from, 71

in American Army, 69

in British Army, 68

in German Army, 68

preparation of material, 70

of recruits, 30

Vacuum cleaning, 173

Varioloid, 81

Vaulting, 52

Vegetables, canned, 156

cooking of, 153 
Vegetables, fresh, 156

green, 150

Vegetins, 25

Venereal diseases, 62, 250

action by Congress, 253

by War Department, 252

causes, 251

education campaign, 252

importance, 250

in tropics, 244

personal prophylaxis, 257

prevalence in army, 250

preventive measures, 251

Ventilation, 37, 163

of transports, 177

Vino, 261

dangers of, 240

Visual apparatus, effects of alcohol on, 266

Vital processes, effects of alcohol on, 262

Vitality, effects of alcohol on, 267

Volunteers, inexperience of, 25

WASH water, disposal of, in camps, 233

Washing hands after defecation, 225

Waste-pipes, draining fixtures, 168

Wastes, 206

classification, 206

disposal of, 206

in camps, 190,218

in garrison, 207

separation of components, 214

sewers, 211

from taps, disposal of in camps, 233

liquid house, disposal, in garrison, 216

solid, 206

Water, 143
Water, drinking-, in tropics, 240 in tropics, 240 wash, disposal of, in camps, 233

Water-closet, 167 dry earth, 207

Public Health Service, 208

Waterproofing of clothing, 92 shoes, 107

Water-supply, 122

bacteria in, 125 destruction, 135

removal, 130

functions, 122

hardness, 124

impurities, 124

necessity, 122

of battlefield, 202

of camps, 193

of transports, 179

pollution, 125

from sewage, 125

determination, 126

purification, 127

by addition of copper sulphate,

128

by chlorin gas, 129

by filtration, 128

by ozone, 129

by precipitation, 127

by sedimentation, 127

by ultraviolet rays, 129

in field, 130

boiling, 137

chemical, 131

Darnall filter, 131

filtration, 131

Forbes' sterilizer, 135, 136

improvised filter, 134

sterilization, 135

methods of, on large scale, 127

on small scale, 129

removal of bacteria, 130 
Water-supply, purification, re- $\mid$ Wooden floors, care of, 172 moval of objectionable sub- Woodhull, 25, 139 stances, 129 quantity required, 123 sources, 123

Weight of equipment, 108 of recruits, 28

Whisky, 260

blended, 260 straight, 260

Wines, 259

Wise, quotation, 22

Wood alcohol, 262

Wool as clothing, 90 disadvantages, 91 merits of, 90 washing, 91

Worry, 39

Wounded, care of, 200

Wounds, location of, 203

YeAST plant, 258

Yellow fever, 82 mosquitoes and, 82 



\section{CORLEGETERT.BOORS}

PUBLISHED BY

\section{W.B.SAUNDERS COMPANY}

West Washington Square

Philadelphia

\section{London: 9, Henrietta Street, Covent Garden}

\section{Daugherty's Economic Zoölogy}

Economic Zoölogy. By L. S. Daugherty, M. S., Ph. D., Professor of Zoölogy, State Normal School, Kirksville, Mo.; and M. C. Daugherty. Part I-Field and Laboratory Guide: I2mo of 237 pages, interleaved. Cloth, \$1.25 net. Part II-Principles: I2mo of 406 pages, illustrated. Cloth, $\$ 2.00$ net.

There is no other book just like this. Not only does it give the salient facts of structural zoölogy and the development of the various branches, but also the natural history-the life and habits. It emphasizes the economic phase throughout, showing the beneficial or harmful tendencies of each animal in the life of man. The illustrations are helpful.

Prof. V. E. Shelford, University of Chicago: "It has many merits and is the best book of the kind on the market."

\section{Striles $\mathbb{N}^{2}$ urtritional PRysiology}

Nutritional Physiology. By Percy G. Stiles, Assistant Professor of Physiology in Simmons College; Instructor in Physiology and Personal Hygiene in the Massachusetts Institute of Technology, Boston. $12 \mathrm{mo}$ of $27^{\mathrm{r}}$ pages, illustrated. Cloth, $\$ 1.25$ net.

Dr. Stiles' new work expresses the most advanced views on this important subject. It takes up each organ, each secretion concerned with the process of digestion, discussing the part each plays in the physiology of nutrition-in the transformation of energy. In fact, the keynote of the book throughout is "energy"-its source and its conservation. The illustrations and homely similes are noteworthy.

Prof. M. E. Jaffa, University of California: "The presentation of the matter is excellent and can be understood by all." 


\section{McFar|and" Biology}

Biology: General and Medical. By Joseph McFarland, M.D., Professor of Pathology and Bacteriology, Medico-Chirurgical College, Philadelphia. I 2 mo of 440 pages, illustrated. Cloth, $\$$ r.75 net.

This work is particularly adaptable to the requirements of scientific courses. There are chapters on the origin of life and its manifestations, the cell and cell division, reproduction, ontogenesis, conformity to type, divergence, structural and blood relationship, parasitism, mutilation and regeneration, grafting, senescence, etc.

Prof. W. R. McConnell, Pennsylvania State College: "It has some admirable features, the most valuable of which is the careful résumé of the subjects of heredity and evolution."

\section{Drew's Inverrebrate Zoölogy}

Invertebrate Zoology. By Gruman A. Drew, Ph. D., Assistant Director of the Marine Biological Laboratory, Woods Hole, Mass. I 2 mo of 2 I 3 pages. Cloth, \$1.25 net. New (2d) Edition.

Professor Drew's work gives the student a working knowledge of comparative anatomy and leads him to an appreciation of the adaptation of the animals to their environments. It is a practical work, expressing the practical knowledge gained through experience. The type method of study has been followed.

Prof. John M. Tyler, Amherst College: "It covers the ground well, is clear and very compact. The table of definitions is excellent."

\section{American Pocket Dictionary}

American Pocket Medical Dictionary. Edited by W. A. NEw Man Dorland, M. D. 677 pages. Flexible leather, $\$ 1.00$ net; thumb index, $\$$ r.25 net.

Eighth Edition.

A dictionary must be full enough to give the student the information he seeks, clearly and simply, yet it must not confuse him with detail. The editor has kept this in mind in compiling this Pocket Dictionary, and he has produced a work of great value to the student. There are over roo, 000 American Medical Dictionaries now in use.

I. V. S. Stanislaus, M.D., Medico-Chirurgical College: "We have been strongly recommending this little book as being the very best." 


\section{Buchaman's Veterinary Bacteriology}

Veterinary Bacteriology. By Robert E. Buchanan, Ph. D., Professor of Bacteriology in the Iowa State College of Agriculture and Mechanic Arts. Octavo of ${ }_{516}$ pages, $2 x_{4}$ illustrations. Cloth, $\$ 3.00$ net.

Professor Buchanan's new work goes minutely into the consideration of immunity, opsonic index, reproduction, sterilization, antiseptics, biochemic tests, culture media, isolation of cultures, the manufacture of the various toxins, antitoxins, tuberculins, and vaccines.

B. F. Kaupp, D. V.S., State Agricultural College, Fort Collins: "It is the best in print on the subject. What pleases me most is that it contains all the late results of research."

\section{Sisson's Veterinary Anatomy}

Veterinary Anatomy. By Septimus Sisson, S. B., V. S., Professor of Comparative Anatomy, Ohio State University. Octavo of 826 pages, $5^{88}$ illustrations. Cloth, $\$ 7.00$ ret. The Standard.

Here is a work of the greatest usefulness in the study and pursuit of the veterinary sciences. This is a clear and concise statement of the structure of the principal domesticated animals-an exhaustive gross anatomy of the horse, ox, pig, and dog, including the splanchnology of the sheep, presented in a form never before approached for practical usefulness.

Prof. E. D. Harris, North Dakota Agricultural College: "It is the best of its kind in the English language. It is quite free from errors."

\section{Sharp's Veterinary Ophthalmology}

Ophthalmology for Veterinarians. By Walter N. Sharp, M. D., Professor of Ophthalmology, Indiana Veterinary College. I $2 \mathrm{mo}$ of 2 ro pages, illustrated. Cloth, $\$ 2.00$ net.

This new work covers a much neglected but important field of veterinary practice. Dr. Sharp has presented his subject in a concise, crisp way, so that you can pick up his book and get to "the point" quickly. He first gives you the anatomy of the eye, then examination, followed by the various diseases, including injuries, parasites, errors of refraction, and medicines used in ophthalmic therapeutics. The text is illustrated. 


\section{Pylès Persona Hygiene}

Personal Hygiene. Edited by Walter L. Pyle, M. D., Fellow of the American Academy of Medicine. I2mo of 515 pages, illustraied. Cloth, \$1.50 net.

Fifth Edition.

Dr. Pyle's work sets forth the best means of preventing disease-the best means to perfect health. It tells you how to care for the teeth, skin, complexion, and hair. It takes up mouth breathing, catching cold, care of the vocal cords, care of the eyes, school hygiene, body posture, ventilation, house-cleaning, etc. There are chapters on food adulteration (by Dr. Harvey W. Wiley), domestic hygiene, and home gymnastics.

Canadian Teacher: "Such a complete and authoritative treatise should be in the hands of every teacher."

\section{Galbraith's Ersercise for Women}

Personal Hygiene and Physical Training for Women By Anna M. Galbraith, M. D., Fellow New York Academy of Medicine. 12mo of $37 \mathrm{x}$ pages, illustrated. Cloth, $\$ 2.00$ net.

Dr. Galbraith's book meets a need long existing-a need for a simple manual of personal hygiene and physical training for women along scientific lines. There are chapters on hair, hands and feet, dress, development of the form, and the attainment of good carriage by dancing, walking, running, swimming, rowing, etc.

Dr. Harry B. Boice, Trenton State Normal School: "It is intensely interesting and is the finest work of the kind of which I know."

\section{MeKenzie On Exercise}

Exercise in Education and Medicine. By R. TAIt McKenzir, M. D., Professor of Physical Fducation, University of Pennsylvania. Octavo of 406 pages, with 346 illustrations. Cloth, $\$ 3.50$ net.

Adopted by U. S. Army.

Chapters of special value in college work are those on exercise by the different systems: play-grounds, physical education in school, college, and university.

D. A. Sargent, M. D., Hemenway Gymnasium: "It should be in the hands of every physical educator." 


\section{rinll's Noma』 Histology}

Normal Histology and Organography. By CharLes HilL, M. D. 12mo of 468 fages, 337 illustrations. Flexible leather, $\$ 2.00$ net.

Second Edition.

Dr. Hill's work is characterized by a brevity of style, yet a completeness of discussion, rarely met in a book of this size. The entire field is covered, beginning with the preparation of material, the cell, the various tissues, on through the different organs and regions, and ending with fixing and staining solutions.

Dr. E. P. Porterfield, St. Louis University: "I am very much gratified to find so handy a work. It is so full and complete that it meets all requirements."

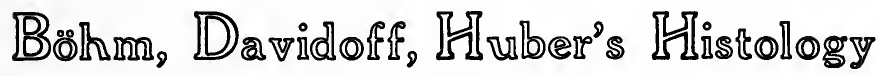

Histology. Вy A. A. Böнм, M. D., and M. von Davidorf, M. D., of Munich. Edited by G. Carl Huber, M. D., Professor of Embryology at the Wistar Institute, University of Pennsylvania. Octavo of 528 pages, 377 illustrations. Flexible cloth, $\$ 3.50$ net.

Second Edition.

This work is conceded to be the most complete text-book on human histology published. Particularly full on microscopic technic and staining, it is especially serviceable in the laboratory. Every step in technic is clearly and precisely detailed. It is a work you can depend upon always.

New York Medical Journal: "There can be nothing but praise for this model text-book and laboratory guide."

\section{reisler" E Embryology}

Embryology. By J. C. Heisler, M. D., Professor of Anatomy, Medico-Chirurgical College of Philadelphia. Octavo of 432 pages, 205 illustrations. Cloth, $\$ 3.00$ net.

Third Edition.

A book of the greatest teaching value. The subject is taken up systematically, treating the development of each tissue, each organ, each region and system in a most thorough way. There are frequent allusions to certain facts of comparative embryology.

Journal American Medical Association: "The text is concise, and yet sufficiently full for a text-book." 


\section{Jordan's Gereral Bacteriology}

General Bacteriology. By Edwin O. Jordan, Ph. D., Professor of Bacteriology, University of Chicago. Octavo of 623 pages, illustrated. Cloth, $\$ 3.00$ net.

Third Edition.

This work treats fully of the bacteriology of plants, milk and milk products, dairying, agriculture, water, food preservation; of leather tanning, vinegar making, tobacco curing; of household administration and sanitary engineering. A chapter of prime importance to all students of botany, horticulture, and agriculture is that on the bacterial diseases of plants.

Prof. T. J. Burrill, University of Illinois: "I am using Jordan's Bacteriology for class work and am convinced that it is the best text in existence."

\section{Eyre?s Bacterriologic Technic}

Bacteriologic Technic. By J. W. H. EYre, M. D., Bacteriologist to Guy's Hospital, London. Octavo of 525 pages, illustrated. Cloth, $\$ 3.00$ net.

Second Edition.

Dr. Eyre gives clearly the technic for the bacteriologic examination of water, sewage, air, soil, milk and its products, meats, etc. It is a work of much value in the laboratory. The illustrations are practical and serve well to clarify the text. The book has been greatly enlarged.

The London Lancet: "It is a work for all technical students, whether of brewing, dairying, or agriculture."

\section{Gortham' Laboratory Bacteriology}

Laboratory Bacteriology. By Frederic P. Gorham, A. M., Associate Professor of Biology, Brown University, Providence. 12mo of 192 pages, illustrated. C'oth. $\$ 1.25$ net.

The subjects of special interest to scientific students are the identification of bacteria of water, milk, air, and soil. Professor Gorham has succeeded in making his instructions clear and easily grasped by the student. The text is illustrated.

Science: "The author has described small points of technic usually left for the student to learn himself." 


\section{Lusks's Elements of $\mathbb{N}$ urtrition}

Elements of Nutrition. By Graham Lusk, Ph. D., Professor of Physiology, Cornell Medical School. Octavo of 402 pages, illus trated. Cloth, $\$ 3.00$ net.

Second Edition.

The clear and practical presentation of starvation, regulation of temperature, the influence of protein food, the specific dynamic action of food-stuffs, the influence of fat and carbohydrate ingestion and of mechanical work render the work unusually valuable. It will prove extremely helpful to students of animal dietetics and of metabolism generally.

Dr. A. P. Brubaker, Jefferson Medical College: "It is undoubtedly the best presentation of the subject in English. The work is indispensable."

\section{Howell's PRysiology}

Physiology. By William H. Howell, M. D., Ph. D., Professor of Physiology, Johns Hopkins University. Octavo of ro20 pages, illustrated. Cloth, $\$ 4.00$ net.

Fifth Edition.

Dr. Howell's work on human physiology has been aptly termed a "storehouse of physiologic fact and scientific theory." You will at once be impressed with the fact that you are in touch with an experienced teacher and investigator.

Prof. G. H. Caldwell, University of North Dakota: "Of all the textbooks on physiology which I have examined, Howell's is the best."

\section{Bergery's Hygiene}

Hygiene. By D. H. Bergry, M. D., Assistant Professor of Bacteriology, University of Pennsylvania. Octavo of 530 pages, illustrated. Cloth, \$3.00 net."

Fourth Edition.

Dr. Bergey gives first place to ventilation, water-supply, sewage, industrial and school hygiene, etc. His long experience in teaching this subject has made him familiar with teaching needs.

J. N. Hurty, M. D., Indiana University: "It is one of the best books with which I am acquainted." 


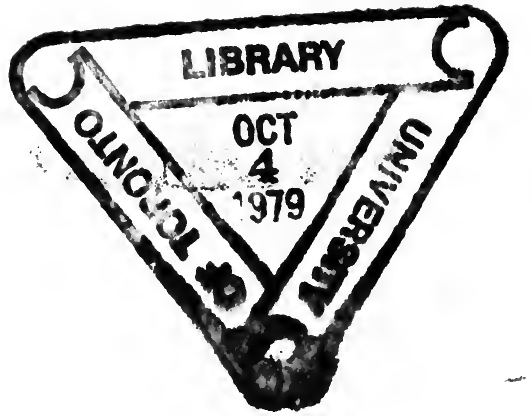




\section{PLEASE DO NOT REMOVE CARDS OR SLIPS FROM THIS POCKET}

\section{UNIVERSITY OF TORONTO LIBRARY}

$\mathrm{UH}$

600

$\mathrm{K} 4$
Keafer, Frank Royer

A text-book of military hygiene and sanitation 
4. $\frac{5 x^{2}}{2}$ 